PNL-7703

\title{
THE HARDWARE ACCELERATOR ARRAY \\ FOR LOGIC SIMULATION
}

By

NORMAN H. HANSEN

A thesis submitted in partial fulfillment

of the requirements for the degree of

MASTER OF SCIENCE IN ELECTRICAL ENGINEERING

WASHINGTON STATE UNIVERSITY

School of Electrical Engineering and Computer Science

MAY 1991 
To the Faculty of Washington State University:

The members of the Committee appointed to examine the thesis of Norman H. Hansen find it satisfactory and recommend that it be accepted.

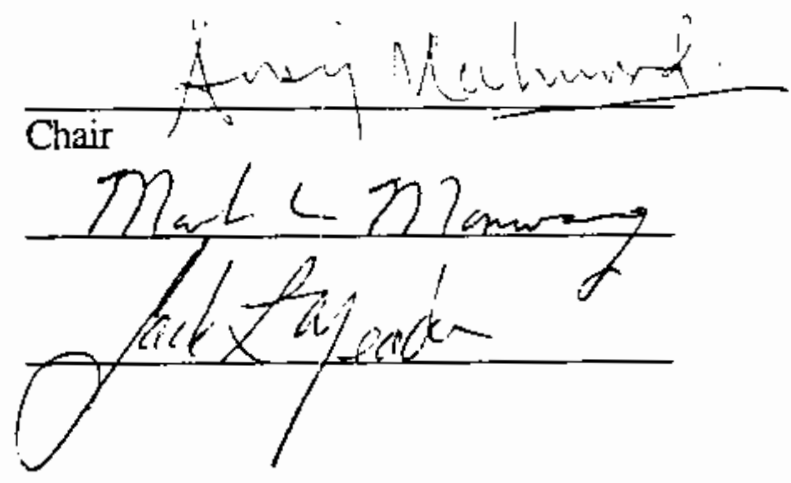




\section{ACKNOWLEDGEMENTS}

I thank Dr. Ausif Mahmood for his guidance and helpful insights throughout the course of the accelerator array research.

I would also like to thank the management of the Pacific Northwest Laboratory for their financial and moral support of my master's program and research.

I would be most ungrateful if I did not acknowledge the endless patience of my dear wife and children. To them I dedicate this thesis. 
iv

\author{
THE HARDWARE ACCELERATOR ARRAY \\ FOR LOGIC SIMULATION \\ ABSTRACT \\ by Norman H. Hansen, M.S. \\ Washington State University \\ May 1991
}

\title{
Chair. Ausif Mahmood
}

Hardware acceleration exploits the parallelism inherent in large circuit simulations to achieve significant increases in performance. Simulation accelerators have been developed based on the compiled code algorithm or the event-driven algorithm. The greater flexibility of the eventdriven algorithm has resulted in several important developments in hardware acceleration architecture. Some popular commercial products have been developed based on the event-driven algorithm and data-flow architectures.

Conventional data-flow architectures require complex switching networks to distribute operands among processing elements resulting in considerable overhead. An accelerator array architecture based on a nearest-neighbor communication has been developed in this thesis. The design is simulated in detail at the behavioral level. Its performance is evaluated and shown to be superior to that of a conventional data-flow accelerator. 


\section{TABLE OF CONTENTS}

ACKNOWLEDGEMENTS . . . . . . . . . . . . . . . . . . . . . iii

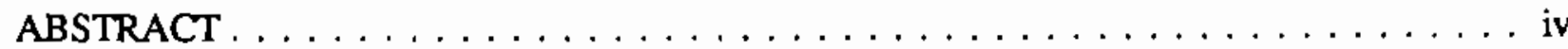

LIST OF TABLES $\ldots \ldots \ldots \ldots \ldots \ldots \ldots \ldots \ldots \ldots \ldots \ldots \ldots$ vii

LIST OF FIGURES $\ldots \ldots \ldots \ldots \ldots \ldots \ldots \ldots \ldots \ldots \ldots \ldots$ viii

Chapter

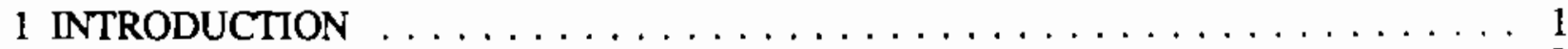

1.1 Approaches to simulation acceleration $\ldots \ldots \ldots \ldots \ldots \ldots \ldots \ldots \ldots$

1.2 Motivation $\ldots \ldots \ldots \ldots \ldots \ldots \ldots \ldots \ldots \ldots \ldots \ldots$

1.3 The event-driven algorithm for the accelerator array . . . . . . . . . 4

2 A FUNCTIONAL DESCRIPTION OF THE HARDWARE ACCELERATOR ARRAY . . . 9

2.1 Accelerator Array $\ldots \ldots \ldots \ldots \ldots \ldots \ldots \ldots \ldots \ldots \ldots \ldots \ldots$

2.2 Array Controller . . . . . . . . . . . . . . . . . . . 11

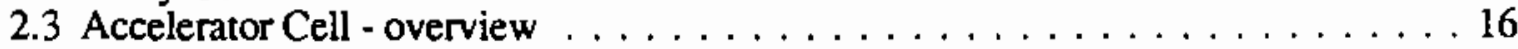

2.4 Functional Description $\ldots \ldots \ldots \ldots \ldots \ldots \ldots \ldots \ldots \ldots \ldots$

2.4.1 Event handling - a functional overview $\ldots \ldots \ldots \ldots \ldots \ldots \ldots$

2.4 .2 Cell Controller . . . . . . . . . . . . . . . . . . 20

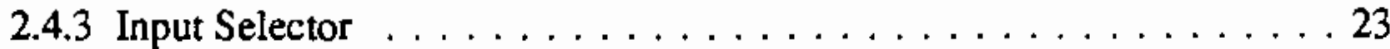

2.4.4 Source Translation Unit $\ldots \ldots \ldots \ldots \ldots \ldots \ldots \ldots \ldots$

2.4 .5 Boolean Logic Unit . . . . . . . . . . . . . . . . . . . . . . 30

2.4.6 Timing Wheel $\ldots \ldots \ldots \ldots \ldots \ldots \ldots \ldots \ldots \ldots \ldots \ldots \ldots$

2.4 .7 Network Switch . . . . . . . . . . . . . . . . . 35

3 PERFORMANCE ANALYSIS $\ldots \ldots \ldots \ldots \ldots \ldots \ldots \ldots \ldots \ldots$

3.1 Behavioral Simulator $\ldots \ldots \ldots \ldots \ldots \ldots \ldots \ldots \ldots \ldots$

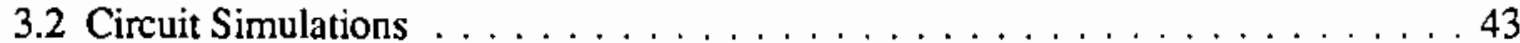

3.2.1 Single inverer $\ldots \ldots \ldots \ldots \ldots \ldots \ldots \ldots \ldots \ldots \ldots$

3.2 .264 -inverer Chain . . . . . . . . . . . . . . . . 45

3.2.3 Pipeline Saturation Test $\ldots \ldots \ldots \ldots \ldots \ldots \ldots \ldots$. . . . . . 49

3.2 .4 Zero-delay path test $\ldots \ldots \ldots \ldots \ldots \ldots \ldots \ldots \ldots \ldots$

3.2 .5 Cross-coupled NAND $\ldots \ldots \ldots \ldots \ldots \ldots \ldots \ldots \ldots$

3.2.6 Rising-Edge Trigger D Flip-Flop . . . . . . . . . . . . . . . . . 59

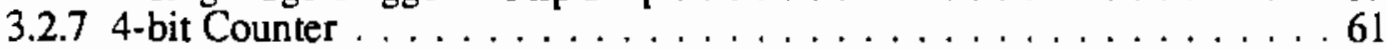

3.2 .8 Multiplier Arrays . . . . . . . . . . . . . . . . . 63

3.3 Comparison to Static Data Flow Architecture . . . . . . . . . . . 66

3.3.1 Static Data-Flow Architecture $\ldots \ldots \ldots \ldots \ldots \ldots 6 \ldots \ldots 6$

3.3.2 Apples and Oranges . . . . . . . . . . . . . . 68

3.3.3 Performance Comparison . . . . . . . . . . . . . . . . . 69

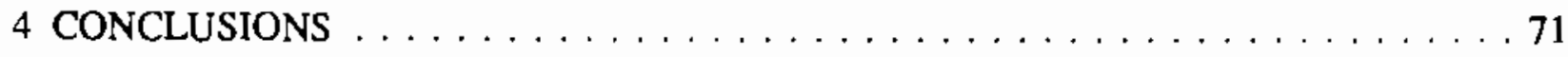

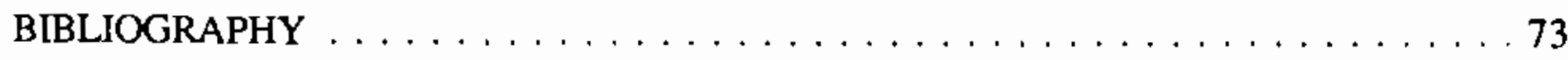


vi

Appendix

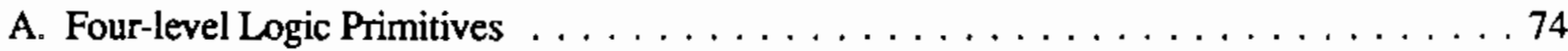

B. Cell Programming Language . . . . . . . . . . . . . . . . . . . 76

C. Behavioral Simulator $\ldots \ldots \ldots \ldots \ldots \ldots$

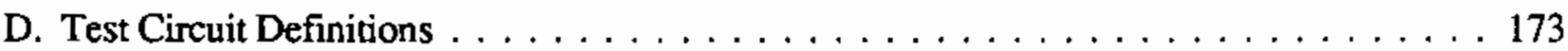

E. Simulation Reports . . . . . . . . . . . . . . . . . . . . 221 


\section{LIST OF TABLES}

Table

3.1 Increase in array time for idle cycles . . . . . . . . . . . . . . . 44

3.2 Event throughput for three configurations $\ldots \ldots \ldots \ldots \ldots \ldots$

3.3 Throughput versus parallel input count $\ldots \ldots \ldots \ldots \ldots \ldots \ldots \ldots \ldots \ldots \ldots \ldots \ldots$

3.4 Throughput versus vertical fanout count $\ldots \ldots \ldots \ldots \ldots \ldots \ldots \ldots \ldots \ldots \ldots \ldots$

3.5 Performance degradation caused by long paths $\ldots \ldots \ldots \ldots \ldots \ldots \ldots \ldots \ldots \ldots$ 
viii

\section{LIST OF FIGURES}

Figure

1.1 A simple logic network and its data-flow graph $\ldots \ldots \ldots \ldots \ldots$

$1.28 \times 8$ array of accelerator cells $\ldots \ldots \ldots \ldots \ldots \ldots$

1.3 Event graph mapped onto $2 \times 2$ array $\ldots \ldots \ldots \ldots \ldots \ldots$

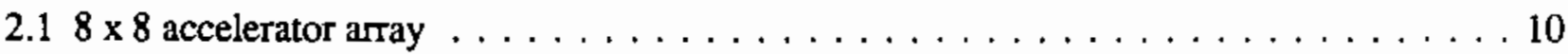

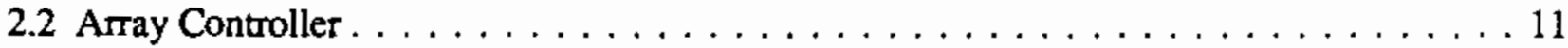

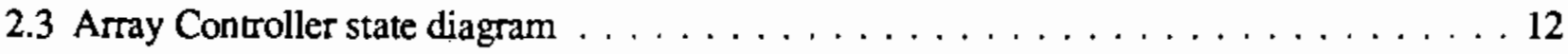

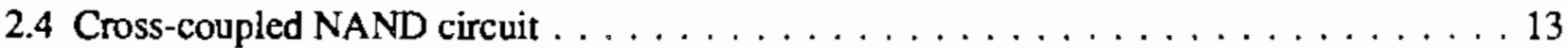

2.5 Cross-coupled NAND circuit timing $\ldots \ldots \ldots \ldots \ldots \ldots \ldots$

2.6 Array Controller timing for cross-coupled NAND circuit $\ldots \ldots \ldots \ldots \ldots \ldots$

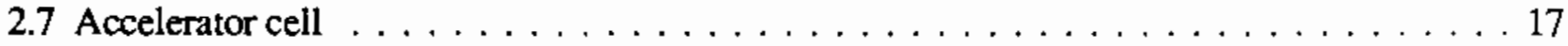

2.8 Typical event flow $\ldots \ldots \ldots \ldots \ldots \ldots \ldots$

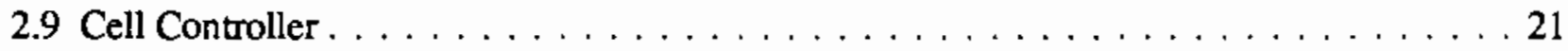

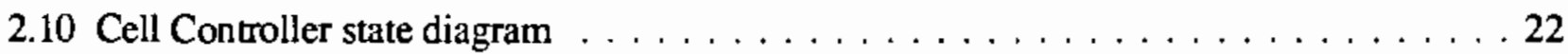

2.11 Input Selector and registers $\ldots \ldots \ldots \ldots \ldots \ldots \ldots$

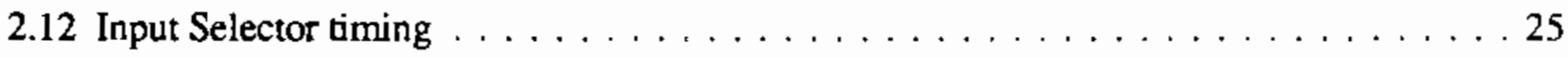

2.13 Source addressing . . . . . . . . . . . . . . . . 27

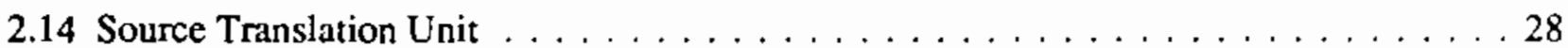

2.15 Source Translation Unit timing . . . . . . . . . . . . . . . . . . . . 29

2.16 Boolean Logic Unit $\ldots \ldots \ldots \ldots \ldots \ldots$

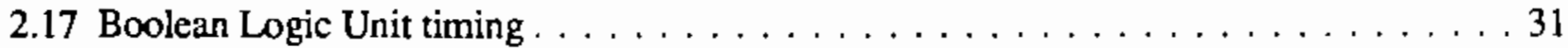

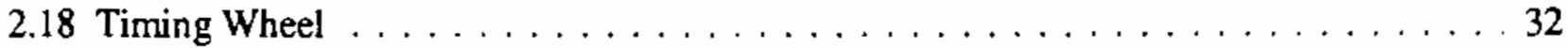

2.19 Timing Wheel timing for SR flip-flop circuit $\ldots \ldots \ldots \ldots \ldots$

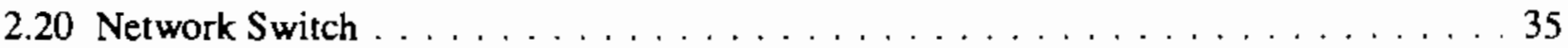

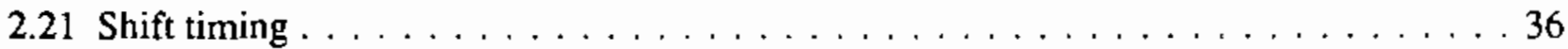


2.22 Rank ordering example . . . . . . . . . . . . . . . . . . 37

2.23 Cross-coupled NAND rank ordering example $\ldots \ldots \ldots \ldots \ldots \ldots \ldots \ldots$

2.24 Cross-coupled NAND mapped onto $2 \times 2$ array . . . . . . . . . . . . . . 39

3.1 Hardware accelerator array $-\operatorname{model} 4.1 \ldots \ldots \ldots \ldots \ldots \ldots$

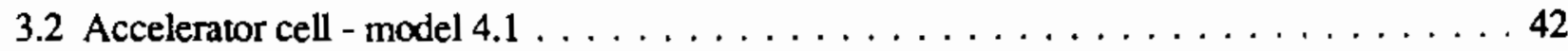

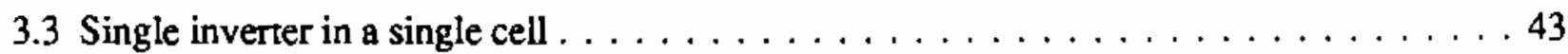

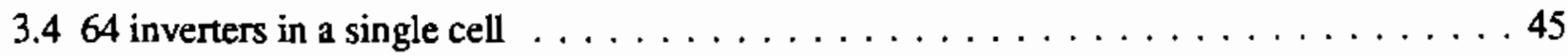

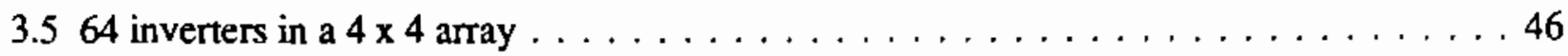

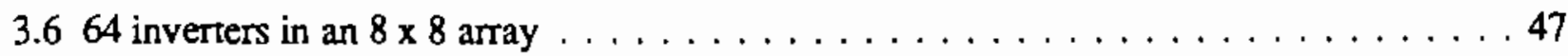

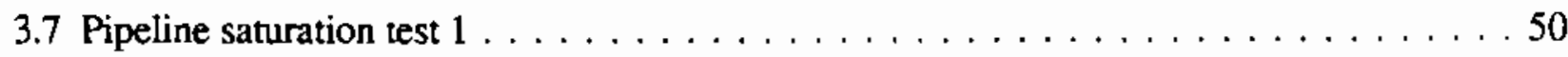

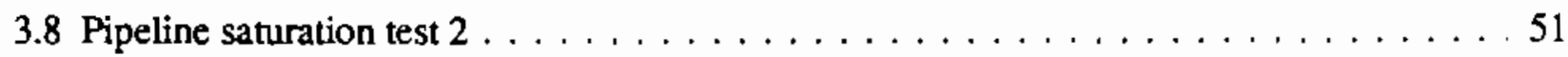

3.9 Saturation test 1 - throughput versus parallel input count $\ldots \ldots \ldots \ldots \ldots \ldots \ldots$

3.10 Saturation test 2 - throughput versus vertical fanout count $\ldots \ldots \ldots \ldots \ldots$

3.11 Zero-delay path test (shown for six wire elements) $\ldots \ldots \ldots \ldots \ldots \ldots \ldots$

3.12 A cross-coupled NAND and its mapping $\ldots \ldots \ldots \ldots \ldots \ldots \ldots \ldots \ldots \ldots$

3.13 Cross-coupled NAND circuit timing $\ldots \ldots \ldots \ldots \ldots \ldots \ldots \ldots$

3.14 Rising-edge trigger $\mathrm{D}$ flip-flop $\ldots \ldots \ldots \ldots \ldots \ldots \ldots \ldots$

3.15 Circuit timing for rising-edge trigger $\mathrm{D}$ flip-flop $\ldots \ldots \ldots \ldots \ldots \ldots$

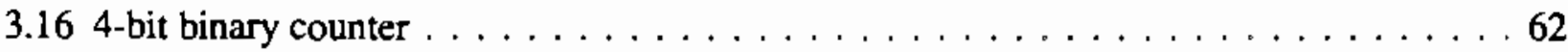

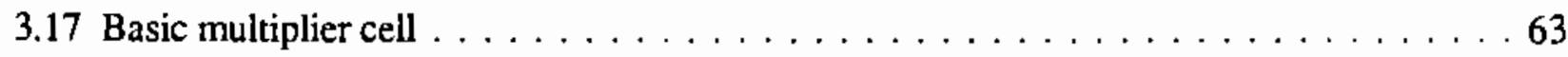

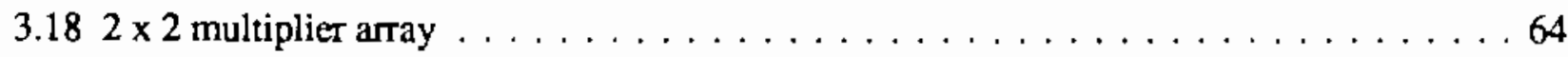

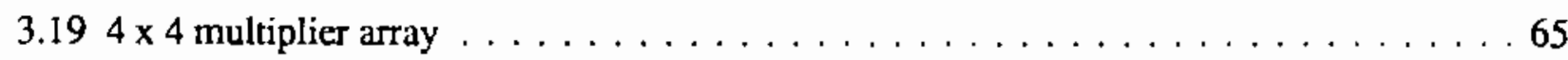

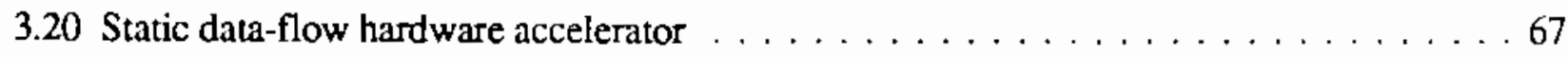

3.21 Relative performances of static data-flow and array accelerators $\ldots \ldots \ldots \ldots 70$ 


\section{Dedication}

To my wife, Janet, and children, Tallia,

David, Joshua and Susanna 


\section{CHAPTER 1}

\section{INTRODUCTION}

A hardware accelerator is a special-purpose hardware module that speeds up logic simulation by exploiting the parallelism inherent in the logic circuit or in the simulation algorithm. Hardware acceleration can be applied to computer-aided design and verification tasks other than logic simulation such as placement, routing and design-rule checking. The use of hardware accelerators for these applications has brought about performance improvements of several orders of magnitude over pure software implementations running on conventional architectures.

For logic simulation, several simulation acceleration architectures have been proposed and, in some cases, commercially implemented. One performance-limiting factor has been the switching bottlenecks that have resulted from dealing with the non-uniform connectivity of the circuit under simulation. In the most extreme situation, any circuit element might be connected to any other circuit element located anywhere in the circuit. A hardware accelerator would have to have some means of providing such communication. Typically, this is achieved with complex switching networks, resulting in high cost and performance degradation for low parallelism.

This thesis explores the design of a hardware accelerator array that uses only nearestneighbor connections. As will be seen in section 2.5 , circuits are mapped onto the array much as they would be laid out on a circuit board. However, this locality of connectivity has a price. Special circuit elements (zero-delay wires) must be created to facilitate long connection paths. The performance of this architecture relative to a popular multi-processor architecture employing switching nerworks will be evaluated. 
1.1 Approaches to simulation acceleration

Compiled Simulation

The Yorktown Simulation Engine [1][2] is an example of compiled simulation. In compiled simulation, every element is evaluated at every simulation cycle, whether or not an actual transition has occurred. In gate-level simulations, the output of a gate is evaluated at every simulation cycle, even when none of the inputs has changed. Because there is no mechanism for event management, only unit-delay or synchronous circuit simulations can be performed.

\section{Event-Driven Simulation}

Event-driven simulators will evaluate an element only if an event occurs. Specifically, in the case of gate-level simulation, a gate is not evaluated unless an input actually changes. In the class of event-driven simulators, of particular interest will be those based on the data-flow architecture [3]. Event-driven simulation requires the tracking and synchronization of events by some means such as a timing wheel. In a timing wheel, events are entered at the time at which they will occur. Events for the current time are extracted and processed possibly generating new events for a future time; these new events are stored back into the timing wheel. The timing wheel mechanism coupled with an operand matching mechanism ensures that events for a particular element will intersect both spatially and temporally. 


\section{Techniques for Simulation Speedup}

There are several techniques for achieving simulation speed-up by development of specialized hardware. These can be grouped broadly under functional specialization and concurrency exploitation. Functional specialization utilizes custom hardware modules for speeding up particular simulation tasks such as event-list processing or element evaluation. Concurrency exploitation takes advantage of the parallelism present in the circuit being simulated or in the simulation algorithm itself to partition simulation activity among multiple processing elements [4].

A discussion of existing hardware accelerators and a relative comparison of their performance can be found in the literature [5].

\subsection{Motivation}

Event-driven processing is a type of data-flow processing. As used in the accelerator anray, events arriving at a gate must intersect temporally. The implication that this has on an eventdriven array is that all event list processing must be synchronized by use of a global clock or by employing a time-tagging algorithm. A lookahead-rollback mechanism as found in the virtual time concept [6] might be used. For architectural simplicity, a global clock is used in the accelerator array. However, to a limited extent, lookahead-rollback is used, in that inputs to a gate are not queued. Instead, outputs are predicted and corrected as needed.

Published research has shown the feasibility of implementing data-flow algorithms on specialized array architectures [7]. Because logic circuitry can be represented by event-driven graphs, this suggested that a method could be found to implement logic simulations on a specially designed processor array. Indeed, as will be shown in this thesis, such an array has been 


\section{4}

successfully designed and modeled.

Certain benefits of this approach to event-driven simulation are apparent. It will be possible to eliminate potential bottlenecks that plague existing event-driven architectures. A nearestneighbor communication algorithm will eliminate complex switching networks. Locality of operand and network definitions will result in greatly simplified operand matching. The architecture will permit essentially unlimited expansion of the array without degradation of performance.

\subsection{The event-driven algorithm for the accelerator array}

This section will treat the simulation algorithm for the accelerator array from a high level, without concern for the details of cell architecture that will be described in later sections.

A logic network is represented by a data-flow graph (fig. 1.1). Each gate in the network is replaced by a node in the graph, and each connection is replaced by an event path. As in the logic network, fanout is allowed. That is, an event may be directed to multiple nodes. The direct connection of separate event paths (shorting outputs) is not allowed. This graph is similar to a datadriven flow graph (with inputs synchronized by simulation time). As such, the mapping techniques of Koren and Peled are applicable [8][9]. However, in some respects, more flexibility exists in the accelerator array architecture, simplifying the mapping. Notably, each cell in the array can be mapped with multiple nodes from the event graph. 


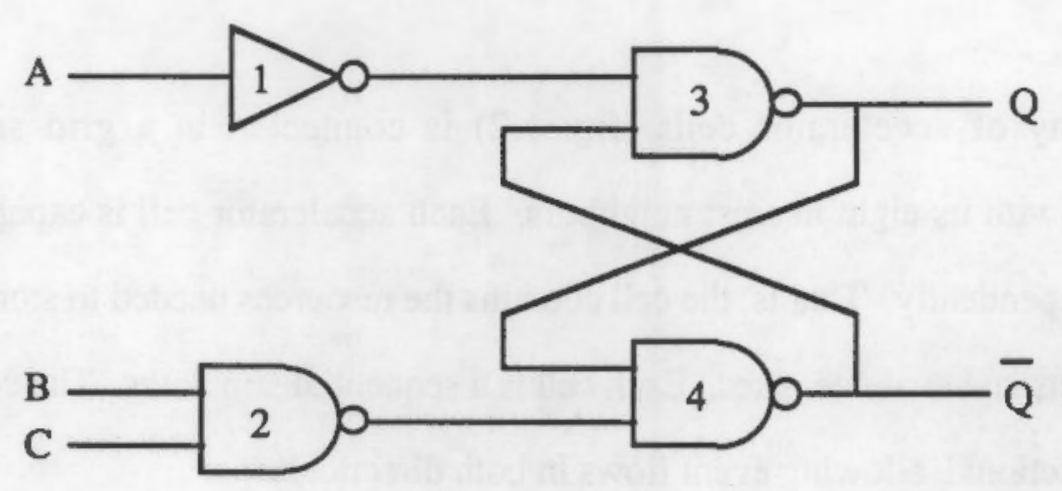

(a) Logic network

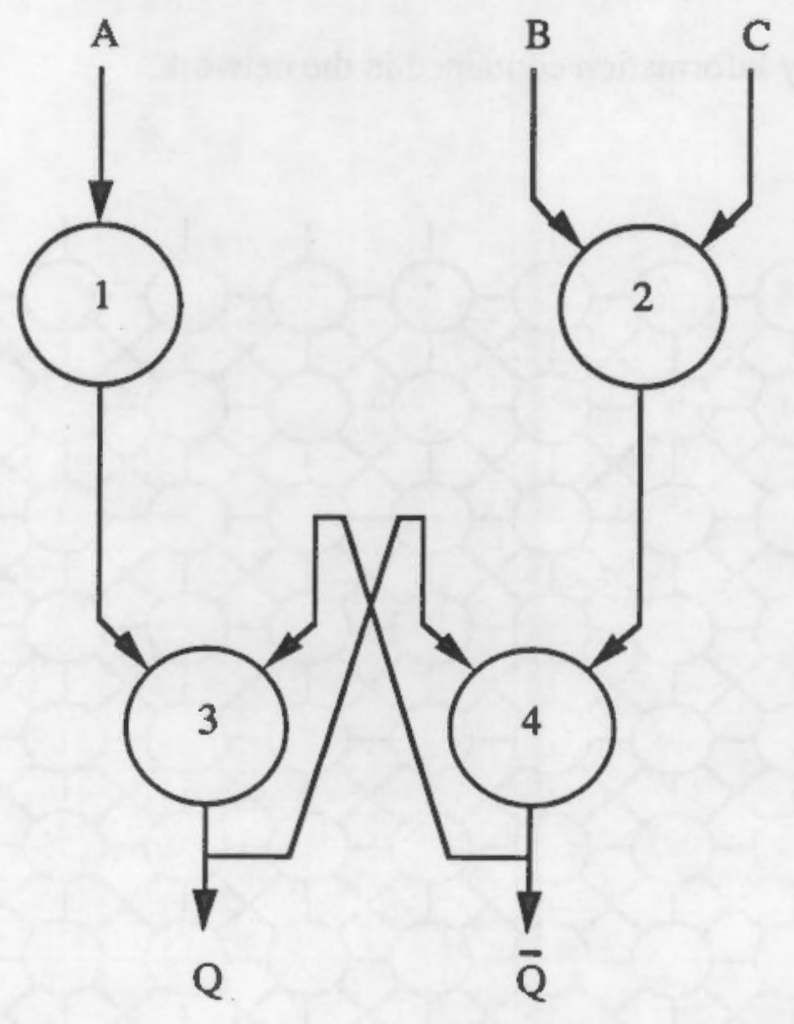

(b) Data-flow graph

Figure 1.1 A simple logic network and its data-flow graph 
An array of accelerator cells (fig. 1.2) is connected in a grid such that each cell communicates with its eight nearest neighbors. Each accelerator cell is capable of performing a simulation independently. That is, the cell contains the resources needed to store and process event and network lists and evaluate gates. Each cell is a sequential simulator. The connections between cells are bi-directional, allowing event flows in both directions.

The mapping of a logic network onto the array is not simply a matter of partitioning among independent simulators. The physical connections between accelerator cells are used to represent much of the connectivity information contained in the network.

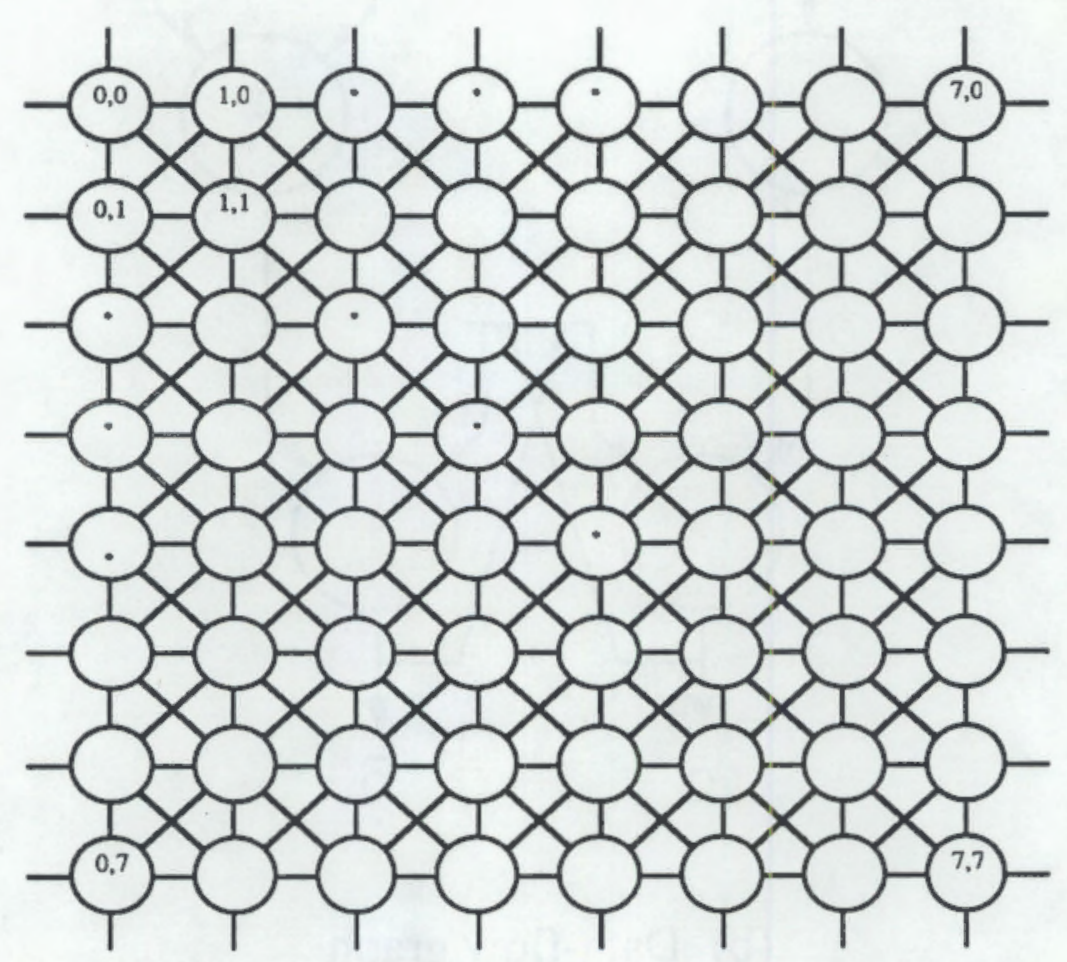

Figure $1.28 \times 8$ array of accelerator cells 
Conceptually, the simplest mapping of the network onto the accelerator array is literal. A more efficient mapping algorithm is discussed in section 2.5. The network is drawn on the same grid as the array, and each gate in the network is mapped onto a cell in the array (fig. 1.3). Wherever connections cross through a cell without connecting to a node, they are represented by zero-delay elements or "wires." The connectivity is represented in each cell by associating with each gate input the source information for its event path. For the accelerator array, using the nearest neighbor algorithm, the source information contains the number of the path on which the event enters the cell. It also contains a code identifying which gate in the neighboring cell generated the event. Associated with each gate output is a switch code identifying to which neighboring cells the output is to be routed. The output may also be routed to another gate in the same cell.

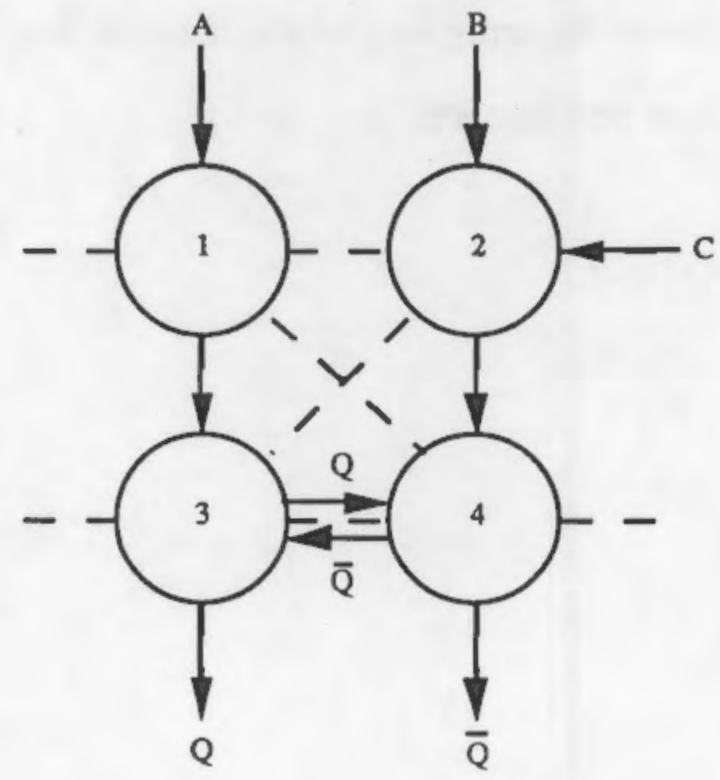

Figure 1.3 Event graph mapped onto $2 \times 2$ array 
As an event arrives at a cell, its source code is used to match it with the correct gate inputs. The gates are evaluated and, if the output changes, it is stored in an event list offset from the current simulation time by the gate delay. When the event matures, it will be fetched from the list and routed according the switch code. The current model for the accelerator array uses global synchronization among all event lists throughout the array.

The marked characteristic of the nearest-neighbor algorithm is that each accelerator cell is "unaware" of any cells in the array other than its nearest neighbors. This locality of connectivity has three benefits. First, the modules required for processing the connectivity information can be quite simple when compared with the complex switching networks that are required to accommodate global connectivity. Second, the address sizes (in our case, the source and switch codes) are small. Third, the size of the array and, hence, network size, can be increased almost indefinitely without degradation of performance. 


\section{CHAPTER 2}

\section{A FUNCTIONAL DESCRIPTION OF THE HARDWARE ACCELERATOR ARRAY}

A specialized array has been designed that implements the algorithm described in Chapter 1. This array has been modeled and simulated, verifying its functionality. The performance of the array is evaluated in Chapter 3. This chapter is concerned with a functional description of the array.

\subsection{Accelerator Array}

The hardware accelerator array (fig. 2.1) consists of accelerator cells arranged in a rectangular grid. Each cell is connected via bi-directional data busses to its eight nearest neighbors. Each cell is also connected to a circuit bus, permitting programming by a host computer. In addition, the perimeter nodes are connected to waveform buffers that can be accessed by the host computer to store test vectors.

Interestingly, the connection of the array is such that it can be configured as either rectangular or hexagonal. This suggests that with modifications to the processing element, standard systolic array algorithms could be implemented on this architecture, presenting the possibility of analog simulations. Conceivably, mixed-mode simulation might be achieved. 


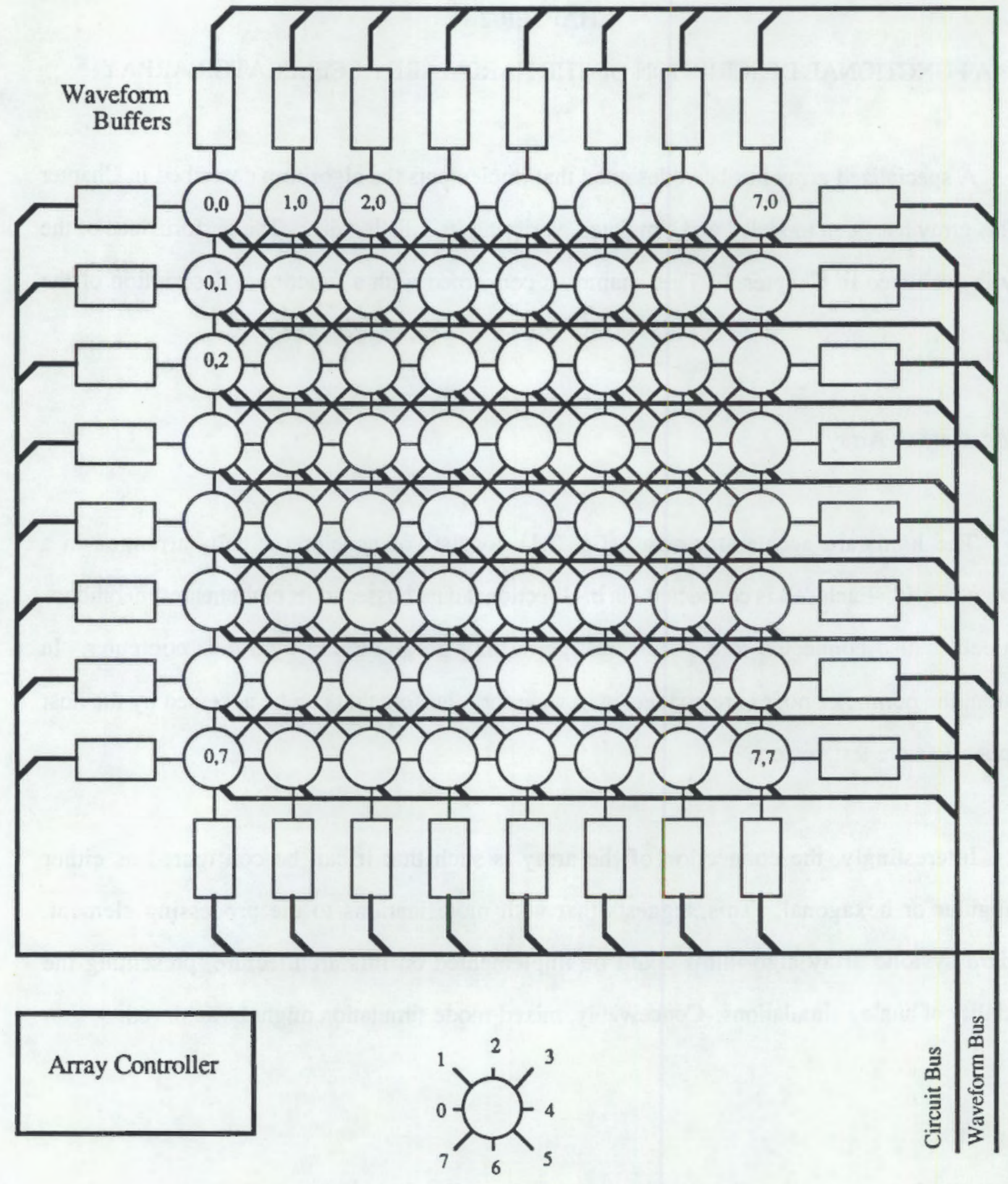

Figure $2.18 \times 8$ accelerator array 


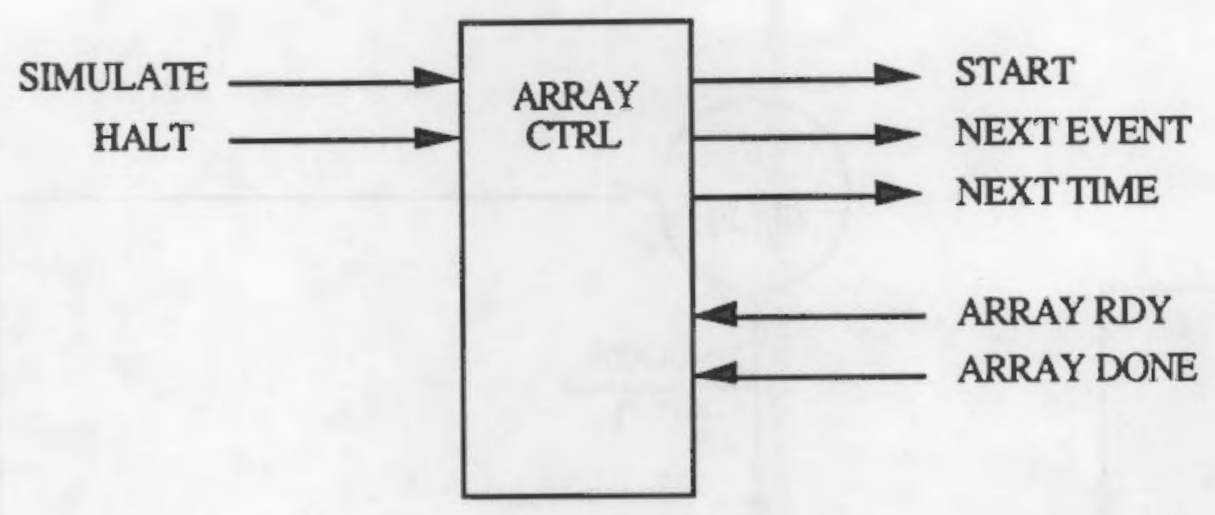

Figure 2.2 Array Controller

\subsection{Array Controller}

The Array Controller (fig. 2.2) provides global synchronization for the array. It is a simple state sequencer with only three states (fig. 2.3). The inputs to the Array Controller are defined as follows:
ARRAY_RDY - Each cell holds this signal low until it has finished processing all events in its Input Registers. Once ARRAY_RDY goes high, the Array Controller will assert NEXT_TIME or NEXT_EVENT, depending on the state of ARRAY_DONE.

ARRAY_DONE - This signal is held low by each cell until all events in the current time position in the Timing Wheel have been processed. When ARRAY_DONE goes high, the Array Controller will assert NEXT_TIME, causing all Timing Wheels to increment. 


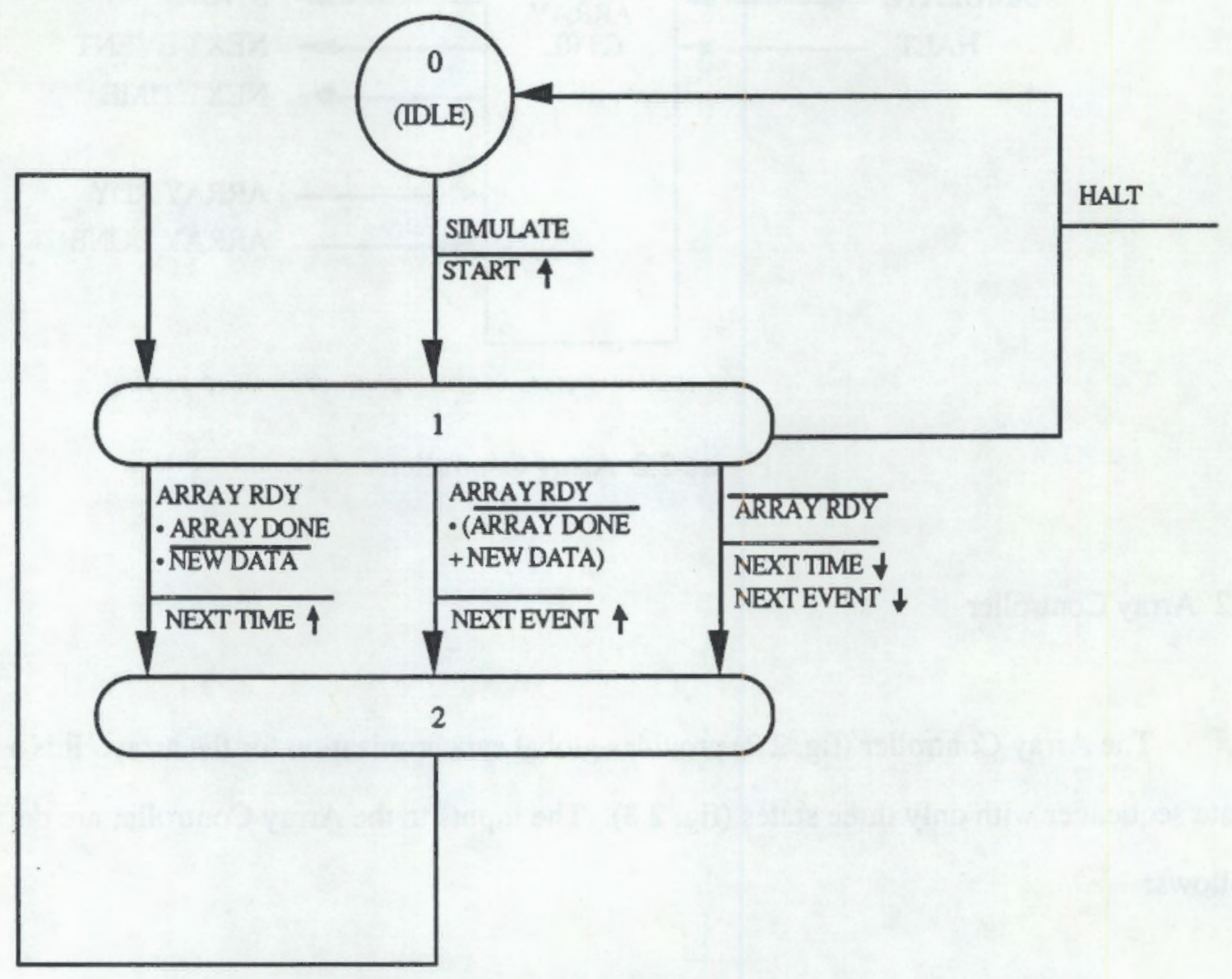

Figure 2.3 Array Controller state diagram

NEW_DATA

- This signal is asserted by a waveform buffer when an external input event occurs. In response to this signal, the Array Controller forces the cells to look for another event at the current time.

Before simulation begins, the Array Controller is in its idle state (0). A START from the host computer causes the Array Controller to advance to state 1 where, on the next clock, it asserts or de-asserts NEXT_TIME and NEXT_EVENT according to the input conditions. If the array is ready but still has events left at the current time, or if there are new external input data, 
NEXT_EVENT will be asserted. If the array is ready and all events for the current time have been processed, then NEXT_TIME will be asserted.

From state 1, the Array Controller will advance to state 2, which is a transitory state permitting the input signals to the Array Controller to stabilize.

The simulation of a cross-coupled NAND or SR flip-flop (fig. 2.4) serves to illustrate the timing of the Array Controller (figs. 2.5 and 2.6). This circuit is programmed into the array such that each gate is in a separate cell.

NEW_DATA is asserted each time data is read from the external input buffer. ARRAY_RDY is low while the cells are busy processing events or incrementing the Timing . Wheel. ARRAY_DONE is high while the current position in the Timing Wheels contains no events. Clearly, for this example, each time new data arrived did not necessarily result in an event being stored in the Timing Wheel.

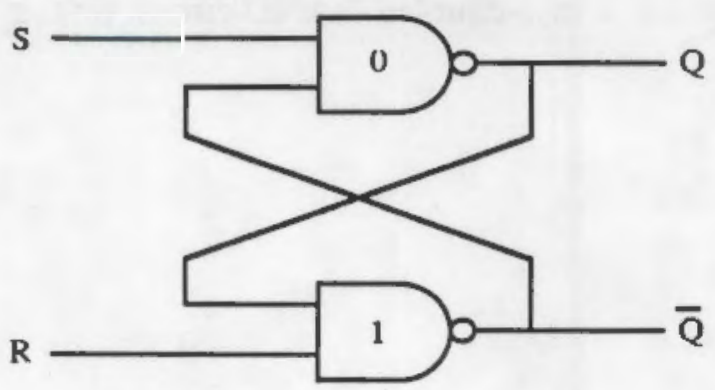

Figure 2.4 Cross-coupled NAND circuit 


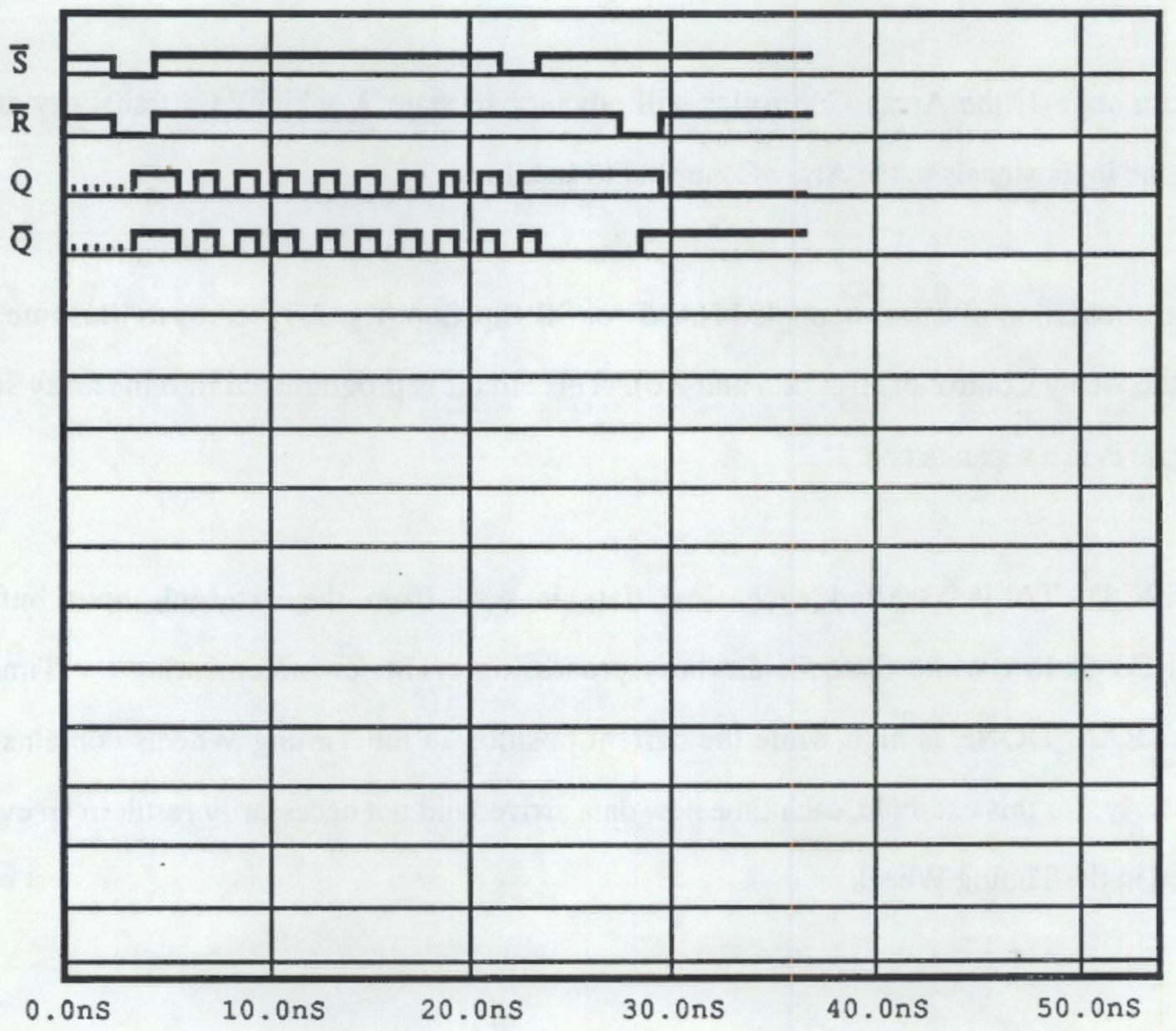

Figure 2.5 Cross-coupled NAND circuit timing 


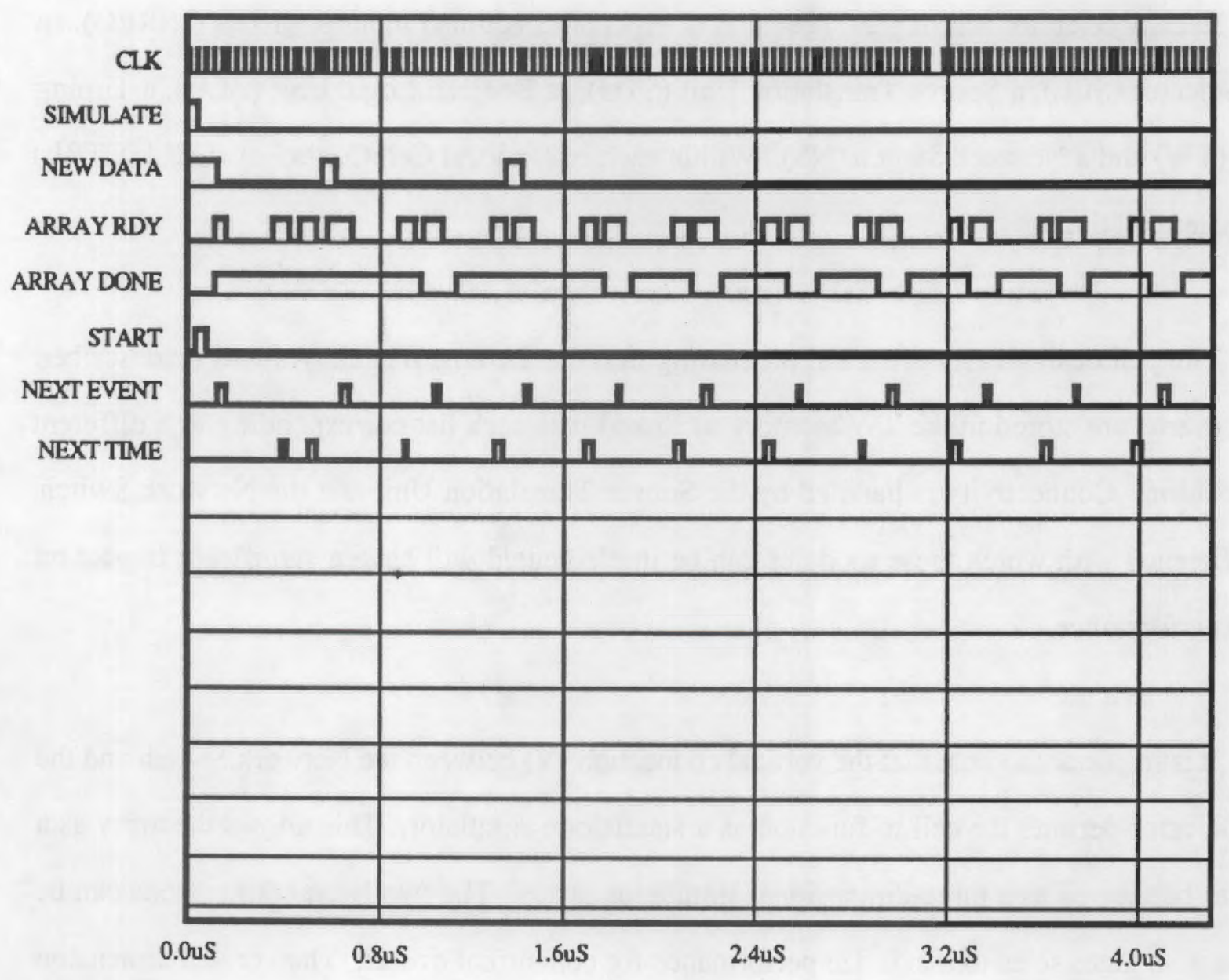

Figure 2.6 Array Controller timing for cross-coupled NAND circuit 


\subsection{Accelerator Cell - overview}

Each accelerator cell (fig. 2.7) consists of eight bi-directional Input Registers (INREG), an Input Selector (SEL), a Source Translation Unit (STU), a Boolean Logic Unit (BLU), a Timing Wheel (TW) and a Network Switch (NS). Within each cell, a local Cell Controller (CELL CTRL) coordinates cell timing.

The cell design casts event list processing into the Timing Wheel. As will be described below, events are stored in the TW memory as linked lists each list corresponding to a different time position. Connectivity is handled by the Source Translation Unit and the Network Switch. The efficiency with which these modules can be implemented will have a significant impact on system performance.

It is important to note that the vertical connection (V) between the Network Switch and the Input Selector permits the cell to function as a standalone simulator. This allows the array as a whole to be viewed as a three-dimensional simulation space. The two lateral dimensions can be mapped with gates so as to maximize performance for concurrent events. The vertical dimension can be mapped to handle inherently sequential structures. 


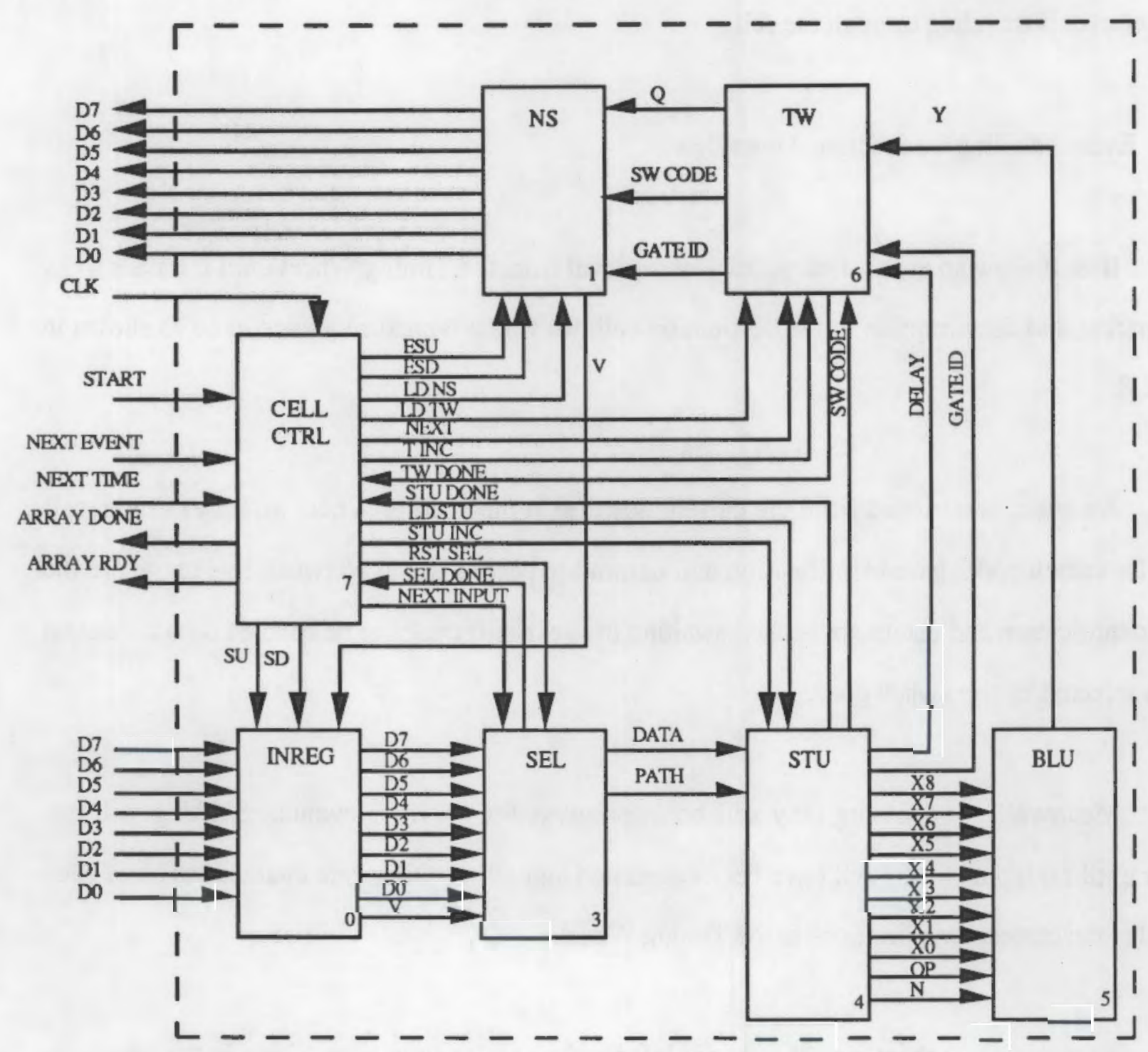

Figure 2.7 Accelerator cell 


\subsection{Functional Description}

Before the cell modules are detailed, it is helpful to consider functionality from the point of view of events traveling through the cell.

\subsubsection{Event handling - a functional overview}

If we follow an event starting from its retrieval from the Timing Wheel until it travels to its destination and consumption in the destination cell, we find a typical sequence to be as shown in fig. 2.8.

An event is retrieved from the current position in the Timing Wheel in, for example, cell 0,0 . Its switch code, gate identification and datum are passed to the Network Switch where the gate identification and datum are latched awaiting the next shift cycles to be enabled onto the output buses selected by the switch code.

Meanwhile, processing may still be in progress for previous events. Shifting will not occur until all inputs to the cell have been consumed and all resulting gate evaluations have been stored at the correct time positions in the Timing Wheel.

Assuming that there is still an event left for the current time somewhere in the array, the Array Controller will signal NEXT EVENT. All the nodes will then begin shifting events up and down in the array. This consists of outputs 0 through 4 transferring data to the Input Registers of neighboring cells while receiving data into inputs 5 through 8 (the vertical connection is also 

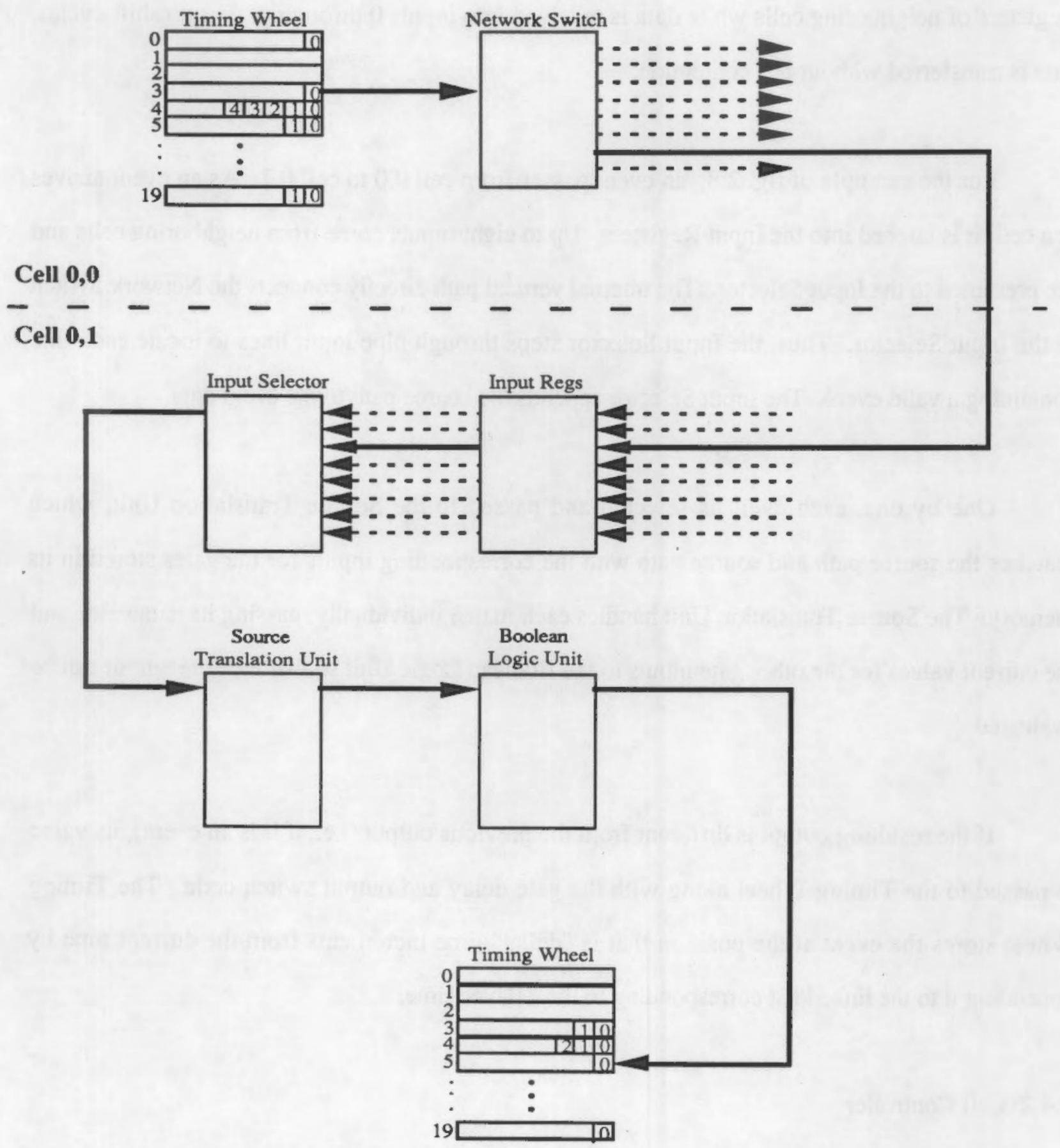

Figure 2.8 Typical event flow 
processed at this time). On the second shift cycle, outputs 5 through 7 transfer data to the Input Registers of neighboring cells while data is received into inputs 0 through 4 . In two shift cycles, data is transferred without bus contention.

For the example of fig. 2.8, an event passes from cell 0,0 to cell 0,1 . As an event arrives at a cell, it is latched into the Input Registers. Up to eight inputs come from neighboring cells and are presented to the Input Selector. The internal vertical path directly connects the Network Switch to the Input Selector. Thus, the Input Selector steps through nine input lines to locate each line containing a valid event. The Input Selector appends the source path to the event data.

One by one, each event is selected and passed to the Source Translation Unit, which matches the source path and source gate with the corresponding inputs for the gates stored in its memory. The Source Translation Unit handles each match individually, passing its data value and the current values for the other gate inputs to the Boolean Logic Unit so that the gate output can be evaluated.

If the resulting output is different from the previous output (i.e., if it is an event), its value is passed to the Timing Wheel along with the gate delay and output switch code. The Timing Wheel stores the event at the position that is "delay" time increments from the current time by appending it to the linked list corresponding to the delayed time.

\subsubsection{Cell Controller}

The Cell Controller (fig. 2.9) is a state sequencer located in each cell of the array. It provides timing for the cell. Each Cell Controller is under the control of the Array Controller described above and provides control signals to the cell modules. Operation of the Cell Controller 
can be understood by examining its state diagram (fig. 2.10).

The two major paths in the state diagram are for Timing Wheel advance and event fetch and process. After START is asserted by the Array Controller, the Cell Controller will initialize advancing to state 2. Here, the Cell Controller will either receive a NEXT_EVENT or a NEXT_TIME. Presuming that there are no events left for the current time in Timing Wheels anywhere in the array, NEXT_TIME will be received. The Cell Controller increments the Timing Wheel to the next time position and asserts NEXT, which causes the first event at the new time (if there is one) to be retrieved. Passing through state 1 , the Cell Controller will check ARRAY_DONE to see if an event was actually retrieved. Assuming that an event was found locally, TW_DONE is low and ARRAY_DONE is pulled low, indicating to the controller that an event needs to be handled.

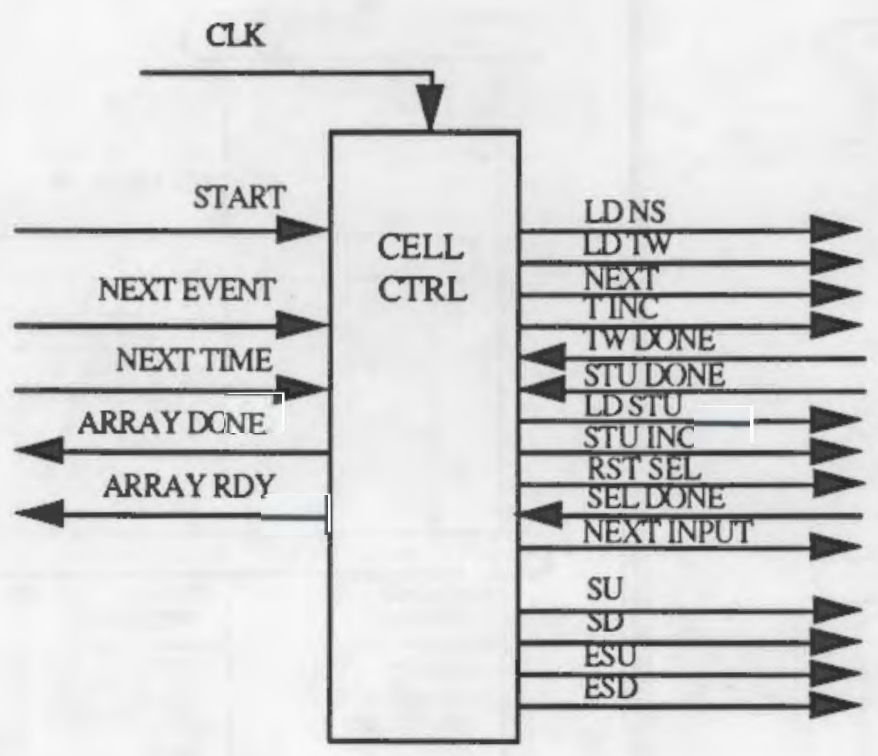

Figure 2.9 Cell Controller 


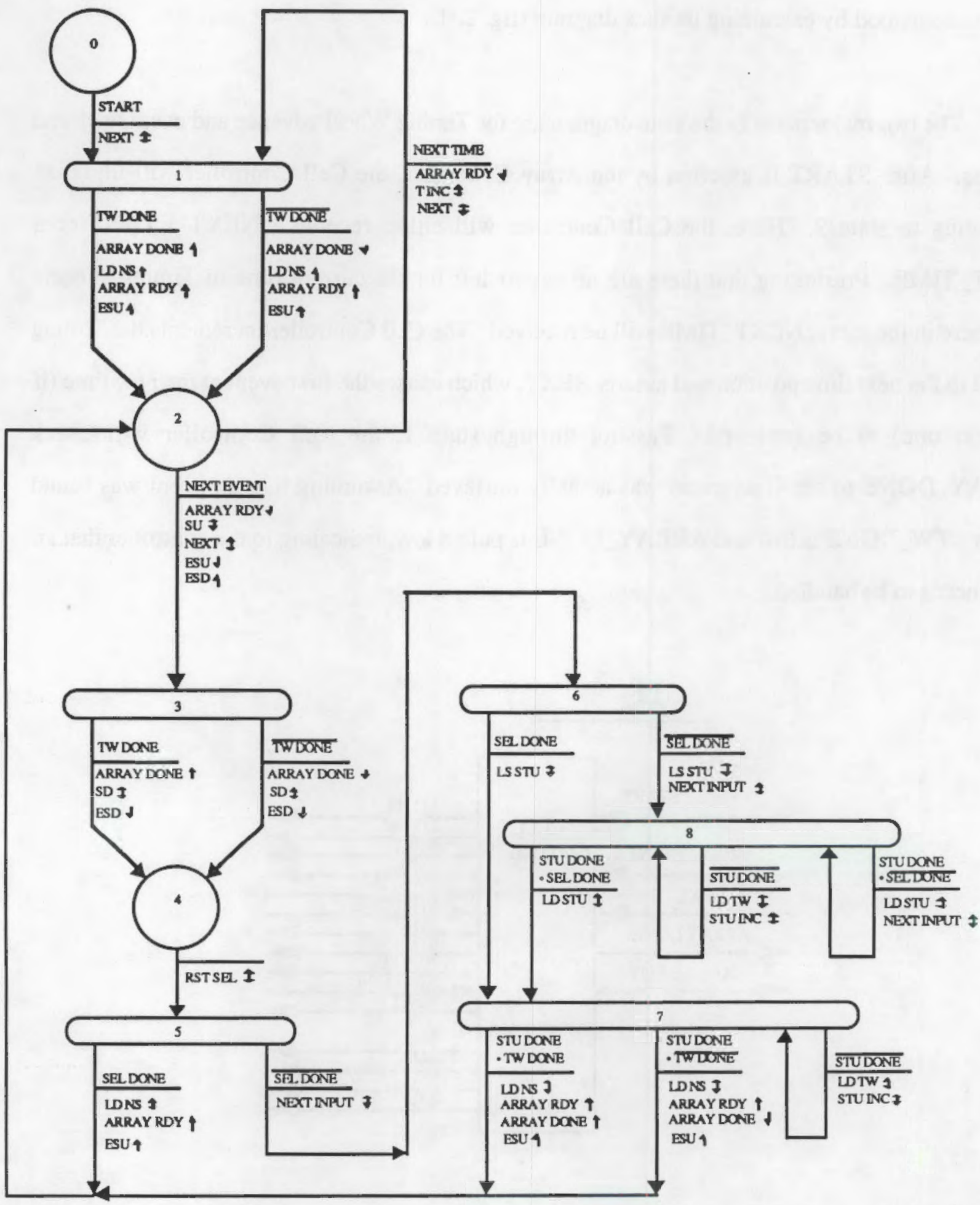

Figure 2.10 Cell Controller state diagram 
Back at state 2, the Cell Controller will now await a NEXT_EVENT, which will initiate the event fetch and process. In passing from state 2 to state 4 , the shift cycles are completed (fig. 2.21). For illustration purposes, assume that precisely one event arrives from a neighboring cell. While the shift cycles are in progress, the next event from the Timing Wheel (if there is one) is retrieved, and the Input Selector is reset to find the first valid event on its nine input paths.

At state 5, the Cell Controller checks SEL_DONE to see if the Input Selector was able to find a valid event. Assuming that one was found, SEL_DONE will be low, and the Controller asserts NEXT_INPUT to retrieve it. Now, at state 6, if the event was the only one, SEL_DONE will go high. The Cell Controller asserts LD_STU to latch the event into the Source Translation Unit.

At state 7, the Cell Controller will check for STU_DONE. Because the event might actually be used by more than one input among the gates stored in this cell, the Source Translation Unit will increment through all the matches and evaluate each gate to which the event is routed. The Cell Controller will assert LD_TW and STU_INC until all the gates needing evaluation are processed. After the last gate is handled, STU_DONE will go high and the Cell Controller will check TW_DONE and assert or de-assert ARRAY_DONE accordingly as it returns to state 2.

Note that ARRAY_RDY is permitted to go high only while the Cell Controller is at state 2. State 2 is the synchronization point with the Array Controller.

\subsubsection{Input Selector}

The Input Selector (fig. 2.11) selects from nine possible inputs to present one input to the 
Source Translation Unit. It skips over any inputs that do not contain valid events. A valid event has the highest-order bit set. When START_SEL is asserted by the Cell Controller, the Input Selector starts scanning its inputs. If it finds a valid event, then SEL_DONE is de-asserted. When NEXT_INPUT is asserted, the input datum and path number are transferred to the Source Translation Unit. Each time the Cell Controller asserts NEXT_INPUT, the Input Selector will look for the next valid input and send it together with the path number to the Source Translation Unit. When the last valid input has been consumed, SEL_DONE will be asserted.

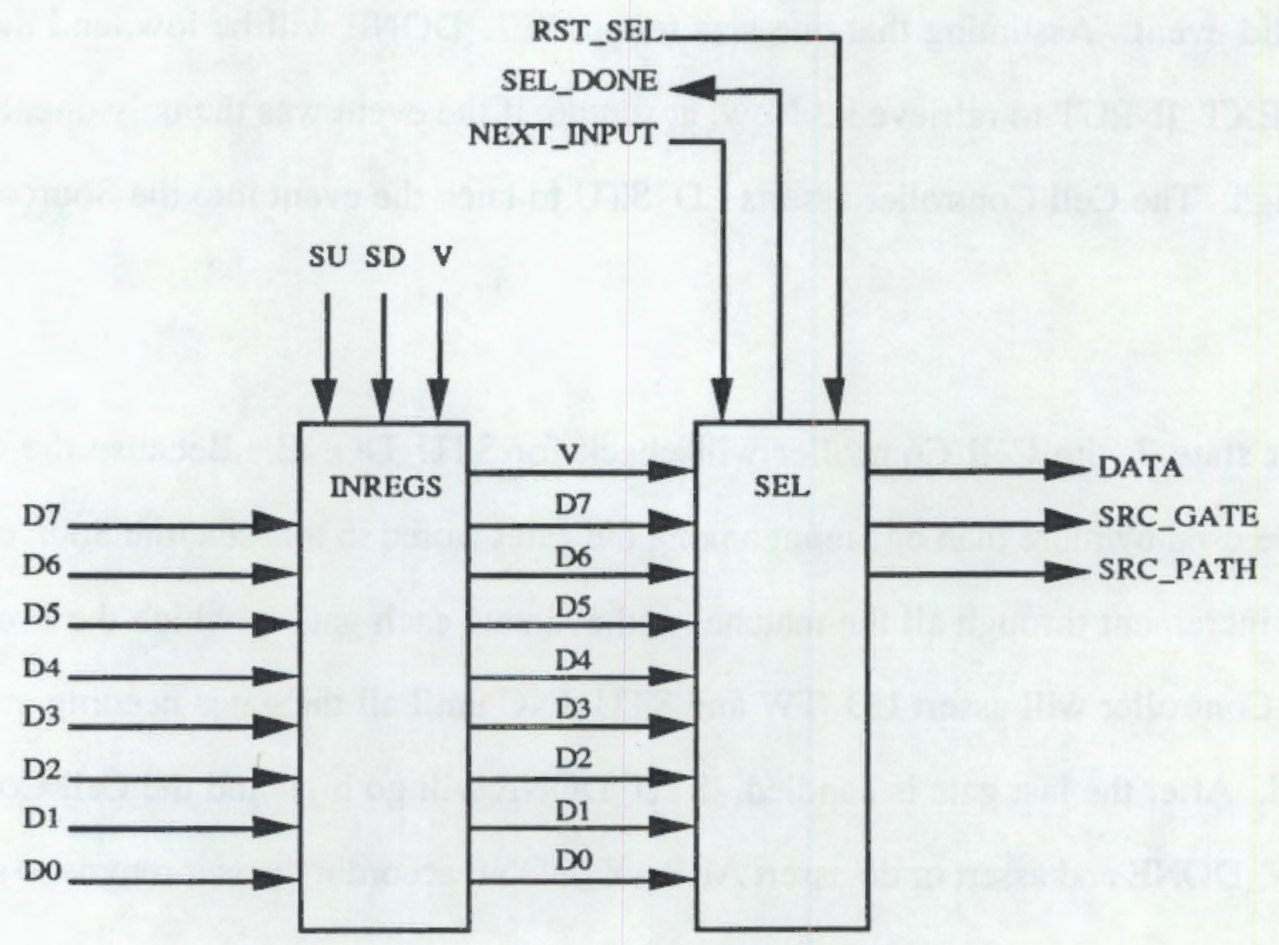

Figure 2.11 Input Selector and registers 
The timing of the Input Selector is shown for the SR flip-flop example (fig. 2.12). This timing is for cell 0,0 in the array. Note that "S" arrives on the D1 input while the cross-coupled connection "Q*" arrives on the D6 input. For this example, nearly every time the Input Selector receives START_SEL, exactly one valid event is found in the Input Registers.

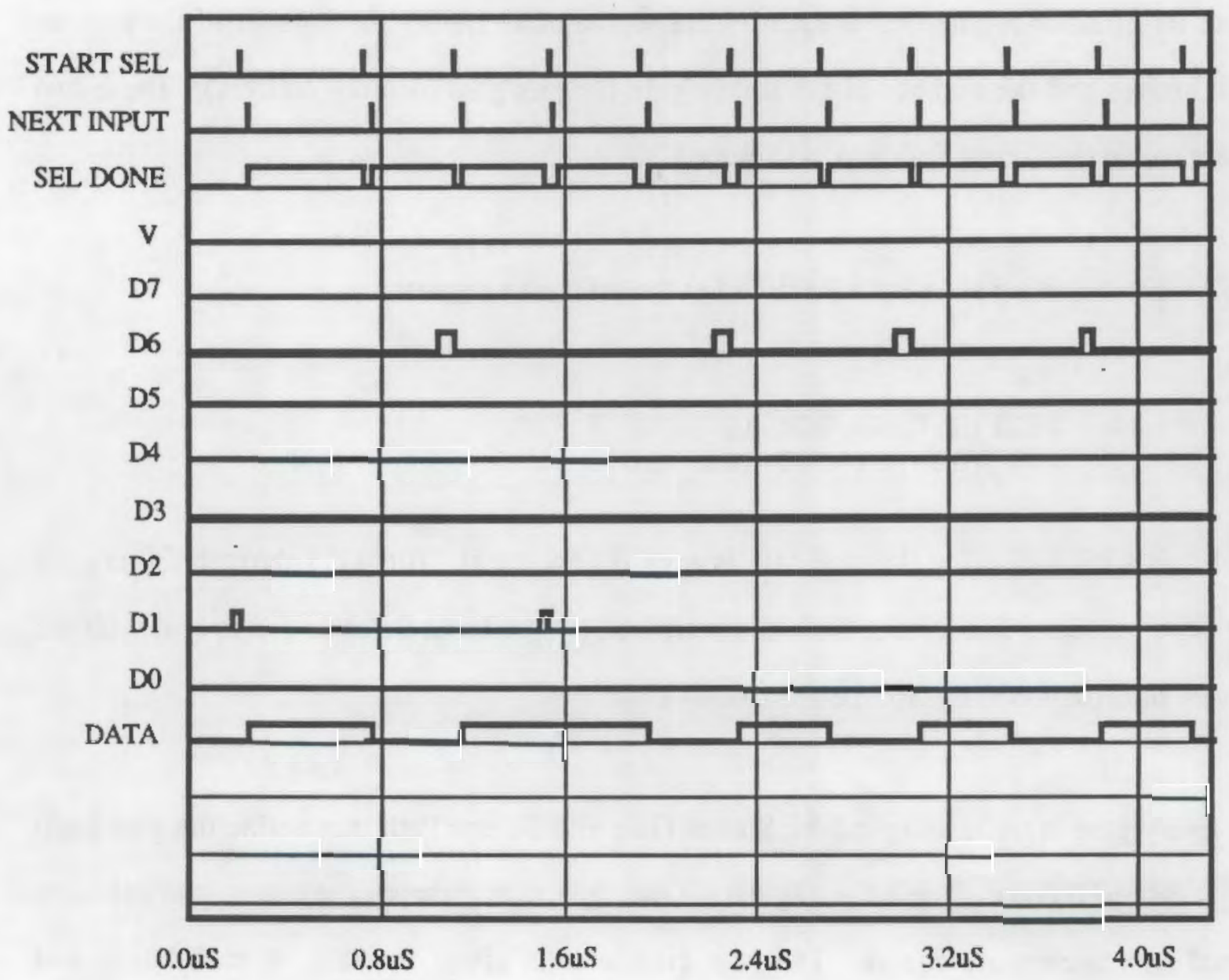

Figure 2.12 Input Selector timing 


\subsubsection{Source Translation Unit}

To understand the operation of the Source Translation Unit, one must first understand the concept of source code matching (fig. 2.13). Each input comes from precisely one output. The gate or wire generating the output must be in one of the nine local cells (i.e., in the same cell as the input or in one of the eight neighboring cells.) Thus, given this locality of connectivity, only two pieces of information are needed to identify the source of an input: the number of the path on which it arrives and the number of the source gate (i.e., its gate memory address). These two values are called the Source Path and the Source Gate.

An event arriving at an Input Register has the following format:

IFL IX |G11|G10|G9 |G8 |G7 |G6 |

IGS IG4 IG3 IG2 IG1 |G0 IDI IDO I

FL is a bit indicating that the data is a valid new event. Bits G11 through G0 are the Source Gate number. The Source Path is determined by the Input Selector and is sent with the input event information to the Source Translation Unit.

Every gate input is assigned the Source Gate and Source Path that define the gate from which its data will come. The incoming data is matched with these source codes, and gates are evaluated as matches are found. The host computer is given the task of calculating and programming the correct source codes for each input as it compiles the logic network.

When LD_STU is received, the Source Translation Unit (fig. 2.14) latches DATA and PATH from the Input Selector. The Source Gate is extracted from DATA and is appended to PATH, forming a source code. The Source Translation Unit then scans its gate memory for 


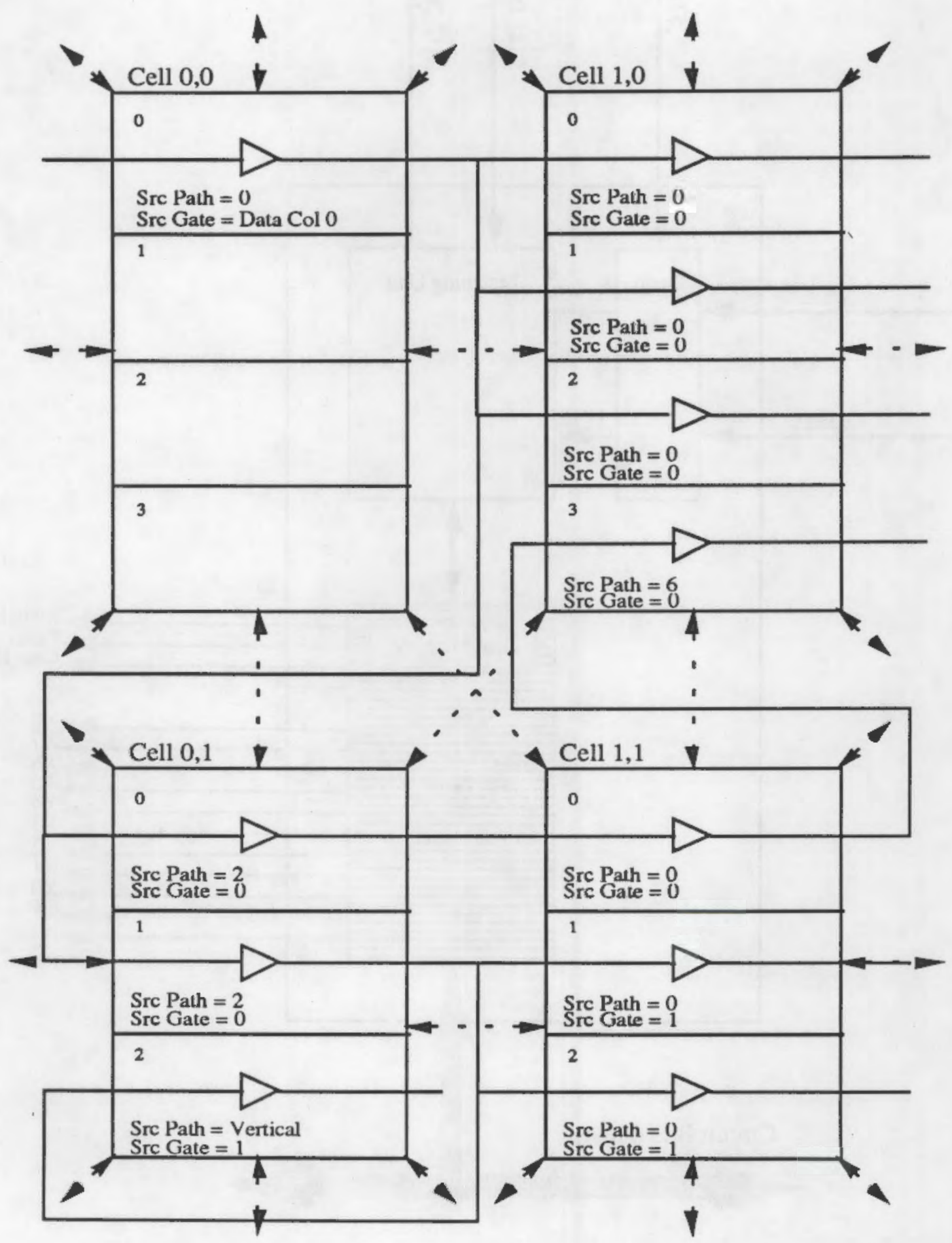

Figure 2.13 Source addressing 


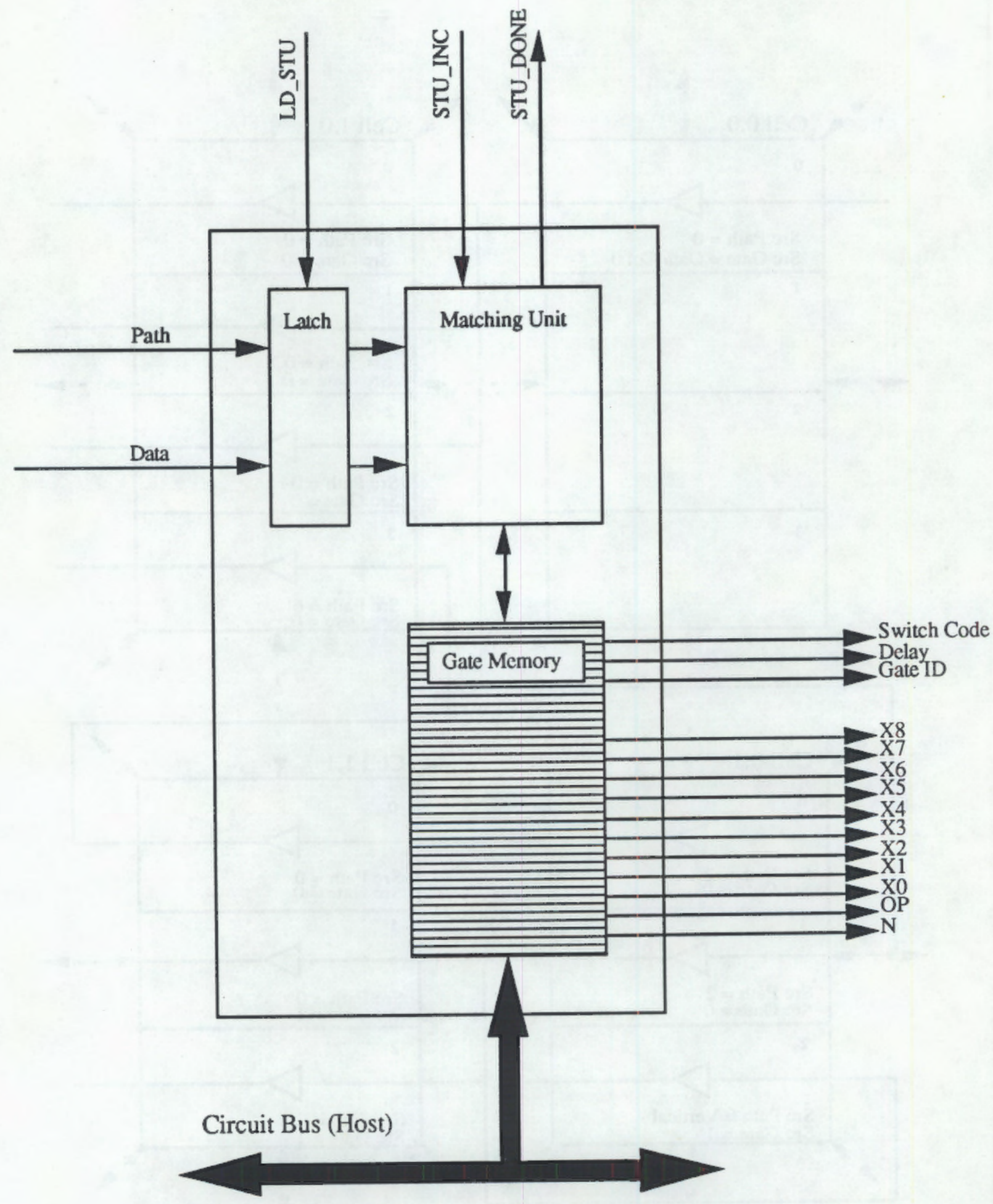

Figure 2.14 Source Translation Unit 
matching source codes. When a match is found, the data value is assigned to the input; the gate definition including its opcode and other input values is forwarded to the Boolean Logic Unit for Evaluation. Each time STU_INC is pulsed, the Source Translation Unit finds the next match. This continues until there are no more matches, at which time STU_DONE is asserted.

Timing for the SR flip-flop example is shown in fig. 2.15. Because only one NAND gate is in the cell, it is easy to follow the activity of "S" on $\mathrm{X} 0$ and "Q" on $\mathrm{X} 1$. Note that "Q" is undefined briefly at the beginning of the simulation.

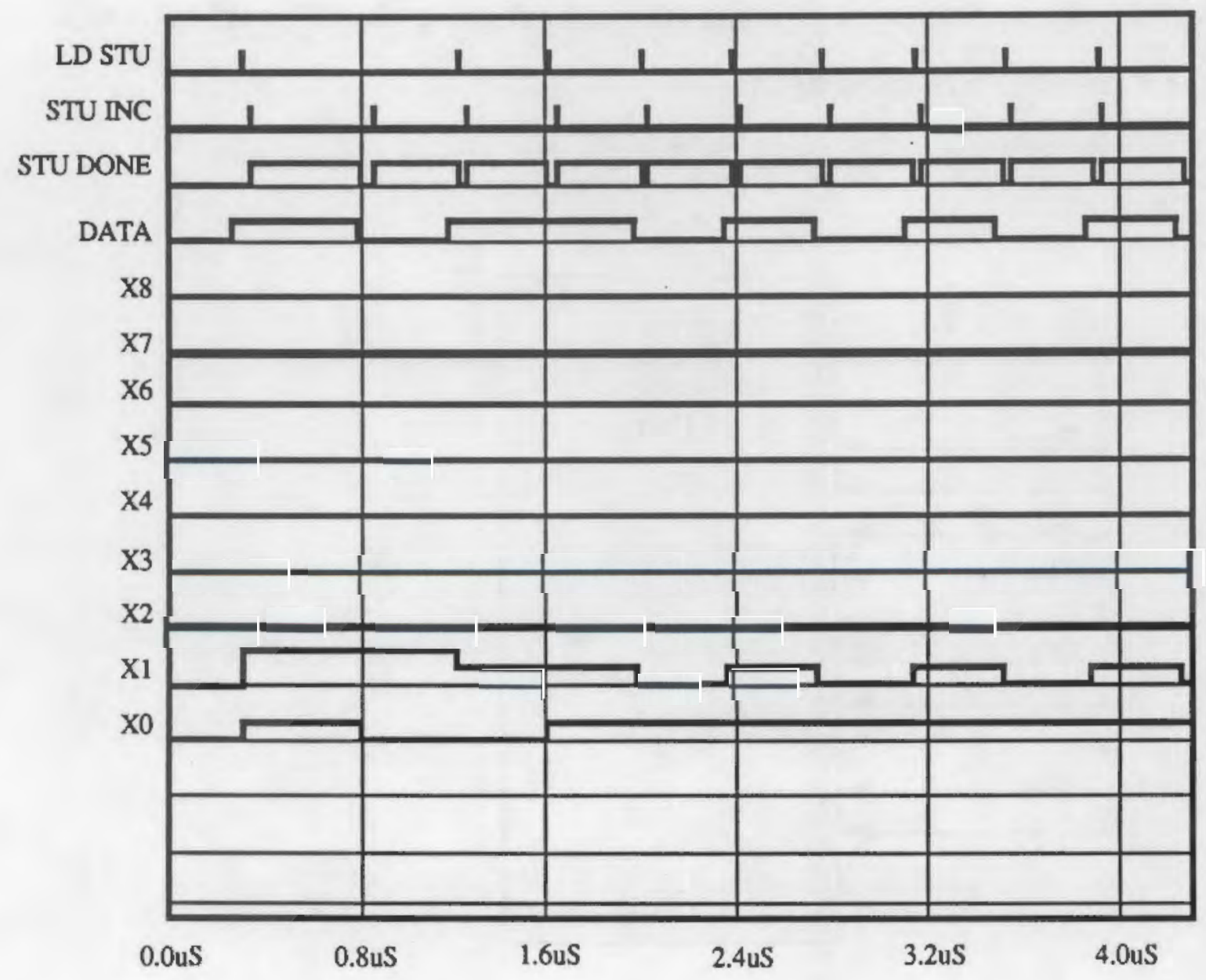

Figure 2.15 Source Translation Unit timing 


\subsubsection{Boolean Logic Unit}

The Boolean Logic Unit (fig. 2.16) consists of combinational logic that implements boolean functions for four-level logic (HI, LO, UNDEF, FLOAT ). The opcode OP selects a different block of combinational logic for each of the following primitives: WIRE, BUF, TRI, INV, AND, OR, XOR, NAND, NOR and XNOR. Appendix A contains the four-level boolean expressions that were developed for these primitives.

Timing for the SR flip-flop example is shown in fig. 2.17. Once again, it should be remembered that only one NAND gate is present in the cell. Y exhibits the correct values for fourlevel logic in response to the indicated inputs.

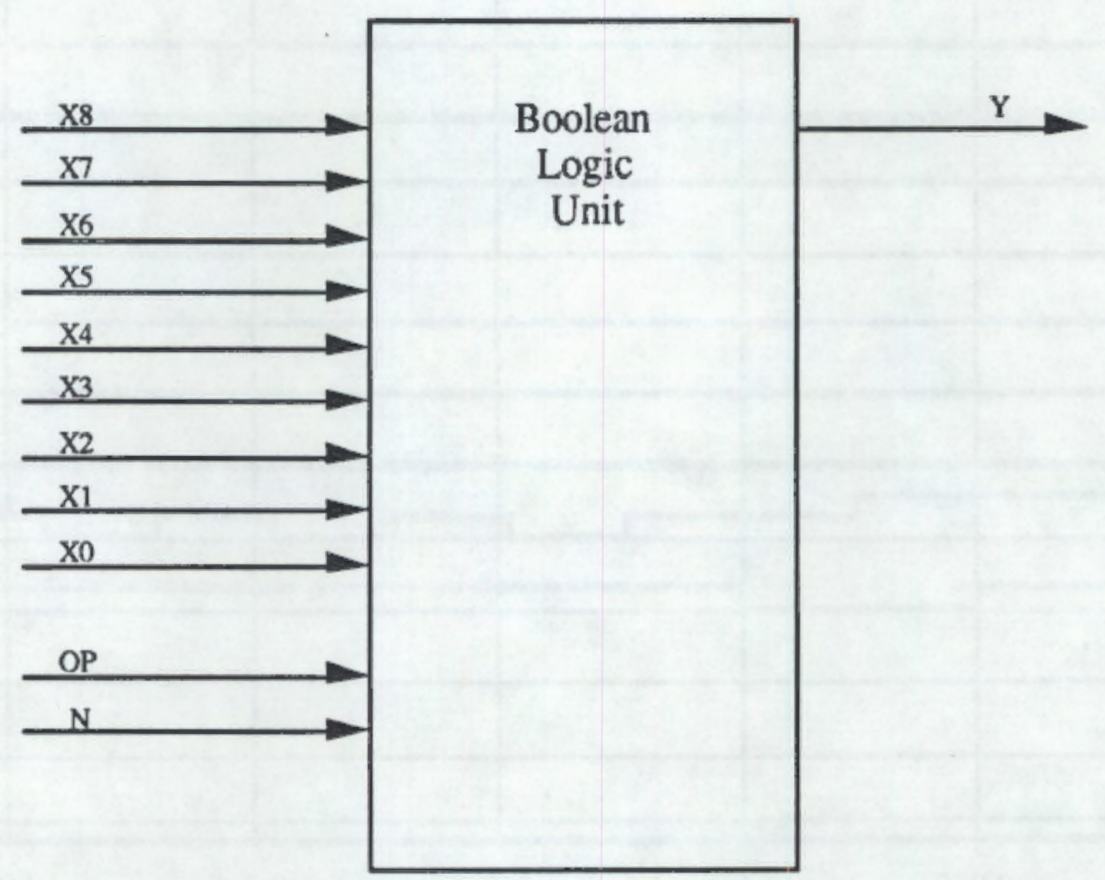

Figure 2.16 Boolean Logic Unit 


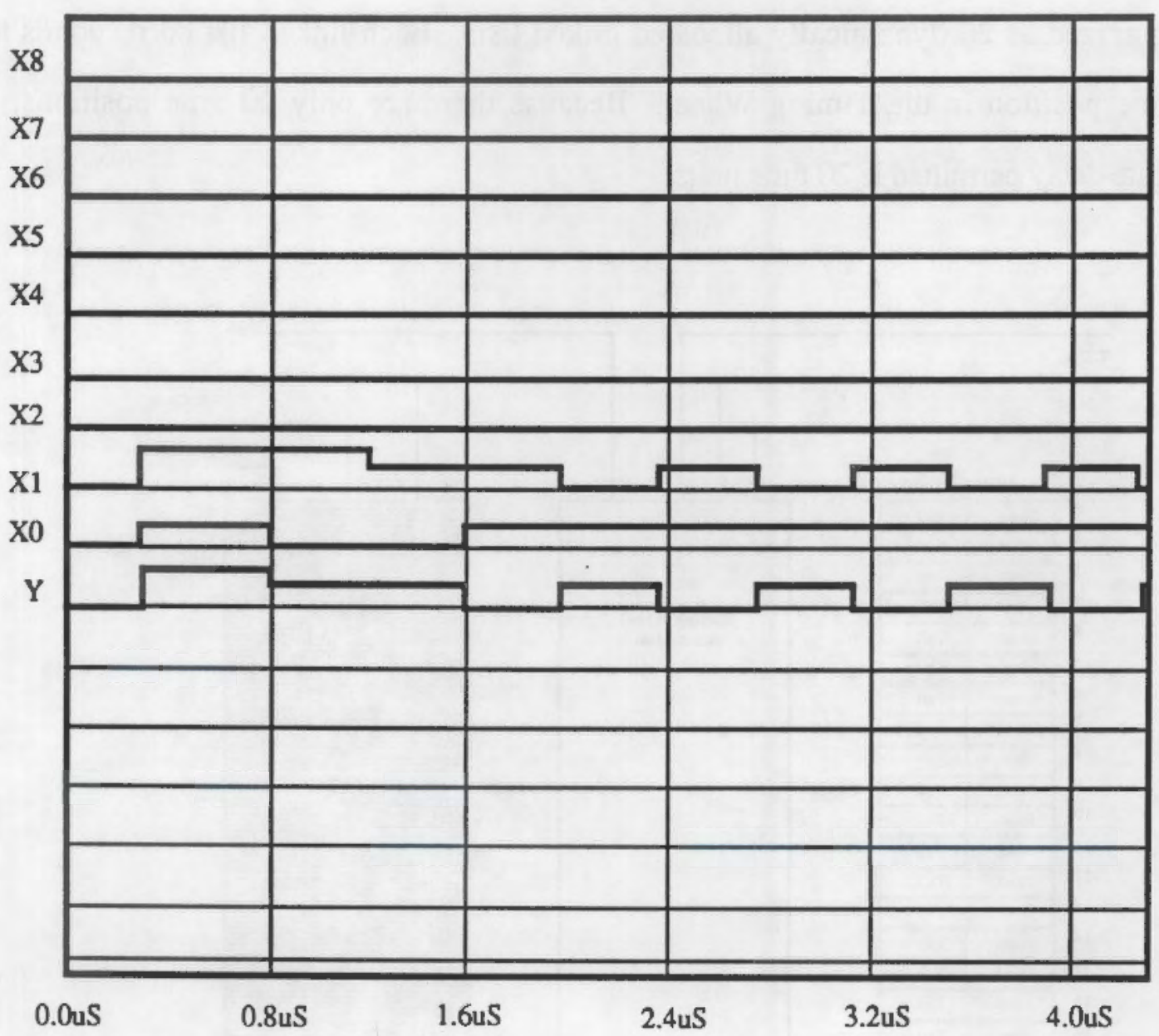

Figure 2.17 Boolean Logic Unit timing 


\subsubsection{Timing Wheel}

The Timing Wheel (fig. 2.18) is the heart of the event-list processing. It consists of a memory organized as $\mathbf{2 0}$ dynamically allocated linked lists. Each linked list corresponds to a different time position in the Timing Wheel. Because there are only 20 time positions, the maximum gate delay permitted is 20 time units.

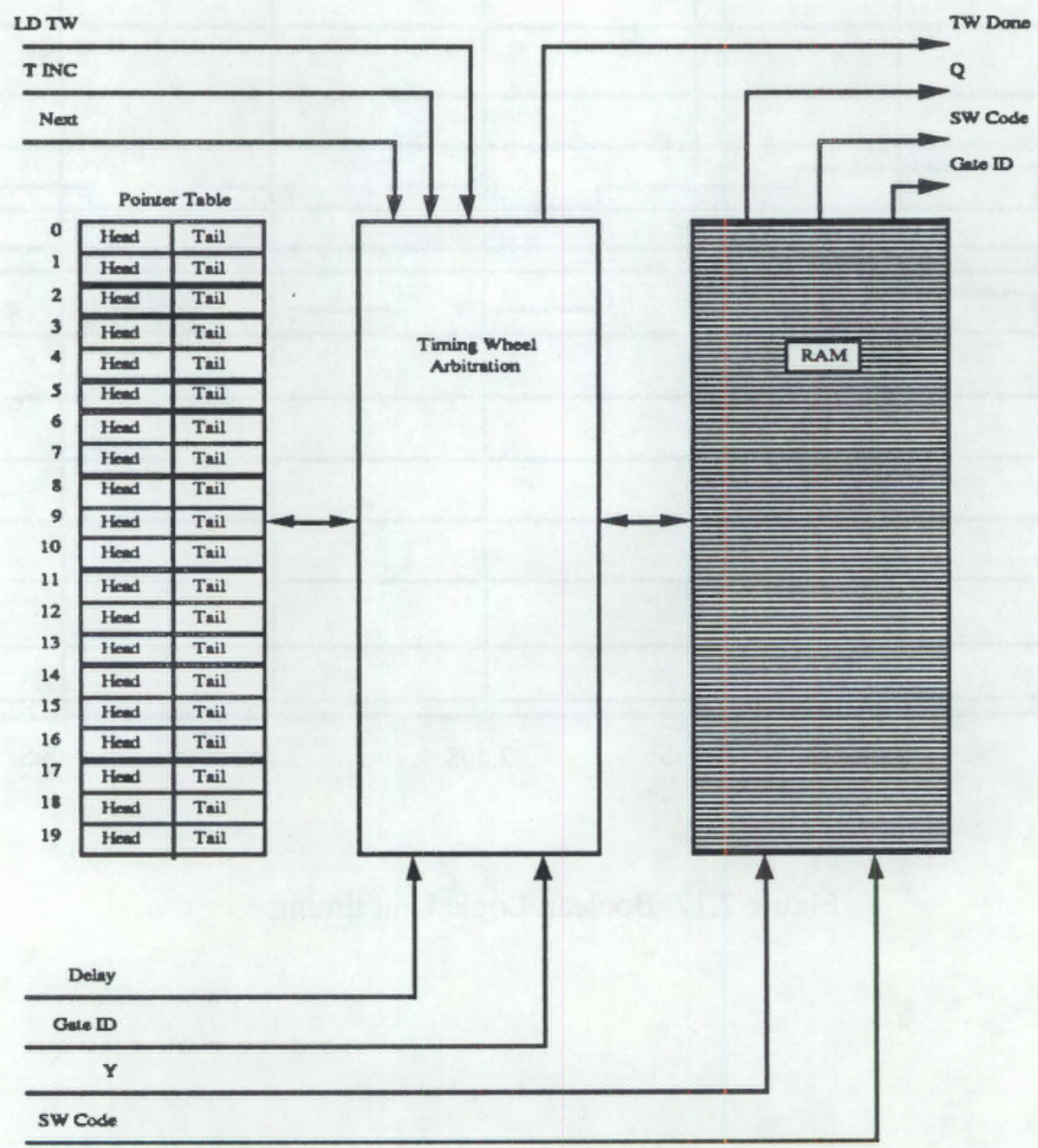

Figure 2.18 Timing Wheel 
The Timing Wheel receives the calculated output value (Y) from the Boolean Logic Unit and the gate identification, switch code and delay count from the Source Translation Unit. When LD_TW is asserted, the output value, gate identification and switch code are added to the linked list corresponding to the time position ((t+delay) mod 20).

Before an event is added to a list, the list is scanned for another occurrence of the gate identification. If it is already in the list, its datum will be replaced by the new value. This is necessary because the Source Translation Unit contains no buffering to permit all inputs for a given time to be accumulated. Gates are evaluated as soon as any new input arrives. If another input for the same time arrives later, it may be necessary to correct the previous "guess."

T_INC increments the current time position by one. NEXT retrieves the next event at the current time. TW_DONE is asserted when there are no more events at the current time.

Zero-delay elements such as WIRE require special handling. As soon as a zero-delay event is loaded into the Timing Wheel, TW_DONE is immediately de-asserted. This ensures that the Cell Controller will not release ARRAY_DONE until the zero-delay event has been handled.

Timing Wheel timing for the SR flip-flop example is shown in fig. 2.19. 


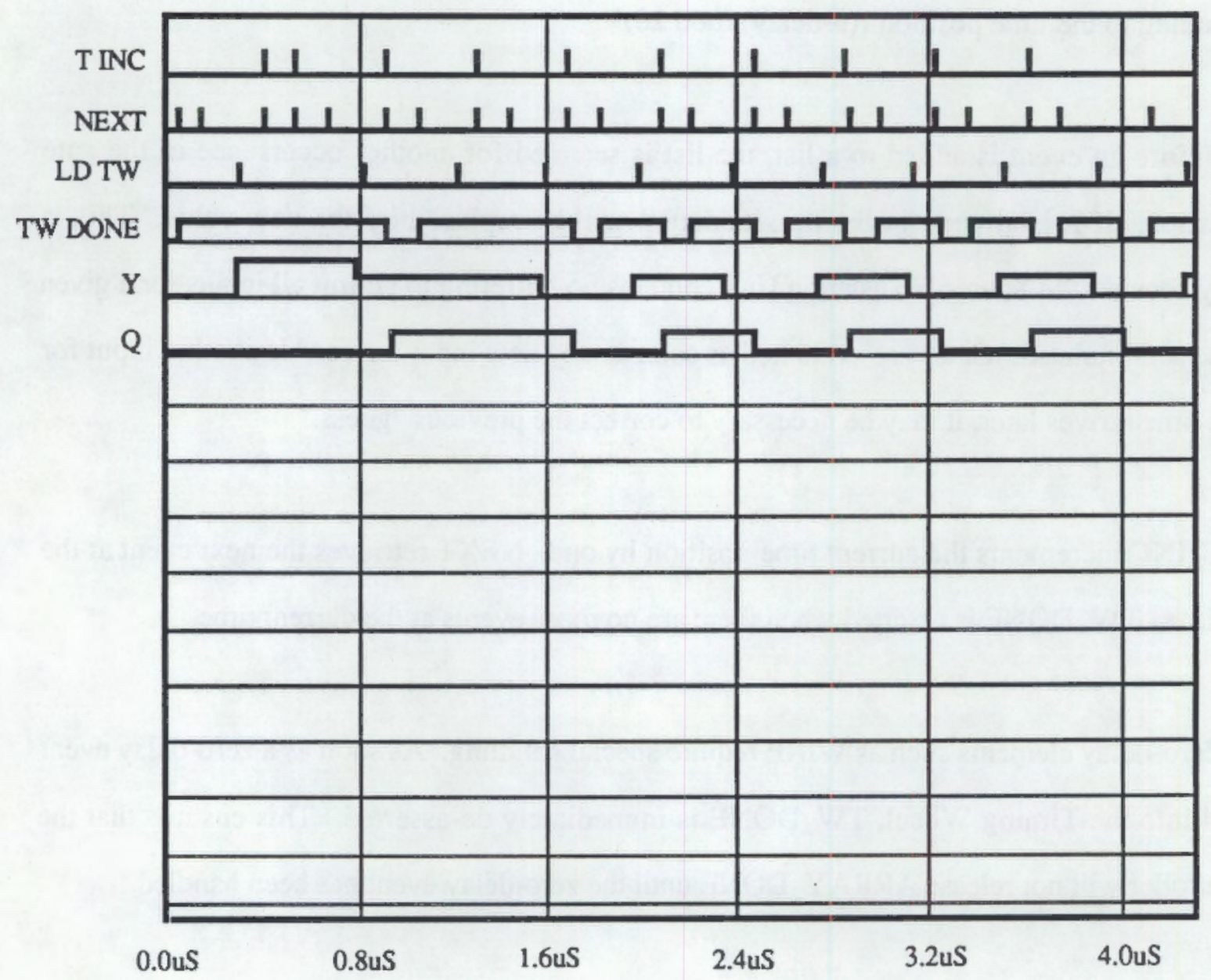

Figure 2.19 Timing Wheel timing for SR flip-flop circuit 


\subsubsection{Network Switch}

The Network Switch (fig. 2.20) is simply a latch with output enables onto nine buses. After an event is retrieved from the Timing Wheel, it is loaded into the Network Switch when LD_NS is asserted. The switch code (SW_CODE) determines onto which buses the outputs will be enabled. The outputs of latches 0 through 3 and $\mathrm{V}$ are enabled for the upshift by ESU. After the data is latched into the neighboring nodes, the outputs of latches 4 through 7 are enabled for the downshift by ESD.

Shift-up and shift-down timing are shown for the SR flip-flop example in fig. 2.21.

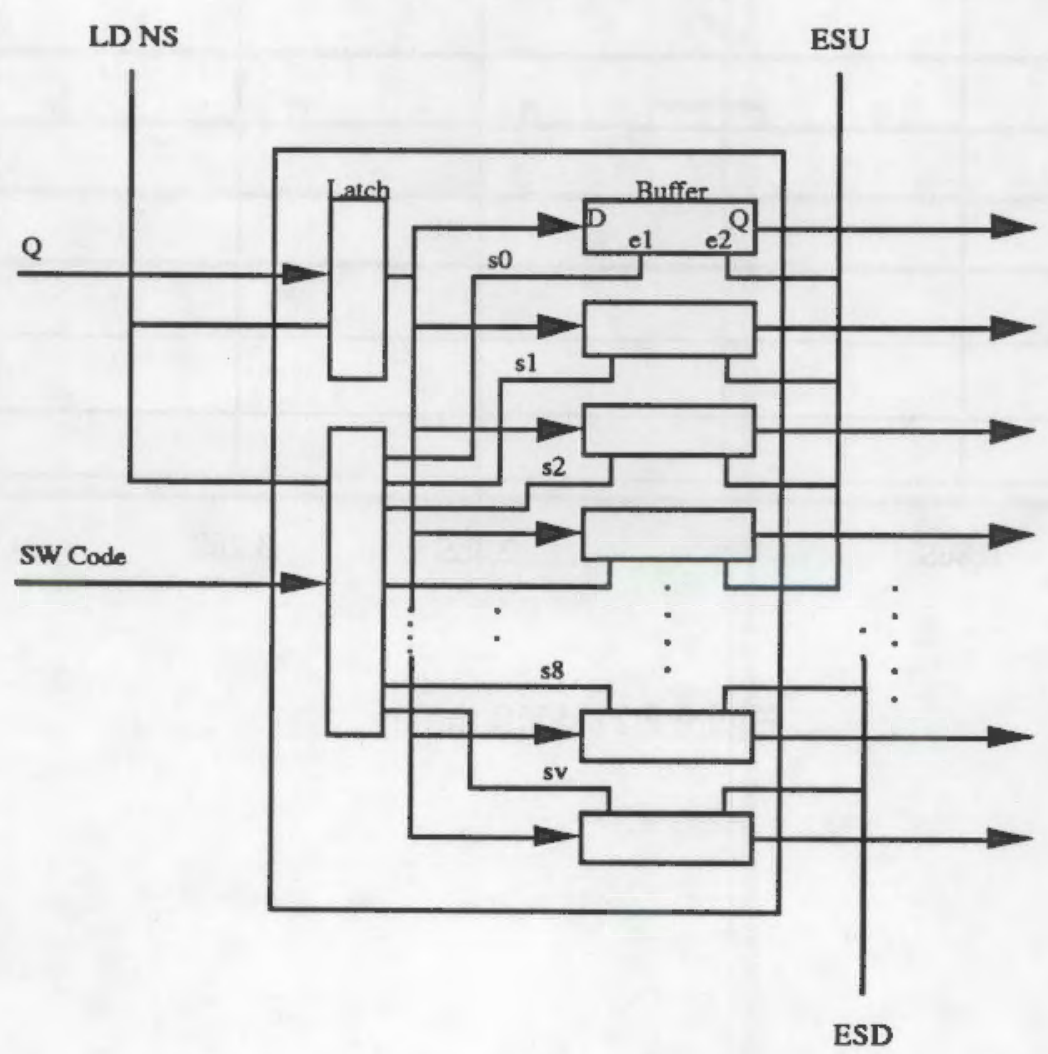

Figure 2.20 Network Switch 


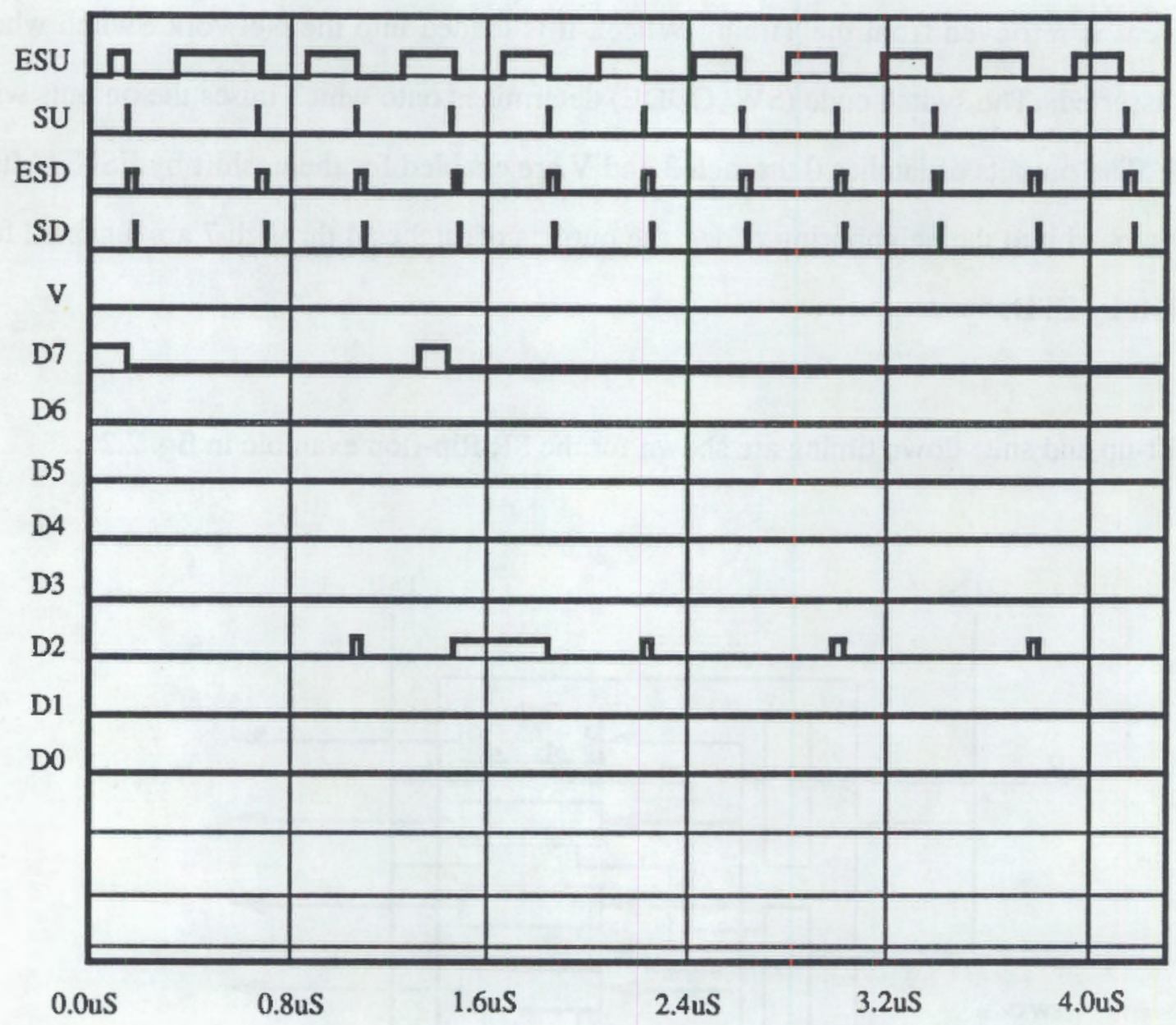

Figure 2.21 Shift timing 


\subsection{Circuit Programming Methods}

A simple circuit programming language (Appendix B) was developed to assist in entering circuits into the array. As a first attempt at exploiting the architectural benefits of the array (i.e., the combination of sequential and parallel capabilities), a simple approach was adopted for deciding the location of gates within the array. This is essentially the rank ordering described by Denneau [2] but here it is used to optimize gate mapping to exploit parallelism.

A rank is assigned to gate " $\mathrm{i}$ " depending on the maximum rank of gates providing inputs to gate " $i$ ". That is, the rank of " $i$ " is one greater than the maximum rank for each gate preceding " $\mathrm{i}$ ". The minimum rank, 0 , is for gates which only have external inputs. Feedback paths are ignored when determining rank.

In fig. 2.22 , gates 0 and 2 have external inputs only; therefore, their rank is " $0 . "$ Gate 1 has an input from gate $0($ rank $=0)$ and an external input. Thus, its rank is 1 . Gate 3 receives inputs from gate $1(\mathrm{rank}=1)$ and gate $2(\mathrm{rank}=0)$. Therefore, the rank of gate 3 is one greater than the maximum rank of gates 1 and 2 , or rank $(3)=2$.

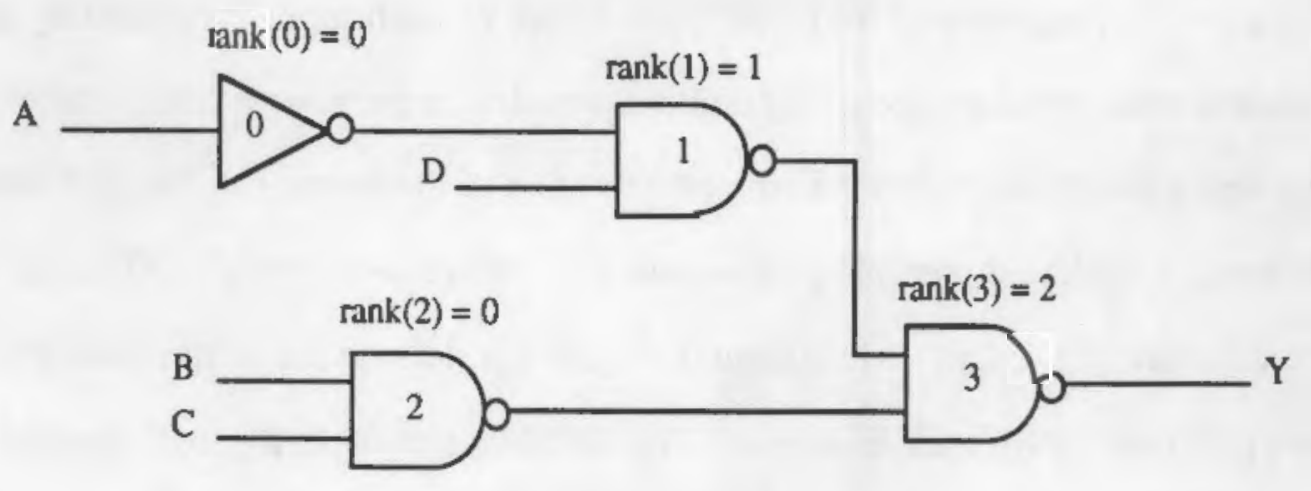

Figure 2.22 Rank ordering example 


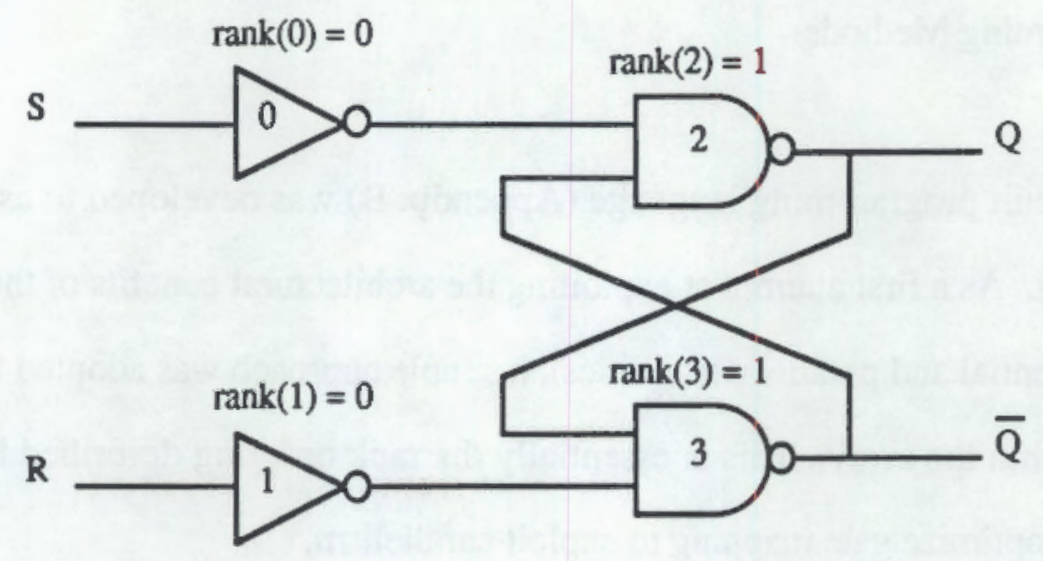

Figure 2.23 Cross-coupled NAND rank ordering example

In the cross-coupled NAND circuit of fig. 2.23 , the indicated ranking was assigned by ignoring the feedback paths.

As gates are assigned to simulator cells in the array, the ranking is used to determine which gates can co-exist in the same cell. Gates with equal rank are distributed across several cells. Gates with different ranks can be placed in the same cell or they can be placed in separate cells as desired. The choice will usually be determined by connection path minimization.

When a gate is programmed into a cell, the source of each input is defined by a source code. The source code is the source gate number appended to the source path number. Thus, when a gate is being programmed into the array, the location of the source gate for each input must already be known. Consider a possible programming of the cross-coupled NAND circuit of fig. 2.23 into a $2 \times 2$ array (fig. 2.24). When input 0 of gate 1 is defined the source gate number (0) and the source path number ( 0 ) must be known. This could be a problem if gate 0 has not yet been defined. Indeed, for much more complex circuits this becomes a significant concern. But, if the gates are programmed into the array in order from lowest to highest rank, this problem is obviated. 


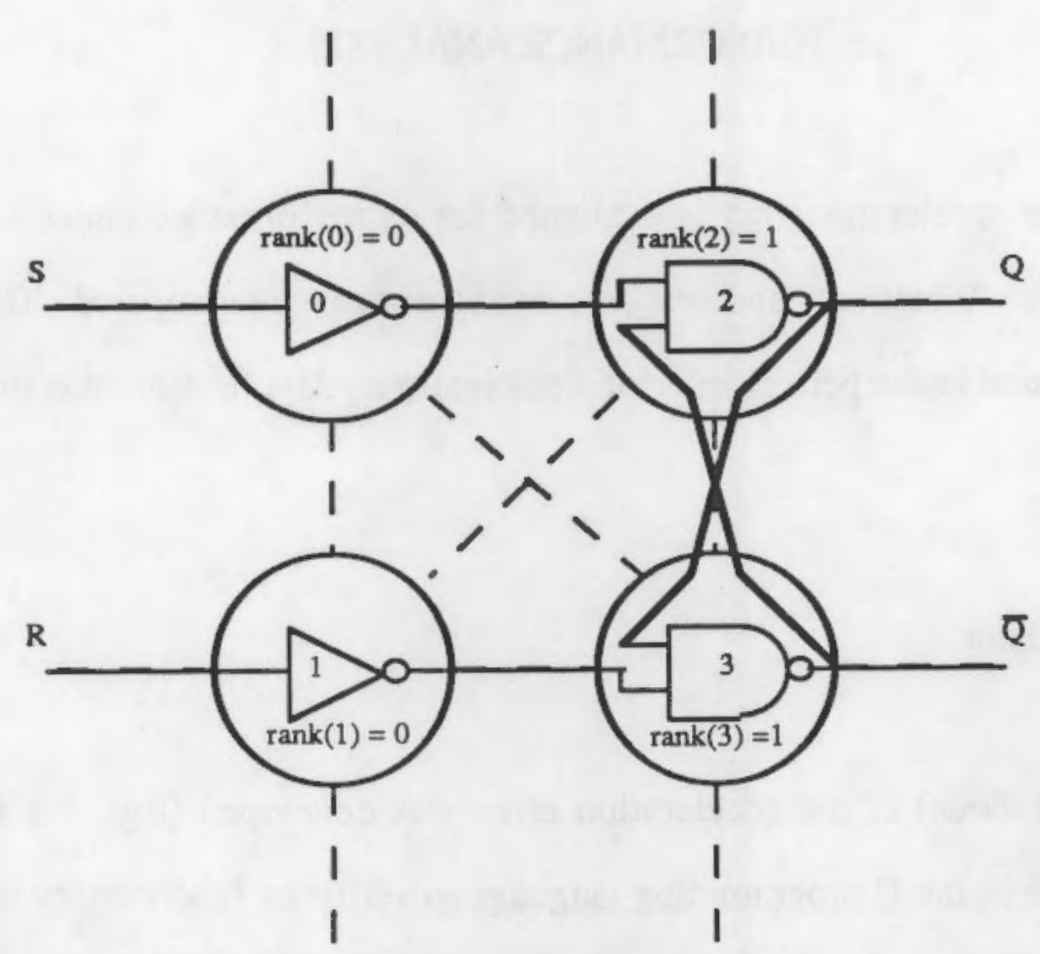

Figure 2.24 Cross-coupled NAND mapped onto $2 \times 2$ array

Thus, the process of entering gates proceeds as first assigning a rank order to the gates, then entering the gates starting with the gates of minimum rank, ensuring that gates of equal rank are not placed in the same cell. Where inputs cannot be placed adjacent to the originating gates, zero-delay elements or wires are added to complete the connection. Obviously, choice of gate location to minimize connection path will improve performance.

One flaw of this technique is that gates of different rank can in fact exhibit significant concurrency. As will be seen in the 64-inverter chain example in section 3.2.2., even though each inverter has different rank, throughput is greatly enhanced by placing each inverter in a separate cell. 


\section{CHAPTER 3 \\ PERFORMANCE ANALYSIS}

The hardware accelerator array is evaluated for its performance under a variety of test circuit configurations. Worst case and best case configurations are compared. The performance of the array is compared to the performance of a conventional data flow architecture for identical circuits.

\subsection{Behavioral Simulator}

A behavioral model of the acceleration array was developed (figs. 3.1 and 3.2) and a simulator was written in the $\mathrm{C}$ programming language to verify its functionality and evaluate its performance. This event-driven simulator (Appendix C) employs a global timing wheel to properly time every event throughout the entire array. The simulator models the behavior of each module in each cell, calculating each module output based on inputs and internal state and entering the output in the timing wheel at an assigned delay. Delays for each module output were determined from elementary module models.

The global timing wheel used by the simulator should not be confused with the timing wheel contained in each accelerator cell. The latter is an actual hardware module. 


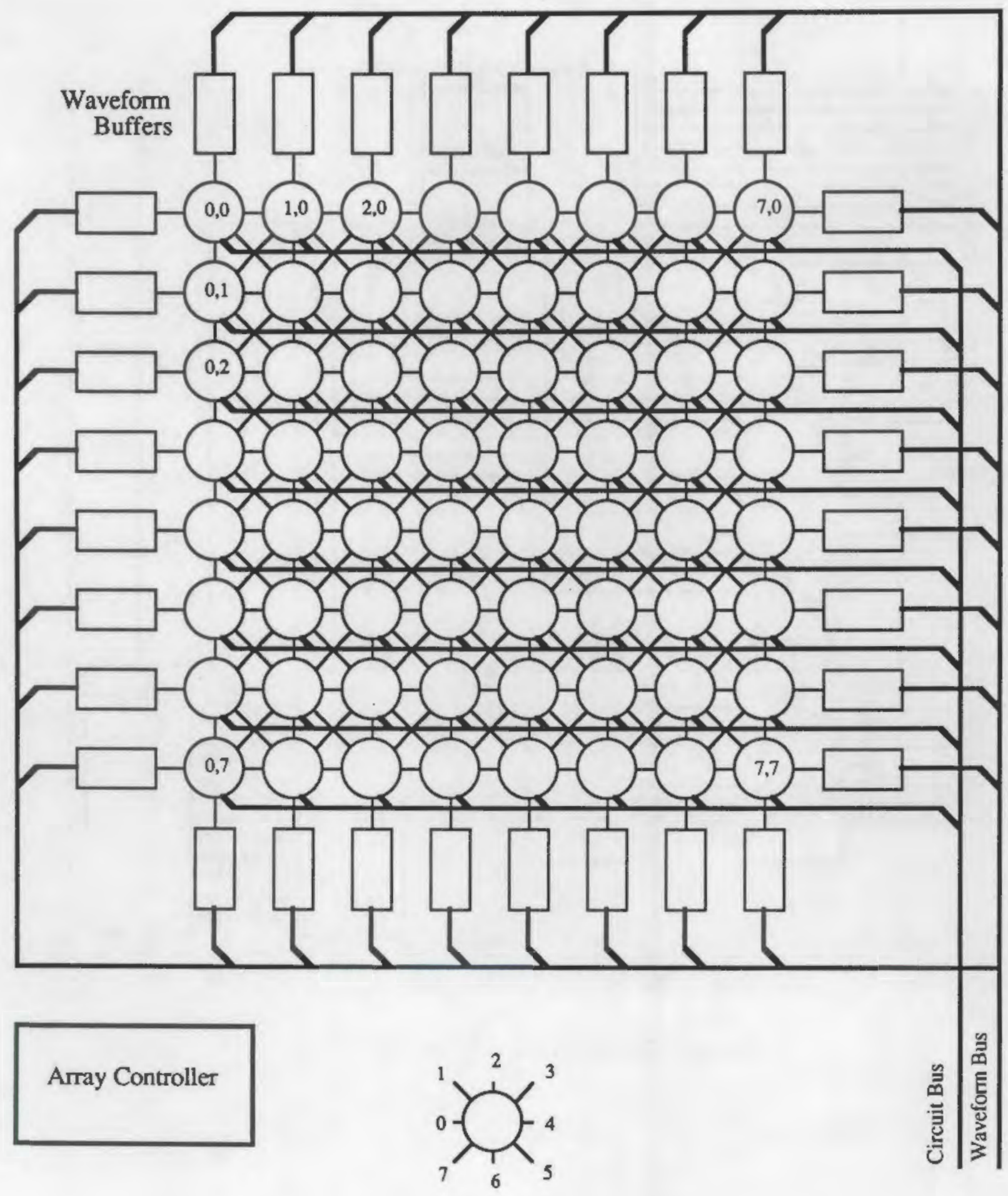

Figure 3.1 Hardware accelerator array - model 4.1 


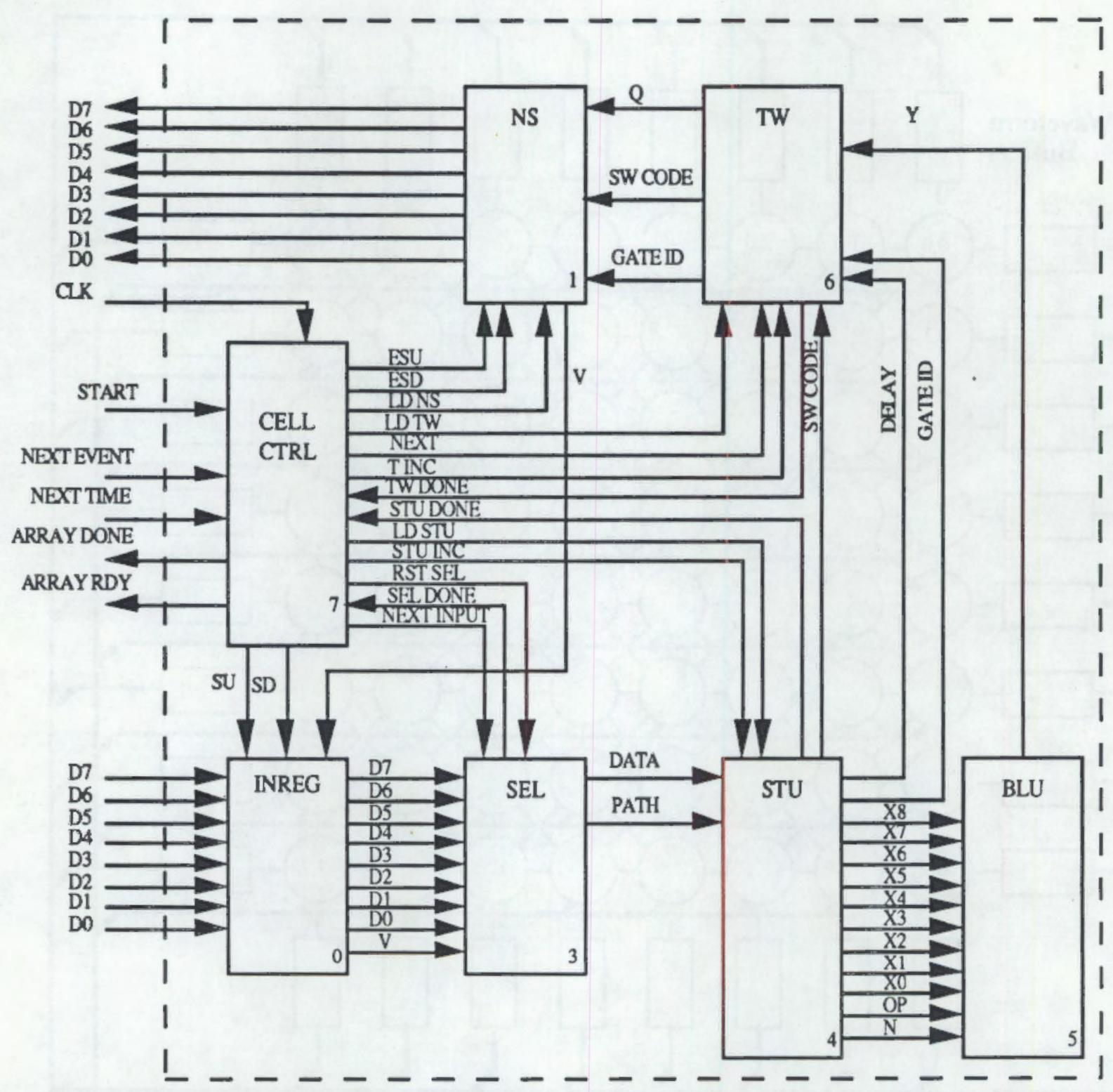

Figure 3.2 Accelerator cell - model 4.1 


\subsection{Circuit Simulations}

For the performance figures calculated in the following simulations, an array clock of $30 \mathrm{~ns}$ is assumed. For the comparative analysis, the same clock period is used for the data flow accelerator. Circuit definitions are found in Appendix D and output files are found in Appendix E.

\subsubsection{Single inverter}

Complexity: 1 gate.

Array Size: 1 cell.

A single inverter (fig. 3.3 ) with delay $=1$ is programmed into a single cell. The input to the gate toggles every simulation clock. This illustrates the performance of the hardware accelerator for a single-input gate evaluated once for each increment of the Timing Wheel. The resulting event throughput is $2.5 \times 10^{6}$ events per second.

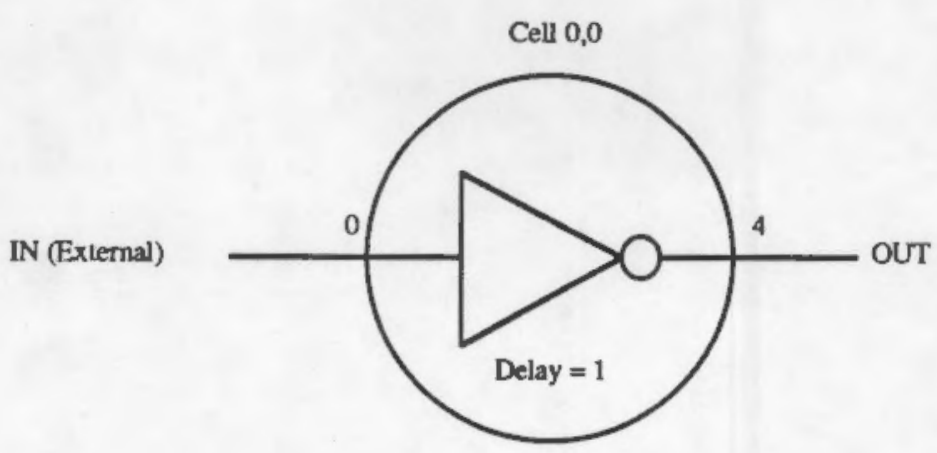

Figure 3.3 Single inverter in a single cell 
By observing the states of the Cell Controller (fig. 2.10), it is apparent that some time will be consumed by idle cycles during which no events are processed but the Timing Wheel is advanced. Additional simulations were run, increasing the circuit time between toggles (events) by one count. The results are tabulated (Table 3.1) showing average array time per processed event (1/throughput) versus circuit time between events.

Table 3.1 Increase in array time for idle cycles

\begin{tabular}{cc} 
Circuit Time/Event & Average Array Time/Event \\
\cline { 1 - 2 } 1 & $405 \mathrm{~ns}$ \\
2 & $725 \mathrm{~ns}$ \\
3 & $853 \mathrm{~ns}$ \\
4 & $981 \mathrm{~ns}$ \\
5 & $1110 \mathrm{~ns}$
\end{tabular}

Although the hardware accelerator array performs event-driven simulations, event synchronization via the Timing Wheel module degrades performance for simulation of widely spaced events. The typical degradation is approximately 11 accelerator clock cycles for the first idle circuit cycle plus 4 accelerator clock cycles for each additional idle circuit cycle. This corresponds to the time needed to increment the Timing Wheels throughout the array and verify that no events are pending. 


\subsubsection{4-inverter Chain}

Complexity: 64 gates.

To explore the effect of programming a circuit into the array in flat (parallel) versus vertical (sequential) configurations, the same circuit (a 64-inverter chain) was entered in three different ways.

Configuration 1 (fig. 3.4): A chain of 64 inverters is programmed into a single cell. The first inverter (with the external input) is in gate memory 0 of the cell. The last inverter (with the external output) is in gate memory 63. This configuration is an example of purely vertical programming. In this mode, the cell behaves as a single sequential simulator.

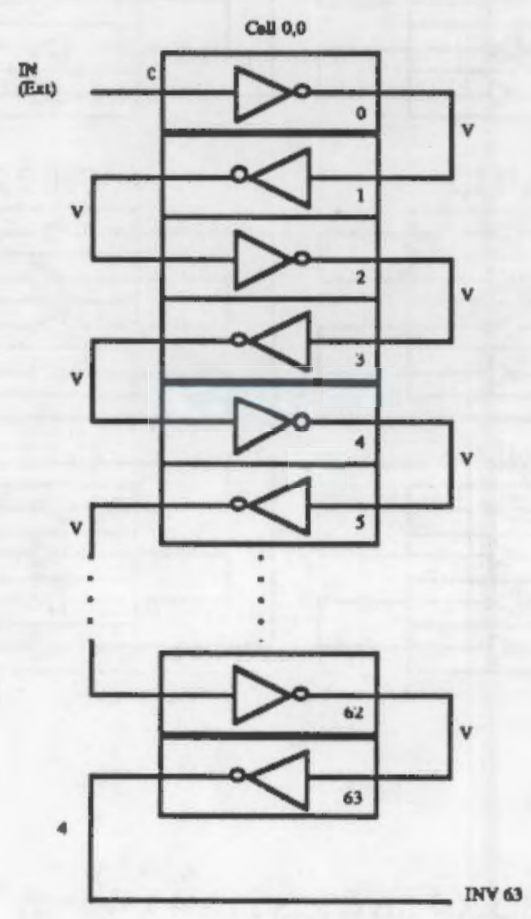

Figure 3.464 inverters in a single cell 
Configuration 2 (fig. 3.5): The inverter chain is programmed into a $4 \times 4$ array. Each cell contains four inverters from the chain. Events enter each cell and flow through the inverters starting with the one at position 0 and leaving through the inverter at position 3 . The groups of four inverters are arranged such that events pass from the top left cell $(0,0)$ all the way to the right, then go to the next row and proceed to the left. Thus, the event path is serpentine through the array. This configuration is a combination of lateral and vertical programming.

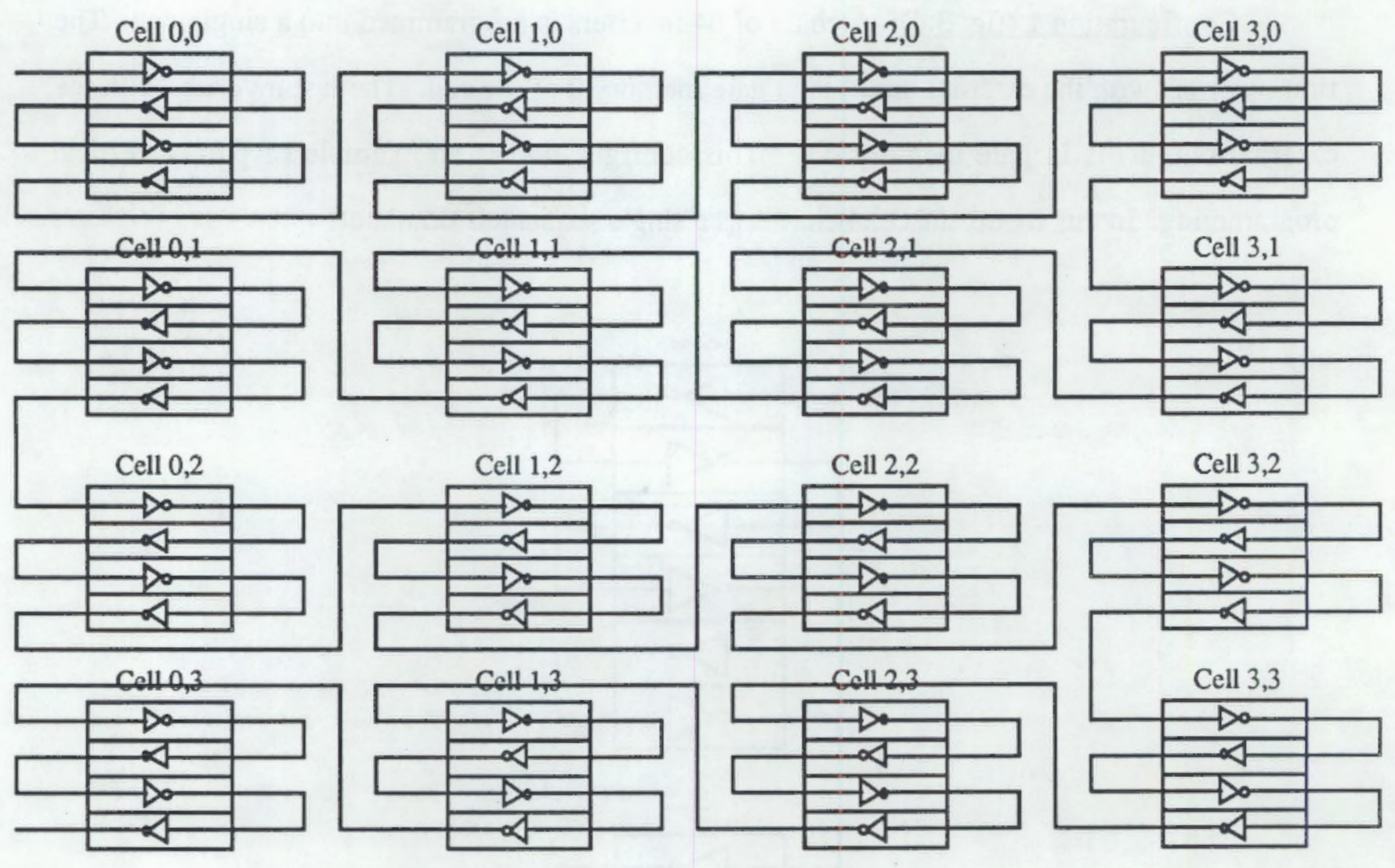

Figure 3.564 inverters in a $4 \times 4$ array 
Configuration 3 (fig. 3.6): The inverter chain is programmed into a $16 \times 16$ array with one gate in each cell. Events enter the chain in the top left cell $(0,0)$ and proceed toward the right. The events travel in a serpentine pattern across the entire array. This configuration is an example of purely lateral programming.

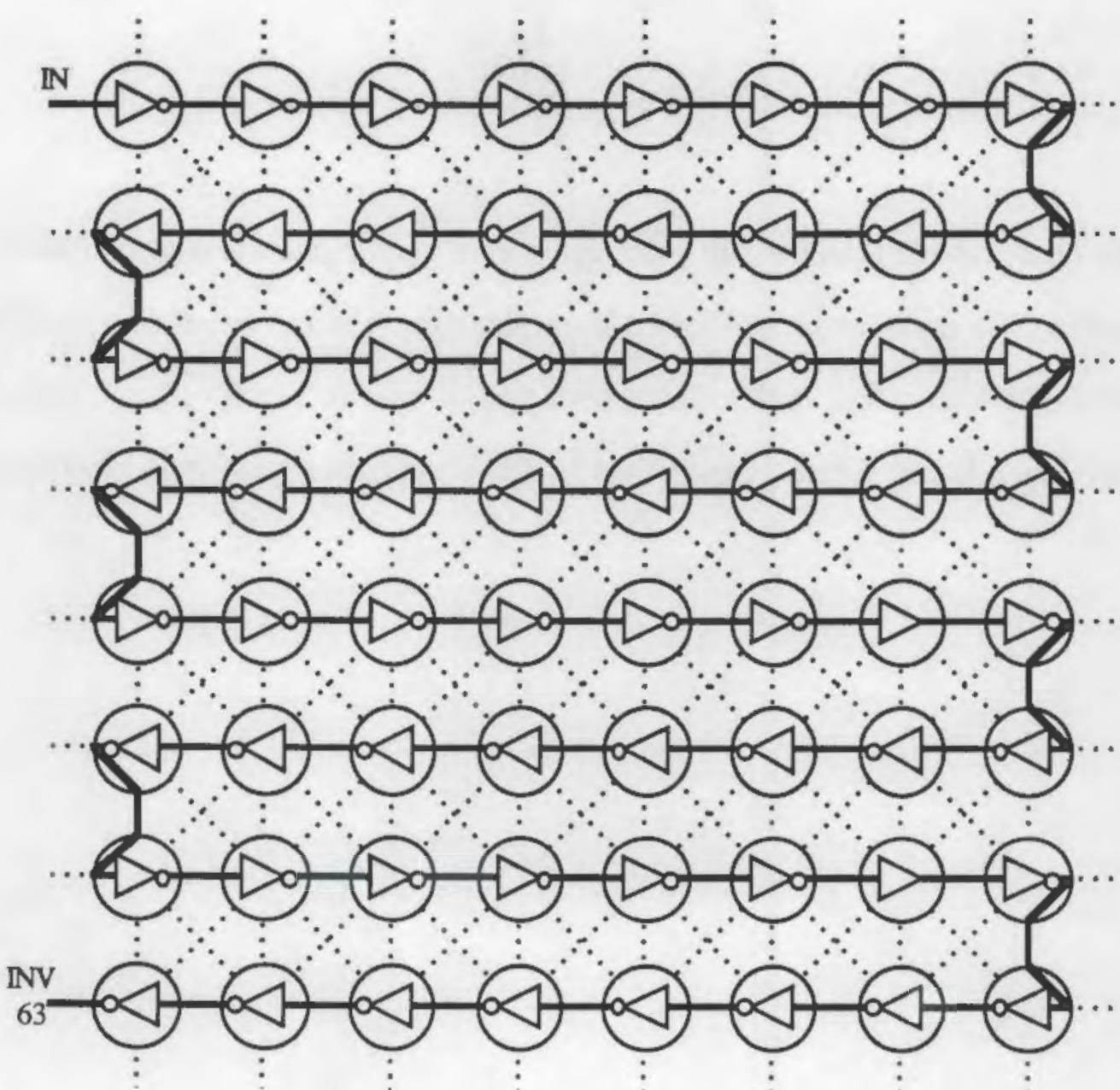

Figure 3.664 inverters in an $8 \times 8$ array 
The input data set for each configuration is identical and consists of a bit toggling each circuit clock cycle. The output files are found in Appendix E. The throughput performances are listed in Table 3.2 .

Table 3.2 Event throughput for three configurations

Configuration

Single Cell

$4 \times 4$ Array

$16 \times 16$ Array
Event Throughput (x 106 events/second)

3.816

26.076

84.442

It should be noted that until the data propagates from the input to the output of the chain, many gates remain at an undefined condition. Hence, throughput is somewhat degraded for all three configurations because of idle cycles. Because of pipelining within each cell, the throughput for 64 inverters in a single cell is much greater than $1 / 64$ th of the throughput for 64 inverters in an $8 \times 8$ array. 


\subsubsection{Pipeline Saturation Test}

Another analysis of interest is the performance of the pipeline within each node. Each input is retrieved by the Input Selector and handed to the Source Translation Unit for processing while the Input Selector locates the next valid input. The Source Translation Unit performs source matching, one gate input at a time. When a match is found, the operands and opcode are sent to the Boolean Logic Unit with ultimate destination in the Timing Wheel. While events are being stored in the Timing Wheel, additional source matching is performed in the Source Translation Unit.

Two simple tests can be performed to evaluate the pipeline performance. These are described in the following paragraphs.

Pipeline saturation test 1 (fig. 3.7): From one to eight parallel inputs arrive for different gates in a single node. This test measures how much additional time is required to handle each additional parallel input. In this case, the Input Selector must select each separate input and forward it to the Source Translation Unit for matching and evaluation. 


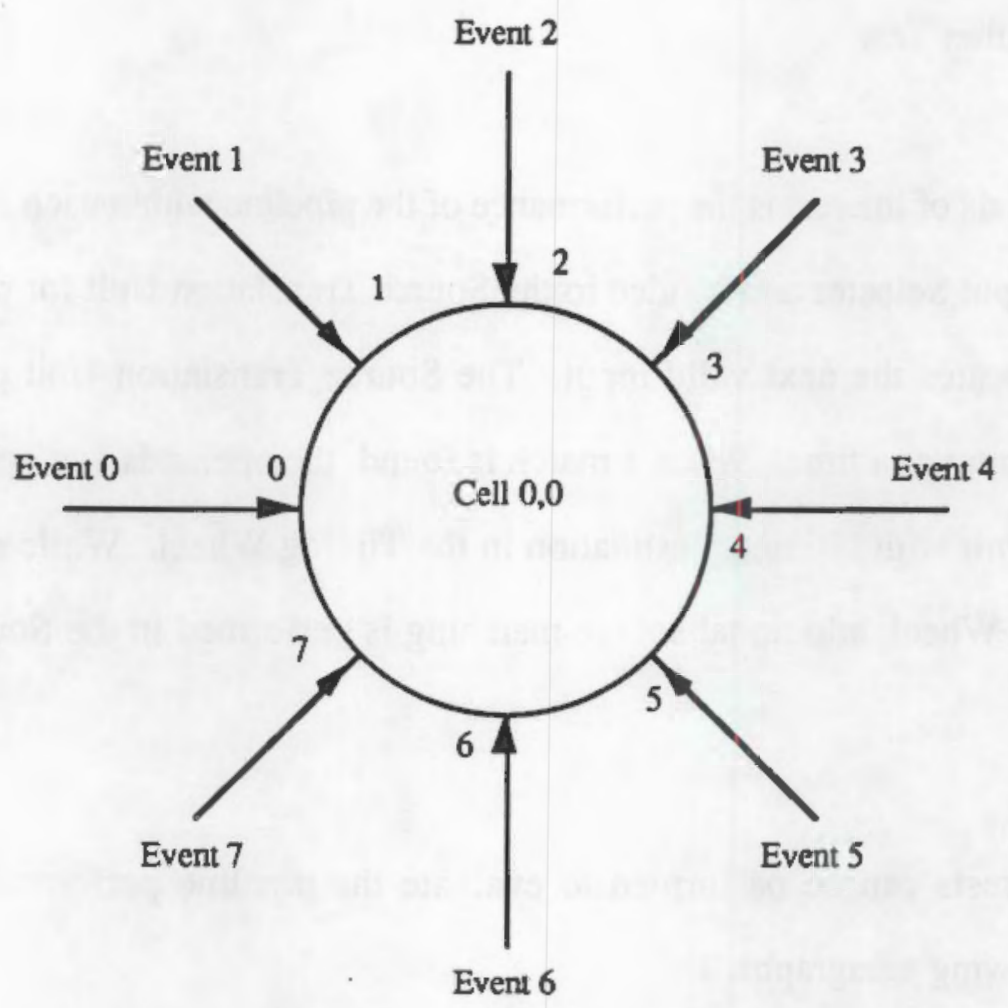

Figure 3.7 Pipeline saturation test 1

Pipeline saturation test 2 (fig. 3.8): From one to eight gates inputs have input source codes matching an event arriving at a node. The time required to handle each input as the pipeline becomes more loaded is evaluated. This is an example of vertical fanout, which is limited only by gate memory depth but may degrade performance when taken to an extreme level. Vertical fanout is handled by the Source Translation Unit, which matches the event with each gate input having the correct source code. 


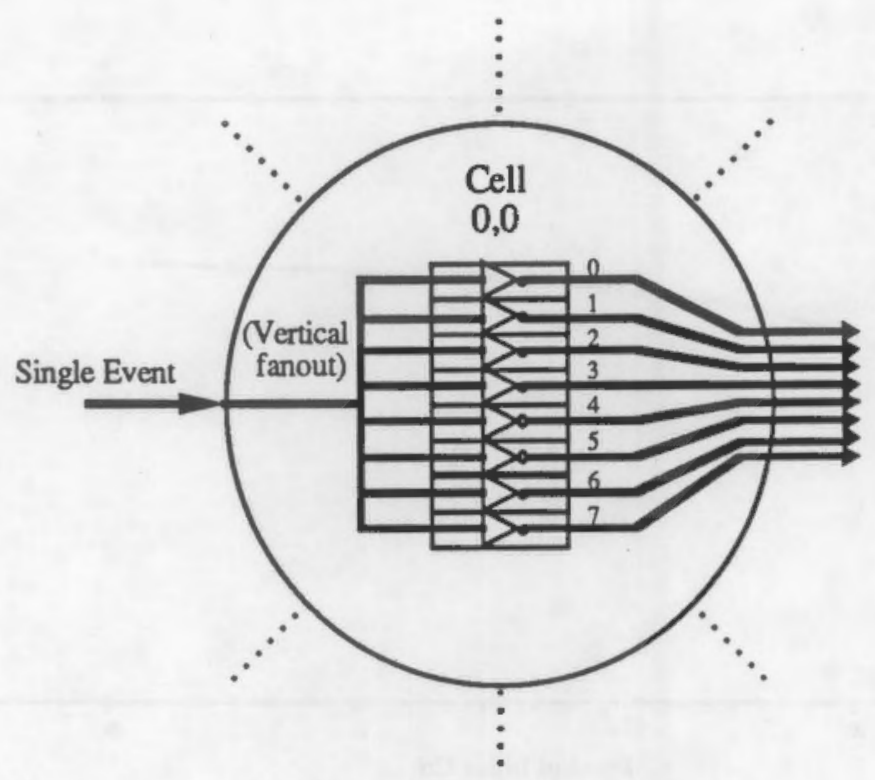

Figure 3.8 Pipeline saturation test 2

\section{Pipeline Saturation Test Results}

The input data for each input is simply a bit sequence that toggles every circuit clock cycle. The results of the pipeline saturation tests are tabulated in this section. The results for test 1 are listed in Table 3.3.

Table 3.3 Throughput versus parallel input count

\section{Parallel Input Count Throughput ( x 106 events/second)}




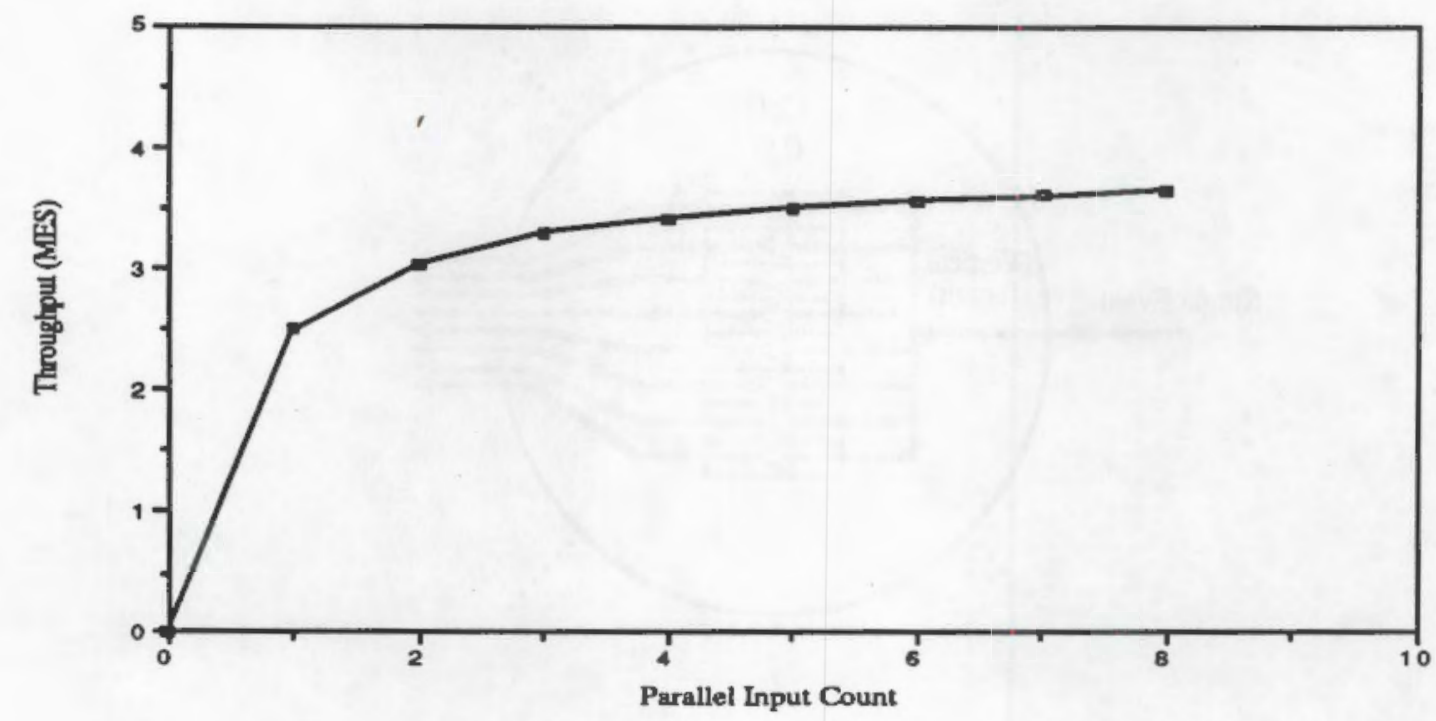

Figure 3.9 Saturation test 1 - throughput versus parallel input count

As can be seen in fig. 3.9, the throughput approaches an upper limit (near $3.7 \times 10^{6}$ events per second) as the number of parallel inputs increases.

The value of this high throughput for parallel inputs may not be significant for some circuits because that degree of parallelism rarely exists unless the inputs were derived from a common clock. [10] 
Table 3.4 displays the results of pipeline saturation test 2 .

Table 3.4 Throughput versus vertical fanout count

\begin{tabular}{cc} 
Vertical Fanout Count & Throughput $(\times 106$ events/second $)$ \\
\hline 1 & 2.486 \\
2 & 3.038 \\
3 & 3.528 \\
4 & 3.616 \\
5 & 3.851 \\
6 & 3.860 \\
7 & 4.008 \\
8 & 3.995
\end{tabular}

As can be seen in fig. 3.10 , source matching saturates at a throughput of approximately 4.0 x $10^{6}$ events per second. A high throughput accommodating large fanouts can be significant to overall simulation performance. It should be noted that very high fanouts can be accommodated by making use of lateral fanout in combination with vertical fanout. Lateral fanout is simply the distribution of events to neighboring nodes via the Network Switch. 


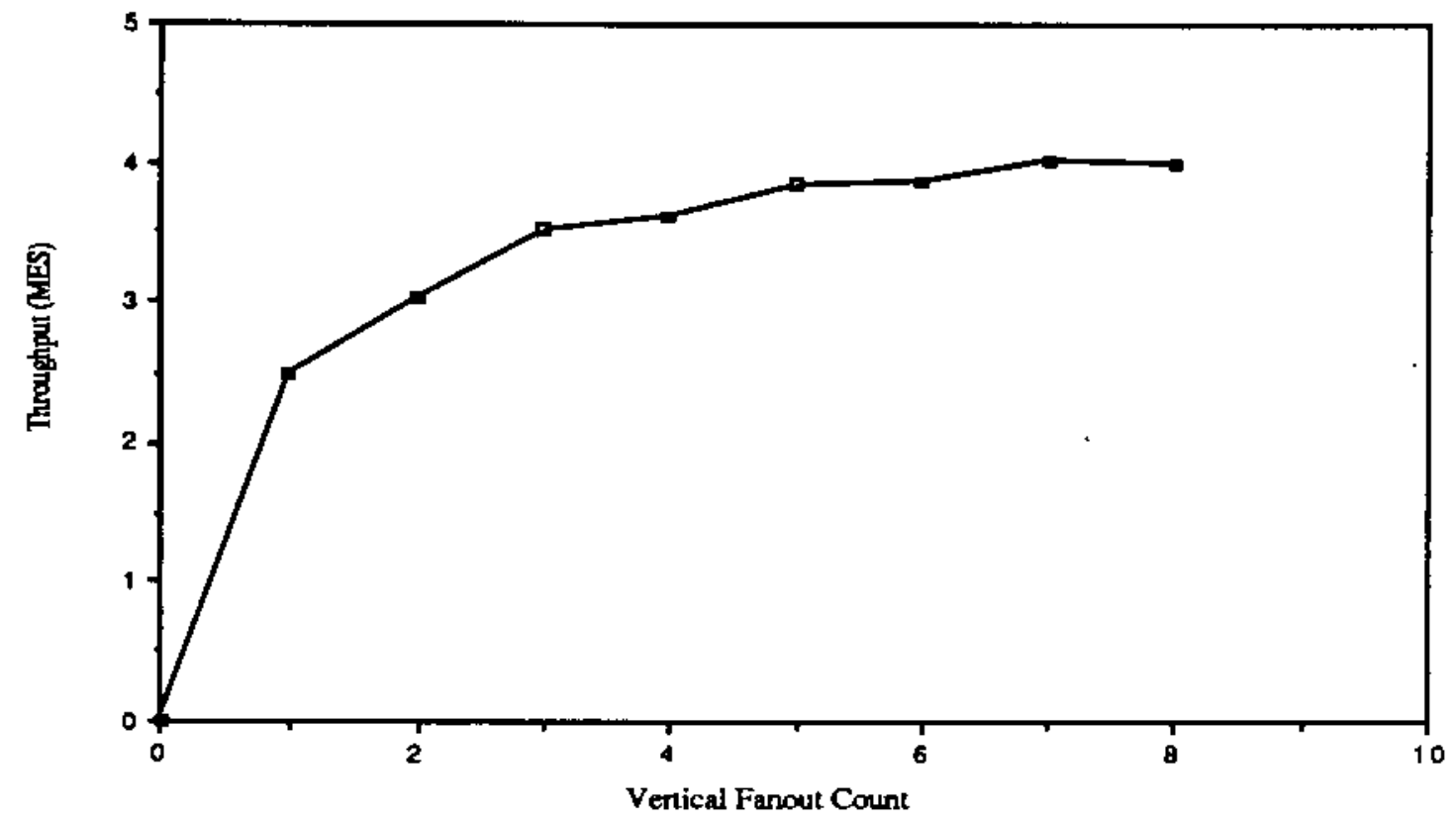

Figure 3.10 Saturation test 2 - throughput versus vertical fanout count

\subsubsection{Zero-delay path test}

A simple test was devised to determine the time required to process a zero-delay wire connection. The test circuit (fig 3.11) consists of two inverters separated by from zero to eight zero-delay wires. The input data stream consists of a single bit toggled every clock cycle. The results are shown in Table 3.5. 


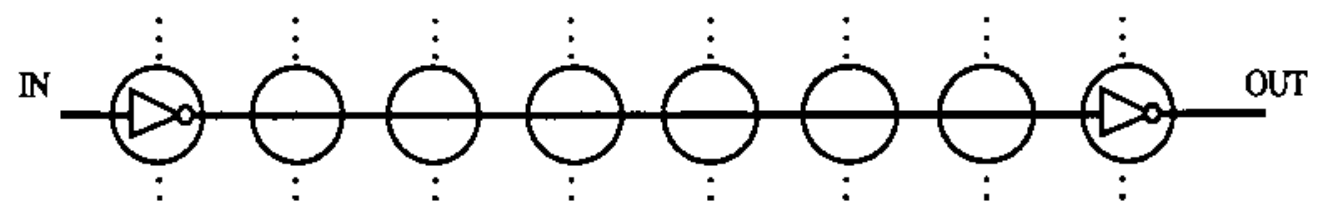

Figure 3.11 Zero-delay path test (shown for six wire elements)

Table 3.5 Performance degradation caused by long paths

\begin{tabular}{ccc} 
Zero-delay wires & Array time/event(ns) & Increment(ns) \\
\cline { 3 - 3 } 0 & 208 & 0 \\
1 & 438 & 230 \\
2 & 667 & 229 \\
3 & 895 & 228 \\
4 & 1128 & 233 \\
5 & 1356 & 228 \\
6 & 1587 & 231 \\
7 & 1815 & 228 \\
8 & 2046 & 231
\end{tabular}

The average time consumed by each additional wire connection is $230 \mathrm{~ns}$. This is a worst case test because, for a typical circuit, the processing of wire connections might occur in parallel with the processing of other circuit elements. 


\subsubsection{Cross-coupled NAND}

Complexity: 2 gates.

Array Size: 2 cells

The cross-coupled NAND (fig. 3.12a) demonstrates the performance of the system for a simple circuit with feedback. In accordance with the cell programming methodology described in section 2.5, the two NAND gates are assigned to separate cells (fig. 3.12b). The $S$ and $R$ inputs are external. The cross-coupled connections pass between the two cells sharing a common data path.

In the simulation, both inputs $(S, R)$ are taken low and then brought high, causing the flipflop to oscillate. The flip-flop is then set and reset. The resulting circuit timing is shown in fig. 3.13 .

The average throughput for this simulation is $3.495 \times 10^{6}$ events per second. Detailed cell timing for this circuit is shown for each cell module in section 2.4 . 


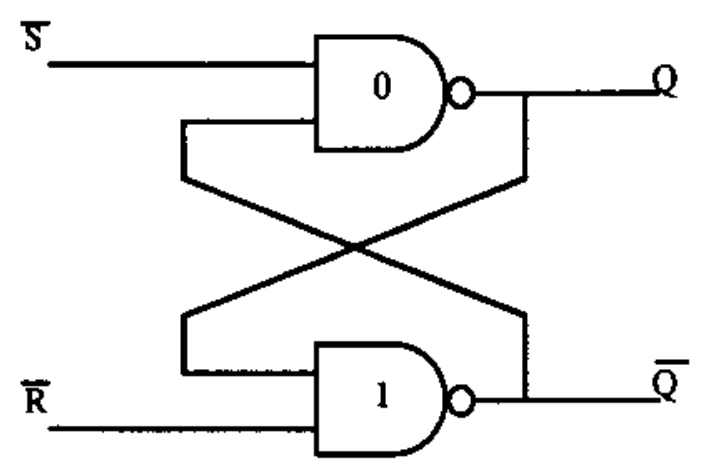

(a) Cross coupled NAND

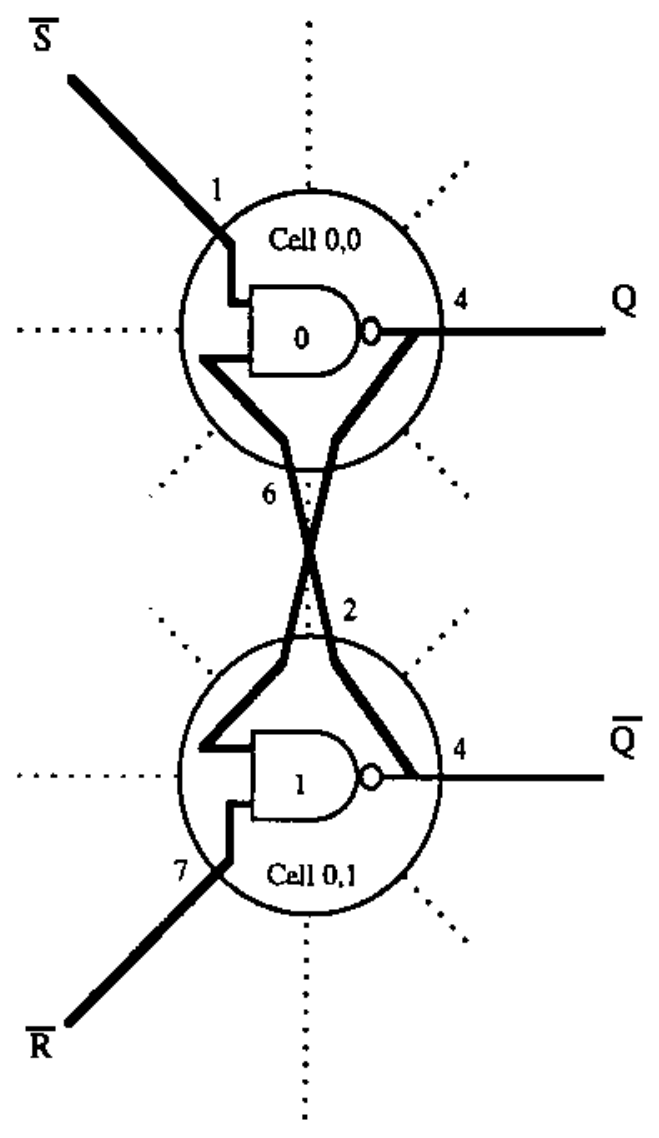

(b) Mapping onto a $1 \times 2$ array

Figure 3.12 A cross-coupled NAND and its mapping 


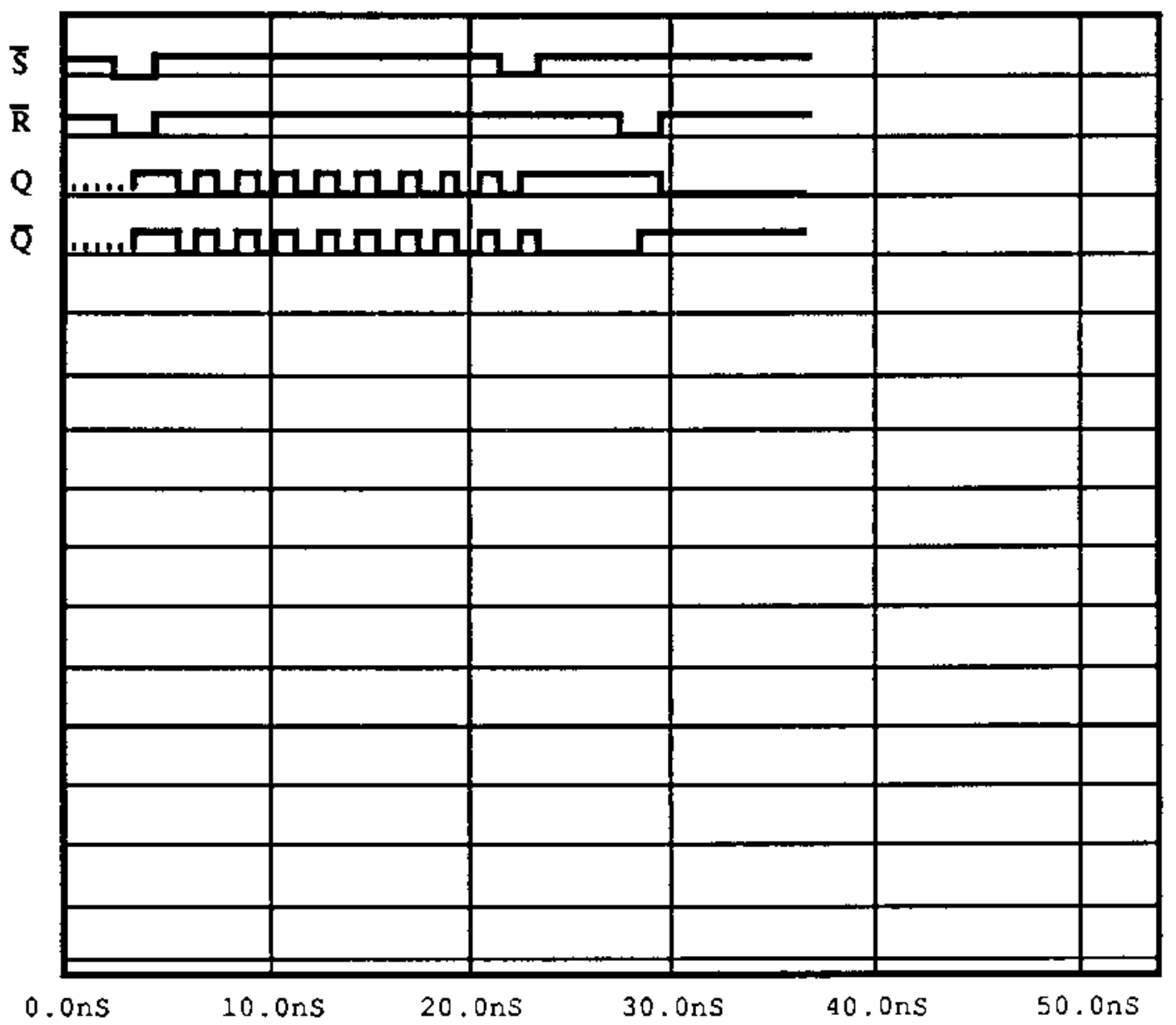

Figure 3.13 Cross-coupled NAND circuit timing 


\subsubsection{Rising-Edge Trigger D Flip-Flop}

Complexity: 6 gates.

Array size: 6 cells.

The rising-edge trigger D flip-flop (RET D FF) (fig. 3.14) is a basic memory element that is used to construct the 4-bit counter simulated in the next section. This circuit demonstrates the performance of the array for a very simple clocked logic element.

The circuit timing is shown in fig. 3.15. The average throughput for this circuit is $2.437 \mathrm{x}$ 106 events per second.

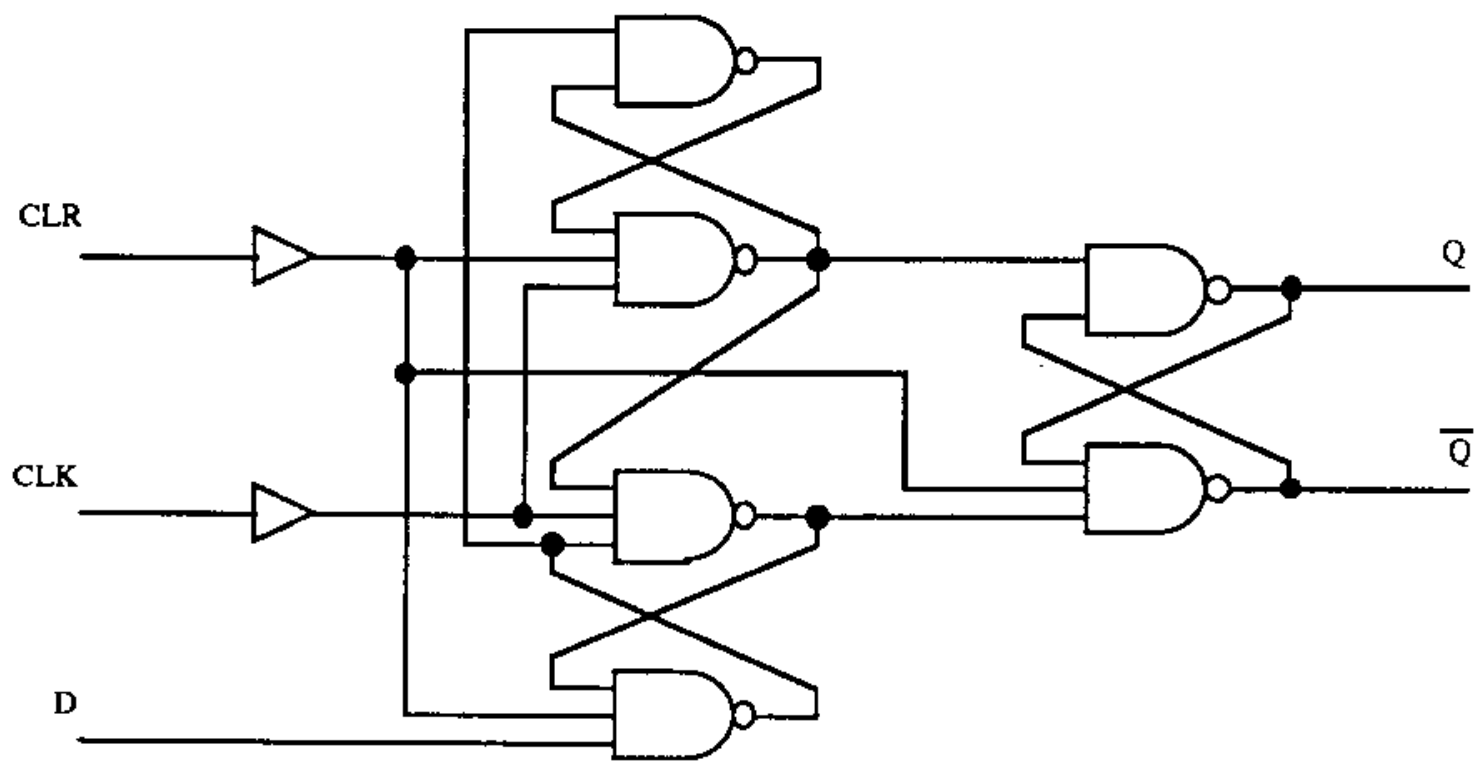

Figure 3.14 Rising-edge trigger D flip-flop 


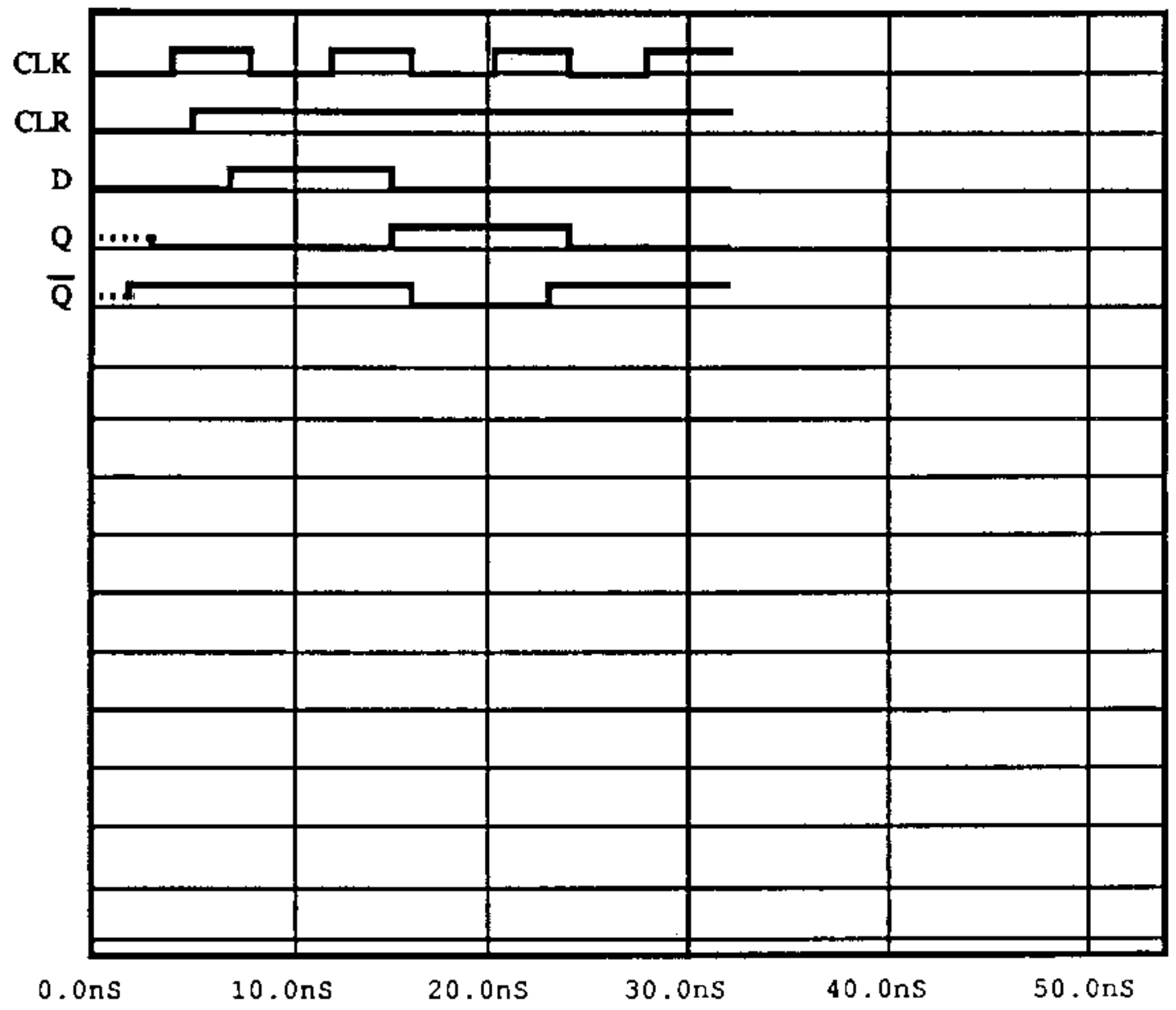

Figure 3.15 Circuit timing for rising-edge trigger $\mathrm{D}$ flip-flop 


\subsubsection{4-bit Counter}

Complexity: 39 gates.

Array size: 30 cells.

Zero-delay wires: 17 .

The 4-bit counter (fig. 3.16) is a clocked circuit constructed from four RET D flip-flops and four next-state decoder circuits. The RET D flip-flops are the same as the one simulated in section 3.2.5. However, to minimize connection paths, each individual flip-flop was programmed into only four cells instead of six. Even so, 17 zero-delay wire connections were required to distribute current states to the next-state decoders. This circuit demonstrates the performance of the array for a slightly more complex clocked circuit. It also demonstrates the performance of the array when several zero-delay wire connections must be employed.

The average throughput for this circuit is $4.276 \times 10^{6}$ events per second. The average throughput is not a factor of four times the throughput for a single RET D flip-flop. This is expected because the level of activity for each flip-flop is much lower in the counter circuit than it was for the simulation in section 3.2.5. Hence, each clock transition will have a lower event count. It should be noted that even during a clock transition, a flip-flop will generate no events if its state remains unchanged. 


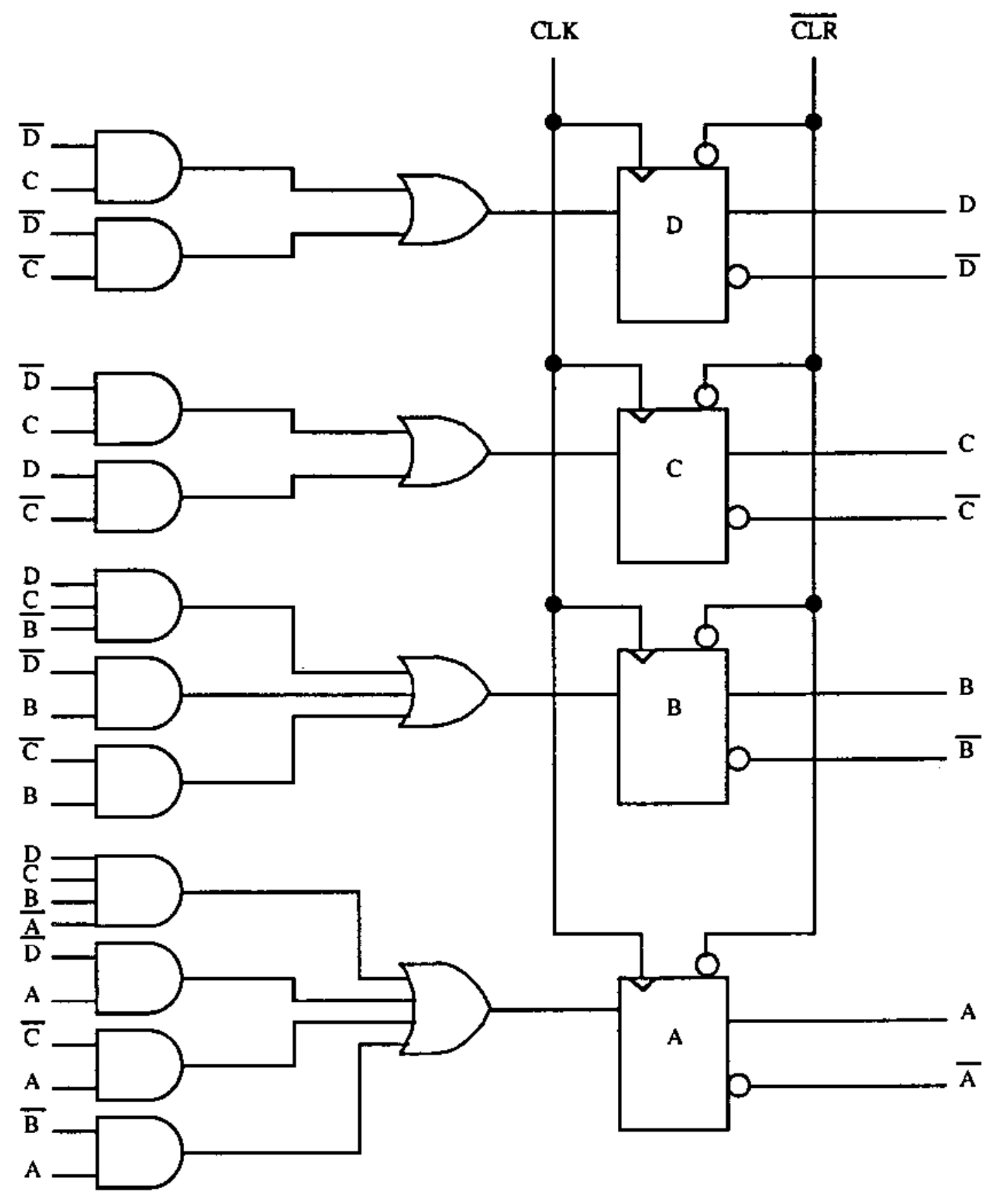

Figure 3.16 4-bit binary counter 


\subsubsection{Multiplier Arrays}

A multiplier array is constructed from the basic cell shown in fig. 3.17. It is a purely combinational circuit and, for large arrays, a significant amount of time may be required for the outputs to stabilize. These simulations demonstrate fairly complex combinational circuits that require a large number of zero-delay wire connections. The design of these multiplier arrays follows Glassner [11].

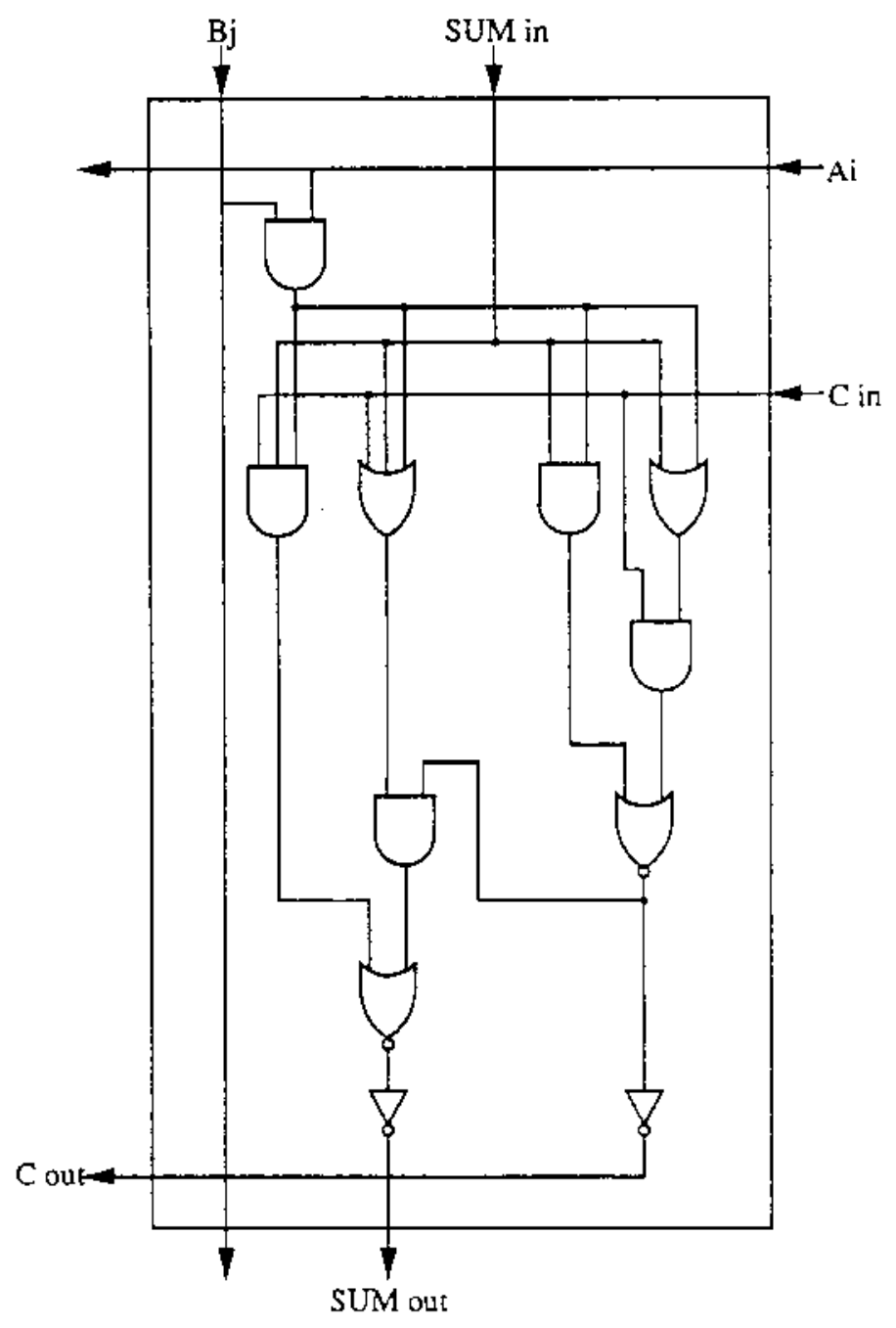

Figure 3.17 Basic multiplier cell 
64

$\underline{2 \times 2 \text { Multiplier Array }}$

Complexity: 44 gates.

Array Size: 16 cells.

Zero-delay wires: 24 .

The interconnection of the basic cells to form a $2 \times 2$ array is shown in fig. 3.18. The input simulation data cover a complete 2 -bit multiplication table. The results of the simulation may be found in appendix $E$. The average throughput for this circuit is $2.076 \times 106$ events per second.

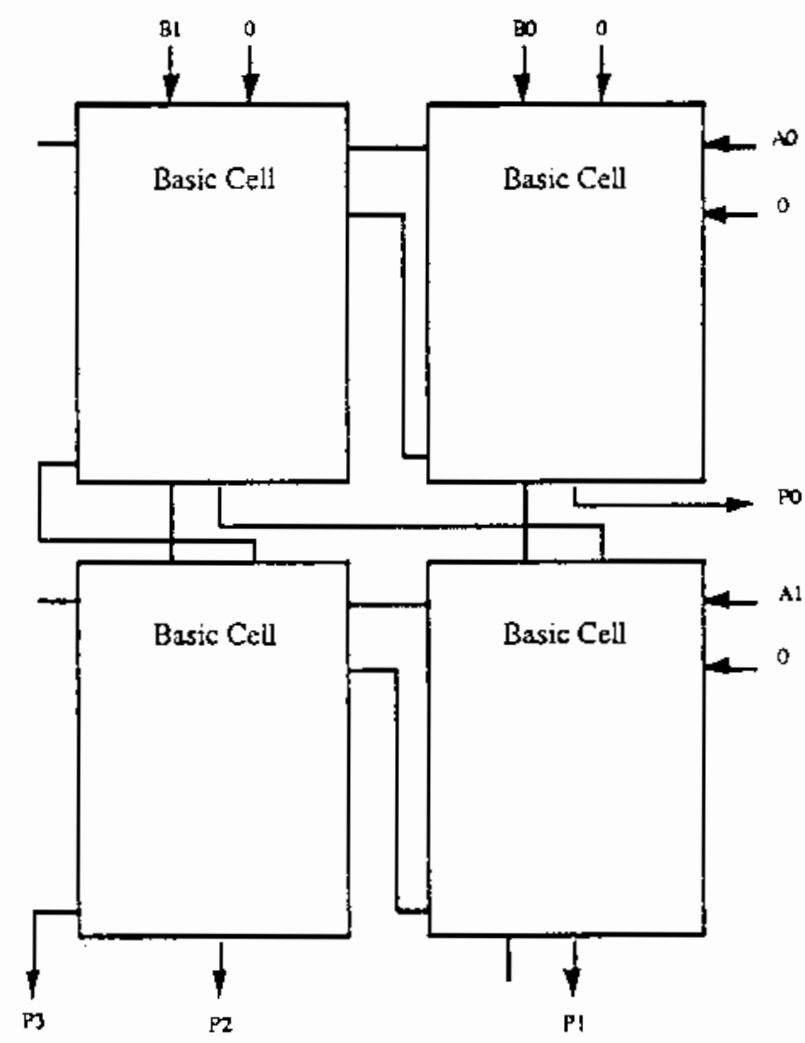

Figure $3.182 \times 2$ multiplier array 


\section{$\underline{4 \times 4 \text { Multiplier Array }}$}

Complexity: 176 gates.

Array size: 64 cells.

Zero-delay wires: 84 .

The $4 \times 4$ array (fig. 3.19) requires more output settling time than is required for the $2 \times 2$ array. Hence, the input file holds each input for more circuit clock cycles. This is a reasonably complex circuit with a significant number of zero-delay wire connections.

The average throughput for this circuit is $5.479 \times 10^{6}$ events per second which is quite good considering the number of wire connections.

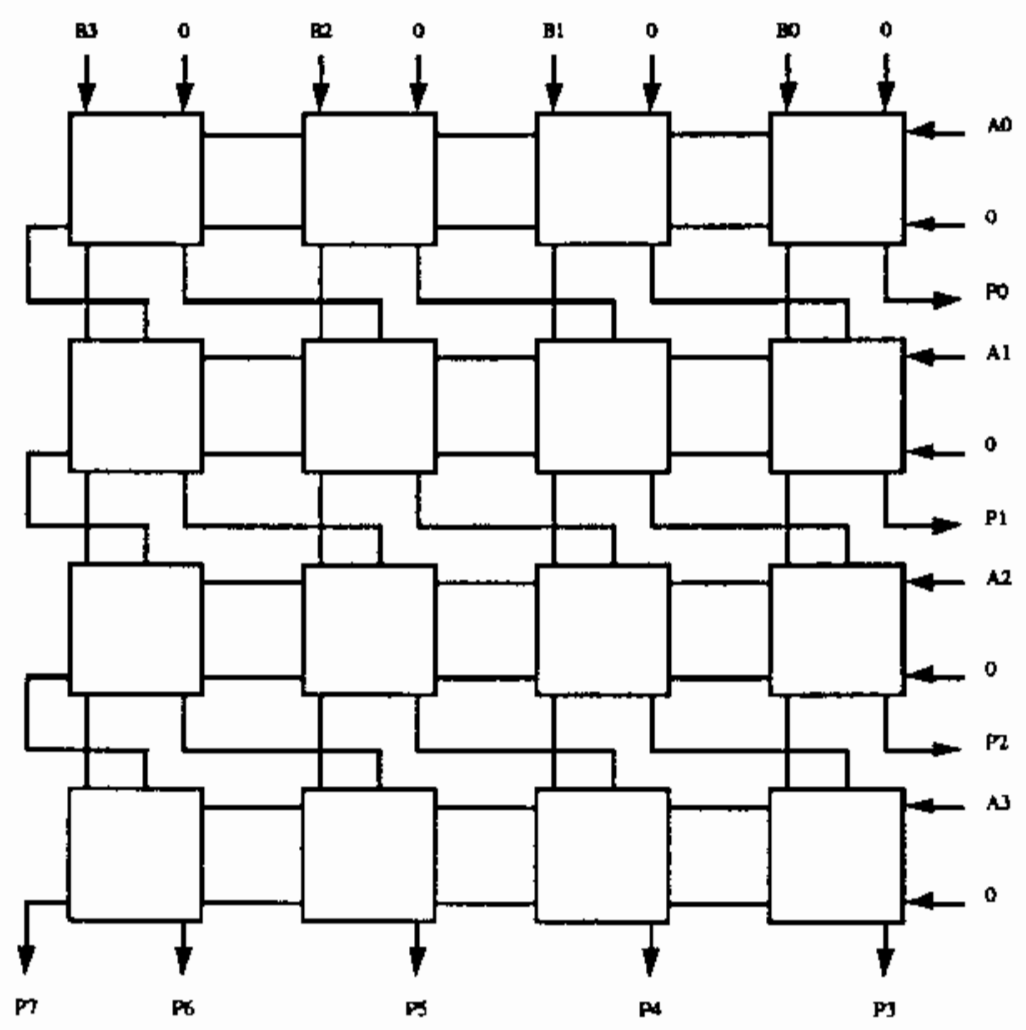

Figure $3.194 \times 4$ multiplier array 


\subsection{Comparison to Static Data Flow Architecture}

It is desirable to compare the performance of the hardware accelerator array to the performance of other hardware acceleration architectures. However, it is difficult to find enough information in the literature to make fair comparisons. One would like to have control over the simulation parameters for both the accelerator array and the other architectures to assure that the comparison is not biased by nonarchitectural factors such as implementation technology. It is also desirable to choose comparable performance metrics between the two architectures. For example, throughput should be measured in terms of events per second, with events defined identically for both architectures such that, for a given simulation, exactly the same number of events will occur.

\subsubsection{Static Data-Flow Architecture}

For performance comparison, a static data-flow architecture was chosen. The data-flow concept for hardware acceleration is in commercial use by Zycad Corp. [12] and Daisy Systems Corp. [13][3]. However, not enough information is available to exactly model the commercial systems. Instead, a model developed and simulated by Kruger [14] and Mahmood is used as a reference. Dr. Ausif Mahmood of Washington State University, Tri-Cities, graciously performed simulations of several of the same circuits described in section 3.2, permitting a direct comparison of performance. Before discussing the results, it is appropriate to summarize the architecture that was modeled.

The static data-flow event-driven logic simulation accelerator (fig. 3.20 ) consists of 16 banks of timing-wheel memory for event list management, 256 memory cells for gate storage and 16 processors for gate evaluations. Input events are distributed from the timing-wheel banks to the 


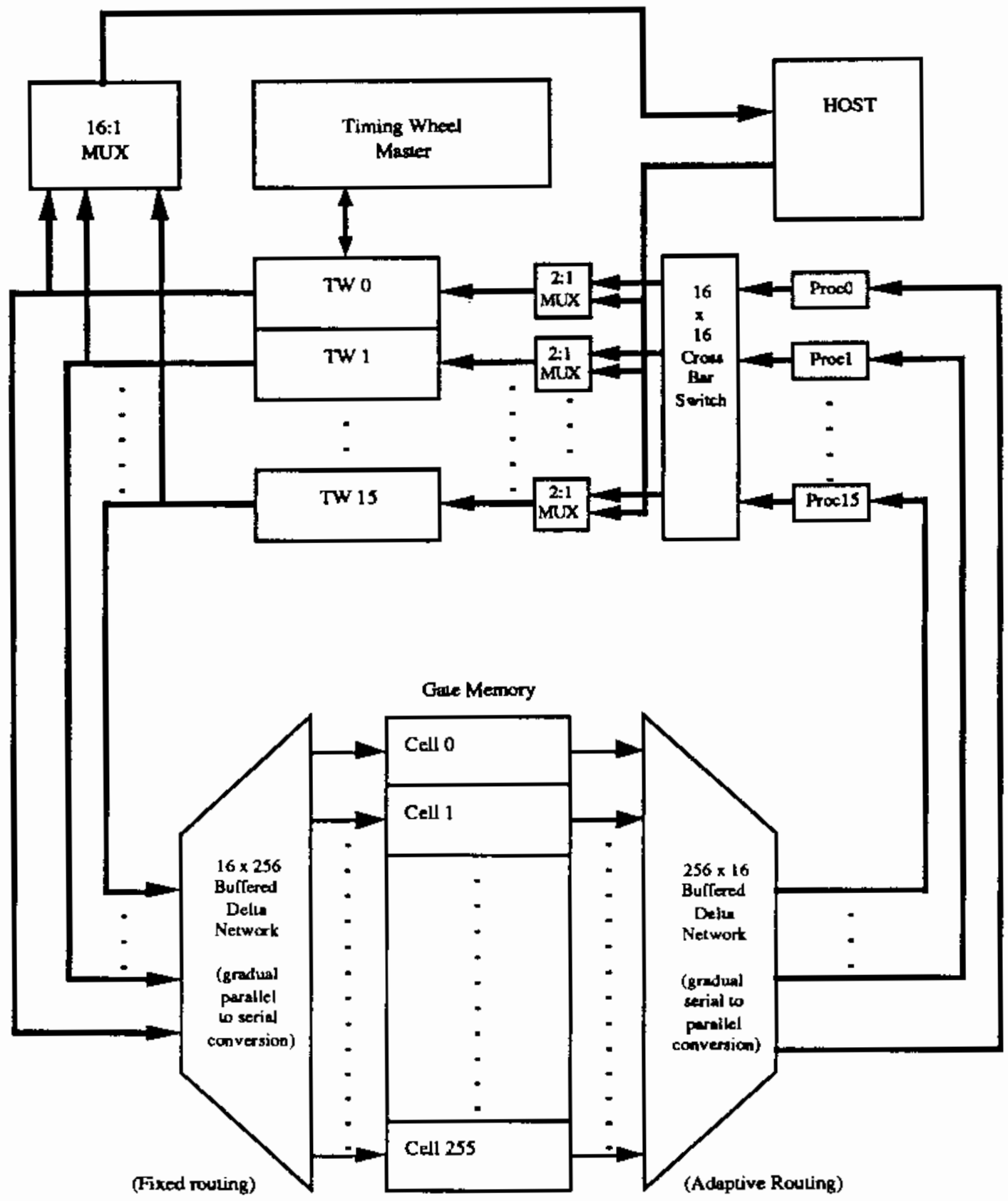

Figure 3.20 Static data-flow hardware accelerator 
memory cells by a $16 \times 256$ delta network that performs gradual parallel to serial conversion. Memory cells receiving a change in input (an input event) send gate information packets through a $256 \times 16$ delta network to available processing elements for evaluation. Result packets are sent to the timing-wheel banks via a parallel cross-bar switch. It is necessary to group events destined for the same gate in a single timing-wheel bank so that all input changes can be accumulated before they are forwarded to the gate memory cells.

Conceptually, the static data-flow accelerator operates very much like the timing-wheel method of a conventional event-driven software simulator. Events are stored at a position in the timing wheel corresponding to the current time plus a gate delay. Events are retrieved from the timing wheel from the current time position and are sent to the gate memory cells. A two-phase algorithm is used for the timing wheel. In the first phase, all input changes are accumulated. In the second phase, events are scheduled for eventual distribution to the memory cells. This ensures proper handling of multiple changes to an element's inputs.

\subsubsection{Apples and Oranges}

There would be little point in performing this performance comparison if there were no consistency in simulation parameters and performance metrics. For this comparison, an equal clock cycle (30 ns) was used for each accelerator, and throughput was measured as average events processed per second. Events resulting from extra connection elements (such as zero-delay wires in the accelerator array) were not counted.

Some question will always remain as to whether the particular model selected for the static data-flow accelerator introduced cerain performance degradations that gave the accelerator array an 
unfair advantage. For example, the data-flow accelerator architecture employs serial data transmission to minimize the number of connections going to the gate memory cells. One might argue that such a technique might also need to be employed in the accelerator array, but this is not expected to be the case because intercell communication is not global and is limited to nearest neighbors.

For the static data-flow accelerator, external input fanout was limited to one. In a few cases, additional input buffers were added to the circuit network to facilitate input distribution. The effect of these additional buffers on throughput was quite small.

\subsubsection{Performance Comparison}

The circuit networks chosen were identical in all respects except for the input buffering mentioned above. External input streams were the same for both systems. The results of the performance comparison are shown in Table 3.6 in millions of events per second (MES) (also see fig. 3.21):

Table 3.6 Relative performances of static data-flow and array accelerators

\section{Circuit}

Single inverter

64 inverters

Basis SR cell

RET D flip flop

4-bit counter

$2 \times 2$ multiplier

$4 \times 4$ multiplier

\begin{abstract}
Static Data-flow
Throughput (MES)
\end{abstract}
0.275

4.370

0.316

0.153

0.622

0.344

0.713
Accelerator Array Throughput (MES)
Speed

$\underline{\text { Ratio }}$

2.466

84.443

3.459

2.437

4.276

2.076

5.479
9.0

19.3

10.9

15.9

6.9

6.0

7.7 
In all cases, the improvement obtained with the accelerator array was significant when compared with the static data-flow architecture. Typically, the greatest contribution to this improvement is the elimination of the overhead associated with global switching networks. As is illustrated by the 64 -inverter circuit, massive parallel resources are available without creating a switching bottleneck in the accelerator array. Even in circuits requiring a significant number of zero-delay connection elements, the accelerator array demonstrated significant improvement over the static data-flow architecture.

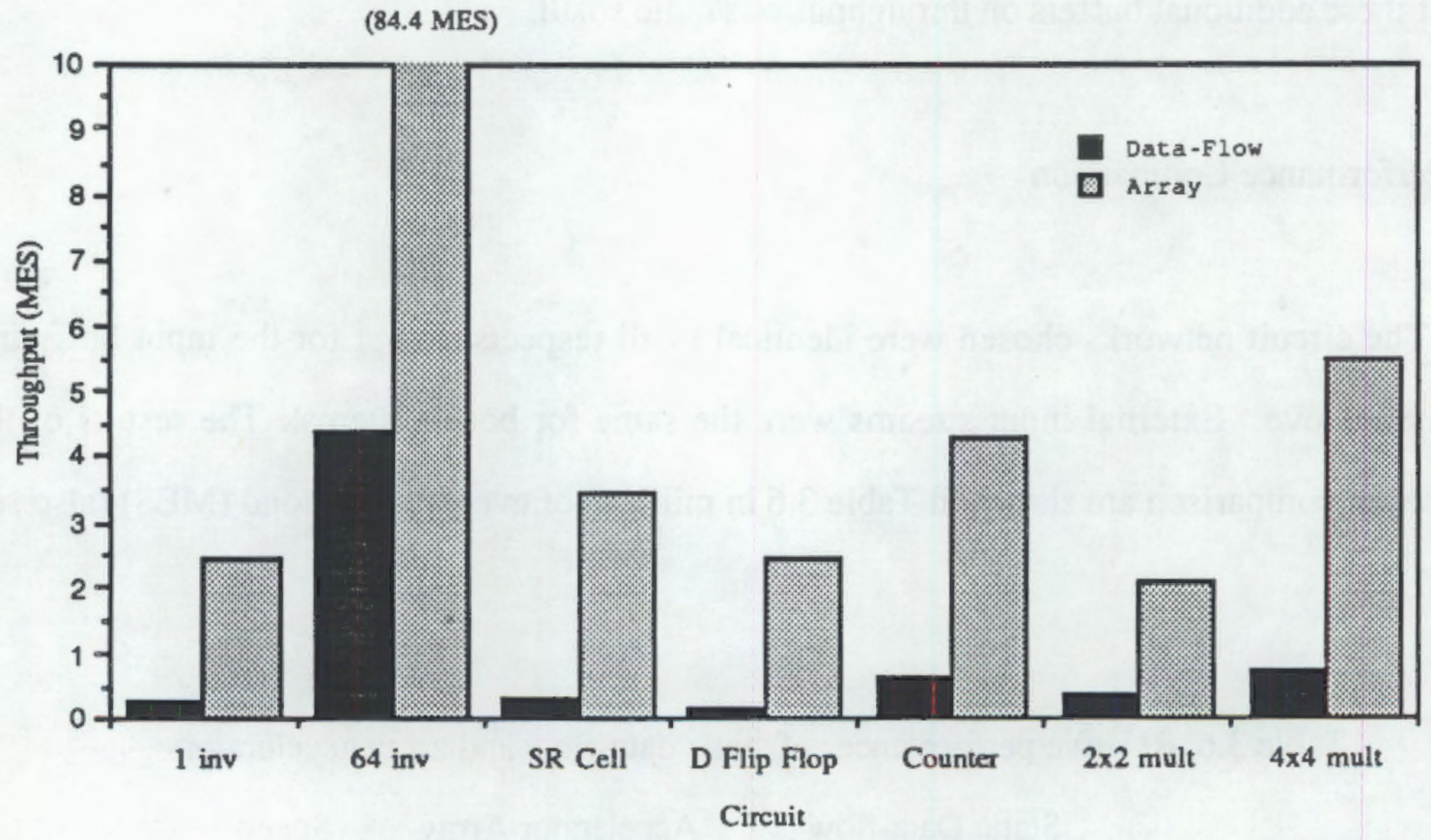

Figure 3.21 Relative performances of static data-flow and array accelerators 


\section{CONCLUSIONS}

A hardware acceleration array was designed and simulated by means of a behavioral simulator. Several test circuits of varying complexity were programmed into the array. It was shown that the array correctly performed gate-level simulations of the test circuits.

It was found that the array could be treated as a three-dimensional simulation space and used to efficiently exploit the inherent concurrency of a test circuit by distributing concurrent events across many cells while sequential events could be arranged in the same cell. It was also found that the connectivity of a test circuit could be efficiently represented in the array by means of a source addressing scheme. Test circuit fanout could be represented by both the physical connections between cells and source code matching within each cell.

A simple algorithm for mapping test circuits into the array was devised. Although it did not provide a unique, most efficient mapping, it was sufficient to accommodate all the test circuits with satisfactory results.

By assuming a basic clock period ( $30 \mathrm{~ns}$ ) it was possible to measure the performance of the array for various test circuits. Overall performance was found to be quite high but also could be degraded by several factors. If there is significant dead time between events, performance will be degraded because time is required to advance the timing wheels and check for valid events. Long zero-delay paths were also found to degrade performance. In the worst case, $230 \mathrm{~ns}$ are required to handle each zero-delay wire element in a path. It was observed, however, that test circuits containing many zero-delay wires still yielded good throughput.

Certain tests specific to the array architecture were performed. It was found that for a chain 
of 64 inverters, throughput ranging from $3.816 \times 10^{6}$ to $84.442 \times 10^{6}$ events per second was attained by programming the test circuit in a purely sequential (all in one cell) configuration or in a purely concurrent (distributed across 64 cells) configuration. It was also found that the rate at which parallel input events are processed saturated at approximately $3.7 \times 10^{6}$ events per second and that source-matching for large fanouts saturates at approximately $4.0 \times 10^{6}$ events per second for a single cell.

A comparison was performed between the accelerator array and a static data-flow accelerator architecture. For the seven test circuits compared, speedup factors ranging from 6.0 to 19.3 were observed. The highest speedups were attained where circuit concurrency could be most efficiently exploited by the array. The best array performance was attained when the test circuit together with the input data set exhibited little dead time and the circuit could be programmed into the array to fully exploit concurrency and minimize zero-delay path length.

In conclusion, the nearest-neighbor array algorithm is quite attractive because it appears to eliminate the switching bottlenecks that can plague global connectivity methods. It is also interesting to note that the array can, in theory, be extended in size indefinitely without performance degradation. Furhermore, the architecture of the array is conducive to other applications.

The performance of the array, however, is highly dependent on the ability of the circuit compiler to detect and exploit circuit parallelism and minimize zero-delay path length. The issue of path length suggests that the most efficient array architecture might include some long communication paths so that a small number of long zero-delay paths can be handled without passing data inefficiently from cell to cell. 


\section{BIBLIOGRAPHY}

1. Pfister, G. F., "The Yorktown Simulation Engine: Introduction," Proceedings of the 19th Design Automation Conference, 1982, pp. 51-54.

2. Denneau, M. M., "The Yorktown Simulation Engine," Proceedings of the 19th Design Automation Conference, 1982, pp. 55-59.

3. Paseman, W. G., "Data Flow Concepts Speed Simulation in CAE Systems," Computer Design, Jan. 1985, pp. 131-140.

4. Wong, K. F., et al., "Statistics on Logic Simulation," Proceedings of the 23rd Design Automation Conference, 1986, pp. 13-19.

5. Blank, T., "A Survey of Hardware Accelerators Used in Computer-Aided Design," IEEE Design and Test, Aug. 1984, pp. 21-39.

6. Jefferson, D. R., "Virtual Time," ACM Transactions on Programming Languages and Systems, Vol. 7, No. 3, July 1985, pp. 404-425.

7. Koren, I., et al., "A Data-Driven VLSI Array for Arbitrary Algorithms," IEEE Computer, Oct. 1988 , pp.30-43.

8. Mendelson, B., et al., "Mapping Data Flow Programs on A VLSI Array of Processors," Proceedings 1987 International Conference on Computer Architecture, June 1987, pp. 72-80.

9. Koren, I., et al., "A Direct Mapping of Algorithms onto VLSI Processing Arrays Based on The Data Flow Approach," Proceedings 1983 Intemational Conference on Parallel Processing, Aug. 1983, pp. 335-337.

10. Soule, L., et al., "Staristics for Parallelism and Abstraction Level in Digital Simulation," Proceedings of the 24th ACM/IEEE Design Automation Conference, 1987, pp. 588-591.

11. Glassner, L. A., et al., The Design and Analysis of VLSI Circuits, Addison-Wesley Publishing Company, Dec. 1985, pp. 52-55.

12. Allenbaugh, D. W., "Attacking the Simulation Botleneck," Digital Design, July 1985, pp. 79-85.

13. Cadlin, G., et al., "Hardware Acceleration of Logic Simulation using a Data Flow Micro Architecture," Communications of the ACM, Dec. 1985, pp. 117-123.

14. Kruger, R., "Design of a Logic Simulation Accelerator Based on Daca-flow Techniques", Master's Project, Washington State University, 1989. 
APPENDIX A. Four-level Logic Primitives

Each four-level value is represented by a 2 -bit code $\left[Y_{1}, Y_{0}\right]$ define as follows:

$$
\begin{array}{lll}
\underline{Y}_{1} & Y_{0} & \text { State } \\
\hline 0 & 0 & \text { LO } \\
0 & 1 & \text { HI } \\
1 & 0 & \text { UNDEF } \\
1 & 1 & \text { FLOAT }
\end{array}
$$

The Boolean Logic Unit implements the following logic-primitive expressions:

$$
\begin{aligned}
& \text { Output: } \mathrm{Y} \\
& \text { Inputs: } A, B, C, D, \ldots \\
& \text { Note: } " \sim "=\text { "NOT" } \\
& "+"=\text { "OR" } \\
& \text { AND } \\
& " \wedge^{\prime \prime}=\text { "XOR" } \\
& Y_{0}=\sim A_{1} A_{0} \sim B_{1} B_{0} \sim C_{1} C_{0} \ldots \\
& Y_{1}=\sim\left(Y_{0}+\sim A_{1} \sim A_{0}+\sim B_{1} \sim B_{0}+\sim C_{1} \sim C_{0}+\ldots\right) \\
& \mathrm{OR} \\
& Y_{0}=\sim A_{1} A_{0}+\sim B_{1} B_{0}+\sim C_{1} C_{0}+\ldots \\
& Y_{1}=\sim\left(Y_{0}+\sim A_{1} \sim A_{0}+-B_{1} \sim B_{0}+\sim C_{1} \sim C_{0}+\ldots\right) \\
& \underline{X O R} \\
& \mathrm{Y}_{1}=\mathrm{A}_{1}+\mathrm{B}_{1}+\mathrm{C}_{1}+\ldots \\
& Y_{0}=\sim\left[Y_{1}+\sim\left(A_{0} \wedge B_{0}^{\wedge} C_{0}^{\wedge} \ldots\right)\right] \\
& \text { NAND } \\
& \mathrm{Y}_{0}=\sim \mathrm{A}_{1} \sim \mathrm{A}_{0}+\sim \mathrm{B}_{1} \sim \mathrm{B}_{0}+\sim \mathrm{C}_{1} \sim \mathrm{C}_{0}+\ldots \\
& Y_{1}=\sim\left(Y_{0}+A_{1} \sim B_{1} \sim C_{1} \ldots\right) \\
& \text { NOR } \\
& \mathrm{Y}_{0}=\sim \mathrm{A}_{1} \sim \mathrm{A}_{0} \sim \mathrm{B}_{1} \sim \mathrm{B}_{0} \sim \mathrm{C}_{1} \sim \mathrm{C}_{0} \ldots \\
& Y_{1}=\sim\left(Y_{0}+A_{1} \sim B_{1} \sim C_{1} \ldots\right) \\
& \mathrm{Y}_{1}=\mathrm{A}_{1}+\mathrm{B}_{1}+\mathrm{C}_{1}+\ldots \\
& Y_{0}=\sim\left(Y_{1}+A_{0} \wedge B_{0} \wedge C_{0}^{\wedge} \ldots\right) \\
& Y_{0}=\sim A_{1} A_{0} \\
& Y_{1}=A_{1}
\end{aligned}
$$

\section{XNOR}

\section{BUF}


TRI

"En" = "Enable"

$\mathrm{Y}_{0}=\sim \mathrm{En}_{1} \sim \mathrm{En}_{0}+\sim \mathrm{En}_{0} \sim \mathrm{A}_{1} \mathrm{~A}_{0}$

$\mathrm{Y}_{1}=\sim\left(\sim \mathrm{En}_{1} \mathrm{E}_{0} \sim \mathrm{A}_{1}\right)$

WIRE

A WIRE with multiple inputs performs a wired $O R$.

$\mathrm{Y}_{0}=\mathrm{A}_{0} \mathrm{~B}_{0} \mathrm{C}_{0} \ldots$

$Y_{1}=A_{1} B_{1} C_{1} \ldots+\left(A_{1} \sim A_{0}+B_{1} \sim B_{0}+C_{1} \sim C_{0}+\ldots\right)$

$+\sim\left\{\left[\left(A_{1}+A_{0}\right)\left(B_{1}+B_{0}\right)\left(C_{1}+C_{0}\right) \ldots\right]+\sim\left(\sim A_{1} A_{0}+\sim B_{1} B_{0}+\sim C_{1} C_{0}+\ldots\right)\right\}$ 
APPENDLX B. Cell Programming Language

This document describes the cell programming language for simulation model 4.1 of the accelerator array.

The gates that can be programmed into the array are currently limited to a primitive set: WIRE, TRI, BUF, INV, AND, NAND, OR, NOR, XOR and XNOR.

The maximum number of inputs per gate is nine.

The input to the behavioral simulator consists of a network definition file and a data file. The outputs are directed to the screen and to an optional output file.

\section{Network Definition File}

The file is a standard DOS ASCII text file. Each line is either a comment or a network definition command.

\section{Title}

The first line of the file is reserved for a title that will be displayed on all analyzer displays and the output file.

\section{Comments}

Any line starting with '*' is a comment. Comments can be of any length up to 160 characters.

Network Definition Commands

Any line starting with '.' is a network definition. For nesting, more than one '.' can be used, but the only effect is to improve readability. A network definition has the following format:

$$
\text { .CMND ( arg1, arg2, } \arg 3 \ldots)
$$

The delimiters between arguments may be spaces, commas, semicolons or parentheses used in any combination. 


\section{Gate Command}

The following general format applies to gate commands:

.GATE ( ninputs, name, $x, y$, gate, sw_code, delay, channel, trig )

where GATE = WIRE, TRI, BUF, INV, AND, NAND, OR, NOR, XOR and XNOR.

\section{Argument Definitions:}

ninputs - The number of inputs to be used for the selected gate. Allowable values:

$\begin{array}{ll}\text { Gate } & \text { Range } \\ \text { WIRE } & 0<\text { ninputs }<10 \\ \text { TRI } & \text { ninputs }=2 \\ \text { BUF } & \text { ninputs }=1 \\ \text { INV } & \text { ninputs }=1 \\ \text { AND } & 0<\text { ninputs }<10 \\ \text { NAND } & 0<\text { ninputs }<10 \\ \text { OR } & 0<\text { ninputs }<10 \\ \text { NOR } & 0<\text { ninputs }<10 \\ \text { XOR } & 0<\text { ninputs }<10 \\ \text { XNOR } & 0<\text { ninputs }<10\end{array}$

name - An ASCII string with no intervening delimiters used to identify the output of the gate on the analyzer display.

$\mathrm{x}$ - The column number (starting at 0 ) of the node in which the gate is to be stored.

$y$ - The row number (starting at 0 ) of the node.

gate - The number (starting at 0 ) of this gate in the node.

sw_code - The switching code for the output of the gate being defined. The output registers have the following codes:

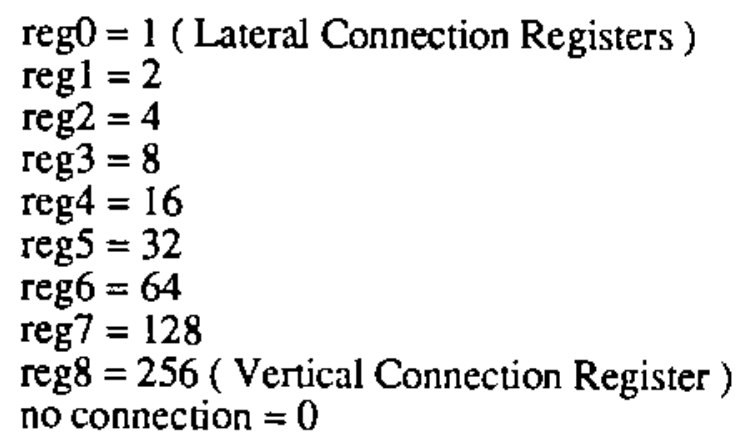


Example: If the output is to be switched out through registers 0,2 and 5 , the switch code would be: 20.

sw_code $=1+4+32=37$

delay - The gate delay for the gate being defined in timing-wheel units. Must be less than

channel - The analyzer channel on which the output for this gate is to be displayed. (Set to 1 for disable).

trig - The analyzer trigger value for this gate if a channel has been enabled. (This is NOT currently implemented in model 4.1.)

$$
\begin{aligned}
\text { trig } & =0=\text { Low } \\
& =1=\text { High } \\
& =-1=\text { Don't Care }
\end{aligned}
$$

\section{Input Definition Command:}

For defining inputs, the following command is used. Input definitions must follow immediately after the corresponding gate definition.

.INP (input_num, src_path, src_gate, col, channel, trig, name )

\section{Argument Definitions:}

input_num - gate input number. The first input is ' 0 '.

src_path - the incoming path on which the data for this input will arrive.

src_gate - The number of the gate in the node from which this input's data will come from. only).

col - The column in the input data file from which this input is to be taken (external input

channel - The analyzer channel on which to display this input.

trig - analyzer trigger level for the selected channel. (Not used in model 4.1).

name - Name to be displayed with analyzer channel.

Notes:

- If the input is external, then the src _gate argument should be set to - 1 and the src_path argument will indicate on which path the input duta will be inserted. In this case, col must be set.

- If no scope display is desired, set channel to -1 .

- A path used for external data CANNOT be used for any other connections. 
Example:

INV ( 1 , OUT, $0,0,0,16,1,1,0)$;

..INP $(0,0,-1,0,0,0$, IN $)$;

These lines program an inverter into cell 0,0 at gate position 0 . The input is extemal and comes from data column 0 in the data file. The output is labeled "OUT" and appears on channel " 1 " of the analyzer. The input is labeled "IN" and appears on channel " 0 " of the analyzer.

\section{Gate-specific Notes}

WIRE - All inputs are wire or'd. If any input is undefined the output is undefined. Tri-stated inputs are ignored. If asserted inputs do not agree, then the output is undefined. A delay of zero may be used. If all inputs are tri-stated, then the output is tri-state.

TRI - Simple TRISTATE buffer. Input 0 is data. Input 1 is enable. If the buffer is enabled, then an undefined or tri-state input will result in an undefined output.

BUF - A buffer. Only input 0 is used. A tri-state or undefined input will result in an undefined output.

INV - Inverter. Only input 0 is used. A tri-state or undefined input will result in an undefined output.

\section{Array Dimension Command}

A command is provided for specifying array dimensions:

.ARRAY ( cols, rows )

\section{Argument Definitions:}

cols - number of columns in the array ( $x$ ).

rows - number or rows in the array $(y)$.

Note: Limitation on a $640 \mathrm{k}$ machine is currently around $8 \times 8$. 


\section{Offset Command}

Commands are provided for offsetting node indices. These offsets are applied to $\mathbf{x}$ and $\mathbf{y}$ indices for all gate and input commands that follow their invocation.

.XOFF ( $\mathrm{x} \_$offset )

.YOFF ( $y_{-}$offset $)$

\section{Argument Definitions:}

$x_{-}$offset - column offset to be applied to $\mathrm{x}$ in the gate and input commands that follow the invocation of XOFF.

y_offset - row offset to be applied to $y$ in the gate and input commands that follow the invocation of YOFF.

Note: Initially $x_{-}$offset $=y_{-}$offset $=0$. These commands are useful for offsetting an existing set of gate definitions to a new location in the array.

\section{Data File Command}

The data file command has the following format:

.DATA(filename)

where filename is the pathname to the data file.

Example:

.DATA(test 1.dat)

\section{Output File Command}

The output file command has the following format:

.OUTFILE(filename)

where filename is the pathname to the data file.

Example:

.OUTFILE(test 1.out) 


\section{Diagnostics Command}

The diagnostics command is used to define internal signals to be displayed on the array timing analyzer display. It has the following format:

.DIAG(x,y,module,input,name,channel,trig);

where

$\mathrm{x}=\mathrm{x}$ coordinate of cell.

$y=y$ coordinate of cell.

module $=$ module identification number:

\begin{tabular}{cl} 
module id & module name \\
\cline { 2 - 2 } 0 & Input Registers \\
1 & Network Switch \\
2 & Array Controller (cell 0,0 only) \\
3 & Input Selector \\
4 & Source Translation Unit \\
5 & Boolean Logic Unit \\
6 & Timing Wheel \\
7 & Cell Controller
\end{tabular}

input $=$ input number for the desired signal

channel $=$ analyzer channel on which to display signal

trig = analyzer trigger level (not used in model 4.1)

Example:

.DIAG $(0,0,2,4$, ARRAY_RDY,1,0);

Displays the ARRAY_RDY signal on the array timing analyzer channel 1. 


\section{Data Dump Command}

The data dump command defines the bits to be dumped to the output file. It also defines how the bits are grouped and the format they are displayed in. The command has the following format:

.DUMP(col,name,name_format,data_format, type $0, \mathrm{x} 0, \mathrm{y} 0$,gate0,input $0,[$ type $1, \mathrm{x} 1, \mathrm{yl}$, gate 1, input $1, \ldots])$

where

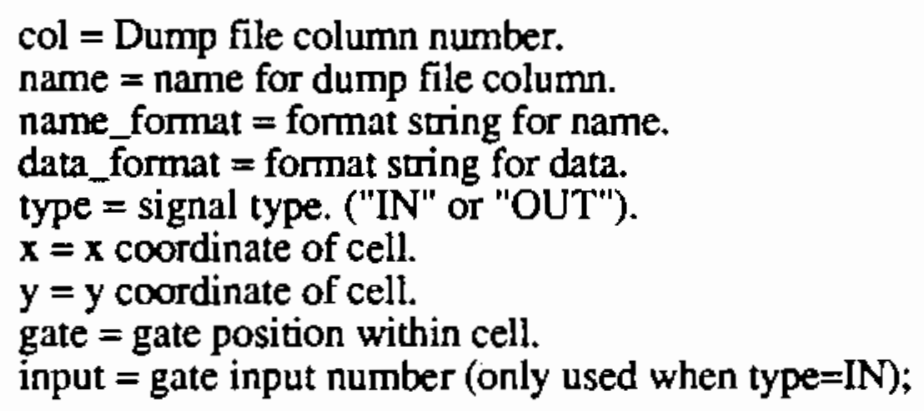

[type $0, x 0, y 0, g a t e 0$ ] defines the lowest order bit of the output word. Up to 16 bits can be defined by appending addition bit definitions. These bits will be treated as a single word and displayed according to the format specified in data format.

\section{Example:}

.DUMP(0,A,\%3s, \%3d,IN , 7,0,2,0,IN, 7,2,2,0,IN,7,4,2,0,IN,7,6,2,0);

A 4-bit value is created from the specified inputs and displayed in column 0 as a decimal number. Column zero is labeled "A". 


\section{Network Definition File Example}

SR Flip-Flop (CKT_1.NET)

*

* Set array dimensions:

*

ARRAY $(1,2)$;

*

* Define a NAND gate in node 0,0 :

*

.NAND $(2, Q, 0,0,0,64,1,2,0)$;

..INP $(0,1,-1,0,0,0, S)$;

..INP( $(1,6,0,0,-1)$;

* Define a NAND gate in node 0,1 :

*

.NAND $\left(2, Q^{*}, 0,1,0,4,1,3,0\right)$;

..INP $(0,7,-1,1,1,0, \mathrm{R})$;

..INP(1,2,0,0,-1);

*

* Input data comes from file RS.DAT:

.DATA ( RS.DAT);

.

* Define diagnostics:

*

.DIAG $(0,0,0,0, S, 0,0)$;

.DIAG $(0,1,0,0, \mathrm{R}, 1,0)$;

.DIAG $(0,0,4,1$, DATA $0,2,0)$;

.DIAG $(0,1,4,1$, DATA $1,3,0)$;

.DIAG $(0,0,5,10, \mathrm{~N} 0,4,0)$;

.DIAG $(0,0,5,9, \mathrm{OP} 0,5,0)$;

.DIAG $(0,0,5,0, \mathrm{X} 00,6,0)$;

.DIAG $(0,0,5,1, \mathrm{X} 10,7,0)$;

.DIAG $(0,0,6,0, Y 0,8,0)$;

.DIAG $(0,1,5,10, \mathrm{~N} 1,9,0)$;

.DIAG $(0,1,5,9, \mathrm{OP} 1,10,0)$;

.DIAG $(0,1,5,0, \mathrm{X} 01,11,0)$;

.DIAG $(0,1,5,1, \mathrm{X} 11,12,0)$;

.DIAG $(0,1,6,0, Y 1,13,0)$;

$*$

* Open output file:

.OUTFILE(CKT_1.OUT);

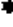

* Define data dump to output file:

*

.DUMP(0,S, \%2s, \% 2d,IN, $0,0,0,0)$;

.DUMP( $(1, \mathrm{R}, \% 2 \mathrm{~s}, \% 2 \mathrm{~d}, \mathrm{IN}, 0,1,0,0)$;

.DUMP(2,Q,\%2s, \%2d,OUT, $0,0,0,0)$;

.DUMP(3,Q*,\%3s, \%3d,OUT, $0,1,0,0)$; 


\section{Input Data File}

The input data file simply consists of data in columns. Data is used from the columns depending on the data column definitions for external data given in the network definitions.

\section{Comments}

As for the network definition file, any line starting with "*" is a comment.

\section{$\underline{\text { Data }}$}

Data is divided up into columns. The first column is numbered ' 0 '. Delimiters for the data may be commas, spaces, parentheses or semicolons. Data is read by the simulator line by line until all the data is exhausted.

\section{Example:}

**************************************

* NAND4.DAT - Data for NAND4.NET *

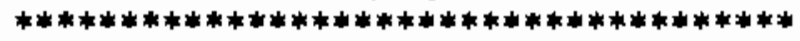

* I3 I2 I1 I0

00000

$\begin{array}{lllll}0 & 0 & 0 & 0\end{array}$

$\begin{array}{lllll}0 & 0 & 1 & 1\end{array}$

$\begin{array}{llll}0 & 0 & 1 & 1\end{array}$

$\begin{array}{llll}1 & 1 & 0 & 0\end{array}$

$\begin{array}{lllll}1 & 1 & 0 & 0\end{array}$

11101

$\begin{array}{llll}1 & 1 & 0 & 1\end{array}$

11110

11110

$\begin{array}{lllll}1 & 1 & 1 & 1\end{array}$ 
APPENDIX C. Behavioral Simulator

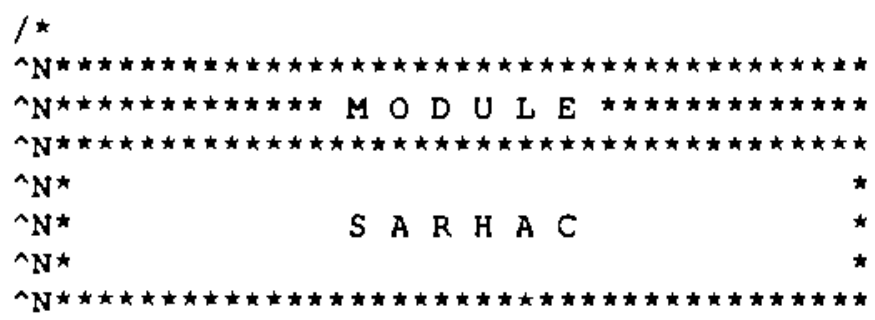

SARHAC

- Simulation model 4.1

Functional Sumnary:

The following modules are currently implemented:

- Array Controller

(CTRL)

- Cell Controller

(NCTRL)

- Input Registers

(INREGS)

- Input Selector

(SEL)

- Source Translation Unit (STU)

- Boolean Logic Unit (BLU)

- Timing Wheel (TW)

- Network Switch (NS)

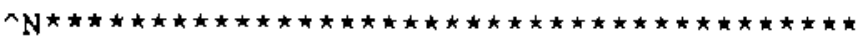

$\star /$

$/ \star$

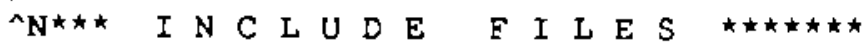

$\star /$

*include 〈alloc.h〉

*include 〈stdio.h>

*include <stdlib.h〉

*include <stdarg.h>

*include <conio.h>

*include 〈ctype.h>

*include 〈graphics.h〉

* include 〈dos.h〉

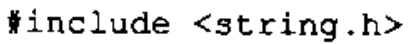

*include "aasim.h"

\#include "vidlib.h"

include "readnet. $h$ " 


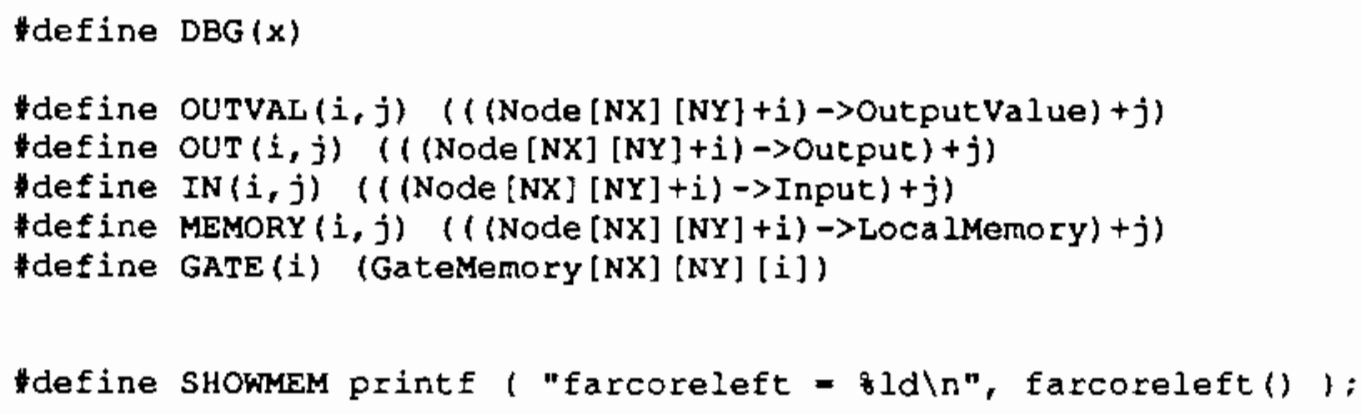

struct OutputRecord 1

int $\mathrm{x}$;

int $Y_{i}$

int ModuleID;

int Input ID;

\} ;

struct ModuleRecord

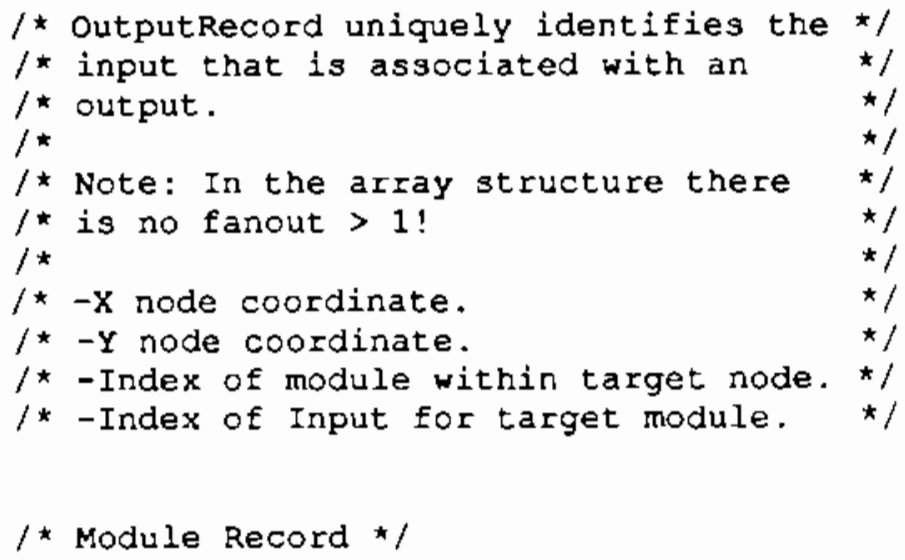




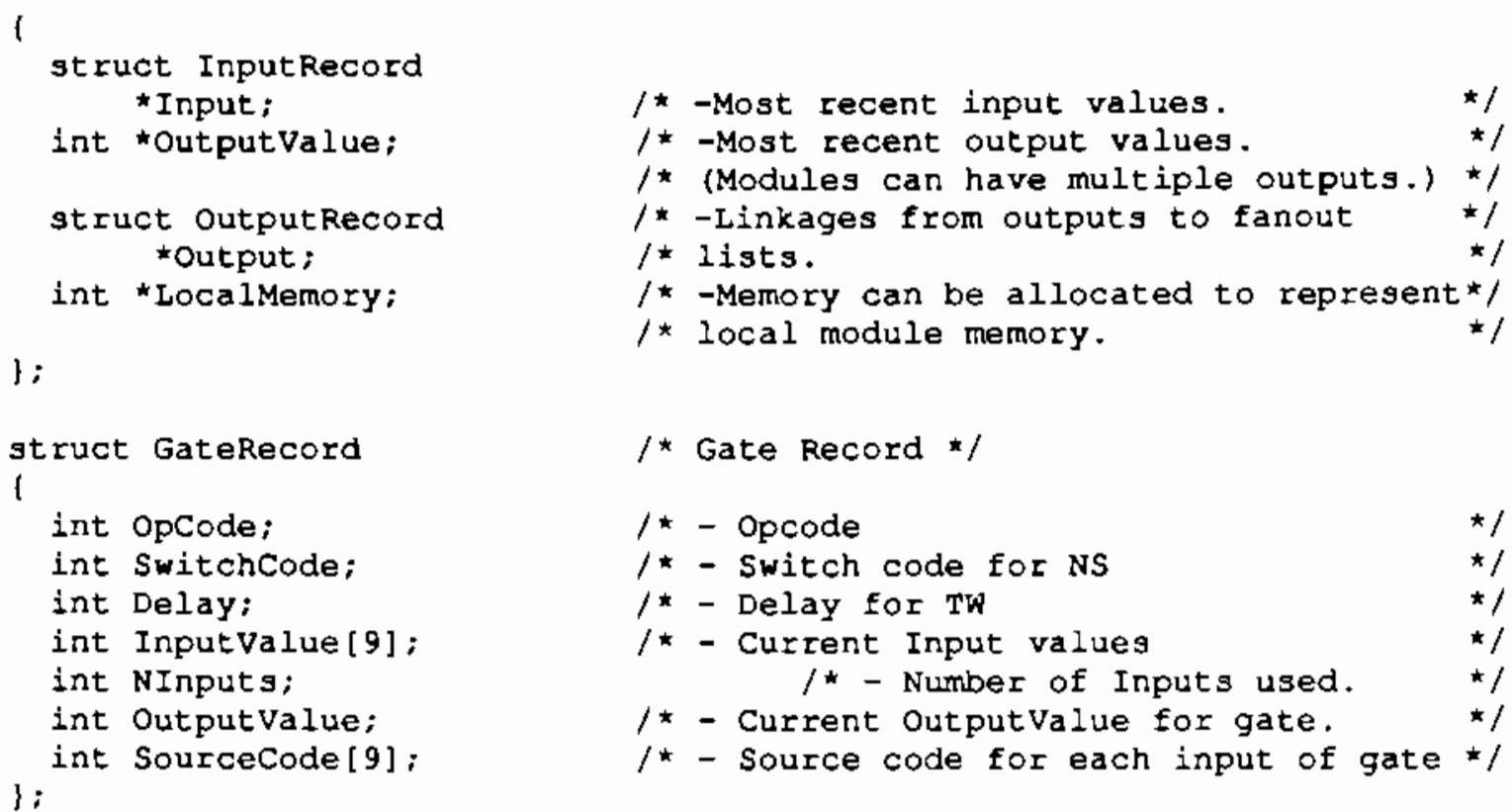

struct GateRecord huge *GateMemory[M] [N] [MAX GATES];

$/ \star$ An array of pointers to gate memories $\star /$

char Gatevalue [M] [N] [MAX_GATES];

$/$ *

Global Timing wheel:

A global timing wheel is implemented for the array. As a new output is generated is is stored in the timing wheel along with the (X, Y,ModuleID, InputID) coordinates for one of the inputs it is intended for.

\section{*}

struct EventRecord

\{

int Outputvalue: $\quad$ - -New output value.

int $\mathrm{X}$;

int $Y$;

int ModuleID;

int InputID;

$/ *$-Target Node $\mathrm{x}$ coordinate.

$/$ /* Target Node $\Psi$ coordinate.

$1 *$-Target Module ID.

$/ \star$-Target Input ID.

struct EventRecord *Next; $/ \star$-Lirkage to next event at current */

; $/ \star$ time.

struct EventRecord *Timingwheel[MAX_DELAY]; * - Timing Wheel */ struct EventRecord *Last [MAX_DELAY]; /* Keeps track of last event in $\star /$ $/ *$ each position of the wheel. */

int Updatelist[M][N][N_MODULES]; /* Updatelist - List is updated as */ 


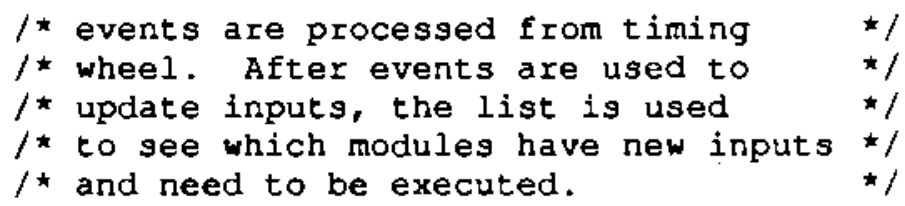

$/ \star$ Node Timing wheels:

An actual hardware module exists in each node implmenting a timing wheel function for circuit simulations. As an output is generated by the Boolean Logic Unit it is stored together with GATE ID, and SWITCH CODE in the timing wheel.

\section{$\star /$}

struct GateEventRecord

$/ \star$ Local node timing wheel record. $\quad$ /

1

int Data;

$l^{\star}$ - Data value.

int SwCode;

$/ \star$ - Switch Code

$/ *$ - Source Gate Identification

struct GateEventRecord *Next; $/ *$ - Pointer to next gate event.

; ;

struct GateEventRecord *TWheel [M] [N] [MAX_GATE_DELAY];

$/$ * Local nóde timing wheel */

struct GateEventRecord *TWLast[M] [N] [MAX_GATE_DELAY];

$/^{\star}$ Pointer to last event in*/

struct GateEventRecord *TWCurrent $[M][N]$;

$/ *$ each $\mathrm{TW}$ position. $\quad$ /

$/ \star$ Pointer to current event $\star /$

$/^{\star}$ in present position in each $\mathrm{TW}$.

int NGate $[\mathrm{H}][\mathrm{N}]$;

$/$ * Number of gates in each node. */

int TWPOS[M] [N] ;

/* Current position in each local node */

$l^{\star}$ timing wheel.

$/$ *

int huge $\star$ Hist;

/* - Histogram array for hist display. */

*/

long $t$;

int $t$. $t w$;

long t_circuit;

long t_circuit_old;

int tflg $=0$;

int UpdateFlg $=0$;

int NMod, NIn;
/* - Current simulation time. */

/* - Current position in global timing */

$/ \star$ wheel.

$/ \star$ Circuit time.

$/ \star$ - Counter used for timing external */

$/ *$ inputs for testing.

$/$ * Elag is set when an update of the */

$/$ * histogram array is desired. */ 


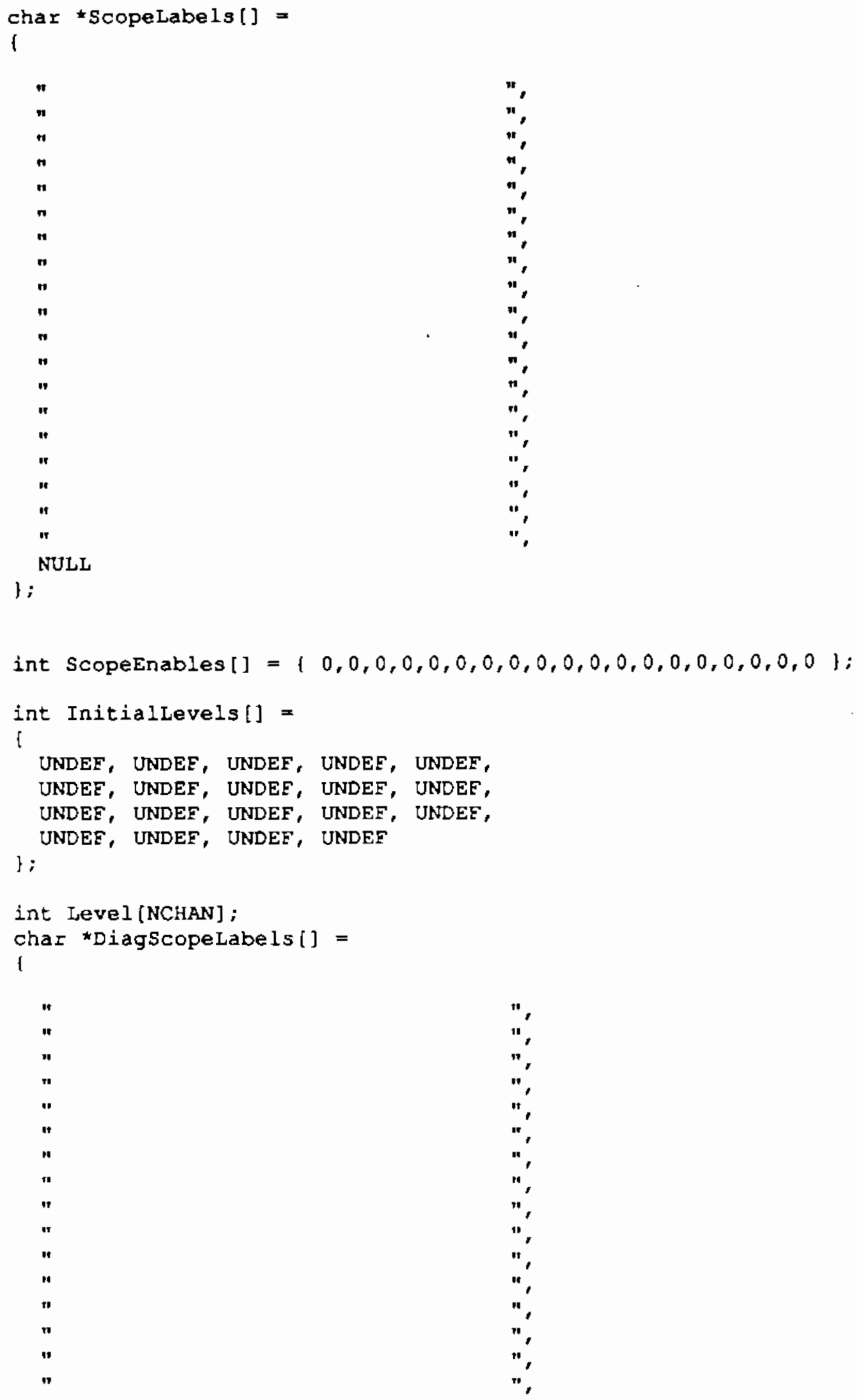

char *Diagscopelabels[] =

",

",

"

,

1

",

",

"

",

",

",

,

",

"

",

",

$"$

",

1 ,

",

",

,

,

",

",

",

1

,

",

", 


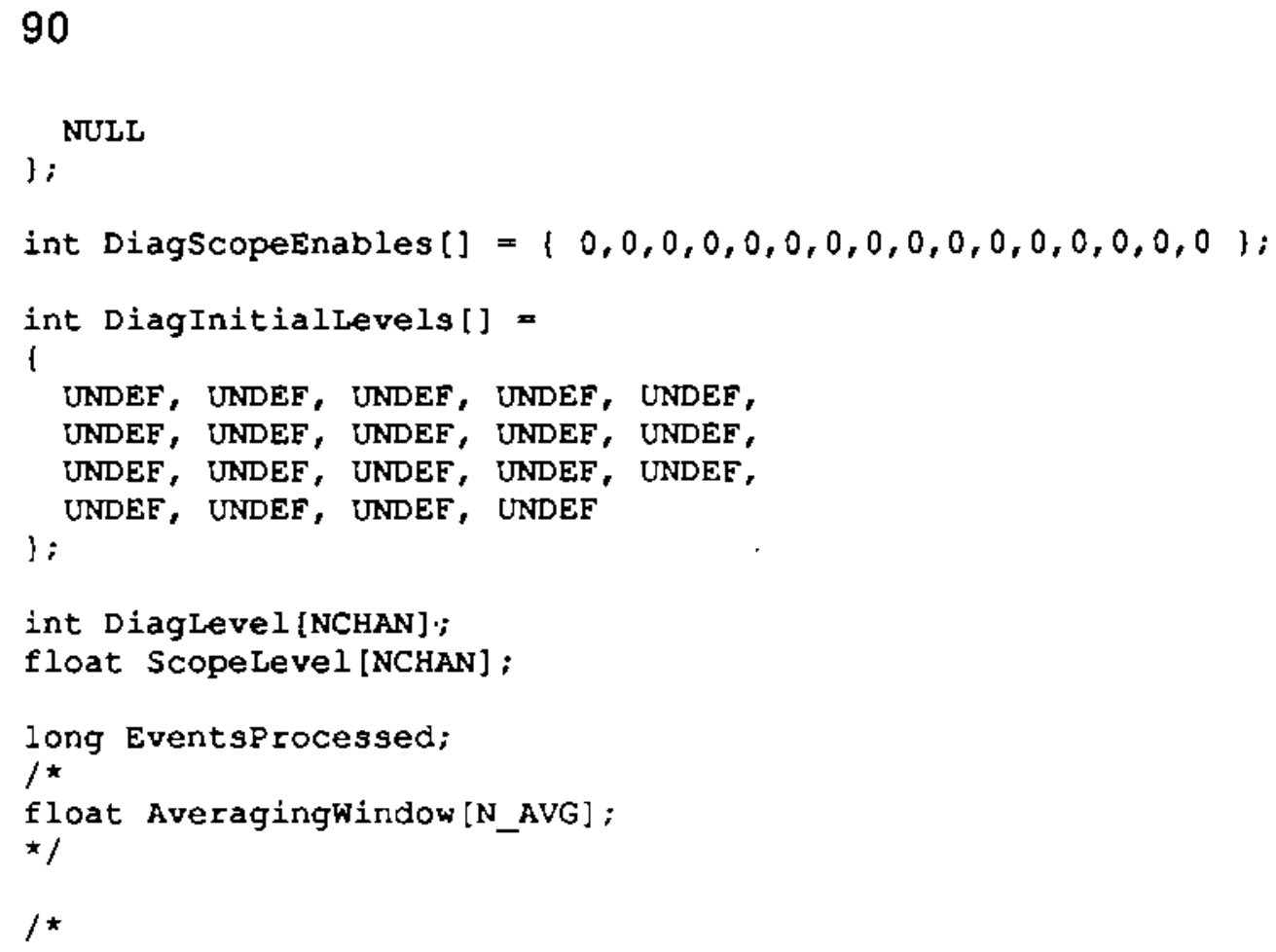




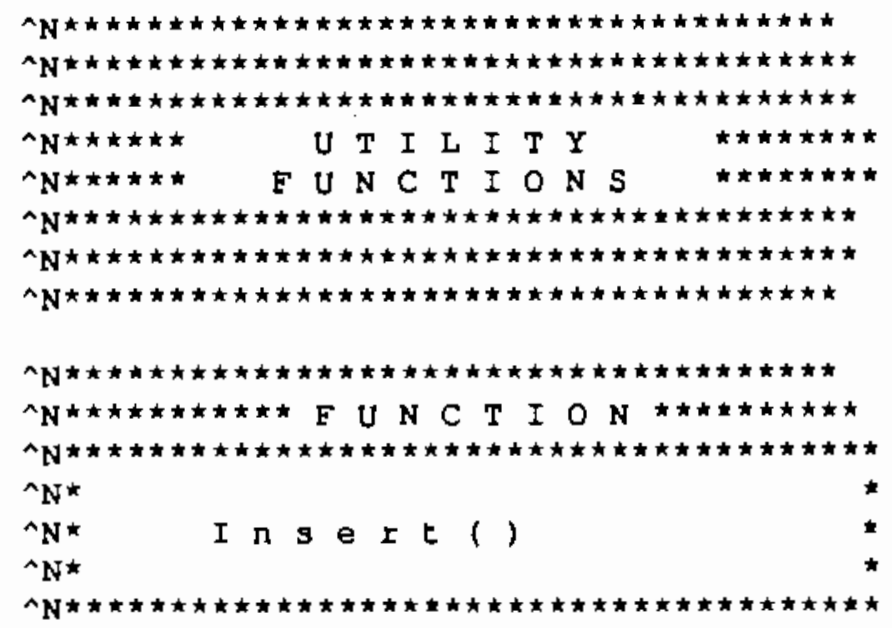

Functional Surmary:

Inserts an entry in the global timing wheel at the current time plus the indicated delay.

If InID $=-1$, then the indicated module will be scheduled for execution without modifying any inputs.

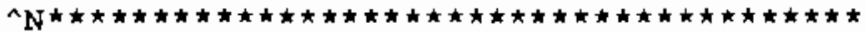

$\star /$

void Insert ( int Value, int $n x$, int ny, int Mod, int InID, int Delay)

1

int Pos:

struct EventRecord *Event;

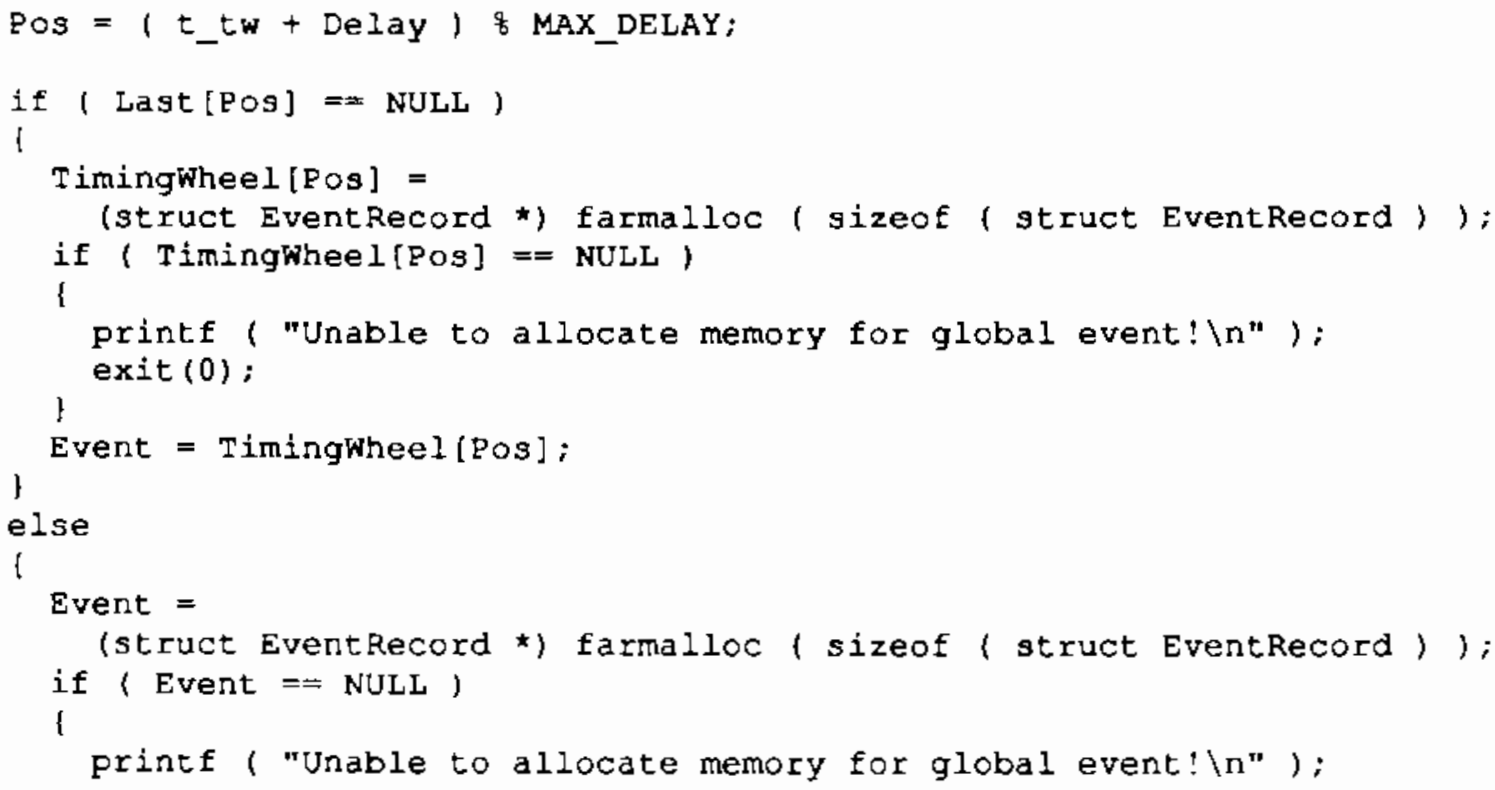




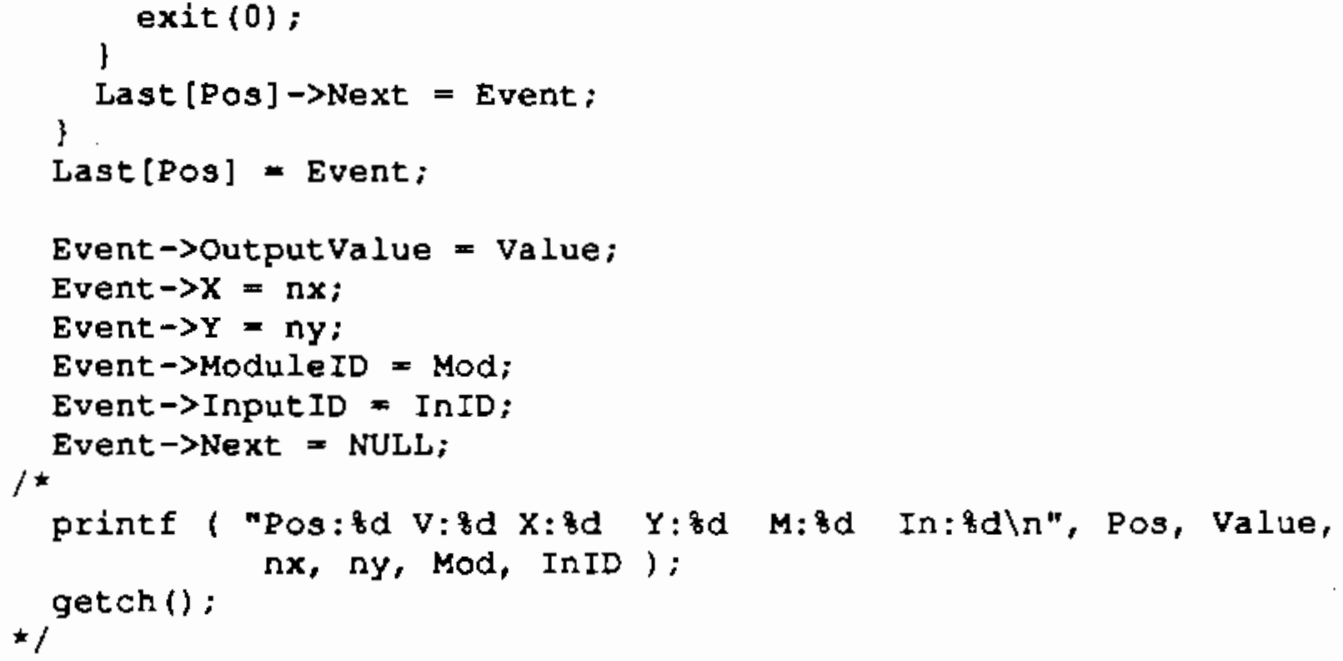




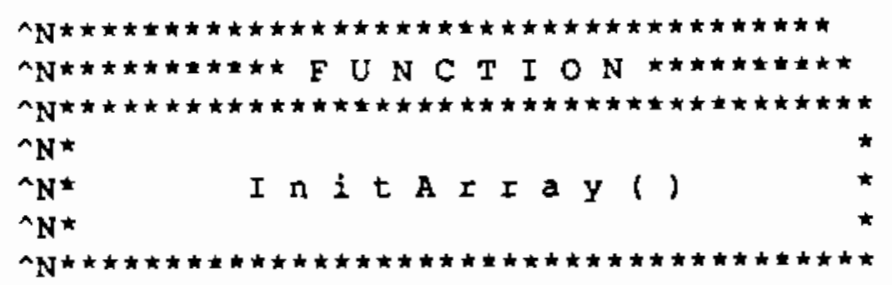

Functional summary:

This function creates and initializes the SARHAC array.

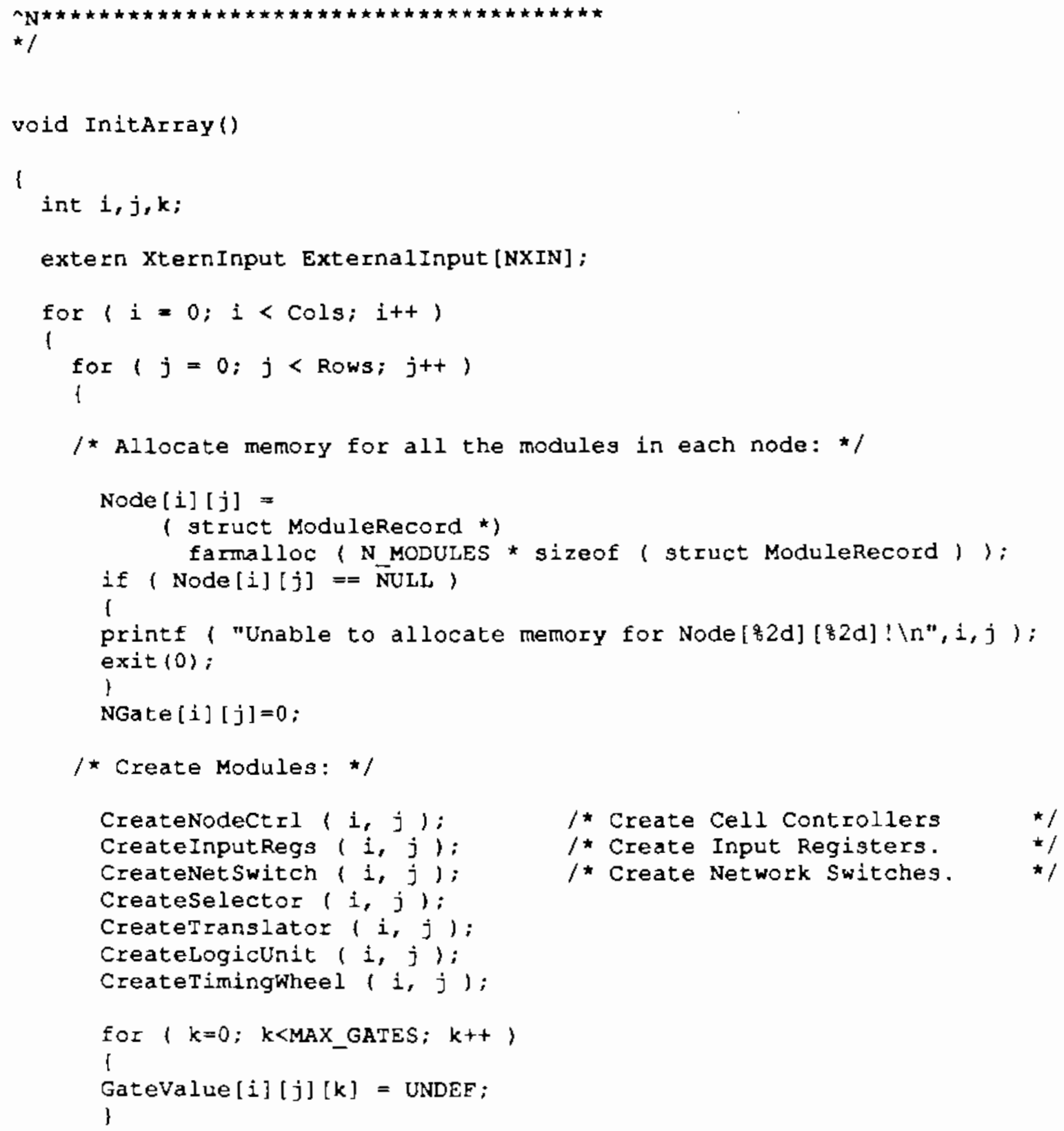




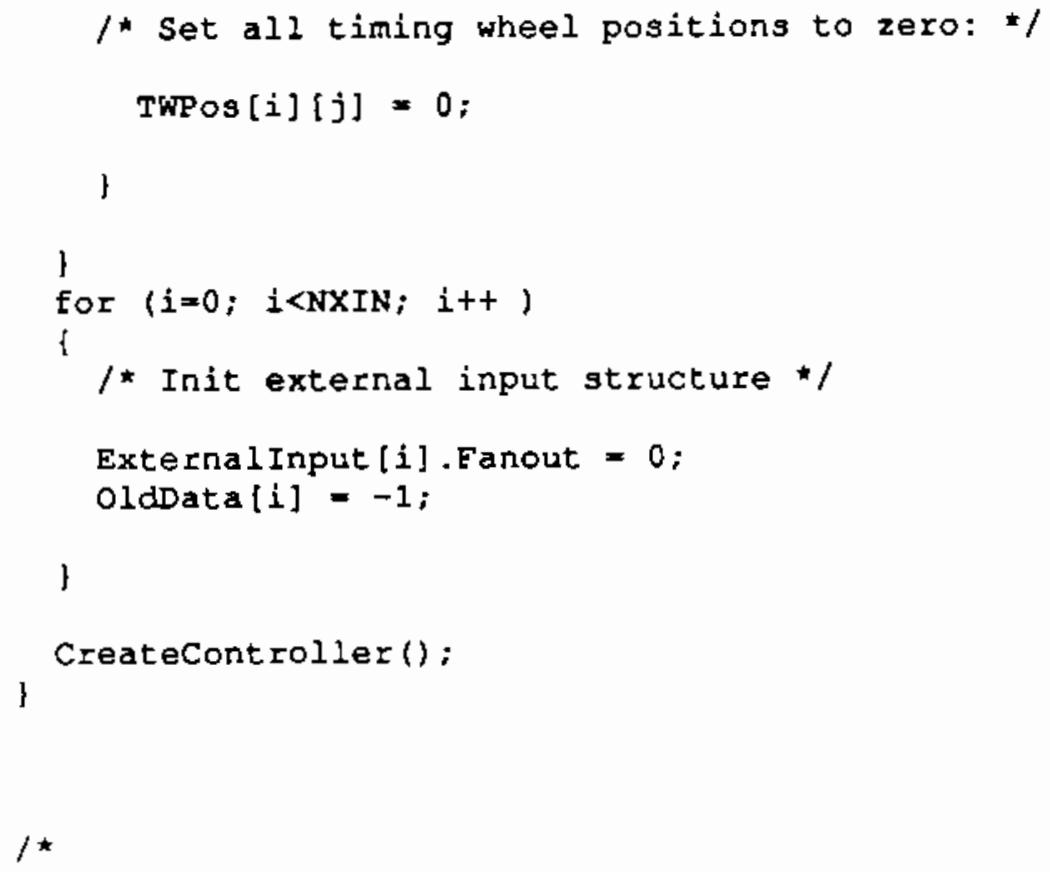




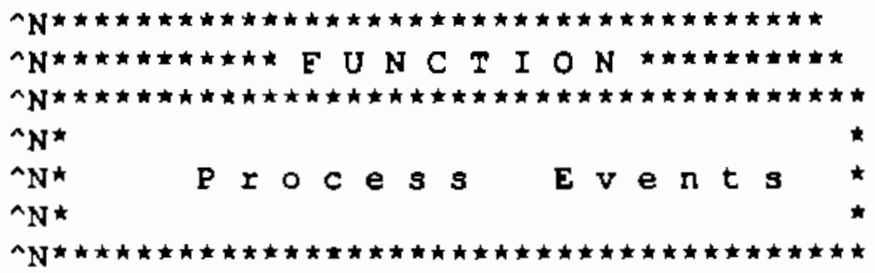

Functional Sumnary:

This function gets the next set of events at the current position in the timing wheel and processes them by routing them to the corresponding inputs.

Return value:

$$
\begin{aligned}
& 0 \text { = Out of input data. } \\
& 1 \text { - Success. }
\end{aligned}
$$

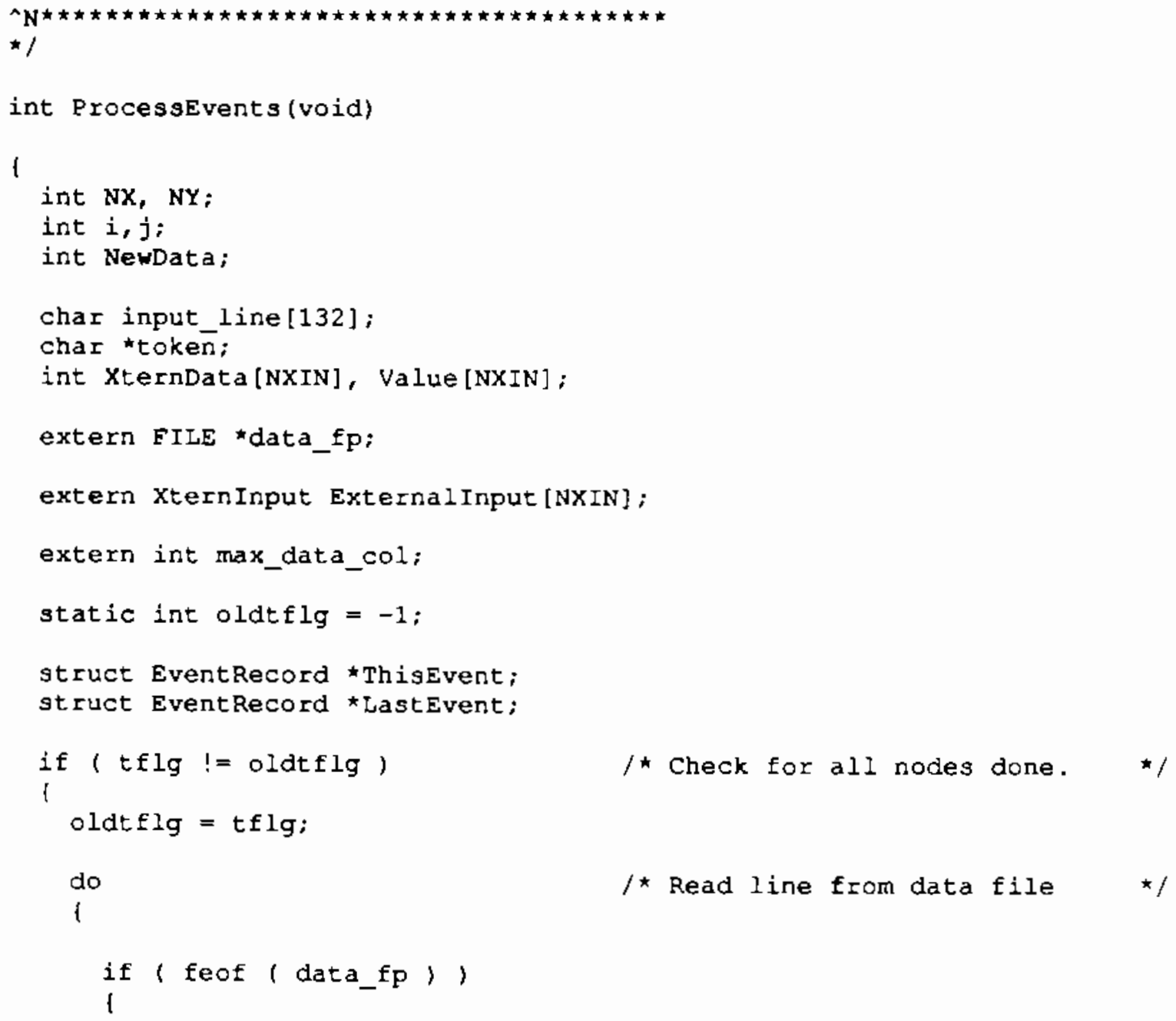




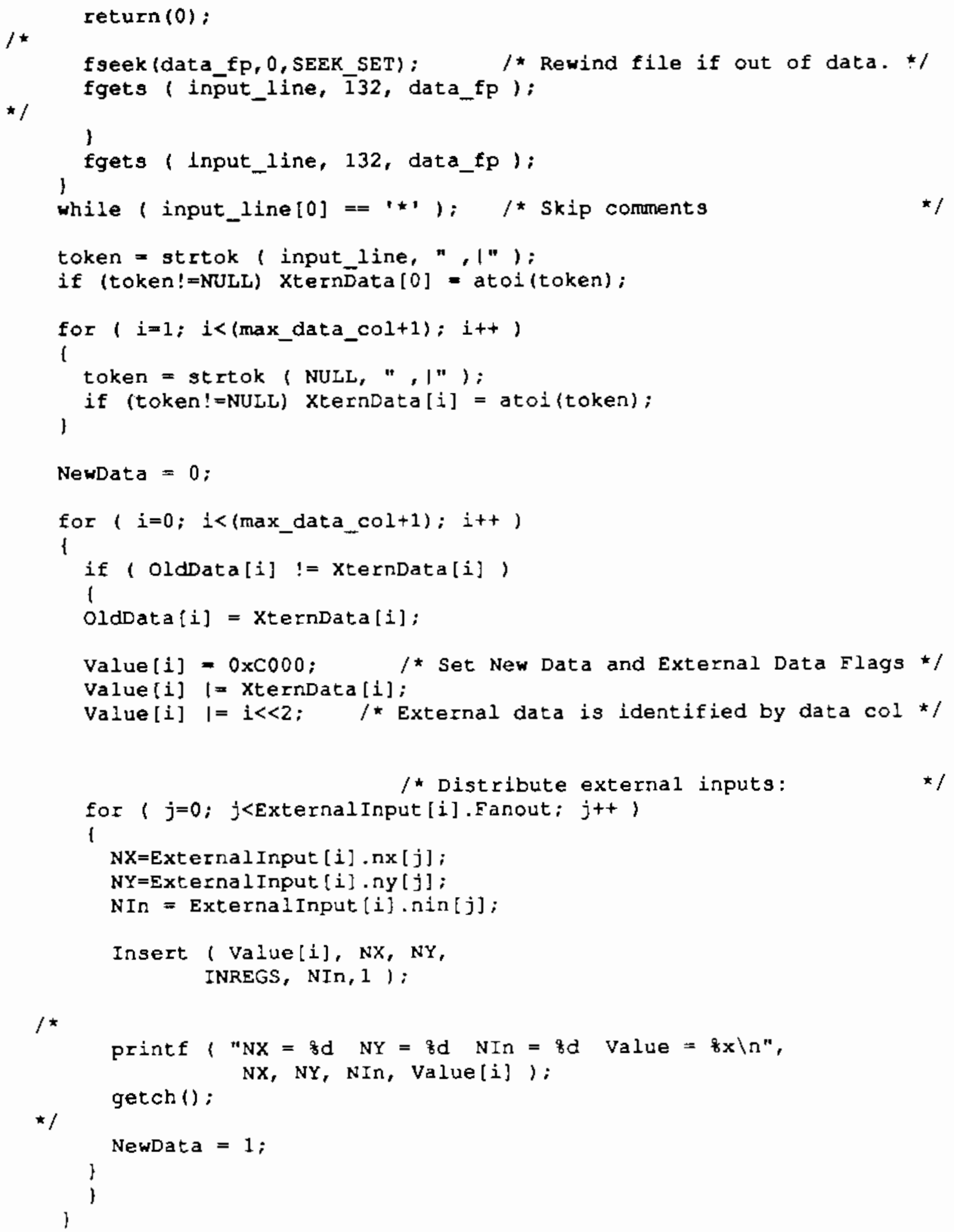




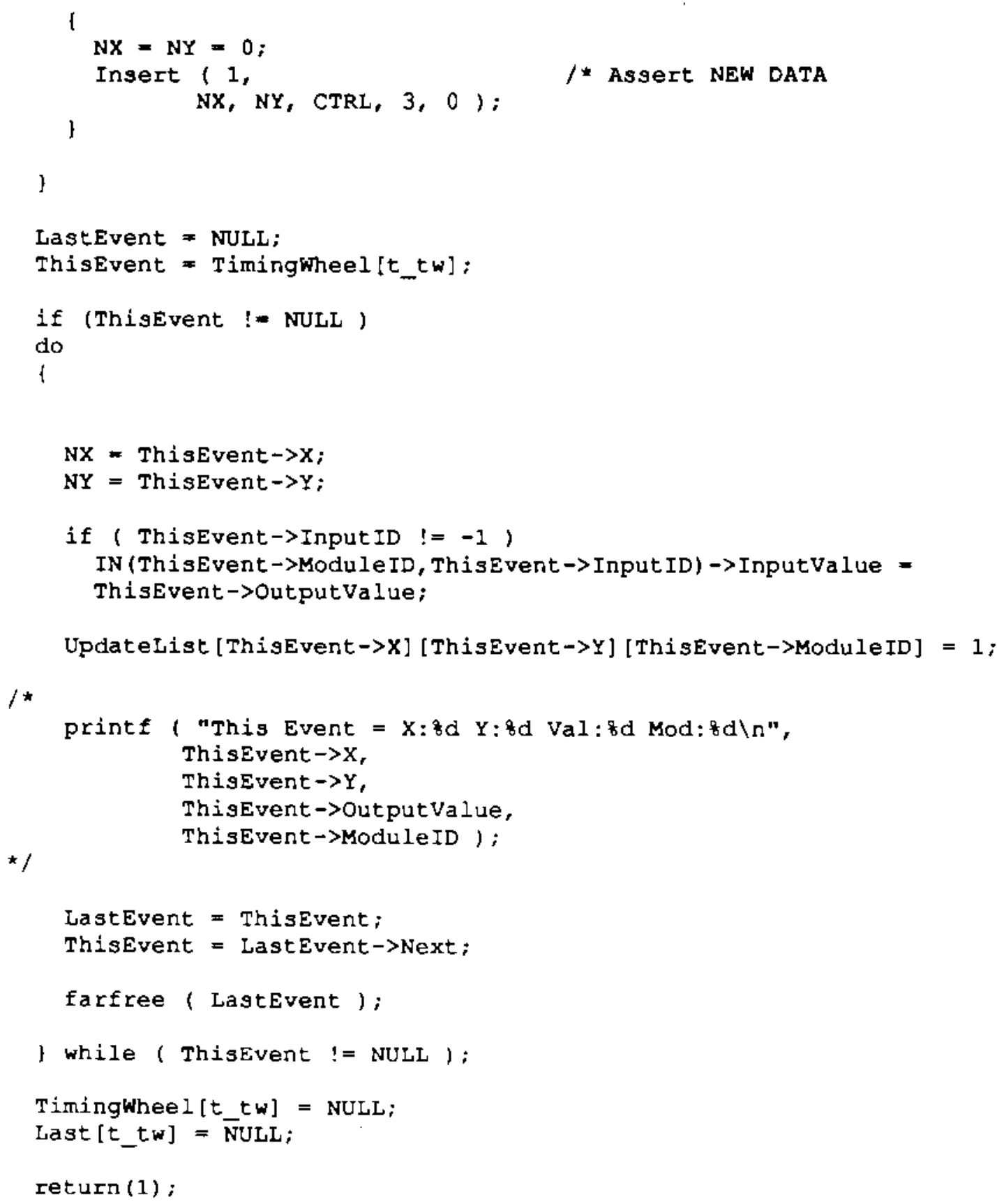




\section{8}

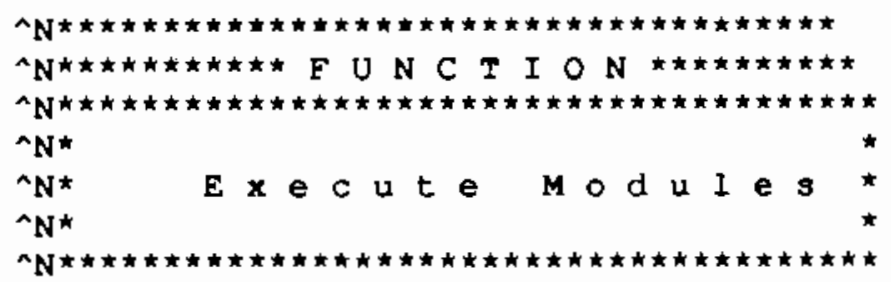

Functional Sumtary:

After all events have been processed, this function executes all the modules that have new inputs, generating new outputs.

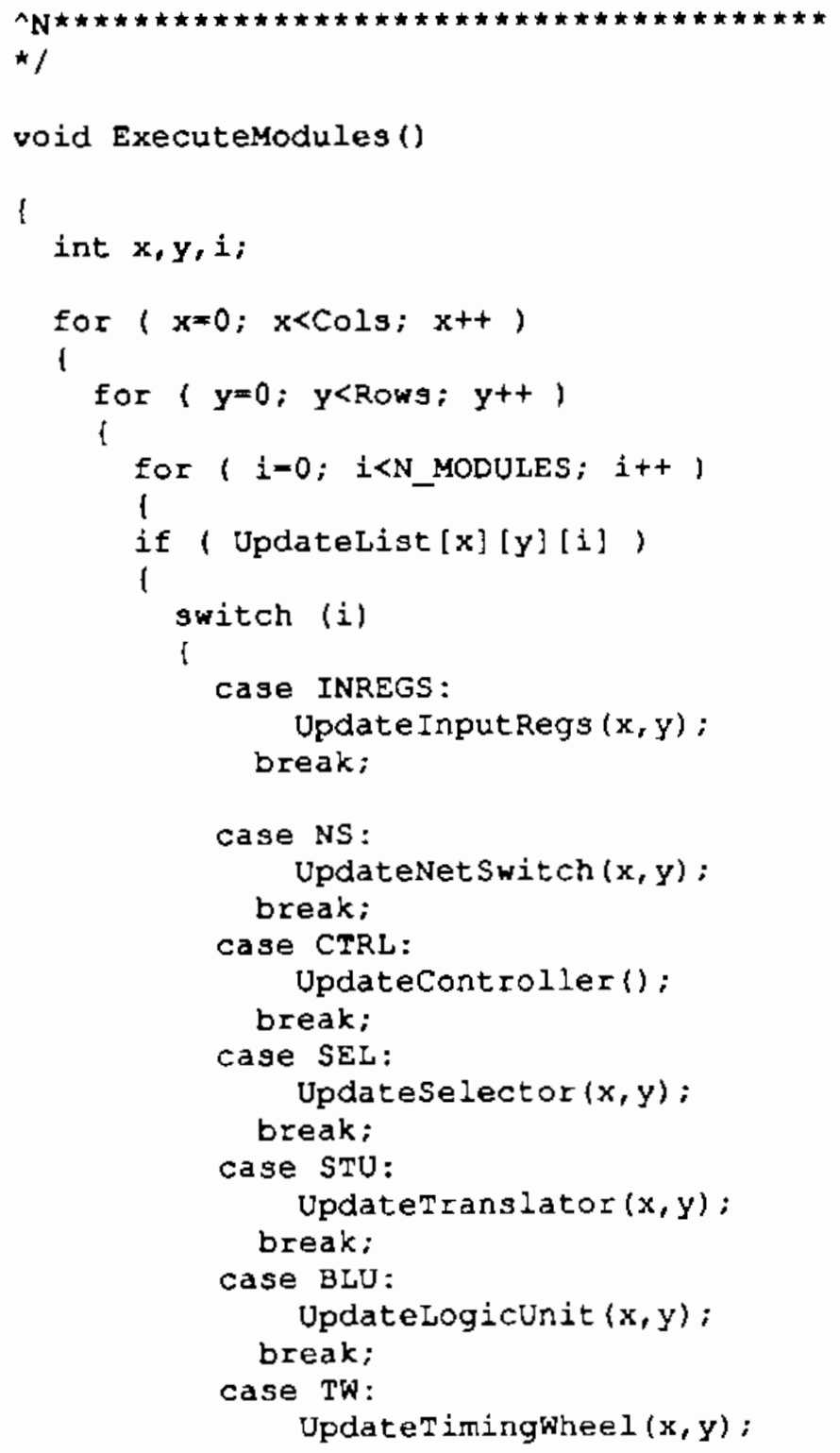




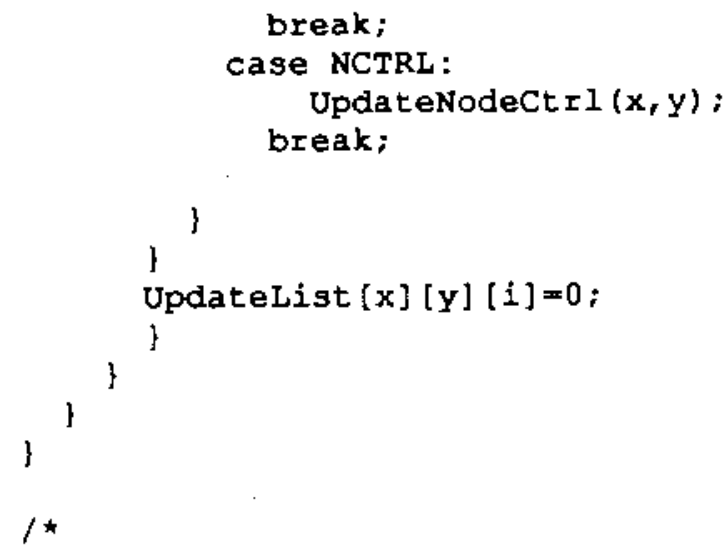




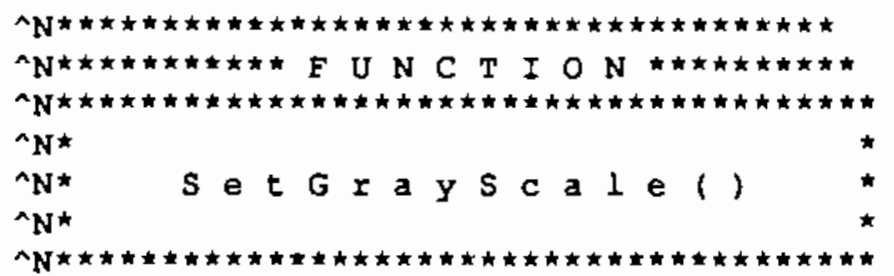

Functional sumary:

This function alters the color registers to create a 16-level gray scale. (Only works with VGA register-level compatible graphics adaptors.)

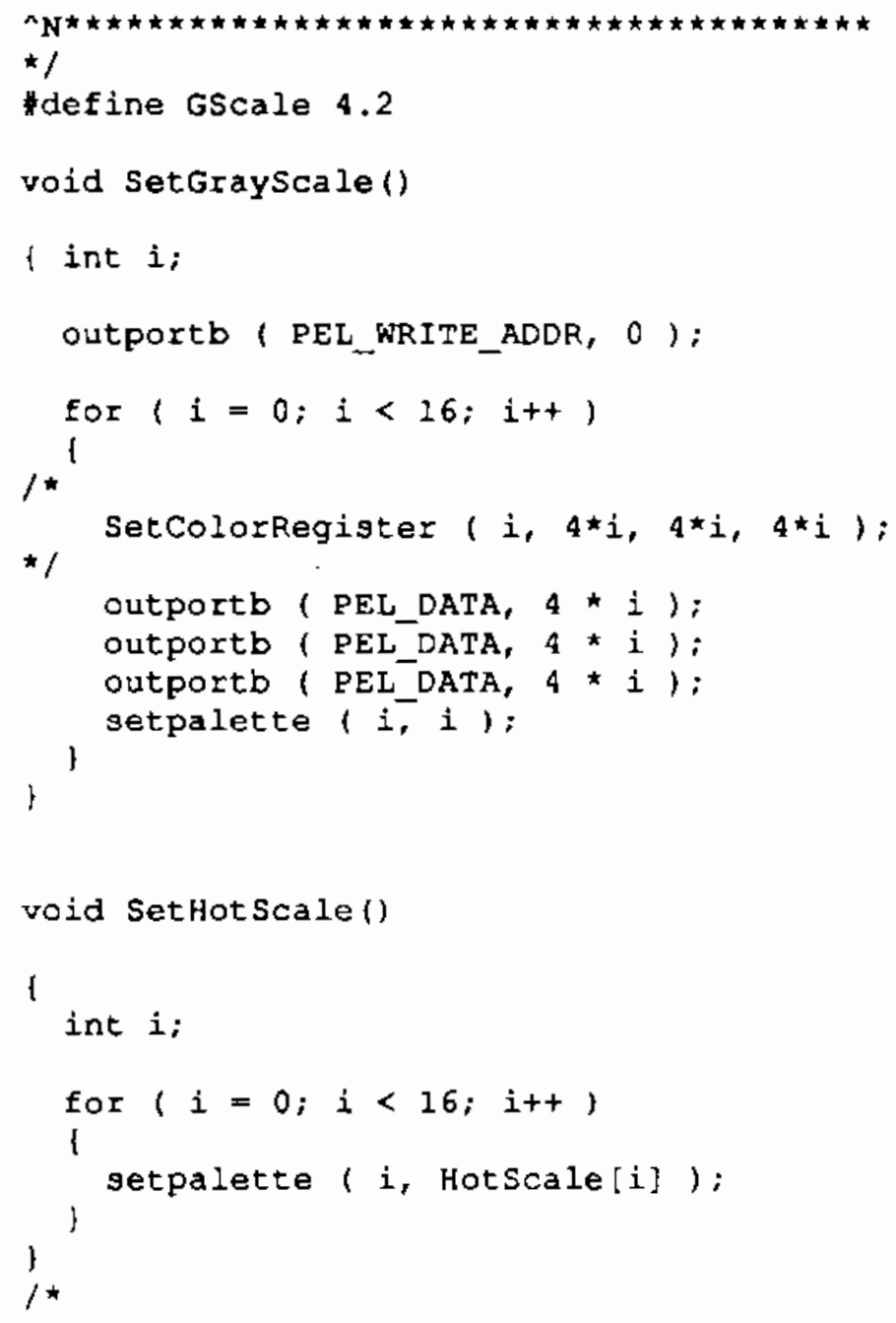




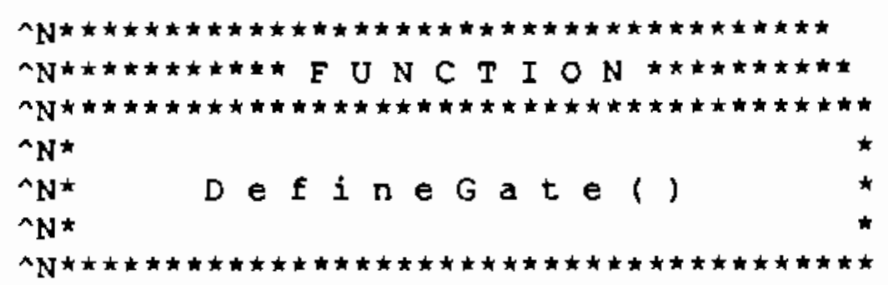

Functional Summary:

This function enters a gate definition into the array's gate mernory.

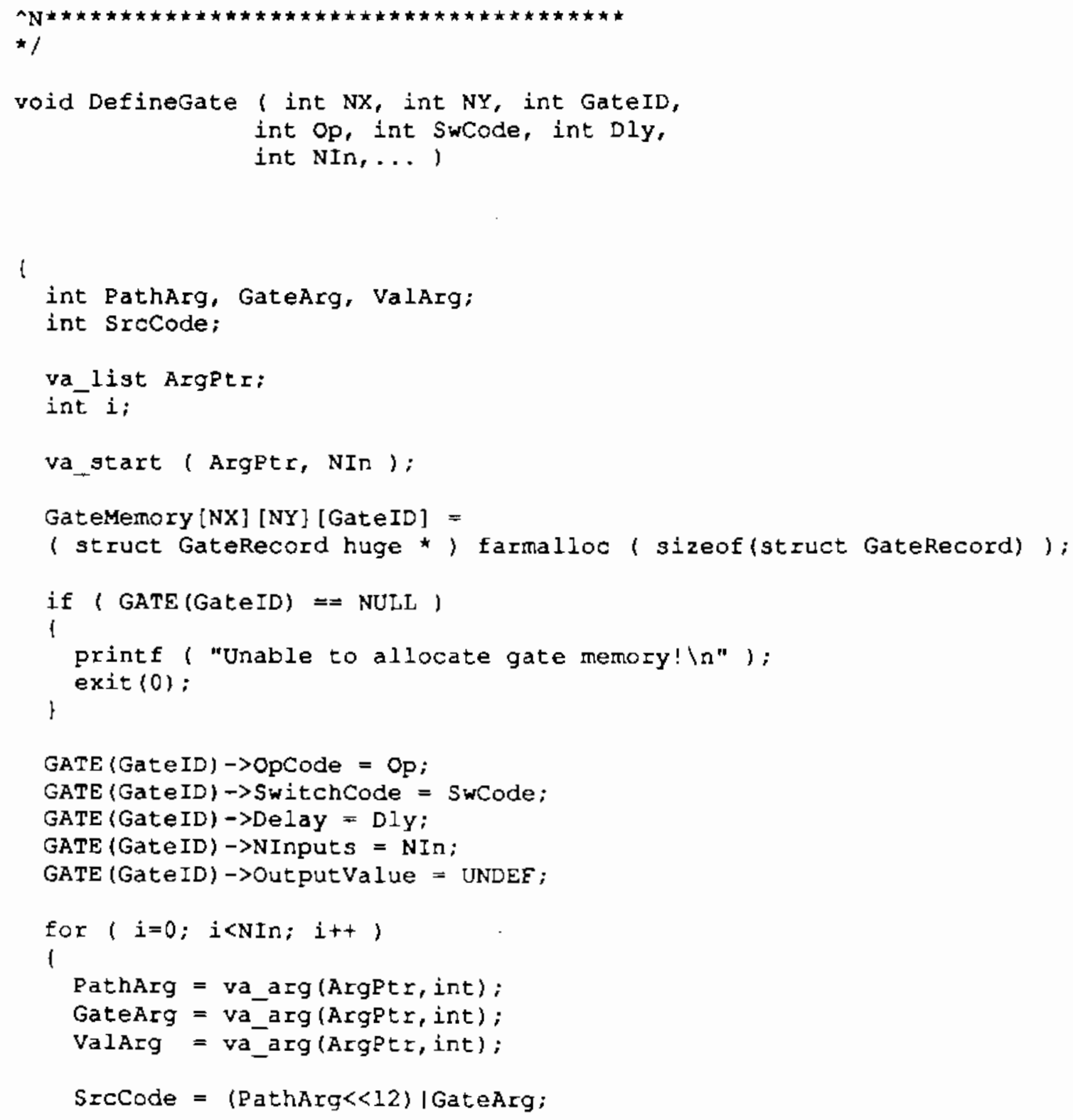




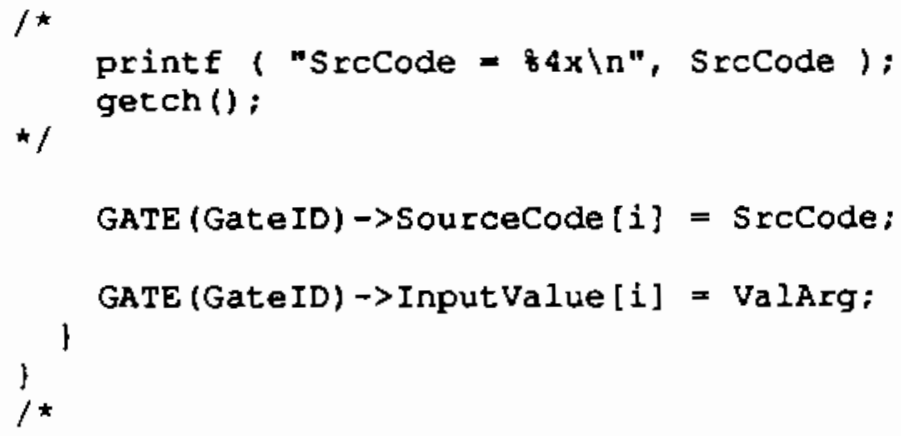



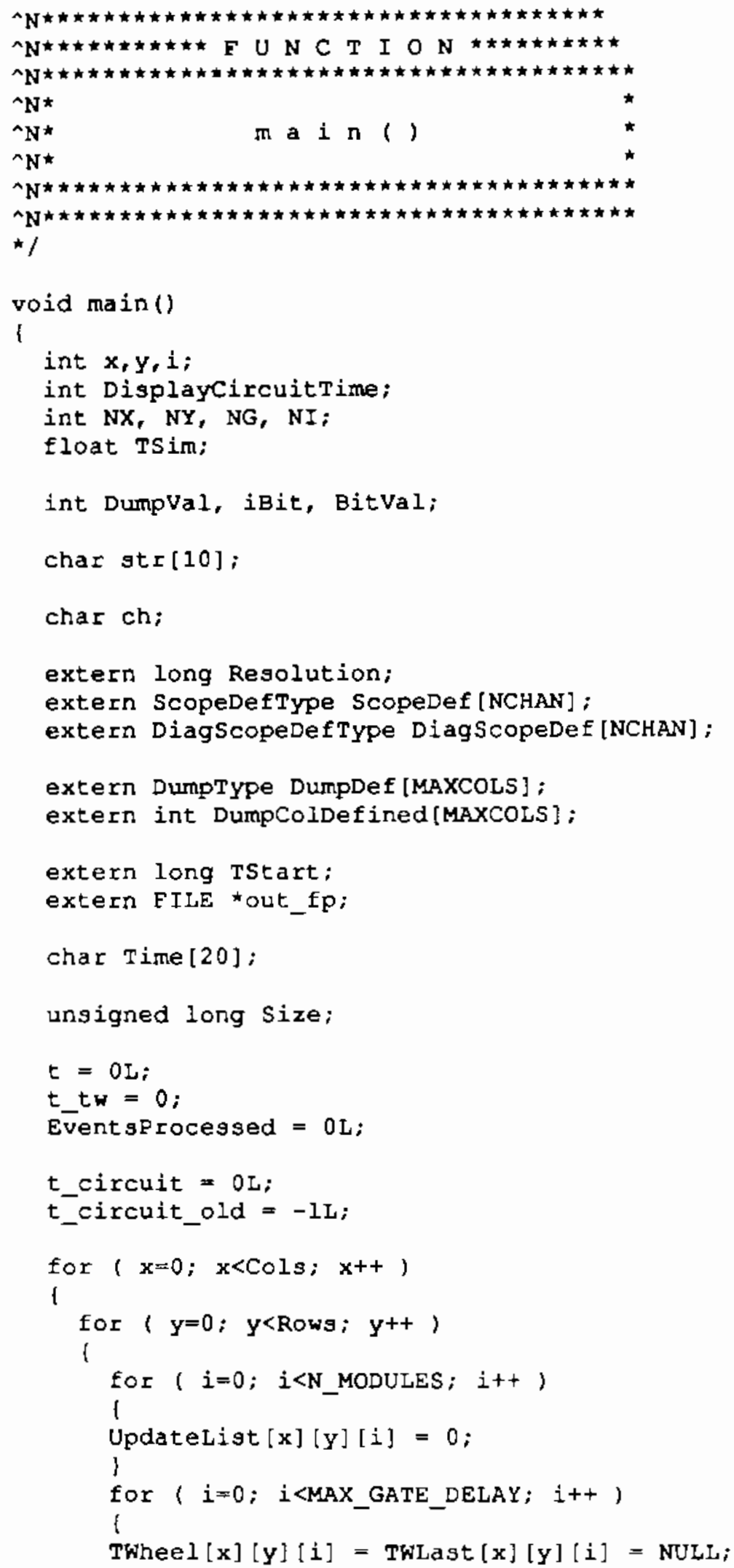


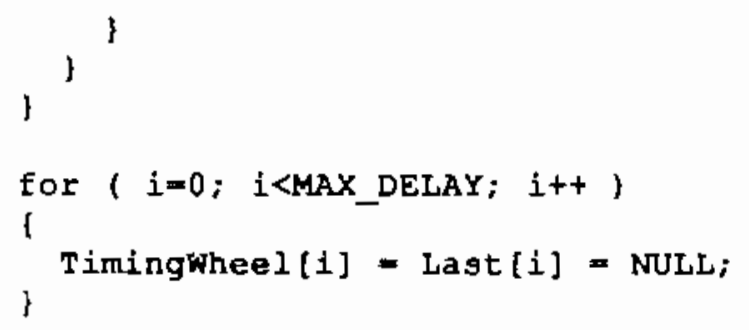




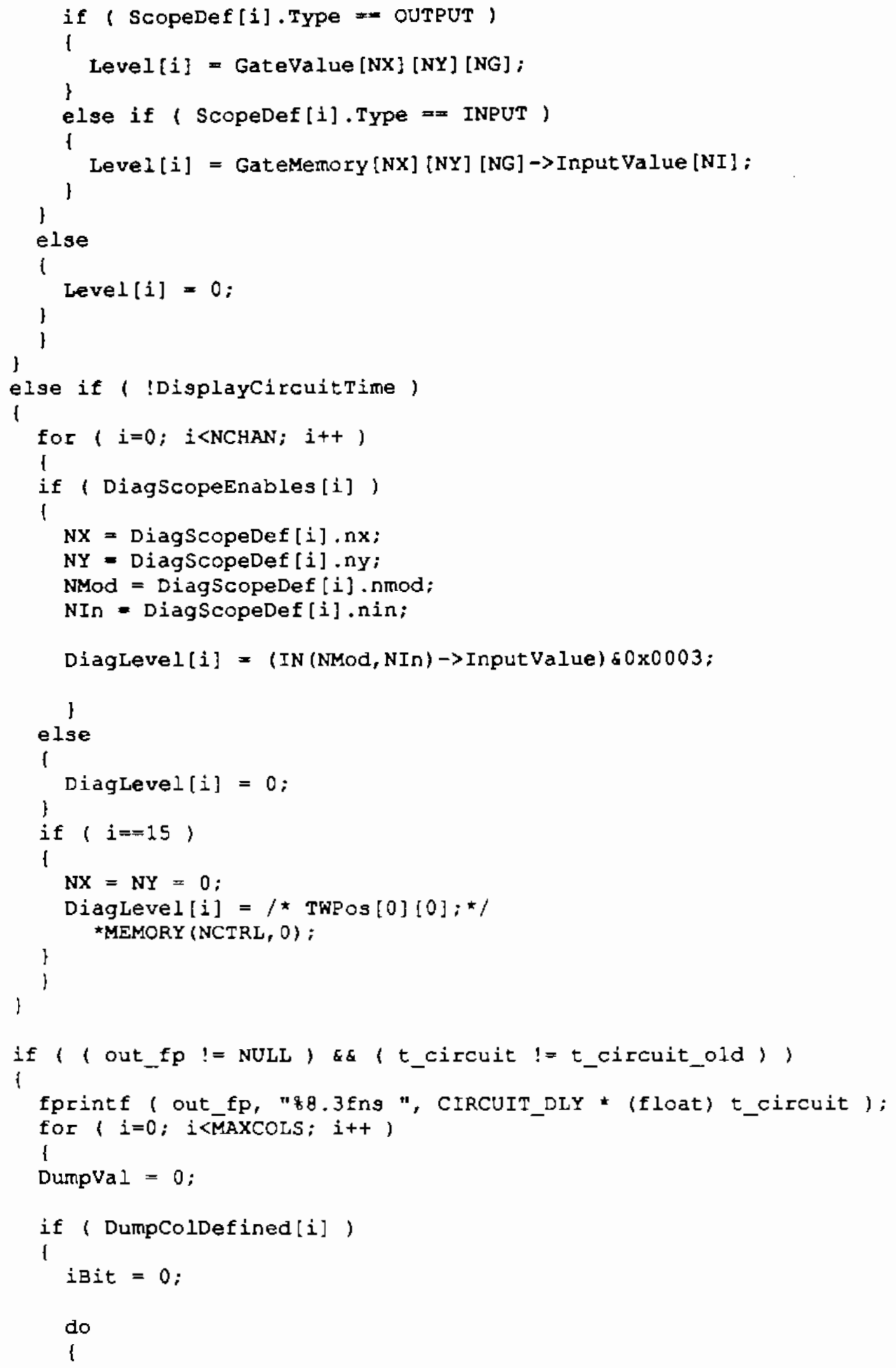




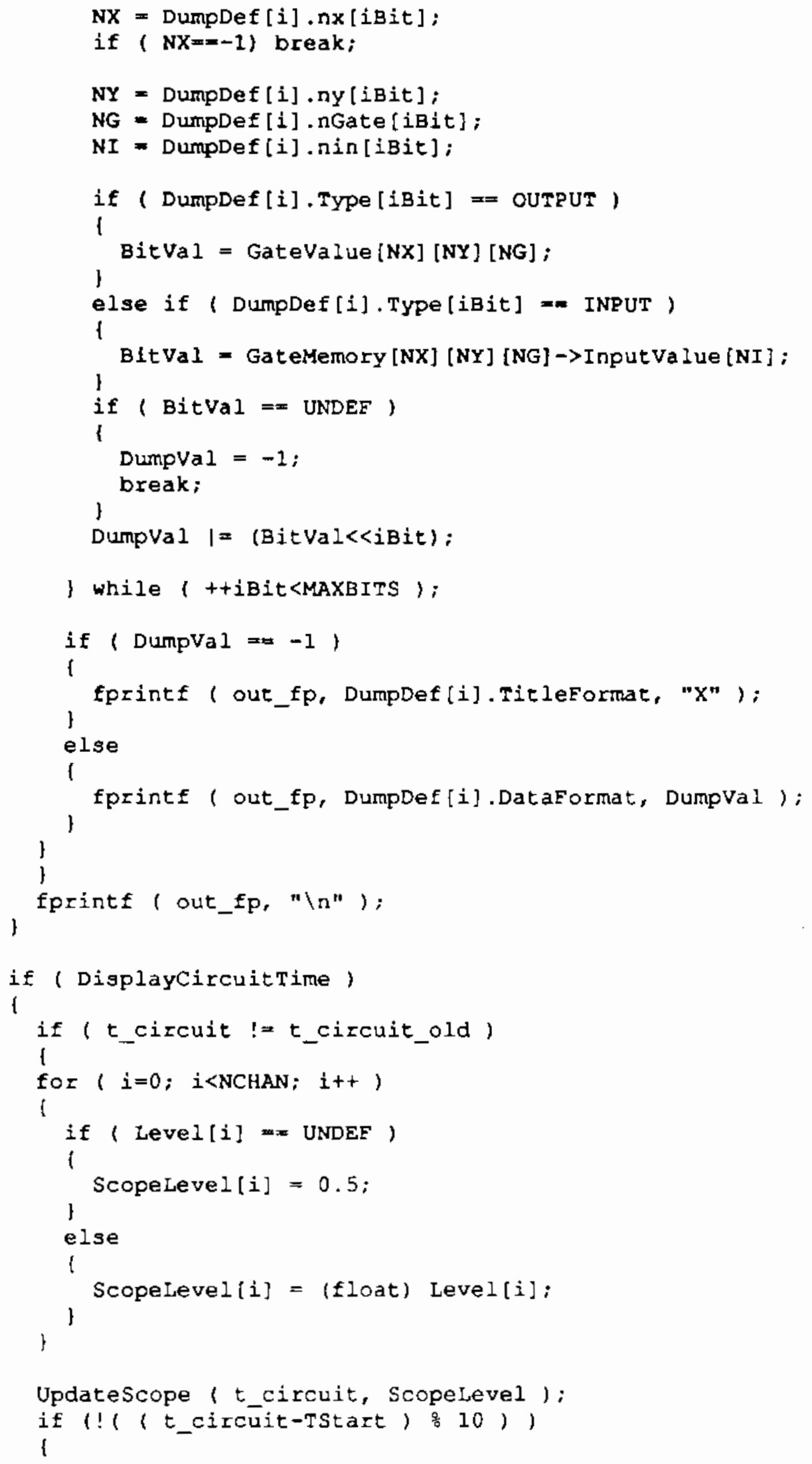




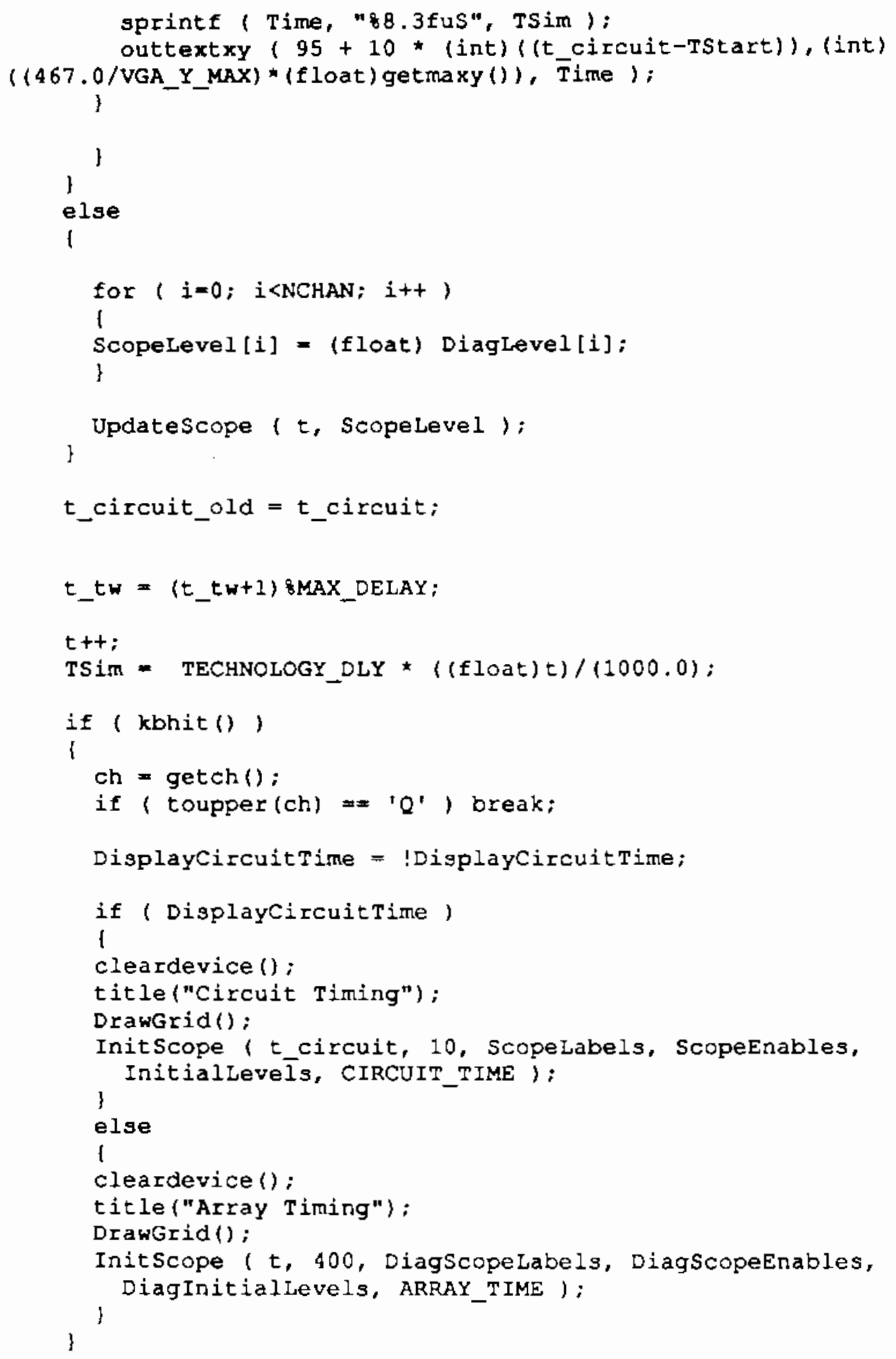




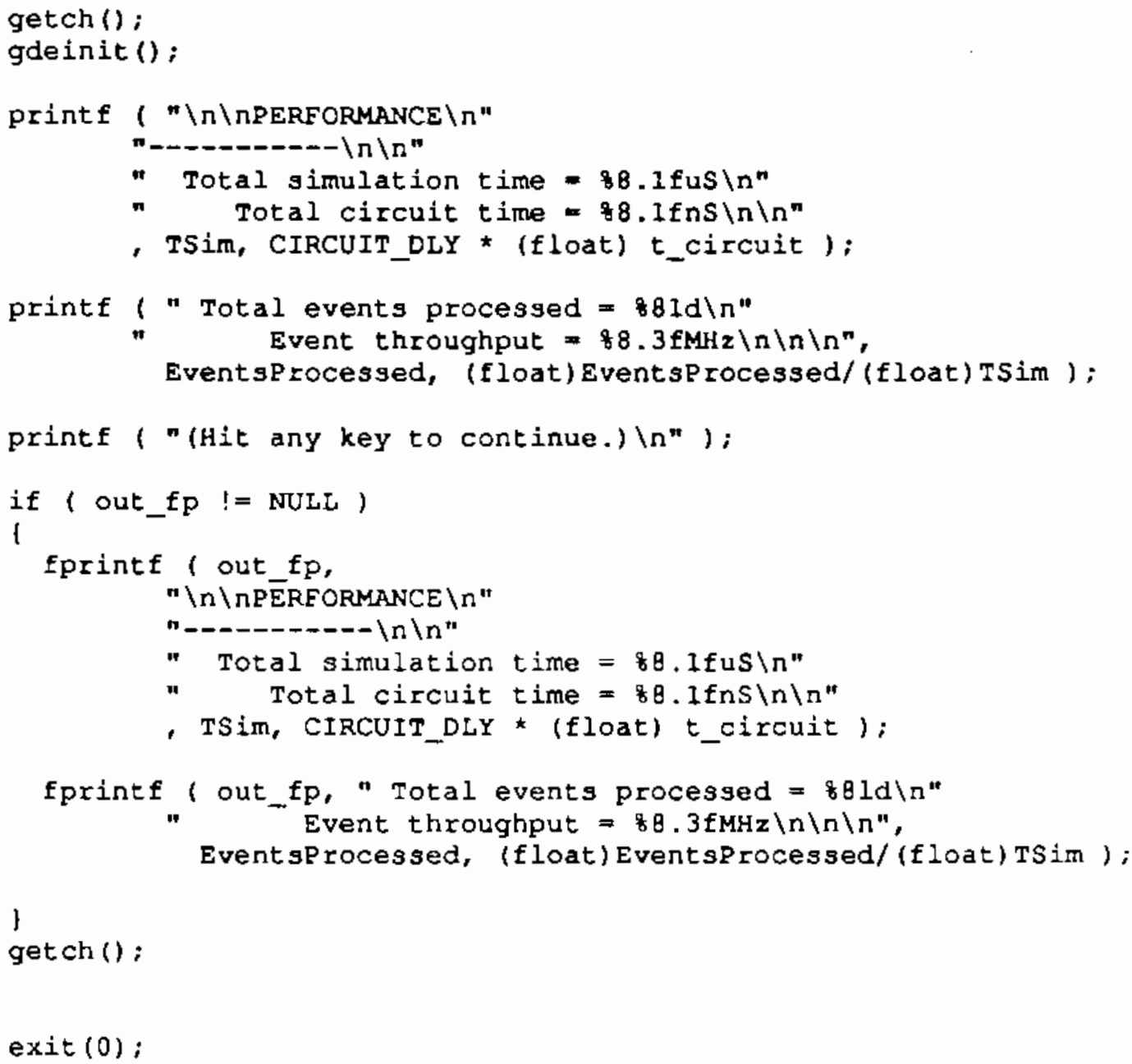




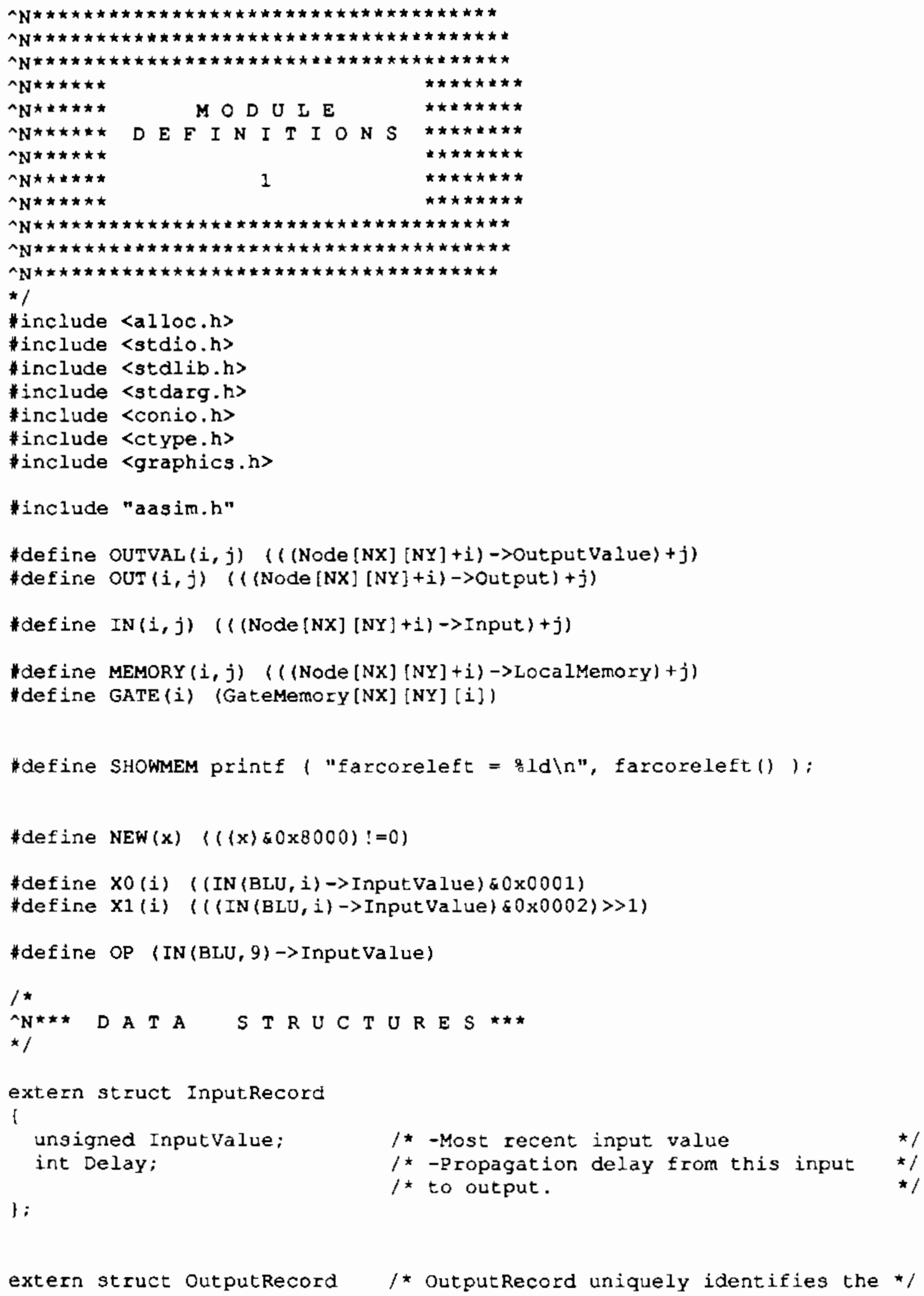




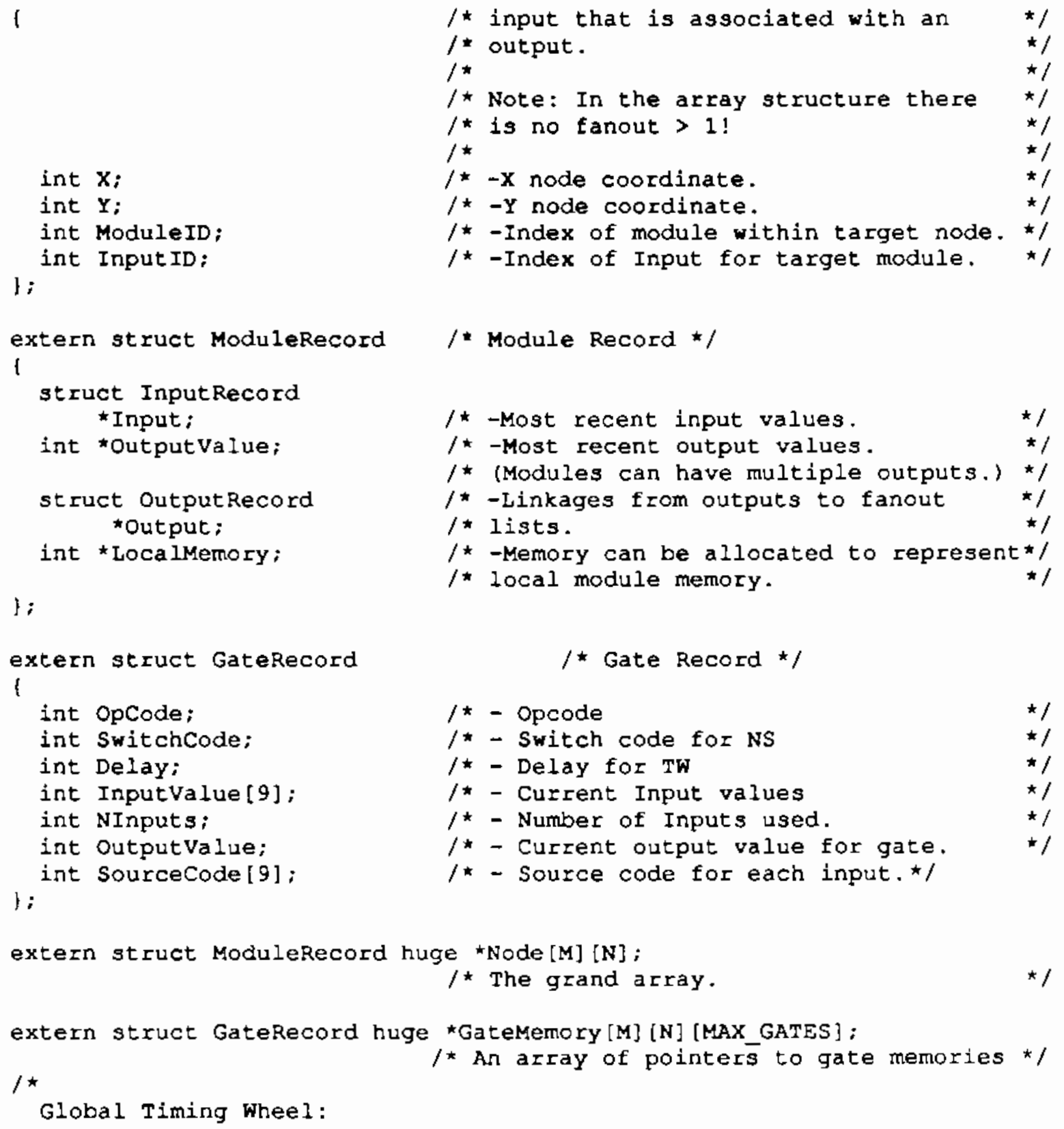

A global timing wheel is implemented for the array. As a new output is generated is is stored in the timing wheel along with the ( $X, Y$, ModuleID, InputID) coordinates for one of the inputs it is intended for.

$\star /$

extern struct EventRecord /* Global Timing Wheel Record */ i

int outputvalue;

int $x$;

int $Y$;

int ModuleID;
$/ *$-New output value.

$1 *$-Target Node $X$ coordinate.

/* -Target Node $Y$ coordinate.

$/ \star$-Target Module ID. 


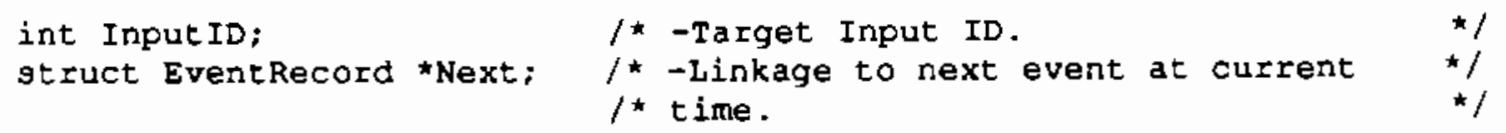
;

extern struct EventRecord *TimingWheel[MAX_DELAY]; $/ *$ - Timing Whee 1 */

extern struct EventRecord *Last [MAX_DELAY];

$/ *$ Keeps track of last event in $\star /$

$/ *$ each position of the wheel. */

extern int UpdateList [M] [N] [N_MODULES];

$/ \star$ Updatelist - List is updated as
$/ \star$ events are processed from timing
$/ \star$ wheel. After events are used to
$/ *$ update inputs, the list is used
$/ \star$ to see which modules have new inputs $\star / /$
$/ \star$ and need to be executed.

$/ \star$

Node Timing wheels:

An actual hardware module exists in each node implmenting a timing wheel function for circuit simulations. As an output is generated by the Boolean Logic Unit it is stored together with GATE ID, and SWITCH CODE in the timing wheel.

*/

extern struct GateEventRecord /* Local node timing wheel record. */ 1

int SwCode: $\quad /^{\star}$ - Switch Code

int Sourcegate; $\quad / \star$ - Source Gate Identification

struct GateEventRecord *Next; /* - Pointer to next gate event. 1 ;

extern struct GateEventRecord *TWheel[M] [N] [MAX_GATE_DELAY];

/* Local node timing wheel */

extern struct GateEventRecord *TwLast[M] [N][MAX_GATE_DELAY]; $/ *$ Pointer to last eveñt in */

$/ \star$ each TW position.

extern struct GateEventRecord * TwCurzent [M] [N];

$1 \star$ Pointer to current event */

/ in present position in each $\mathrm{TW}$.

extern int TWPOS[M][N]; $\quad /$ * Current position in each local node *

$/ \star$ timing wheel.

$\begin{array}{ll}\text { extern long t; } & / \star-\text { Current simulation time. } \\ \text { extern int t_tw; } & / \star-\text { Current position in global timing } \begin{array}{r}\star / \\ \star /\end{array} \\ & / \star \text { wheel. } \\ \text { extern int tflg; } & / \star-\text { Counter used for timing external } / / \\ & / \star \text { inputs for testing. }\end{array}$ 
112

extern long t_circuit;

extern int UpdateFlg;

/* - Flag is set when an update of the */

/* histogram array is desired.

extern char $\star$ Scopelabels[];

extern int Scopernables[];

extern int InitialLevels[];

extern int Level[];

extern int Rows, Cols;

$/ \star$ 


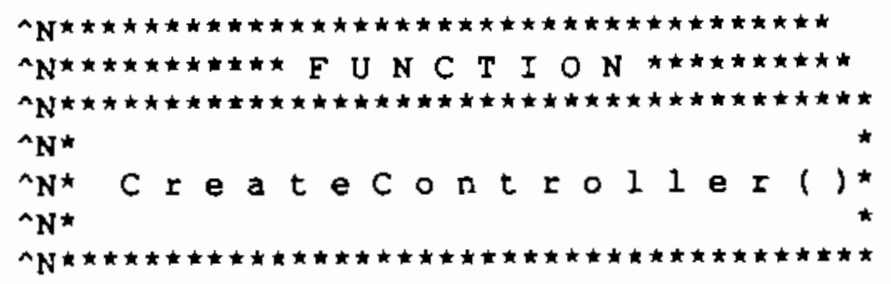

Functional Sumura:

Creates the Array Controller which provides coordination of overall array timing.

Module ID $=2$
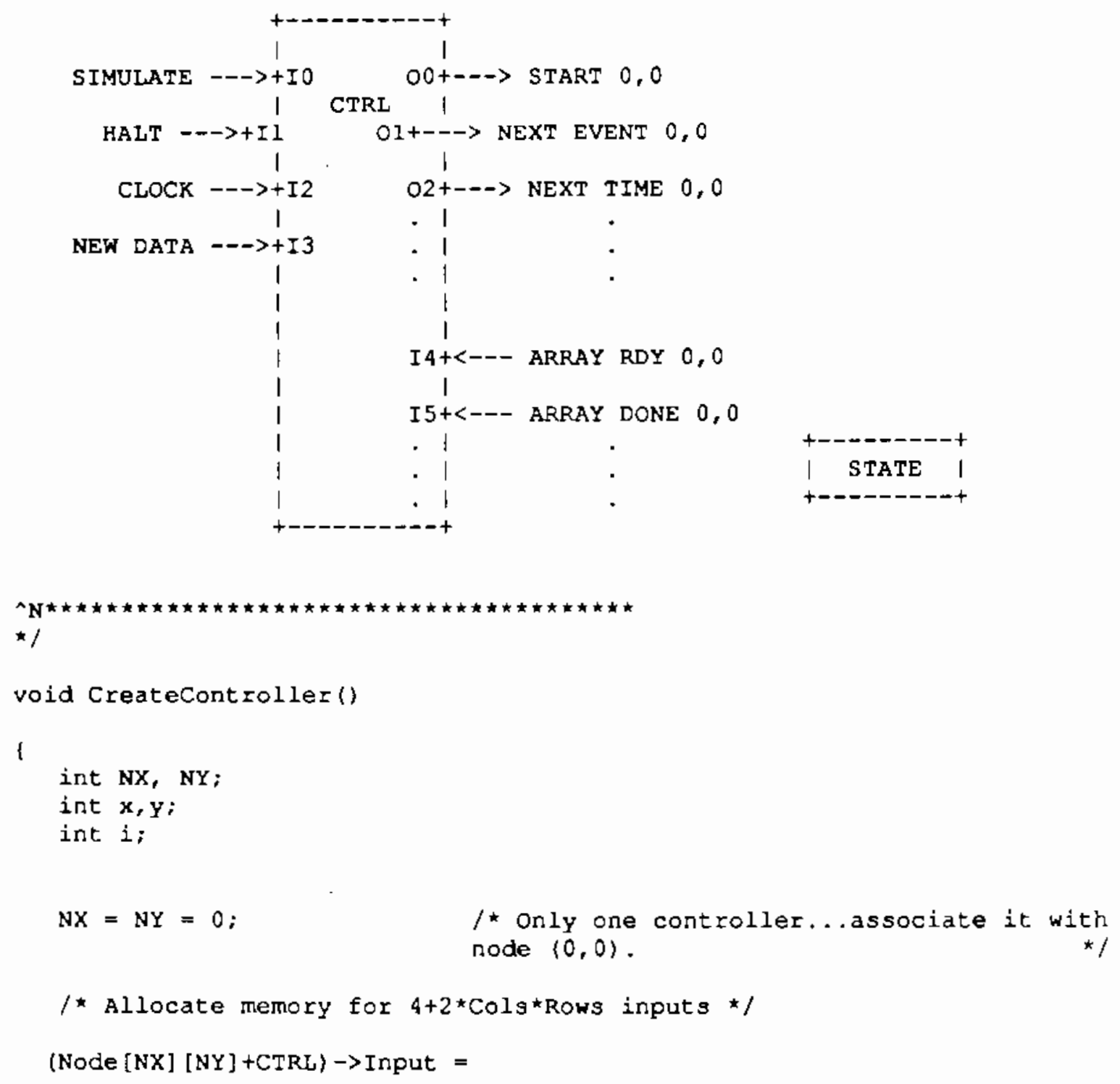


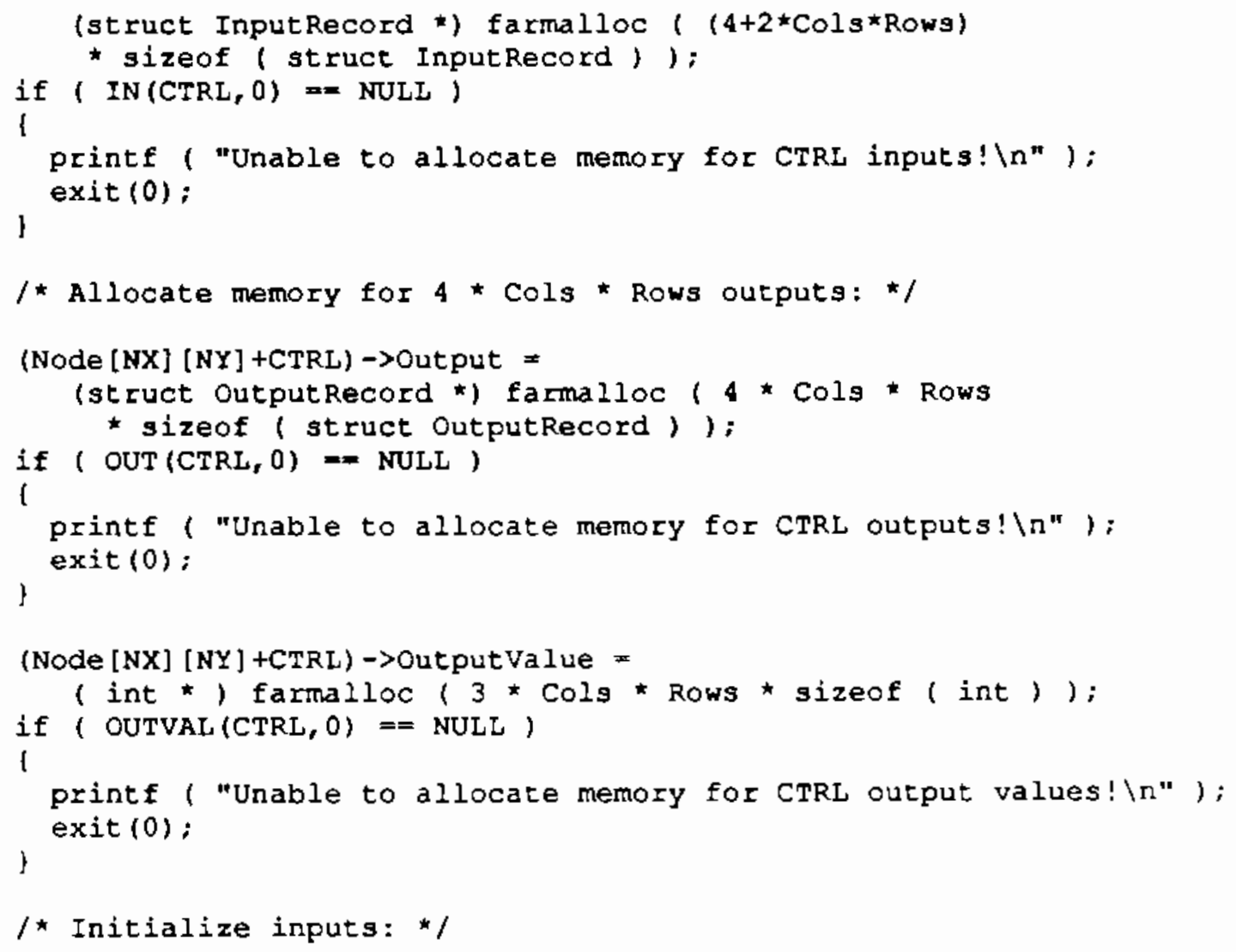




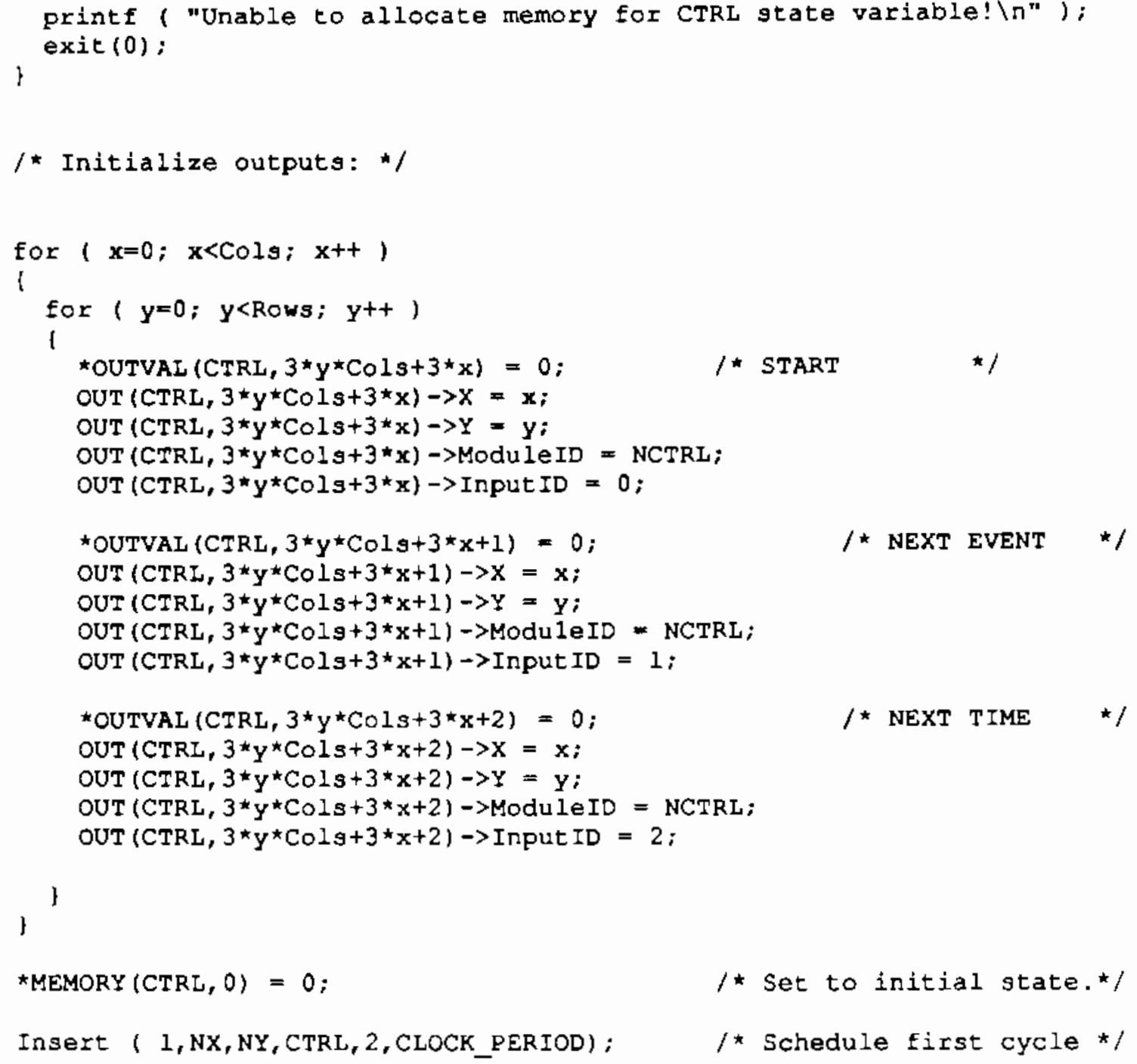


116

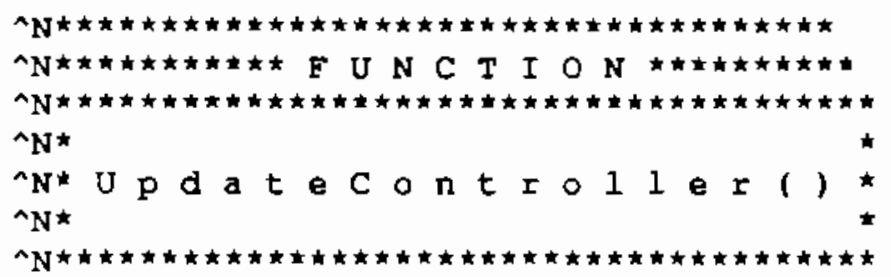

Functional Summary:
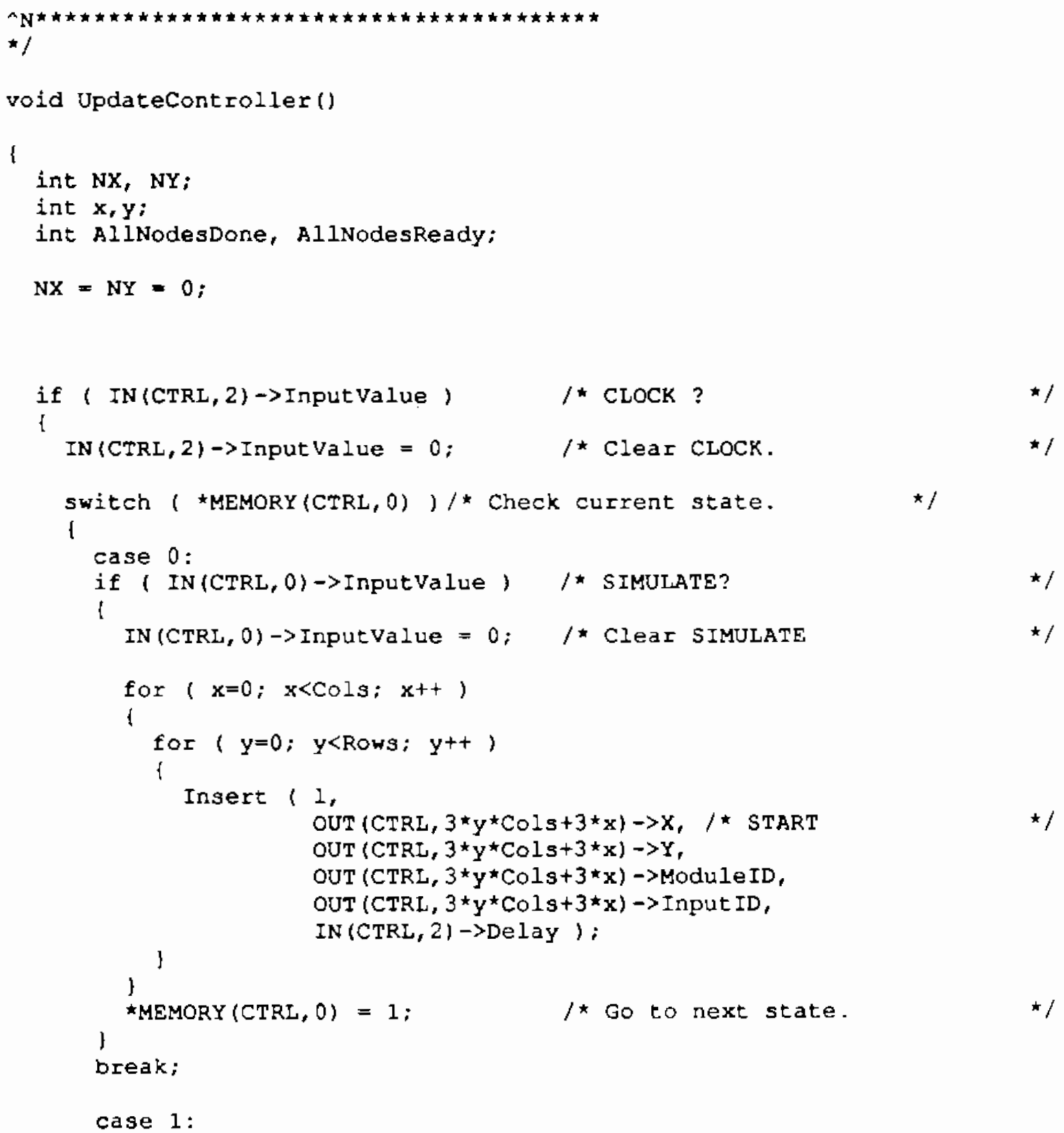


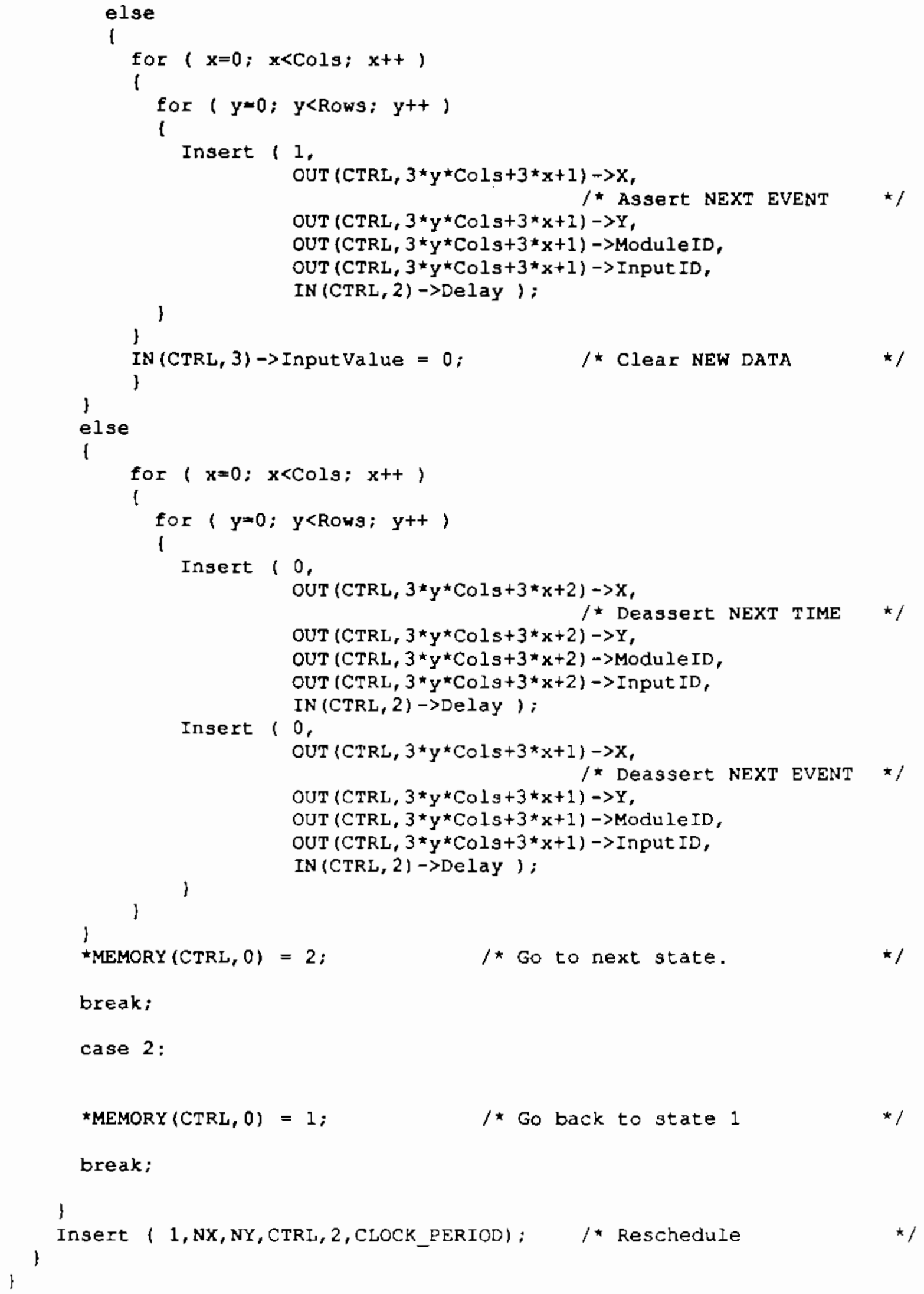




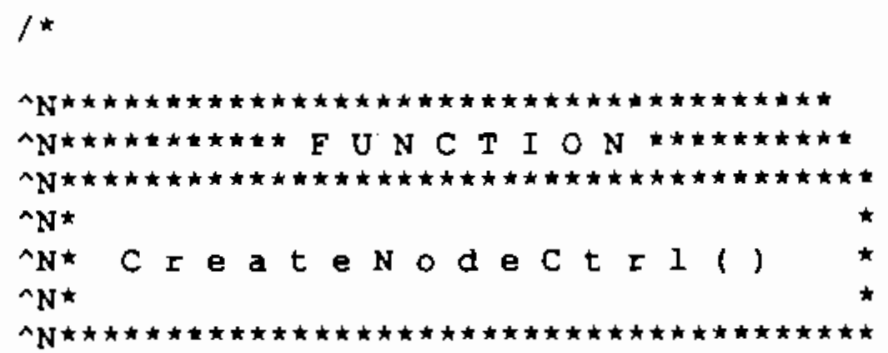

Functional Sumnary:

Creates the local Cell Controller which coordinates the timing of the moduleg within each node.

Module ID $=7$

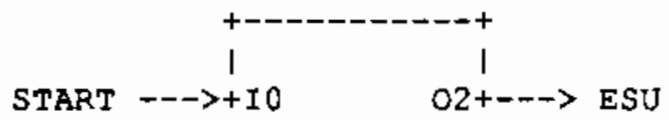

NEXT EVENT --->+II

NEXT TIME $-->+I 2$

ARRAY DONE $<---+00$

1

ARRAY RDY $<--++01$

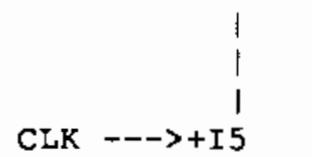

O9+--> LD TW

NCTRL I

$\begin{array}{cc}1 \\ 03+--> \\ 1 \\ 04+--> & \mathrm{ES}\end{array}$

1
OS+-- $\rightarrow$ SD

cuk $-1->+15$

I $110+-->$ NEXT

$1 \quad 11 m$ O INC

$1 \quad 011+-\infty T$ INC

$1012+--->$ ID NS

t-- - - - - +

| STATE |

1

I3+<--- SEL DONE

I

I $4+<---$ TW DONE

1

I $6+<---$ STU DONE

( STU DONE and STU INC added 1

013+---> STU INC

to facilitate vertical fanout. 
$\star /$

void CreateNodeCtrl( int NX, int NY)

l int $i$;

$/$ * Allocate memory for 7 inputs */

(Node $[N X][N Y]+N C T R L)->$ Input $=$

(struct InputRecord *) farmalloc ( 6

- sizeof ( struct InputRecord) );

if ( IN (NCTRL, 0 ) $=$ NULL)

\{

printf ("Unable to allocate memory for NCTRL inputs! $\backslash n$ "); ) exit $(0)$;

/* Allocate memory for 14 outputs: */

(Node $[\mathrm{NX}][\mathrm{NY}]+\mathrm{NCTRL}$ ) ->output *

(struct OutputRecord $\star$ ) farmalloc ( 13

* sizeof (struct OutputRecord) );

if $($ OUT $(N C T R L, 0)==$ NULL )

1

printf ("Unable to allocate memory for NCTRL outputs! \n"); exit (0) ;

)

(Node $[N X][N Y]+N C T R L) \rightarrow$ outputValue $=$

( int *) farmalloc ( 13 * gizeof (int) );

if ( OUTVAL (NCTRL, O) $\Rightarrow$ NULL)

i

printf ("Unable to allocate memory for NCTRL output values! (n"); \} exit (0):

/* Allocate memory for 1 state variable. */

(Node $[\mathrm{NX}][\mathrm{NY}]+\mathrm{NCTRL})->$ LocalMemory $=$

( int *) farmalloc ( sizeof ( int) );

if (MEMORY (NCTRL, 0 ) $=\approx$ NULL)

1

printf ("Unable to allocate memory for NCTRL state variable! $\backslash n$ ");

1 exit (0);

/* Initialize inputs: */

for $(i=0 ; i<7 ; i++)$

1

IN (NCTRL, i) $\rightarrow$ Inputvalue $=0$;

IN (NCTRL, i) $\rightarrow$ Delay $=1$; 


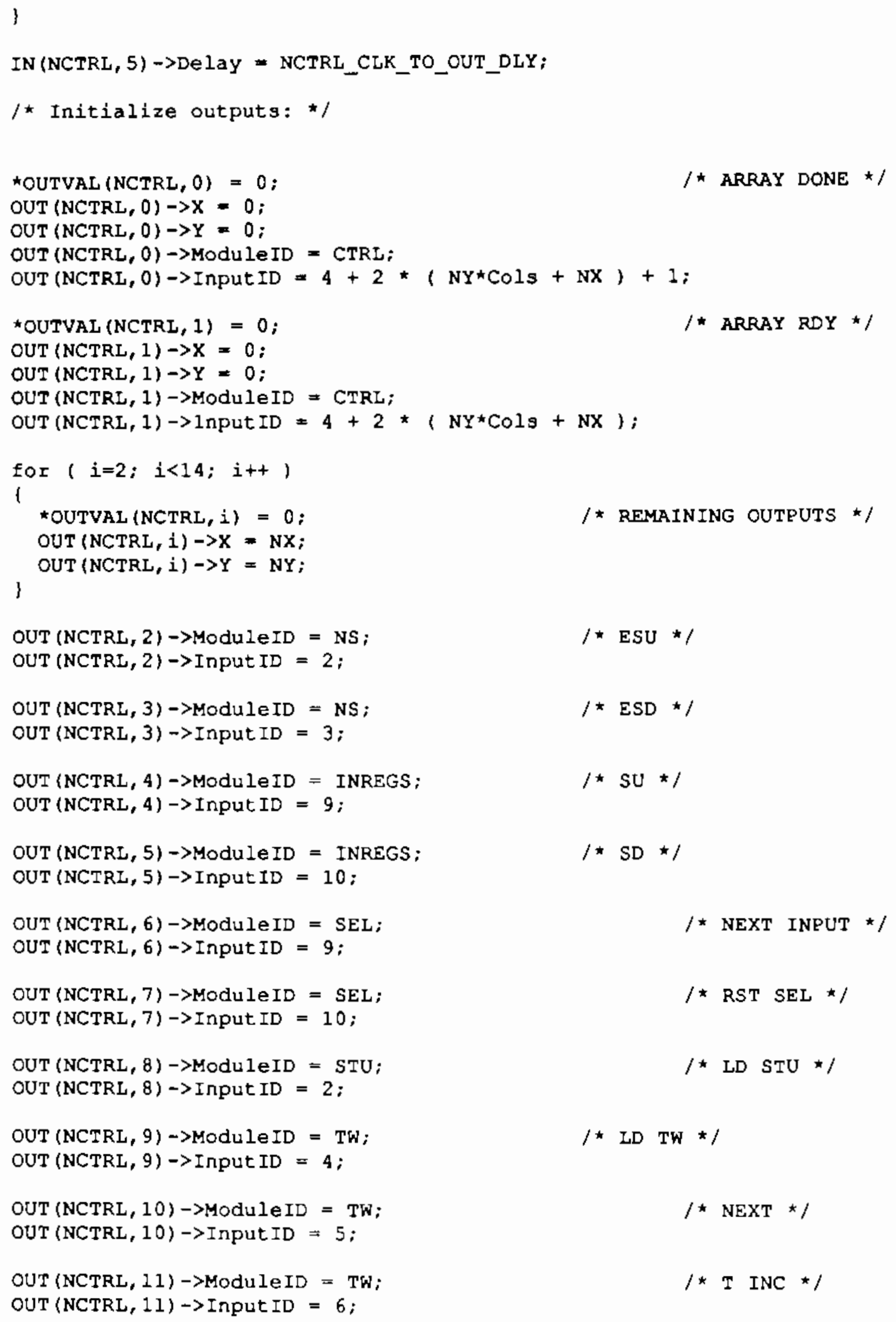




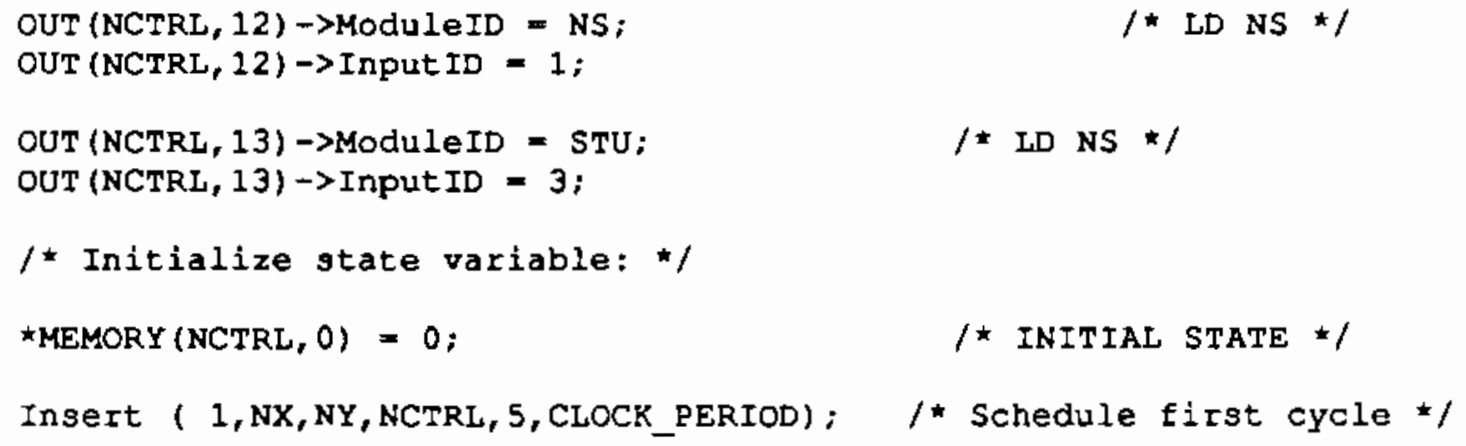




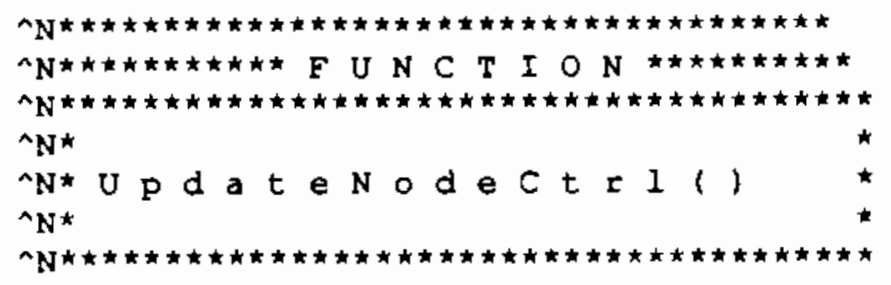

Functional Summary:

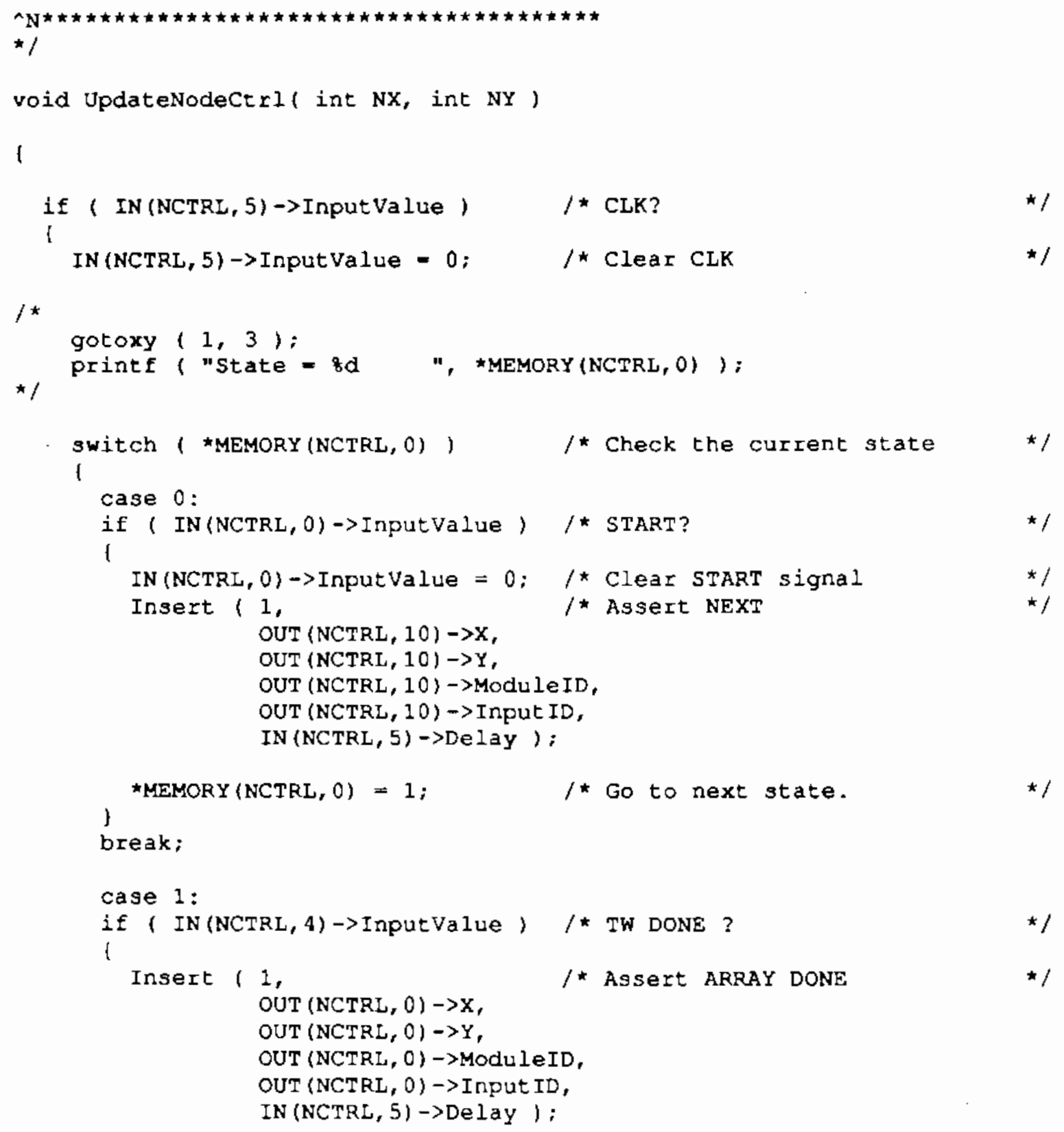




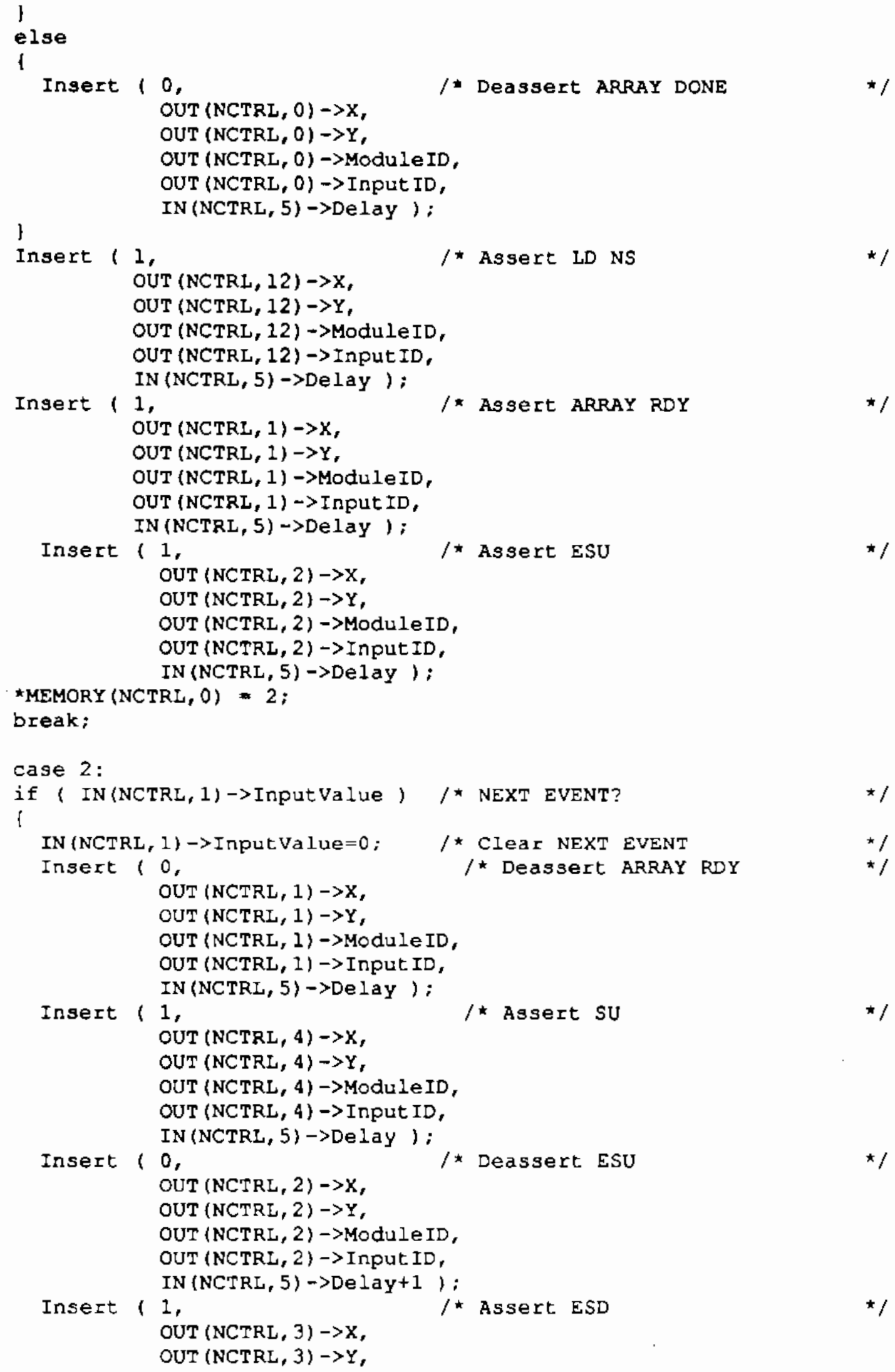




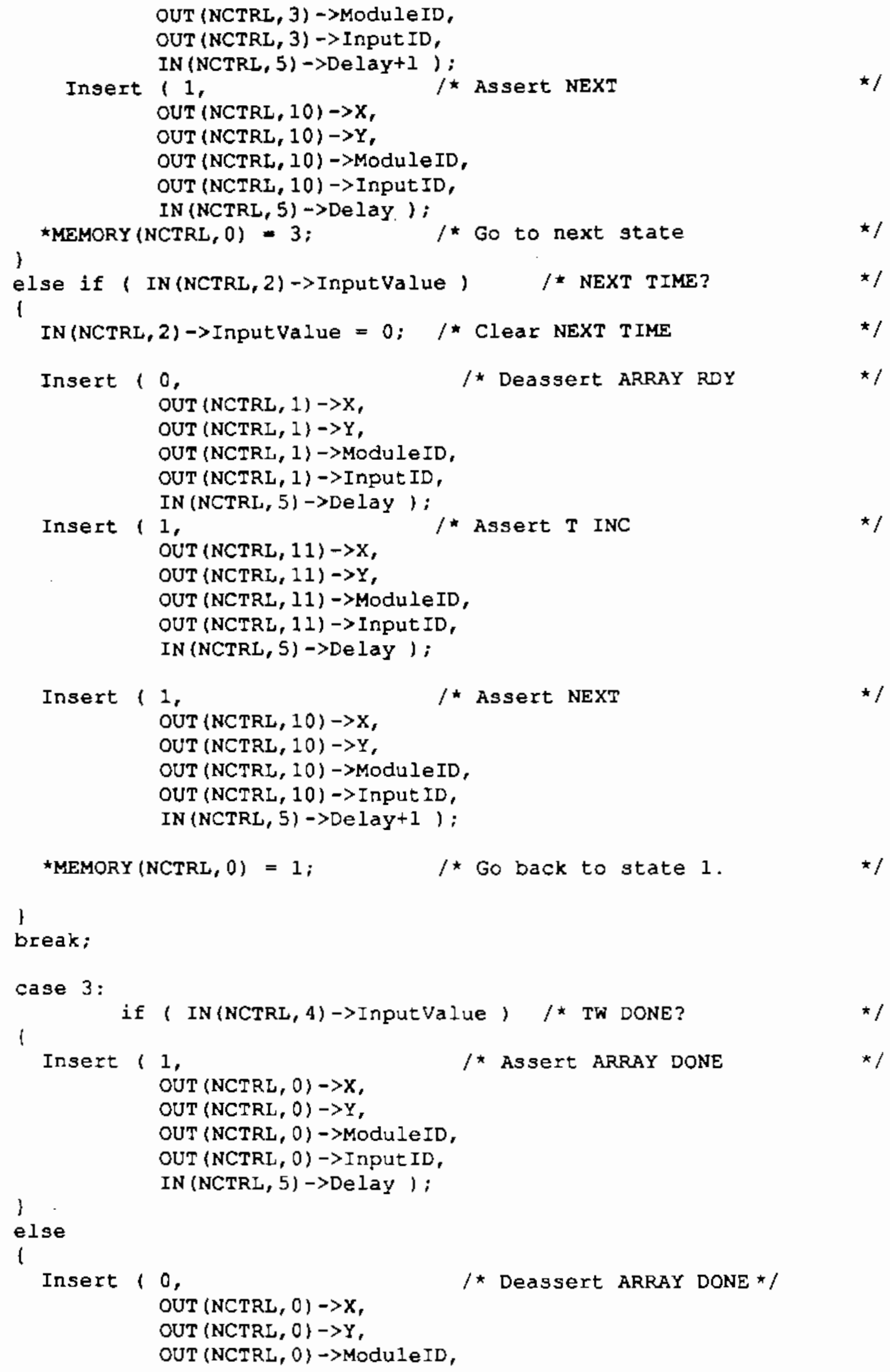




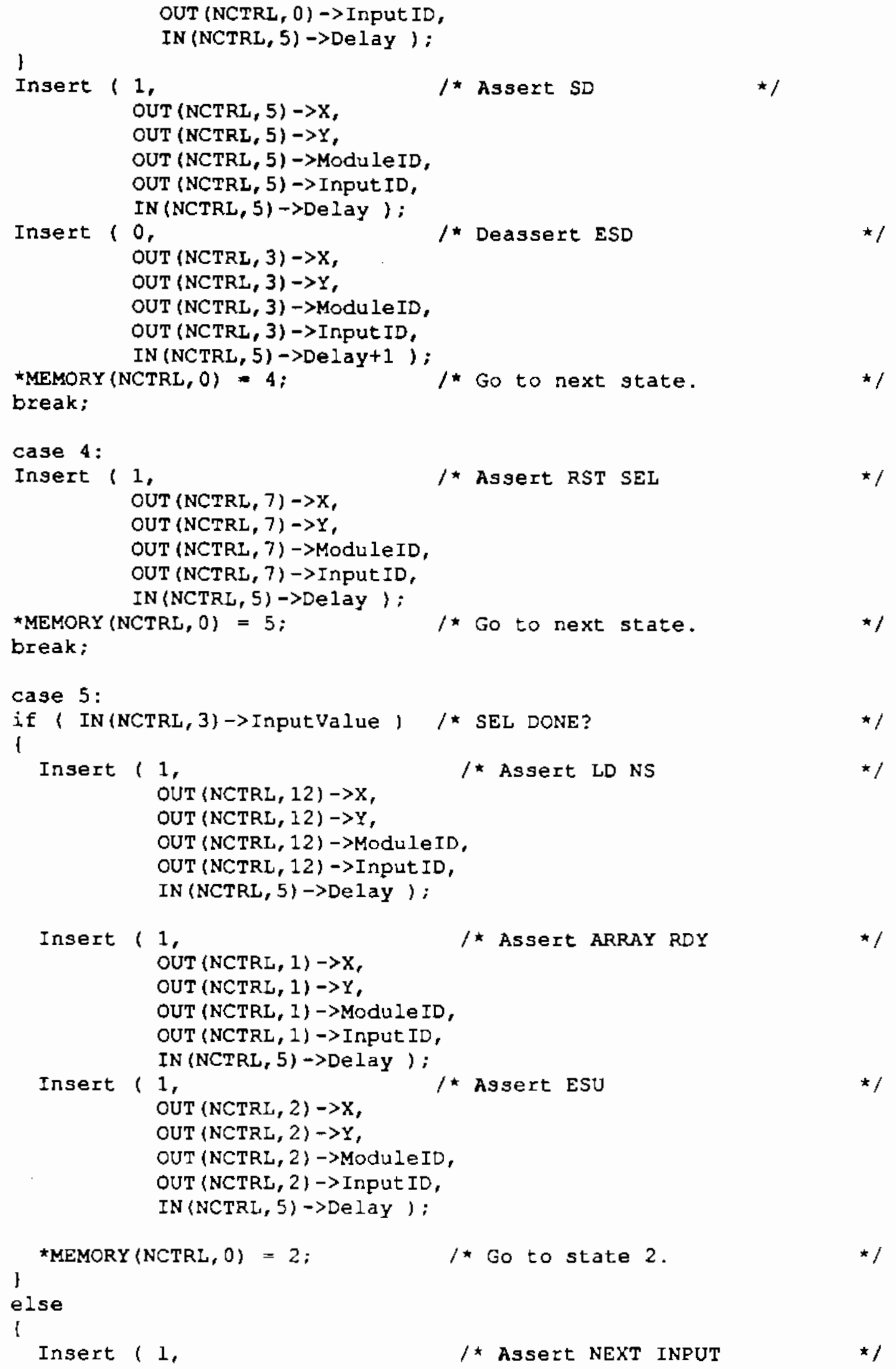




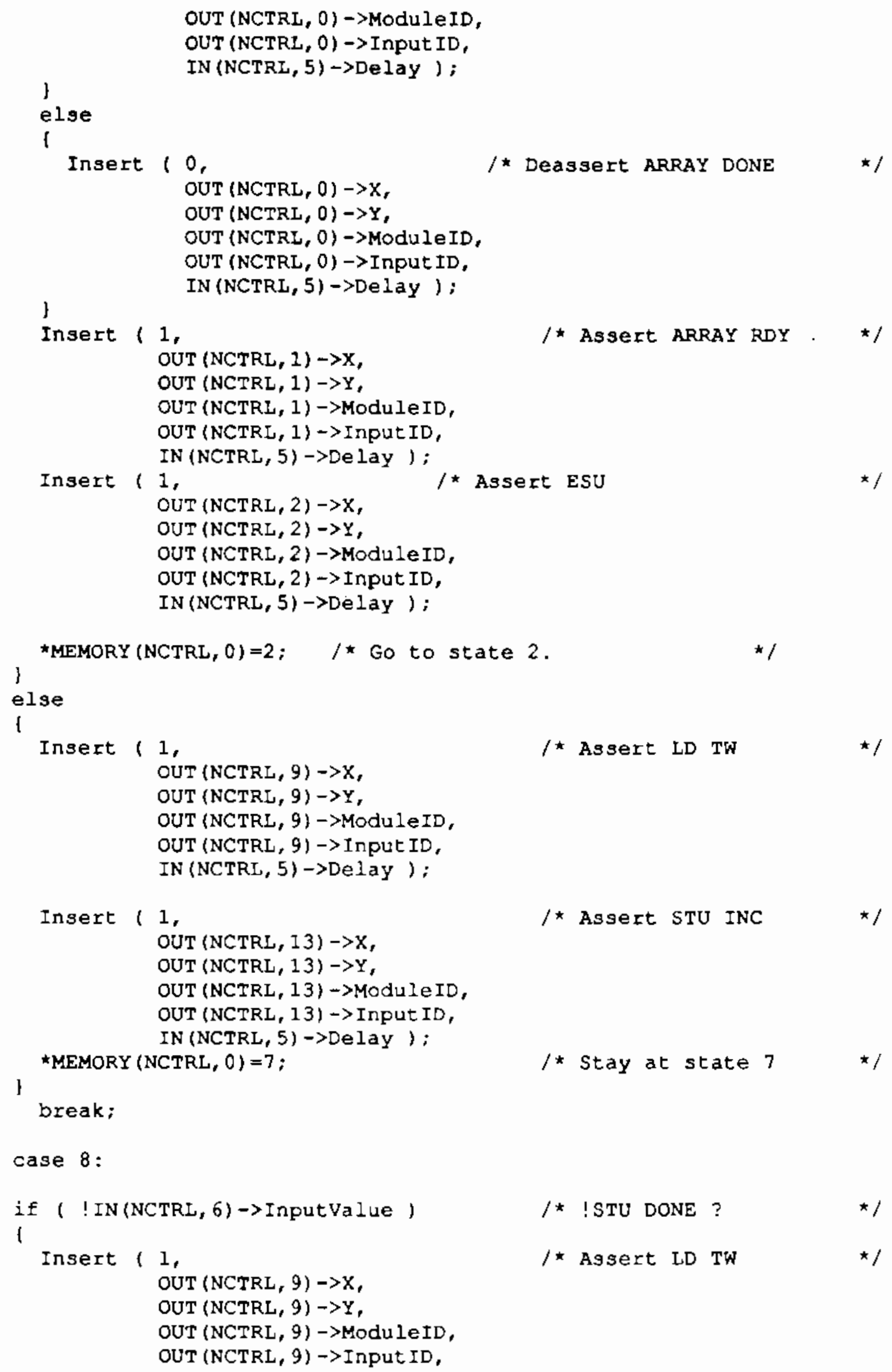


IN (NCTRL, 5) $\rightarrow$ Delay );

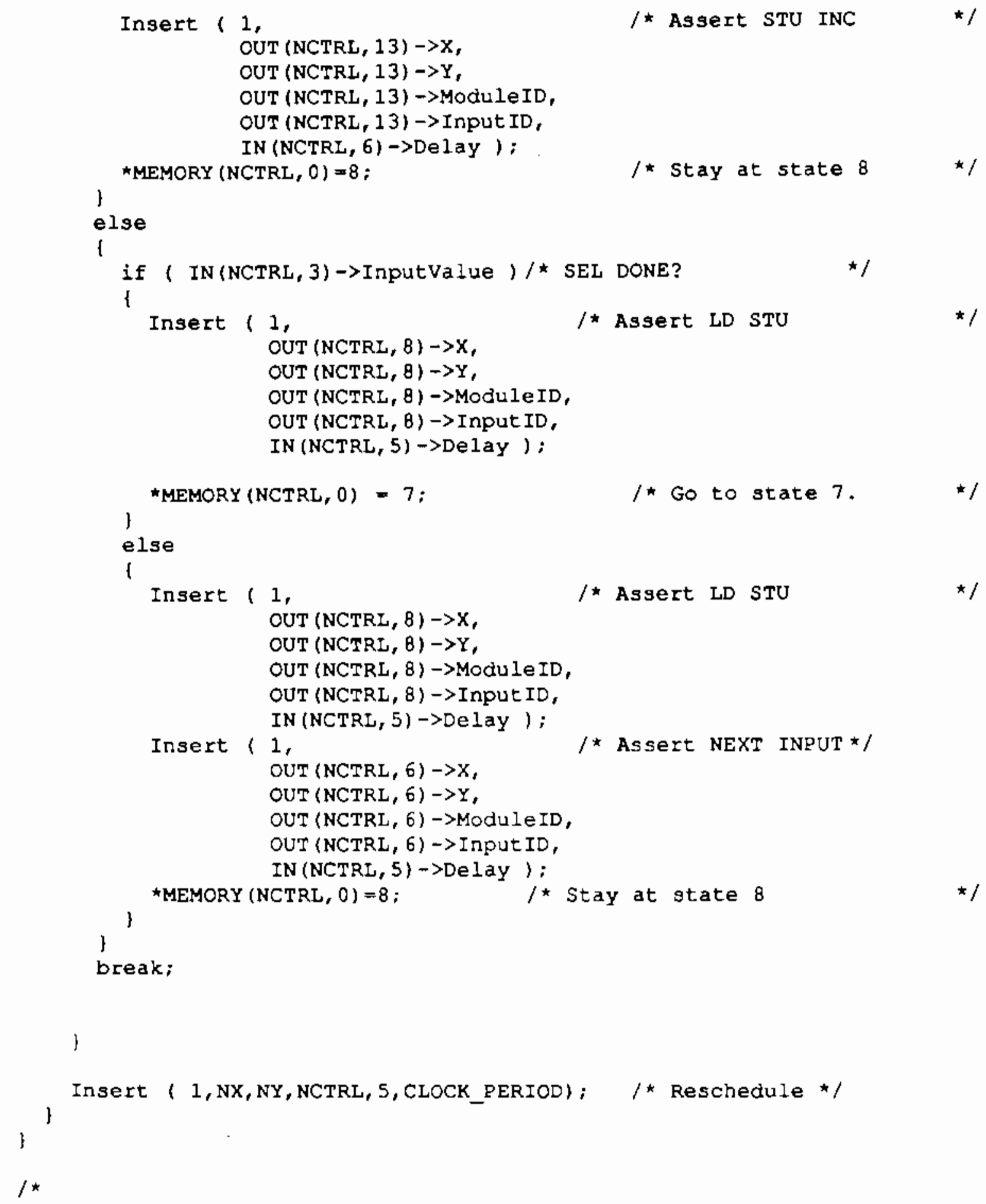




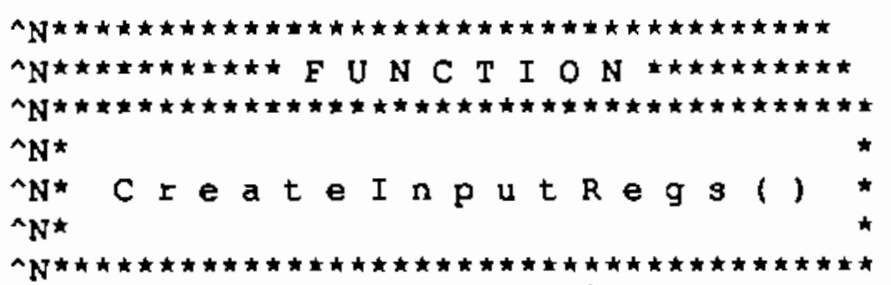

Functional Summary:

This function creates the Input Registerg for a gingle node.

Module ID $=0$.

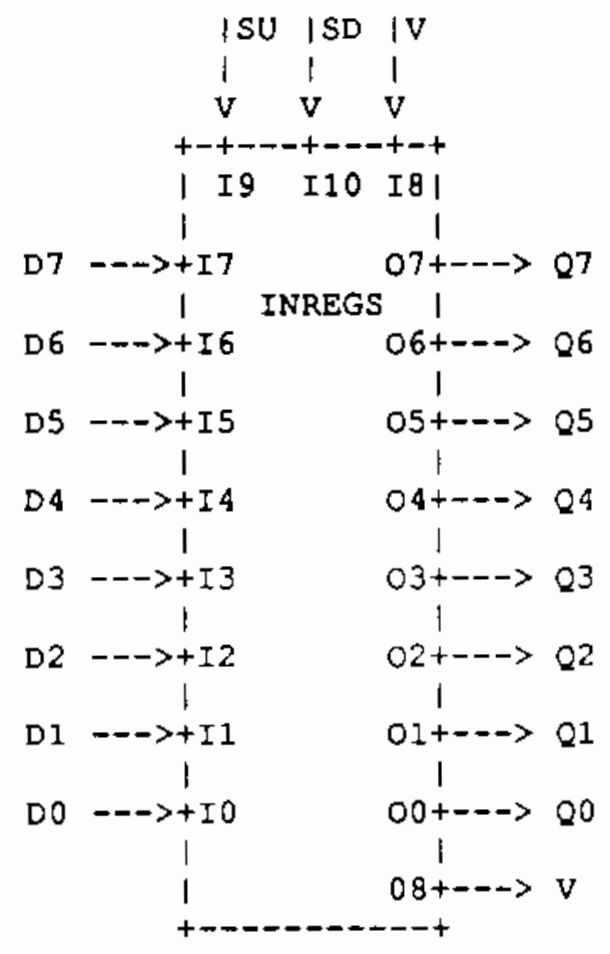

$S U=$ Shift up. $S D=$ Shift down.

$S U$ and SD are signals (pulses).

Each data line is 16 bits organized as follows:

IFL IX IGIIIGIOIGS |G8 IG7 IG6 I

IG5 IG4 IG3 IG2 IG1 |GO ID1 IDO I

Where, 
[G11..G0] = Source Gate Code. The data source code contains the path number (0-7 for lateral paths; 8 for vertical) that the data came in on. This identifies which neighboring node was the source. [G1]..G0] identifies the number of the gate within the node.

I = Data Flag. It is high if the word is valid (new).

$X$ - External Input flag ( = 1 for external input ) if the input is external, [G11..GO] is the column number in the data file from which the data are taken for this input.

$[D \mid D 0]$ = Data. 4-level data value.

Parameters:

NX, NY - Node Coordinates.

Return Value:

void.

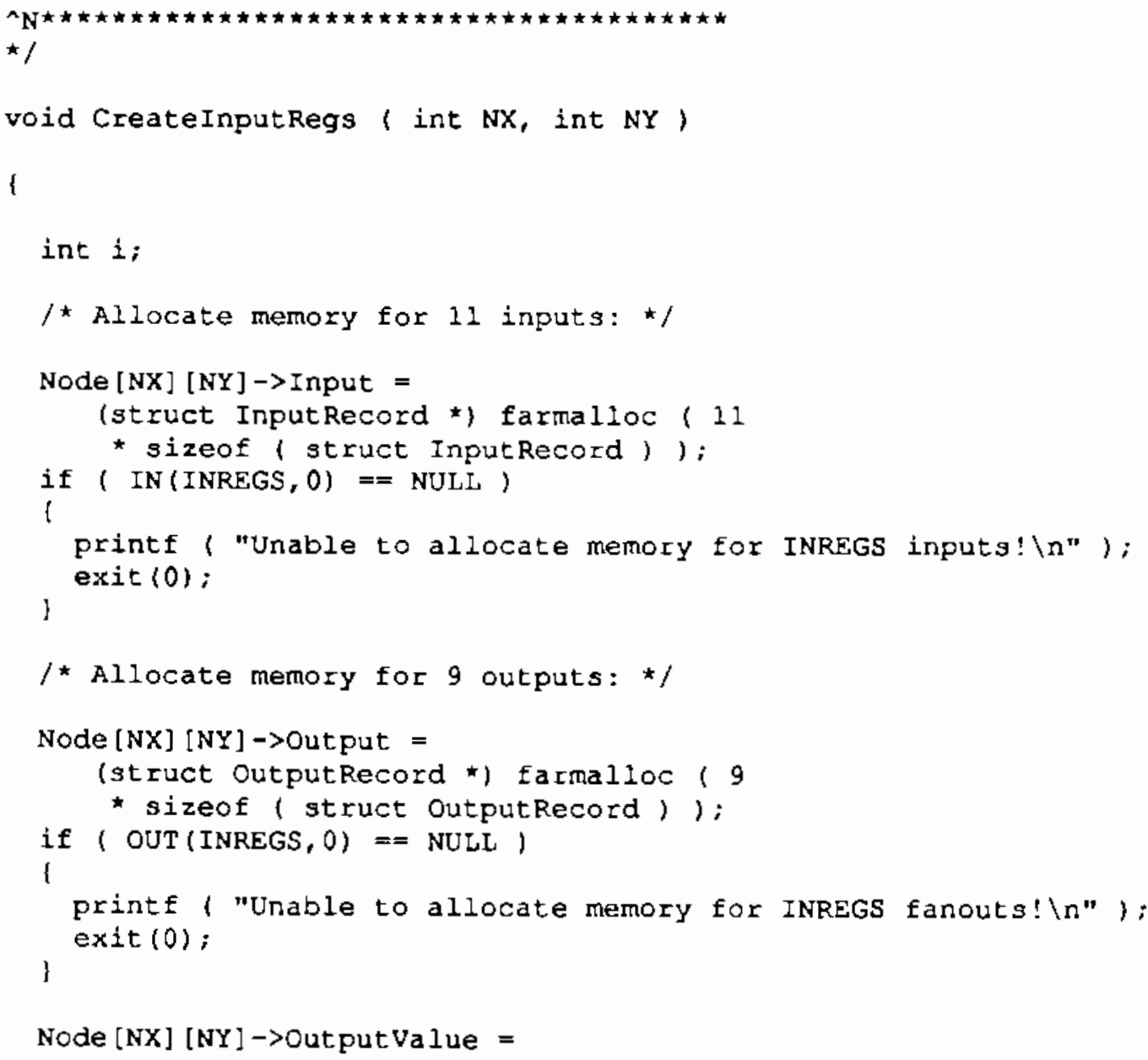




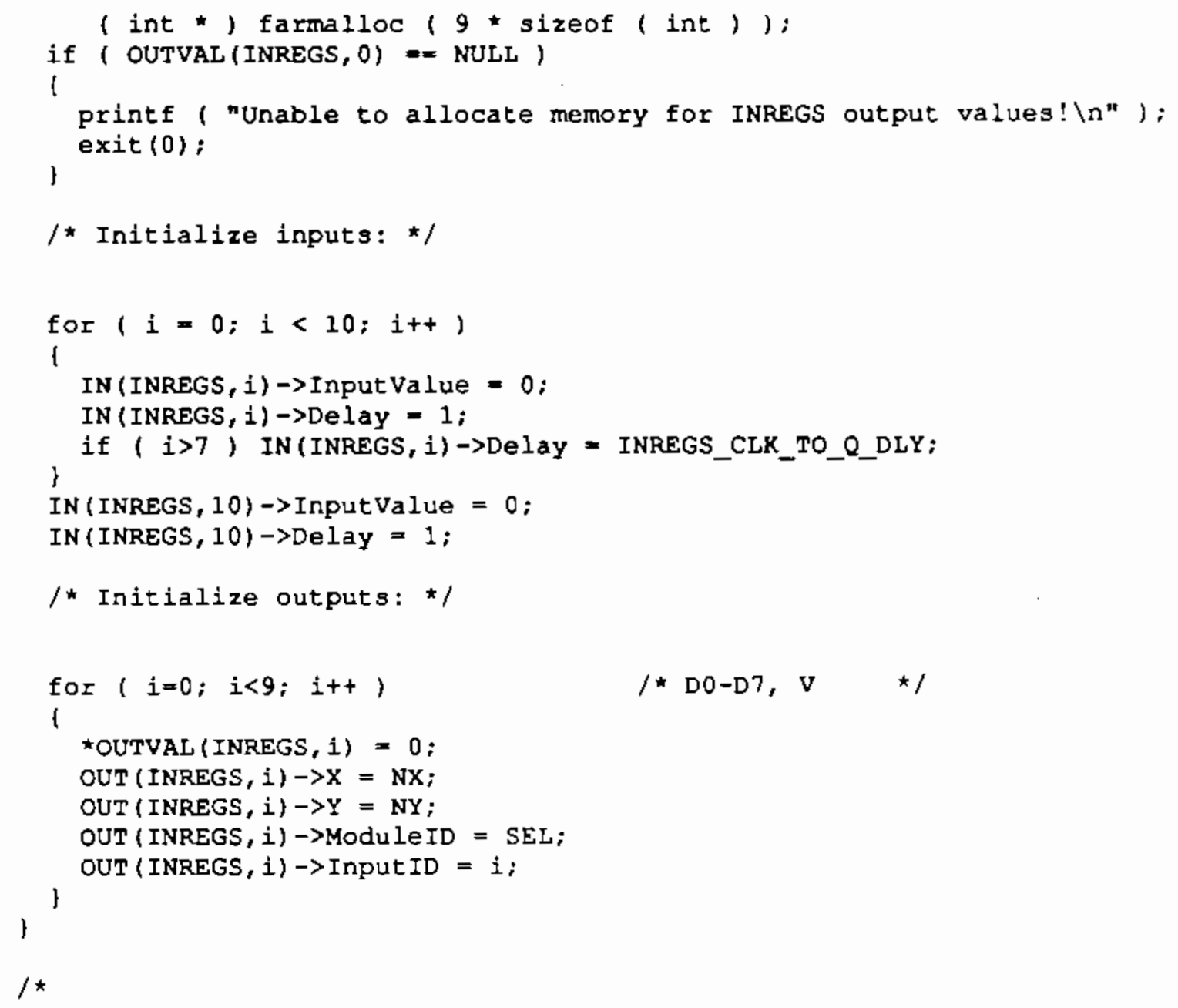




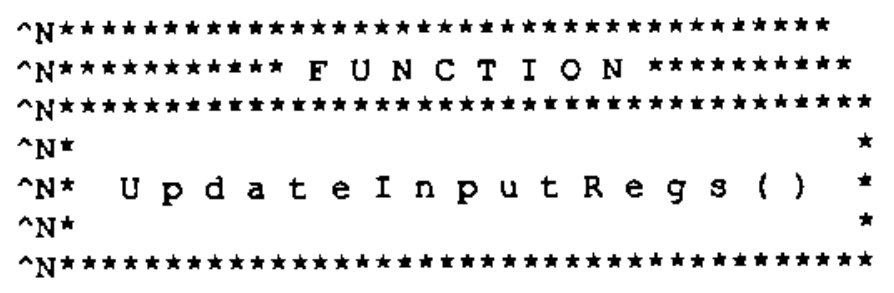

Functional Summary:

This function executes the Input Registers module for the specified node.

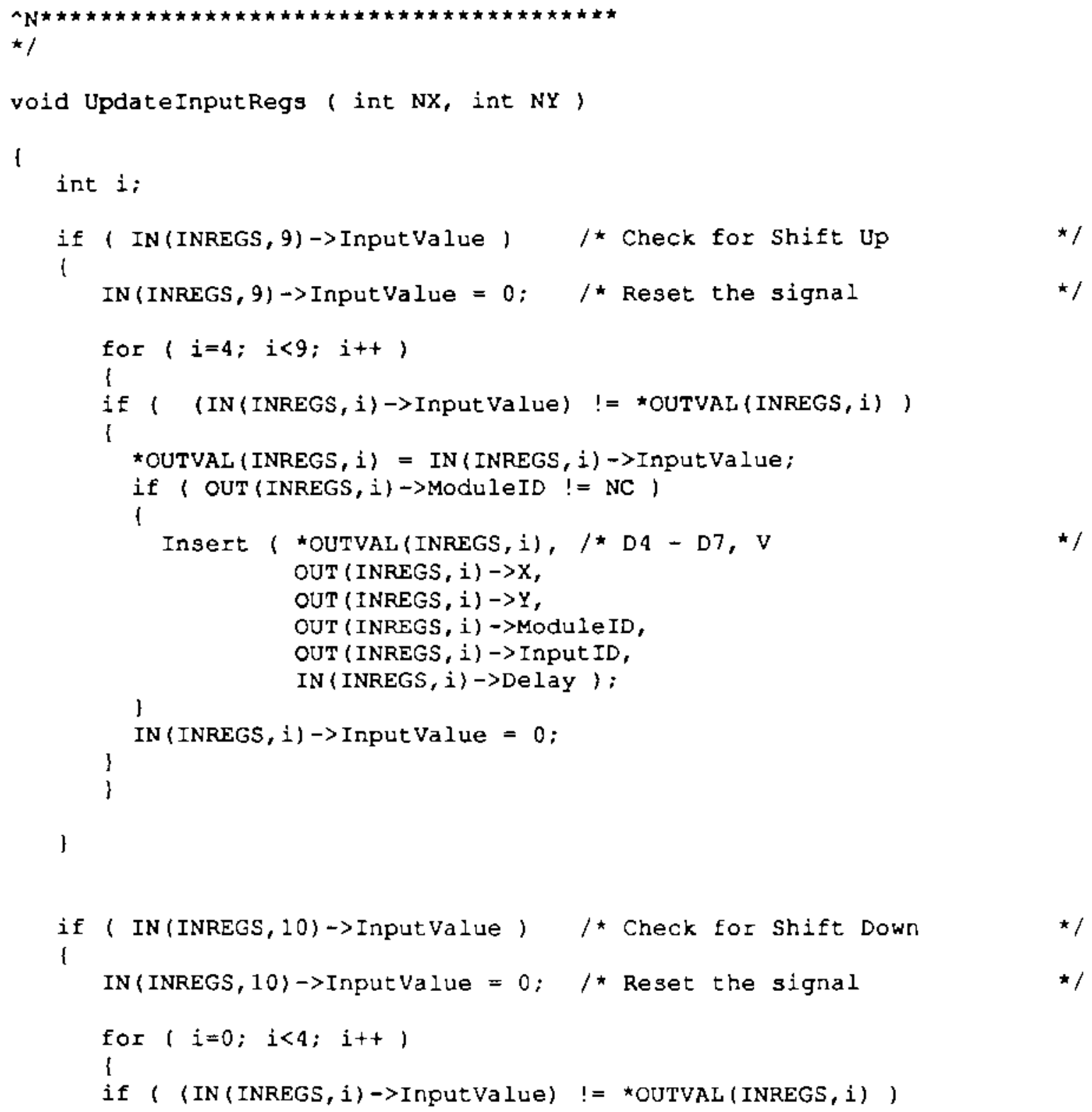




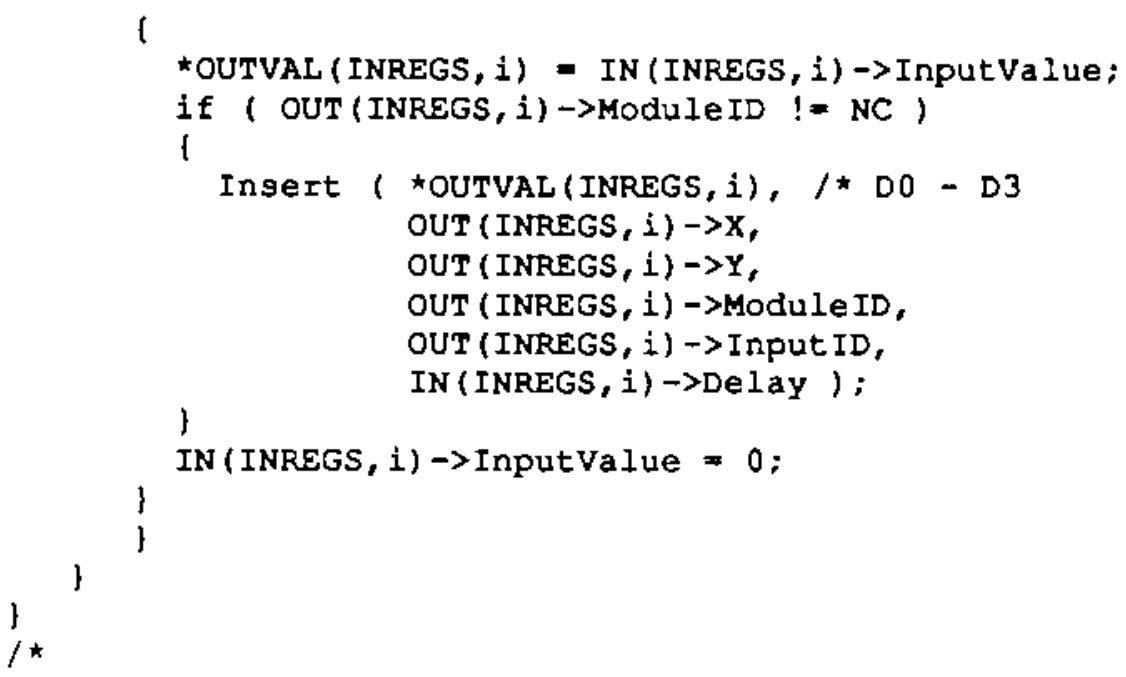




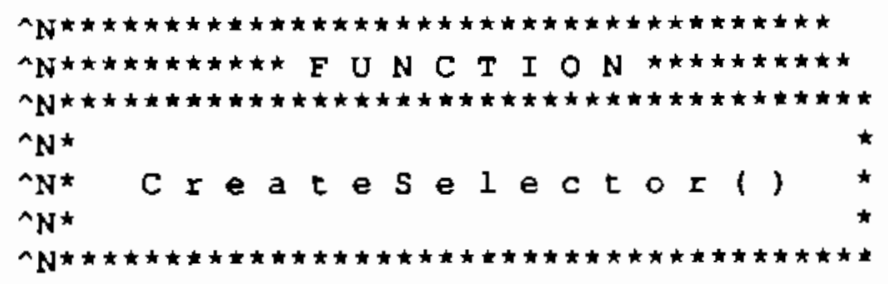

Functional Summary:

This function creates the Input Selector for a single node.

Module ID $=3$.
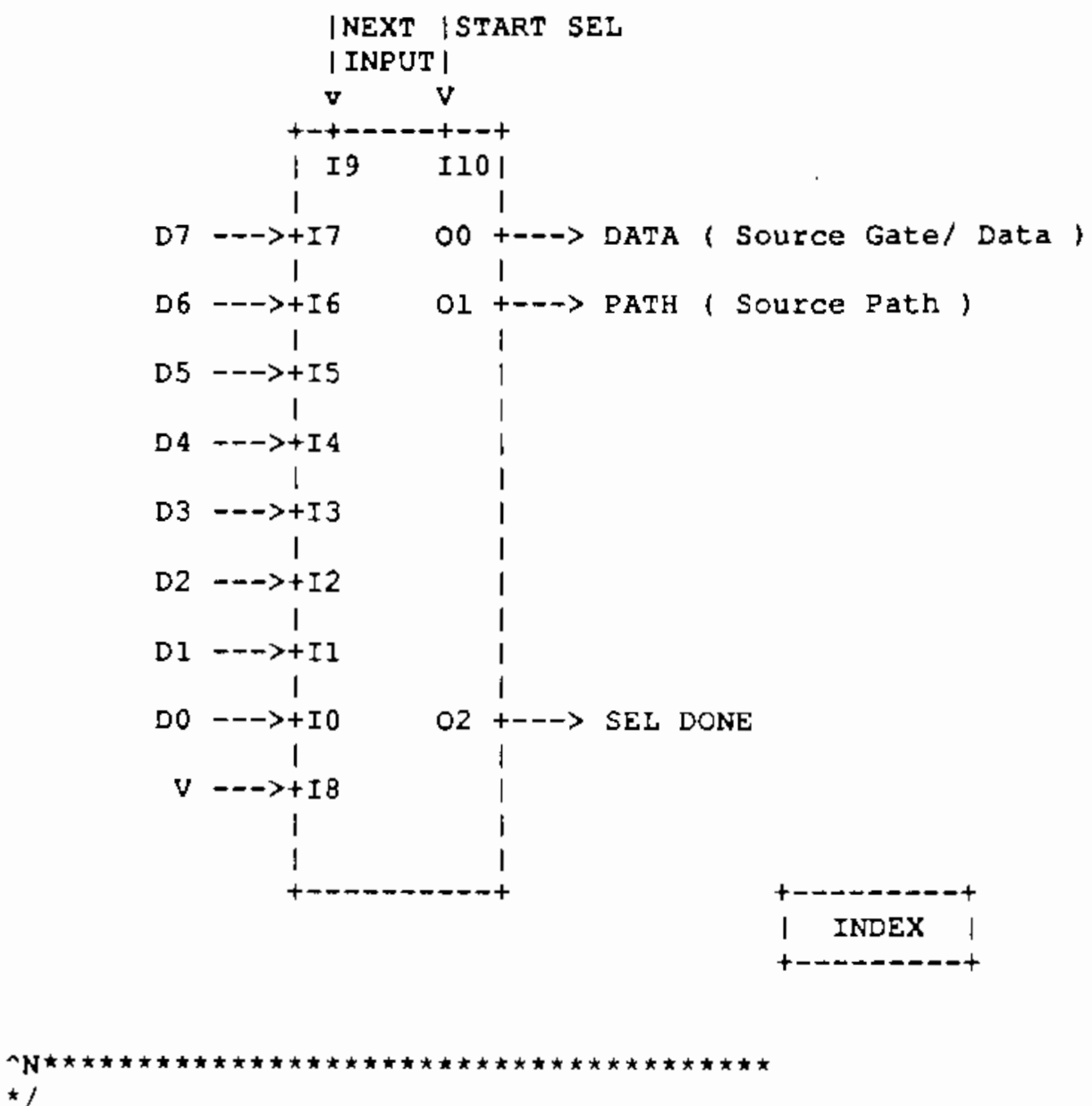

$\star /$

void createselector ( int NX, int NY) 


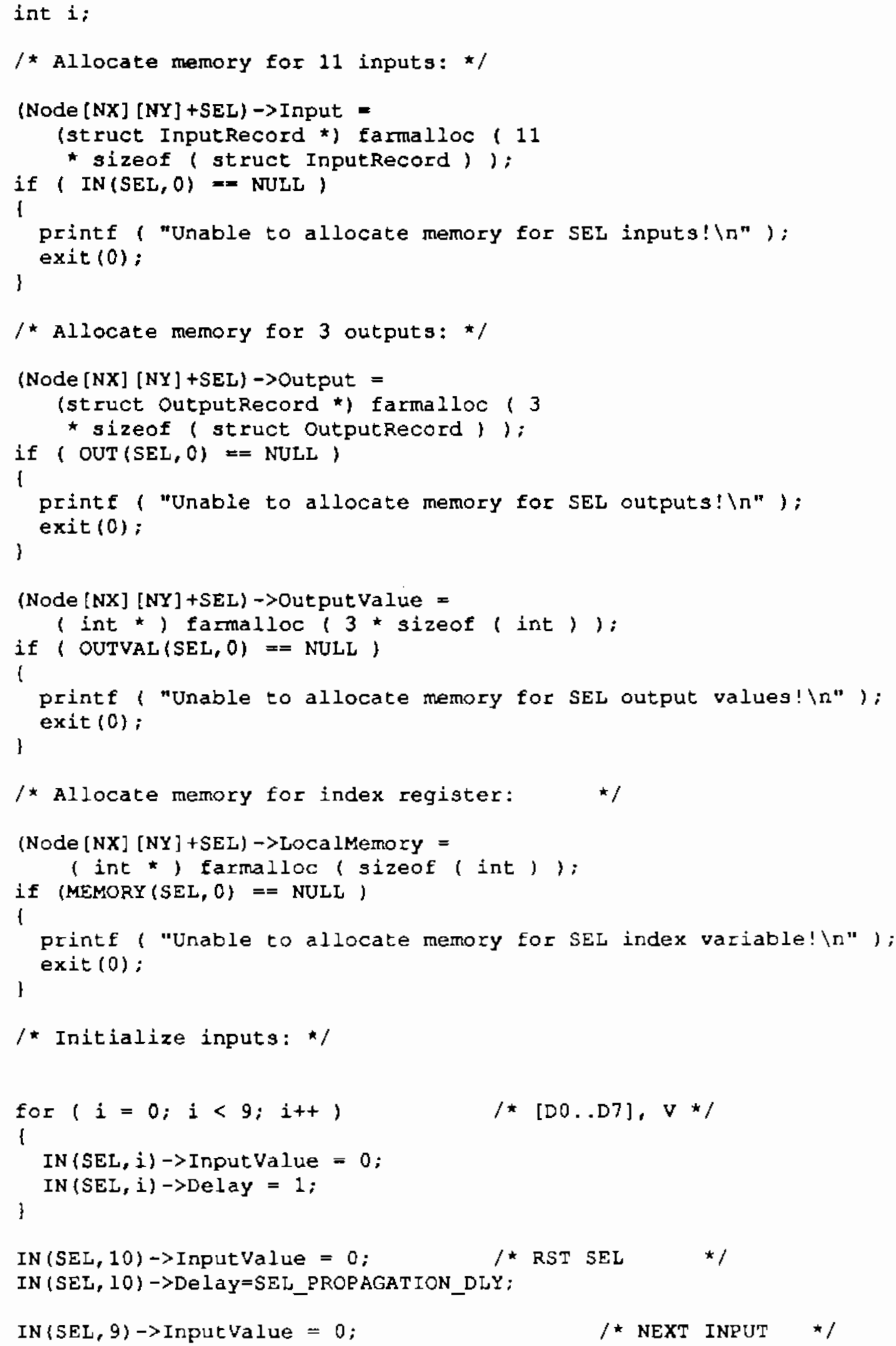




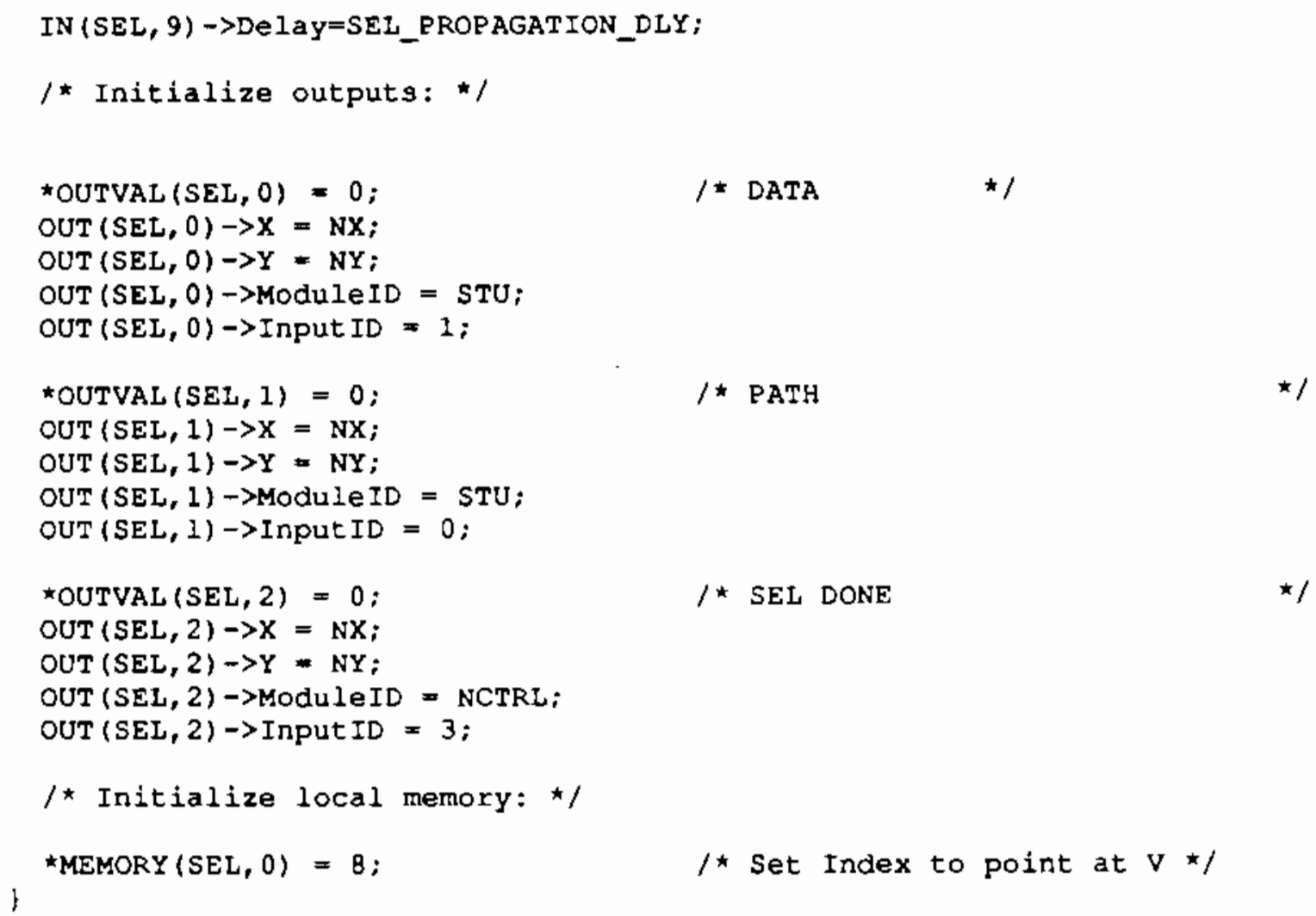




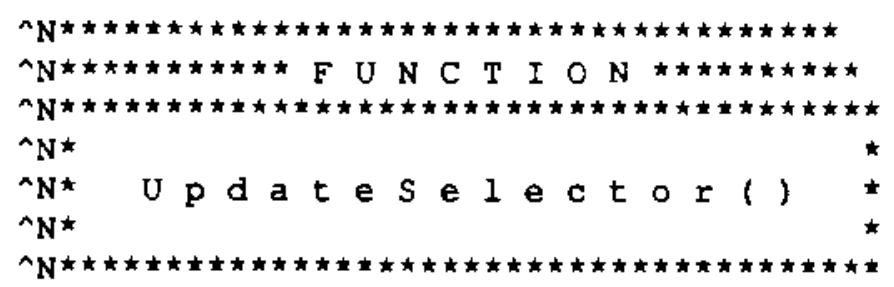

Functional Sumnary:

This function executes the Selector module for the specified node.

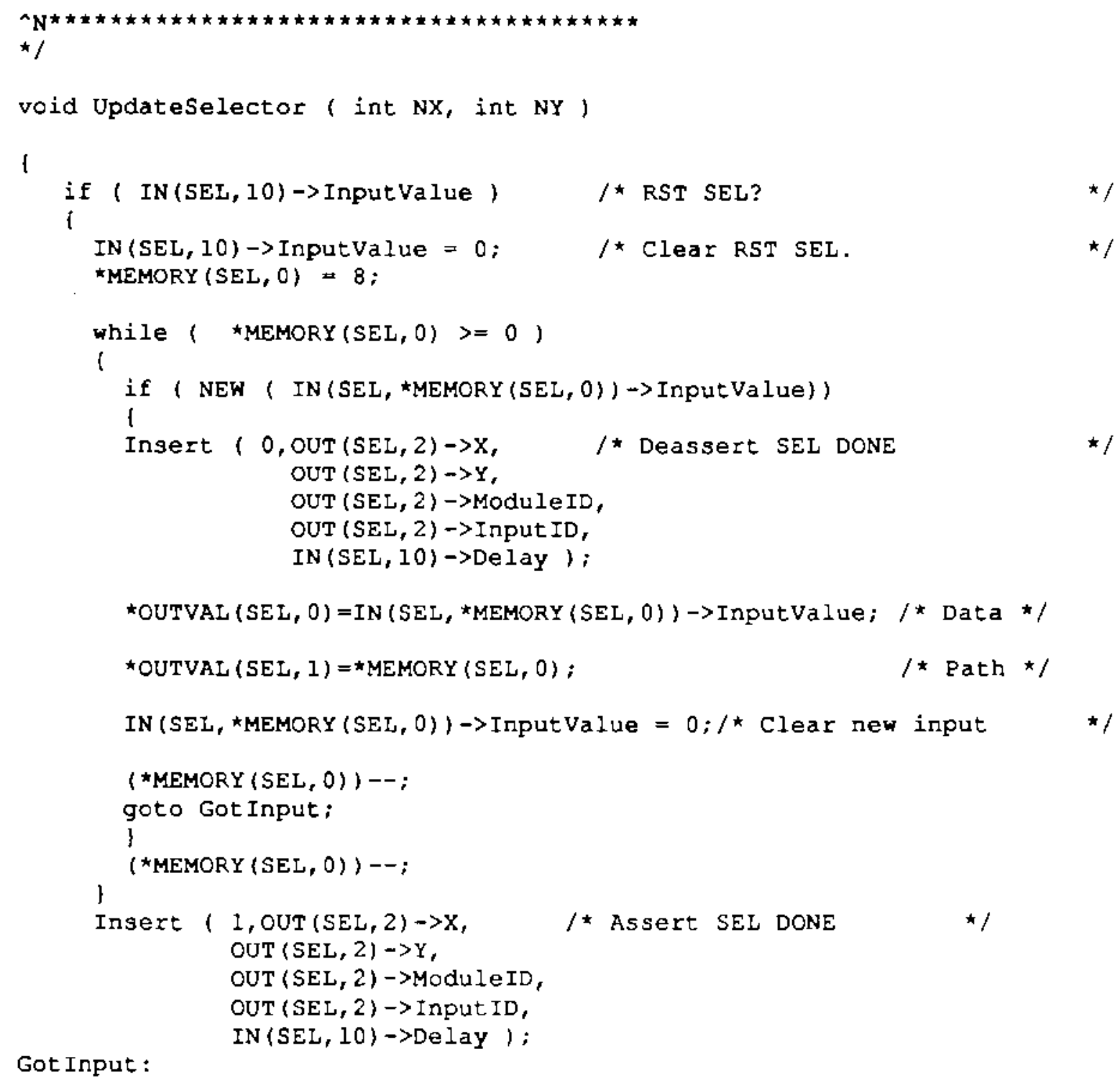

Got Input : 


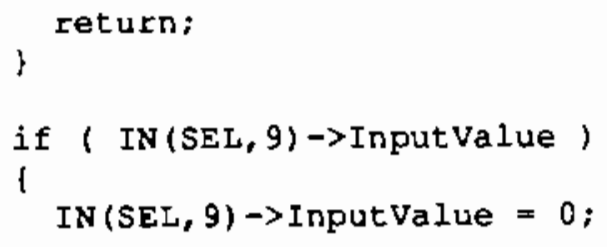

$/ \star$ NEXT INPUT ?

/* Clear NEXT INPUT */

/

/

1




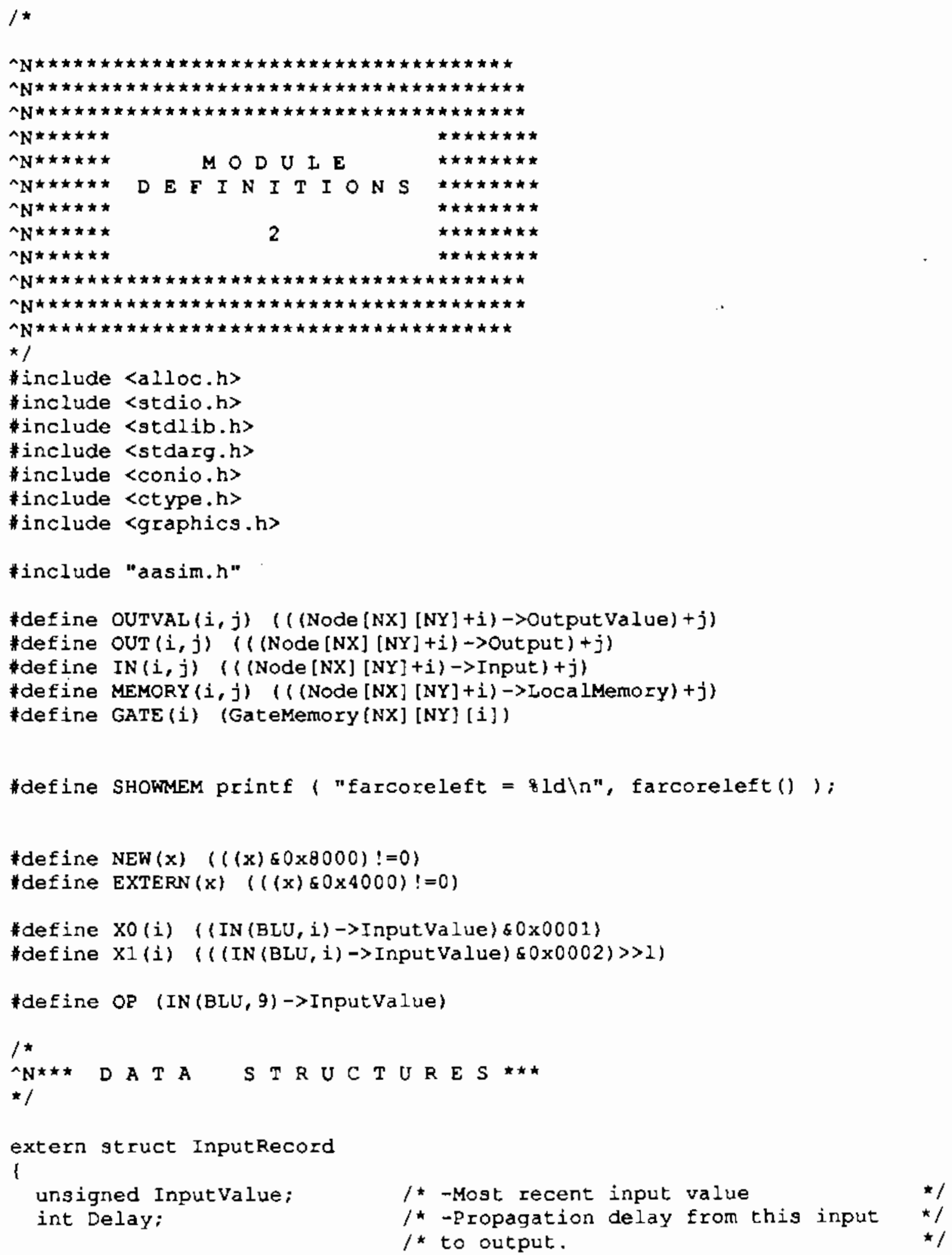




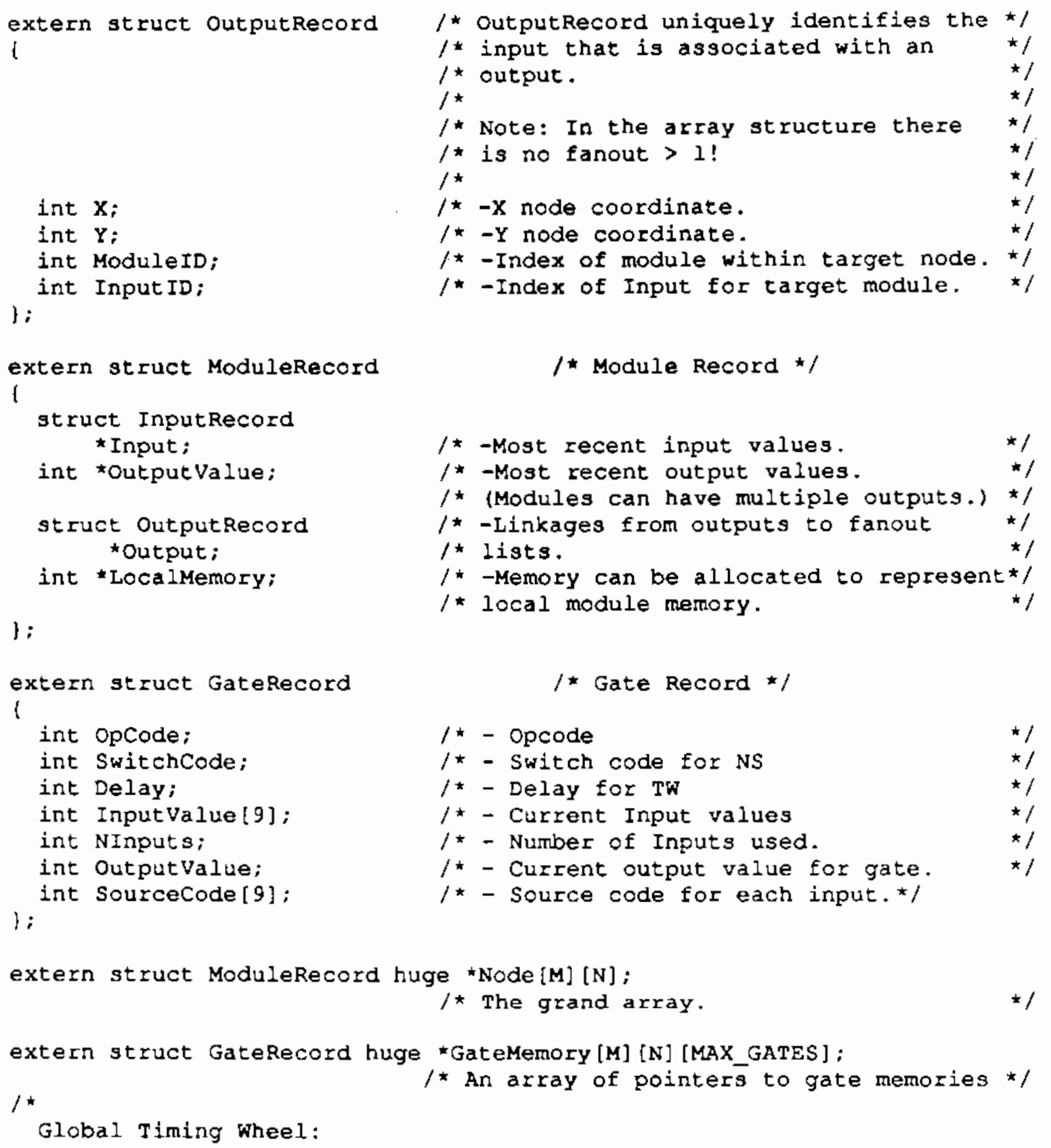

A global timing wheel is implemented for the array. As a new output is generated is is stored in the timing wheel along with the (X,Y, ModuleID, InputID) coordinates for one of the inputs it is intended for.

$\star /$

extern struct EventRecord $/ \star$ Global Timing wheel Record */ 1 


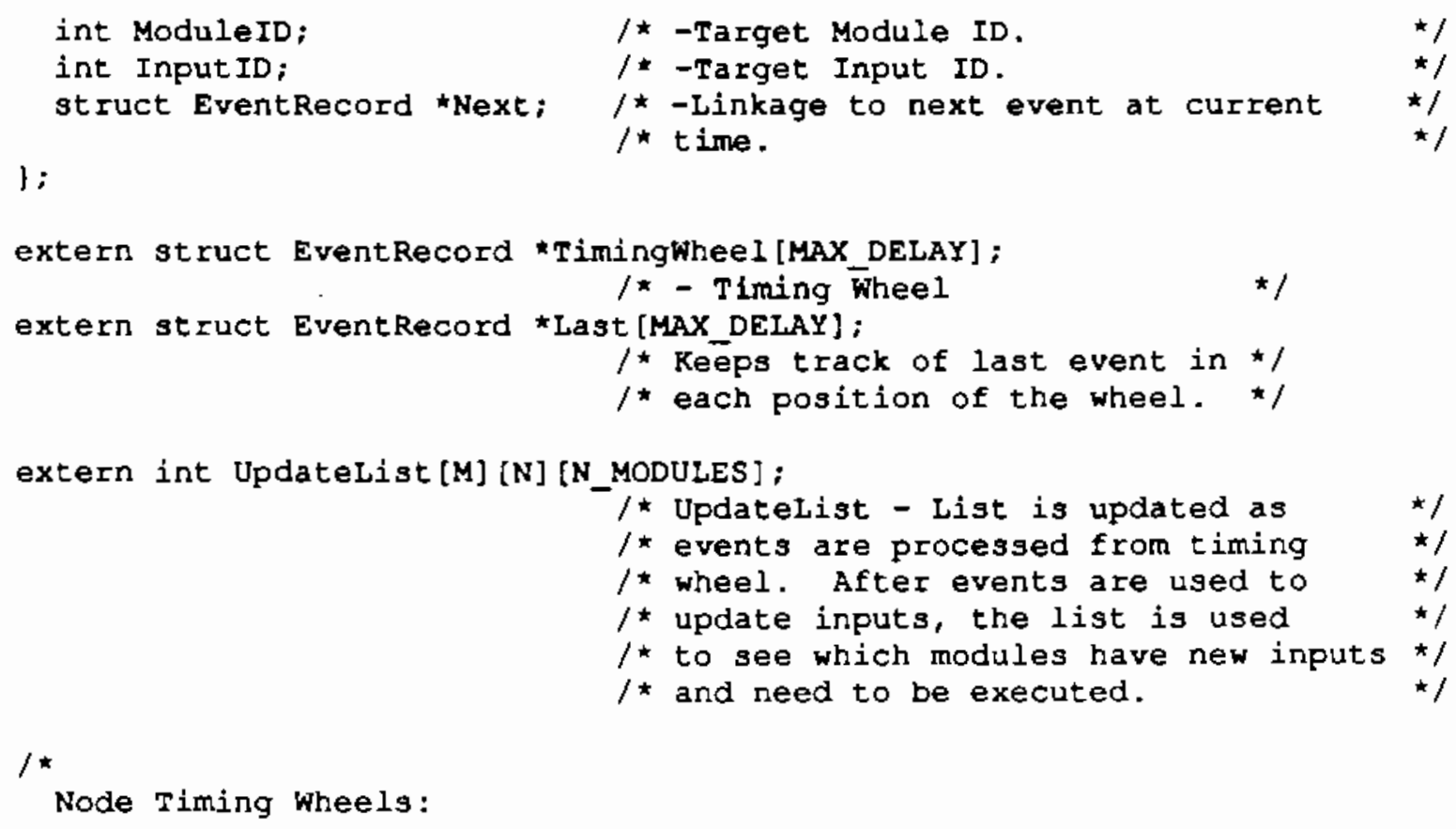

An actual hardware module exists in each node implmenting a timing wheel function for circuit simulations. As an output is generated by the Boolean Logic Unit it is stored together with GATE ID, and SWITCH CODE in the timing wheel.

$\star /$

extern struct GateEventRecord / Local node timing wheel record. */ 1

int Data; $/ *$ - Data value. *1

int SwCode; $\quad /^{*}$ - Switch Code

int Sourcegate; $\quad /^{\star}$ - Source Gate Identification $\quad$ /

struct GateEventRecord *Next; $/ \star$ - Pointer to next gate event. ; ;

extern struct GateEventRecord *TWheel[M] [N] [MAX_GATE DELAY];

$/$ * Local node timing wheel */

extern struct GateEventRecord *TWLast [M] [N] [MAX_GATE_DELAY];

$/ *$ Pointer to lagt event in*/

$/ \star$ each Tw position. /

extern struct GateEventRecord ${ }^{*}$ TwCurrent $[M][N]$;

/* Pointer to current event */

$/ \star$ in present position in each TW. $\quad$ /

extern int TWPOs[M] $[\mathrm{N}]$; $\quad /$ * Current position in each local node */

$/ *$ timing wheel.

extern int huge *Hist: $\quad /$ - Histogram array for hist display. */

extern long $t ; \quad / *$ - Current simulation time. $/$

extern int $t_{-} t w ; \quad / *$ - Current position in global timing */

$/ \star$ wheel. 


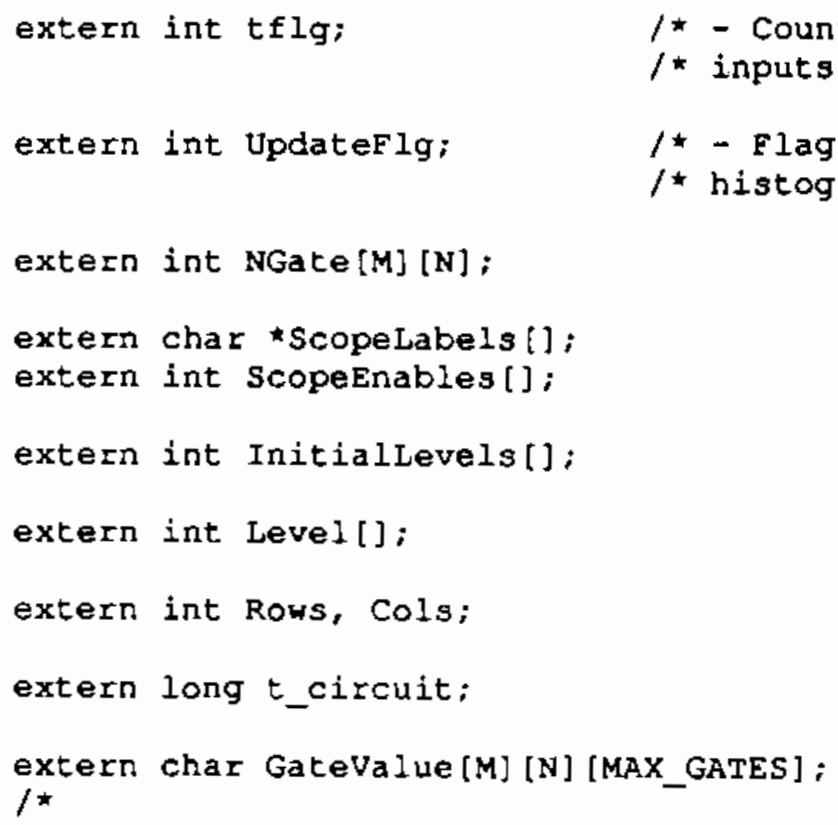

extern int NGate[M] [N] ;

extern char * ScopeLabels [];

extern int ScopeEnables[];

extern int InitialLevels[];

extern int Level[];

extern int Rows, Cols;

extern long t_circuit;

extern char GateValue[M] [N] [MAX_GATES];

$/$ * 


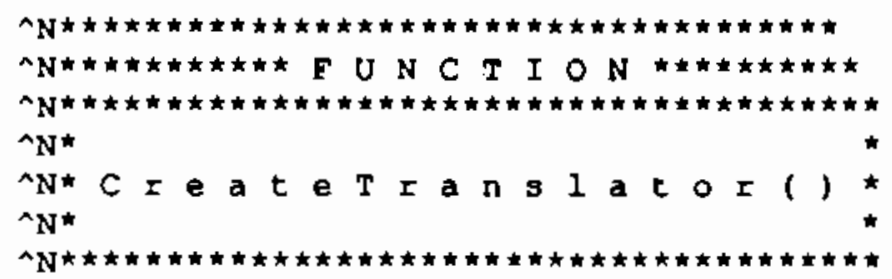

Functional Sumary:

This function creates the Source Translation Unit for a single node.

Module ID $=4$.

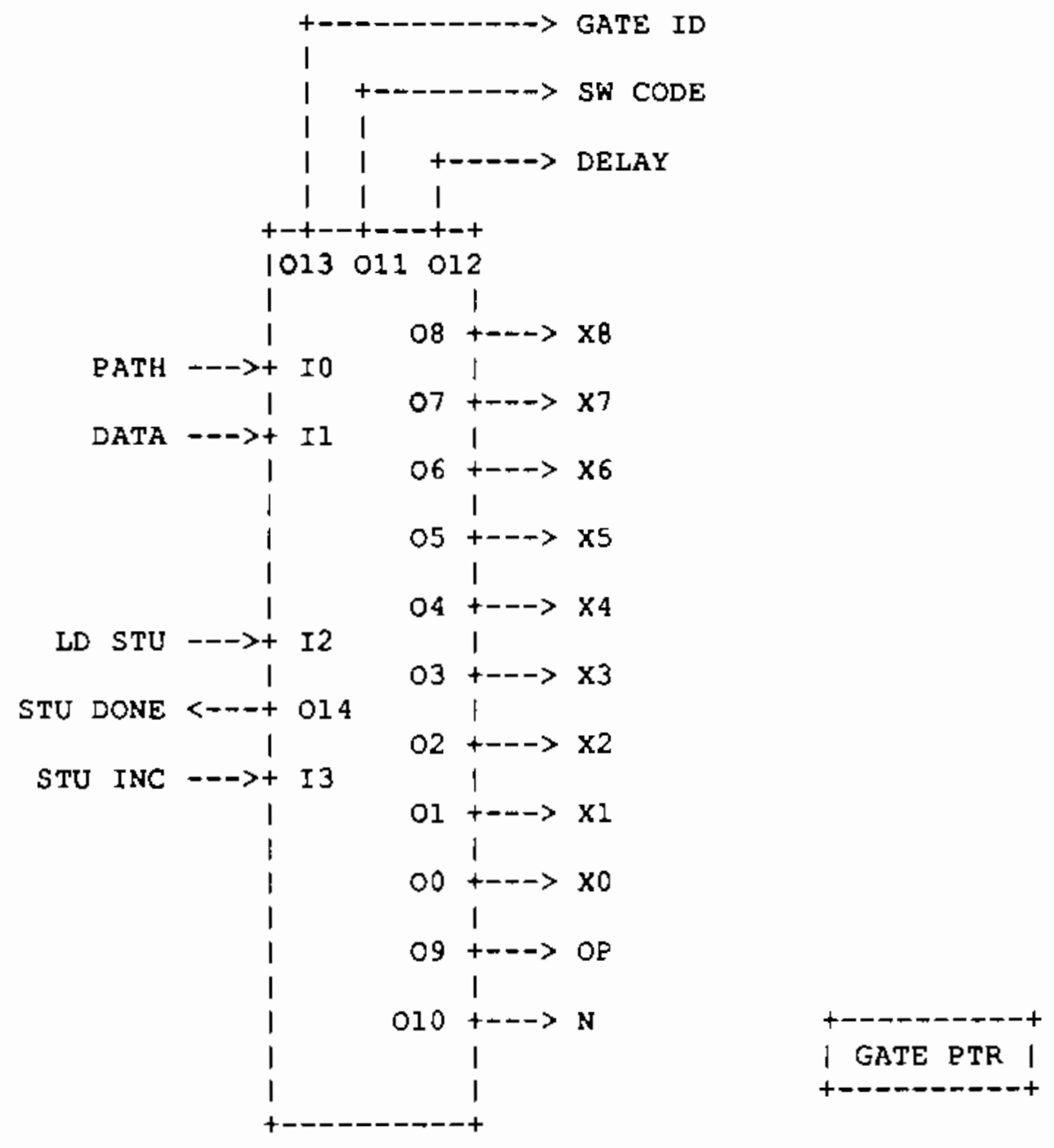


INPUTS

-ーー-ー

PATH - Input path:

[P3|P2 |P 1 |P0]

$0-7$ = lateral connection .

$B$ - vertical connection.

DATA - Input data:

1---|X |G11/G10|G9 IG8 IG7 IG6 I

IGS IG4 |G3 |G2 |GI |GO |DI IDO ।

Where $\mathrm{x}=$ External Input Flag ( 1 mexternal input)

[Gl1-G0] = Source gate ID. (oI data column for external input)

$[D 1, D 0]=4$-level data value.

Note: Source Code $=[F 3-P 0, G 11-G 0\rfloor$

OUTPUTS

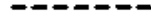

$x 8 . . x 0=4$-level logic values:

[D1 |D2]

OP = OPCODE for Boolean Logic Unit.

SW CODE - Switch code:

[SB|S7|S6|S5|S4|S3|S2|SI|SO]

For each bit set to ' ${ }^{\prime}$ ', the corresponding output is enabled in the Network Switch.

DELAY - Gate Delay:

A value stored with the gate description representing the propagation delay of the gate.

GATE ID - Current gate number to be sent to timing whee1. This will be sent with the data as part of the source code. 
N - Number of inputs used in a multiple input gate.

Parameters :

NX, NY - Node Coordinates.

Return value:

void.

Note: STU DONE and STU INC facilitate vertical fanout.

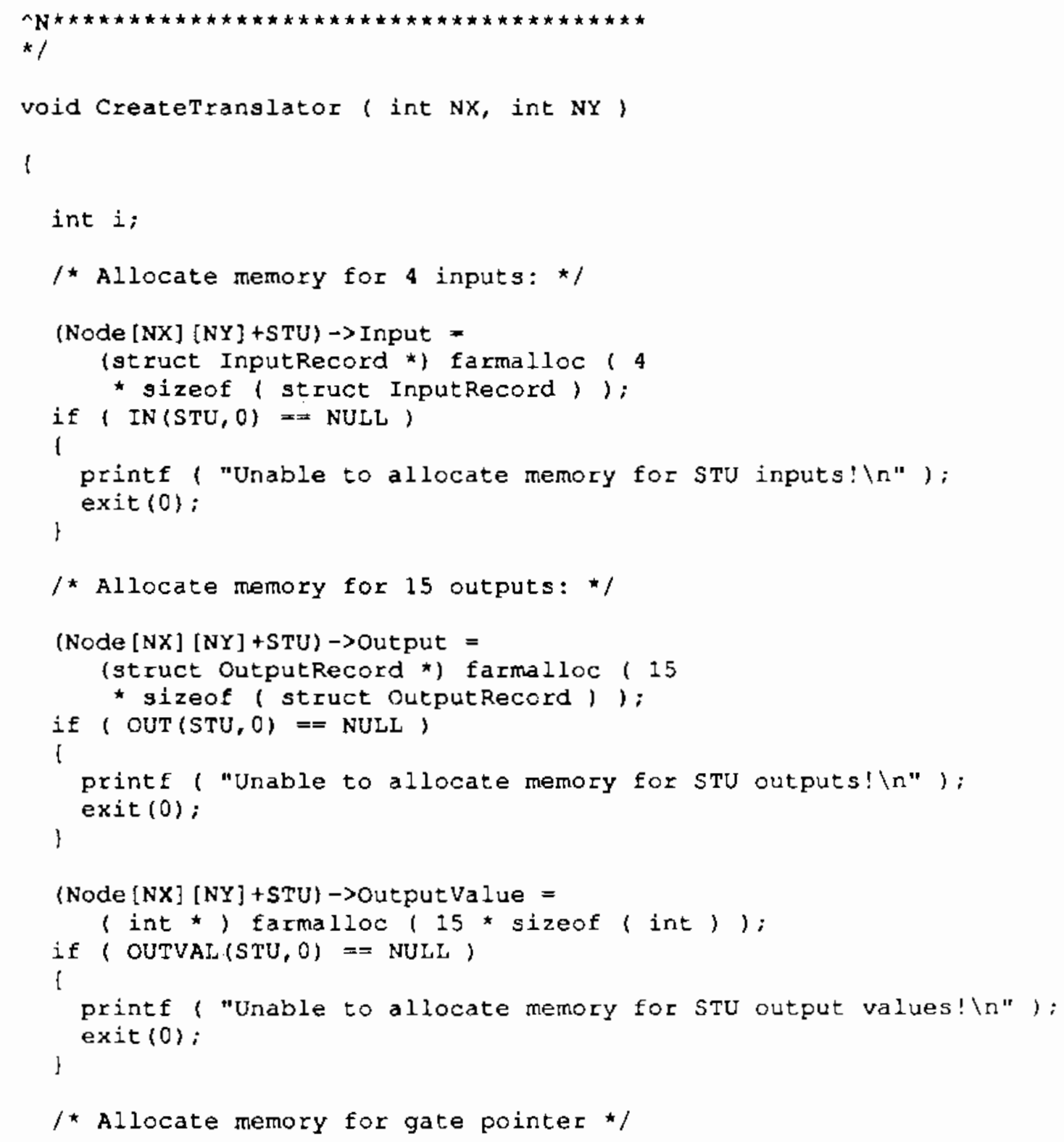




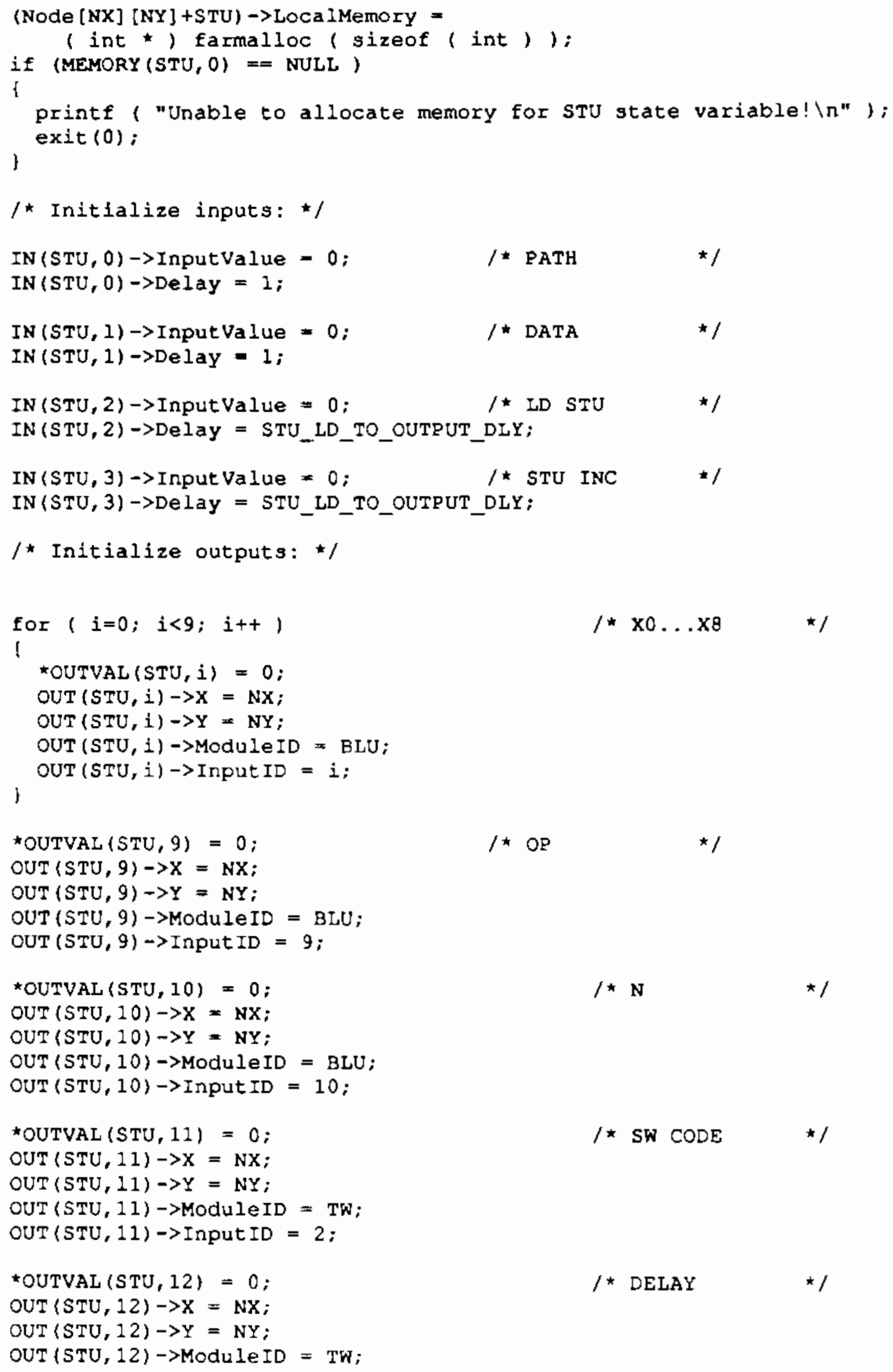




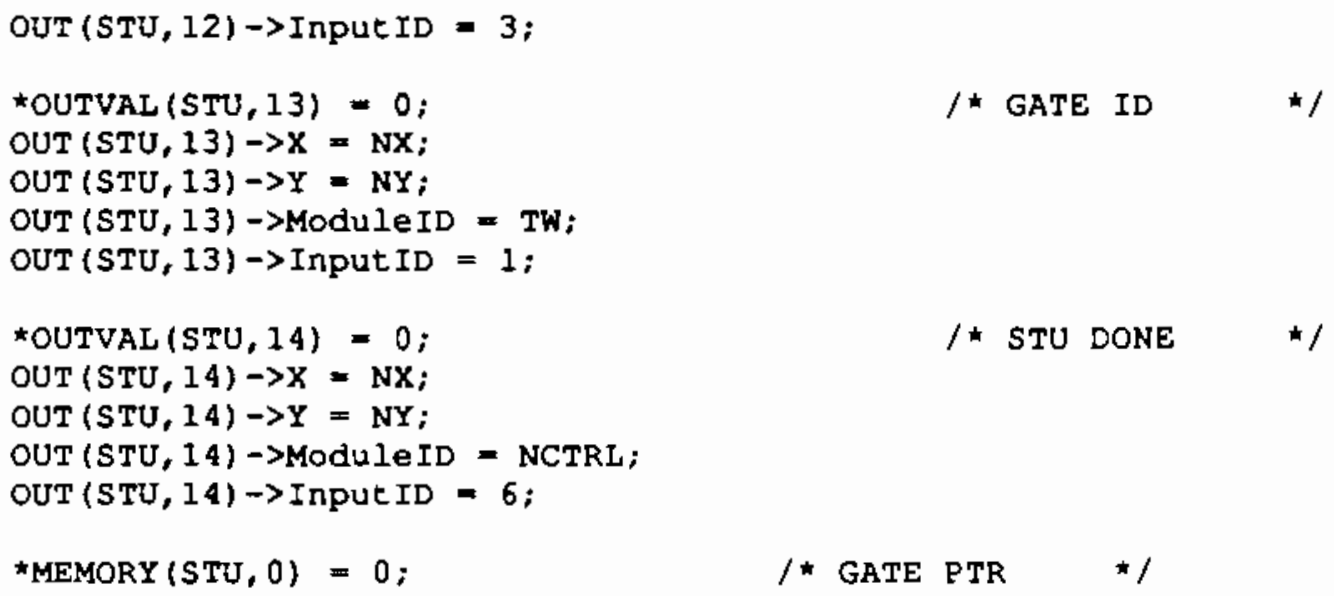

\section{/ *}




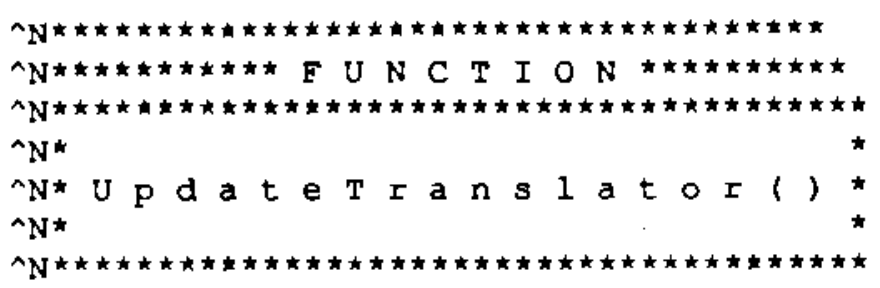

Functional Summary:

This function executes the Translator module for the specified node.

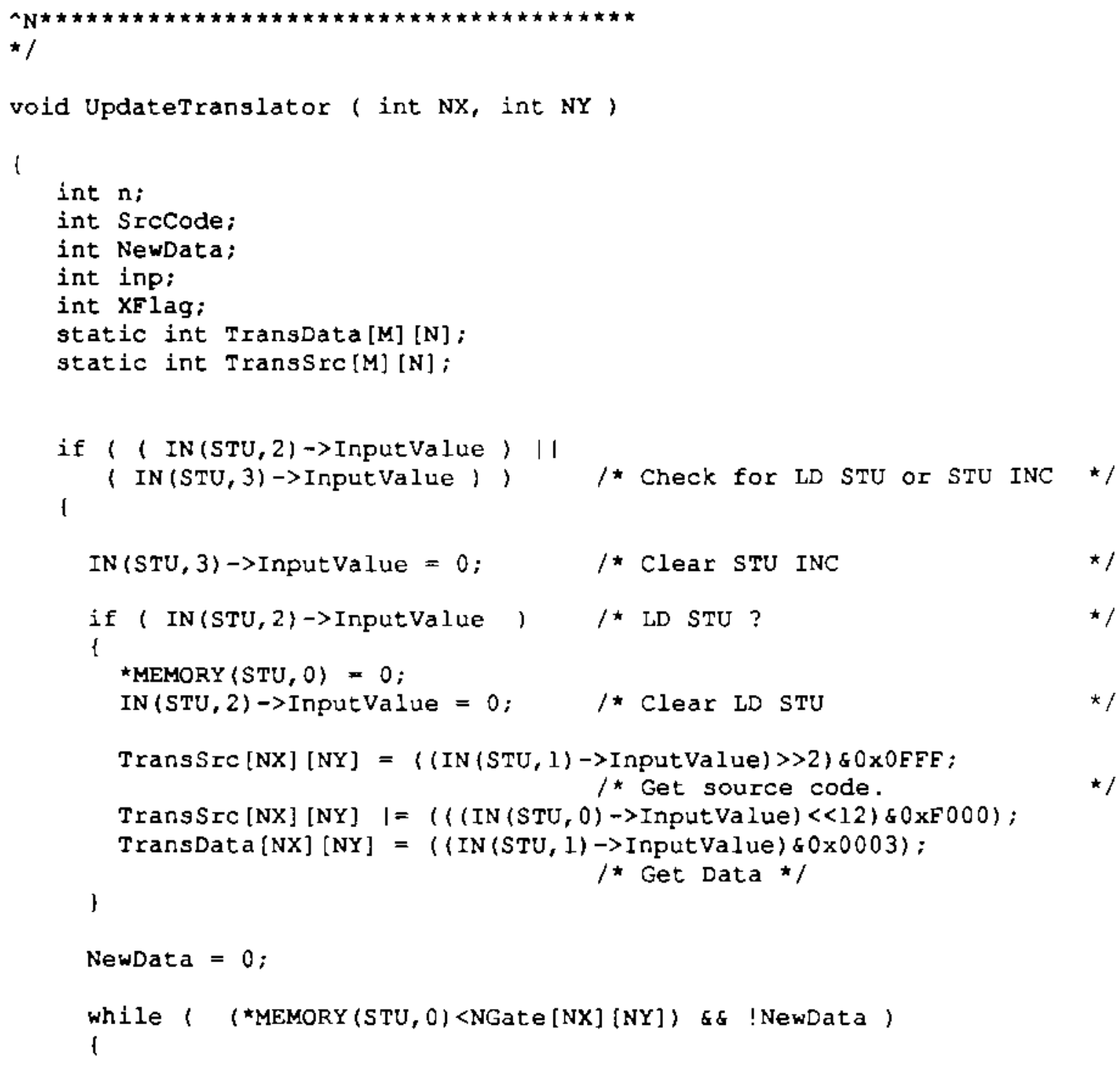


n=GateMemory [NX] [NY] [ MEMORY (STU, O) ] ->NInputs ;

for (inp=0; inp<n; inpt+)

I

if (GateMemory[NX] [NY] [ ${ }^{*} \operatorname{MEMORY}(\mathrm{STU}, 0)$ ] ->SourceCode [inp] $==\operatorname{TransS}[\mathrm{NC}](\mathrm{NY}])$

I

GateMemory [NX] [NY] [ $\operatorname{MEMORY}(\mathrm{STU}, 0)] \rightarrow$ InputValue [inp] = TransData $[\mathrm{NX}][\mathrm{NY}]$;

NewDat $a=1$;

)

\}

if ( NewData)

I

for ( inp=0; inp<n; inpt+)

i

Insert ( GateMemory[NX] [NY] [ MEMORY (STU, 0)]->InputValue [inp], OUT (STU, inp) $\rightarrow X$, OUT (STU, inp) $\rightarrow$ Y, OUT (STU, inp) $\rightarrow$ ModuleID, OUT (STU, inp) $\rightarrow$ Input ID, IN (STU, 2) $\rightarrow$ Delay );

\}

Insert ( GateMemory [NX] [NY] [ MEMORY (STU, 0) ] ->OpCode,

OUT (STU, 9) $\rightarrow$ X,

$1 \star \mathrm{OP}$

*

OUT (STU, 9) $->Y$,

OUT (STU, 9) $\rightarrow$ ModuleID,

OUT (STU, 9) ->Input ID,

IN (STU, 2) $\rightarrow$ Delay) ;

Insert ( GateMemory[NX] [NY] [ MEMORY(STU, 0)]->NInputs,

OUT (STU, 10) $\rightarrow \mathrm{X}$,

$/ * \mathrm{~N}$

*/

OUT (STU, 10) $\rightarrow \mathrm{Y}$,

OUT (STU, 10)->ModuleID,

OUT (STU, 10) $\rightarrow$ Input ID,

IN (STU, 2) $\rightarrow$ Delay);

Insert ( GateMemory[NX] [NY] [ \#MEMORY (STU, 0) ] -> SwitchCode,

OUT (STU, 11) $\rightarrow \mathrm{X}$,

$/ \star$ SW CODE

$\operatorname{OUT}(\mathrm{STU}, 11) \rightarrow \mathrm{Y}$,

OUT (STU, 11) $\rightarrow$ ModuleID,

OUT (STU, 11) ->Input ID,

IN (STU, 2) $\rightarrow$ Delay );

Insert ( *MEMORY (STU, 0),

$/$ * GATE ID */

OUT (STU, 13) $\rightarrow$ X, 


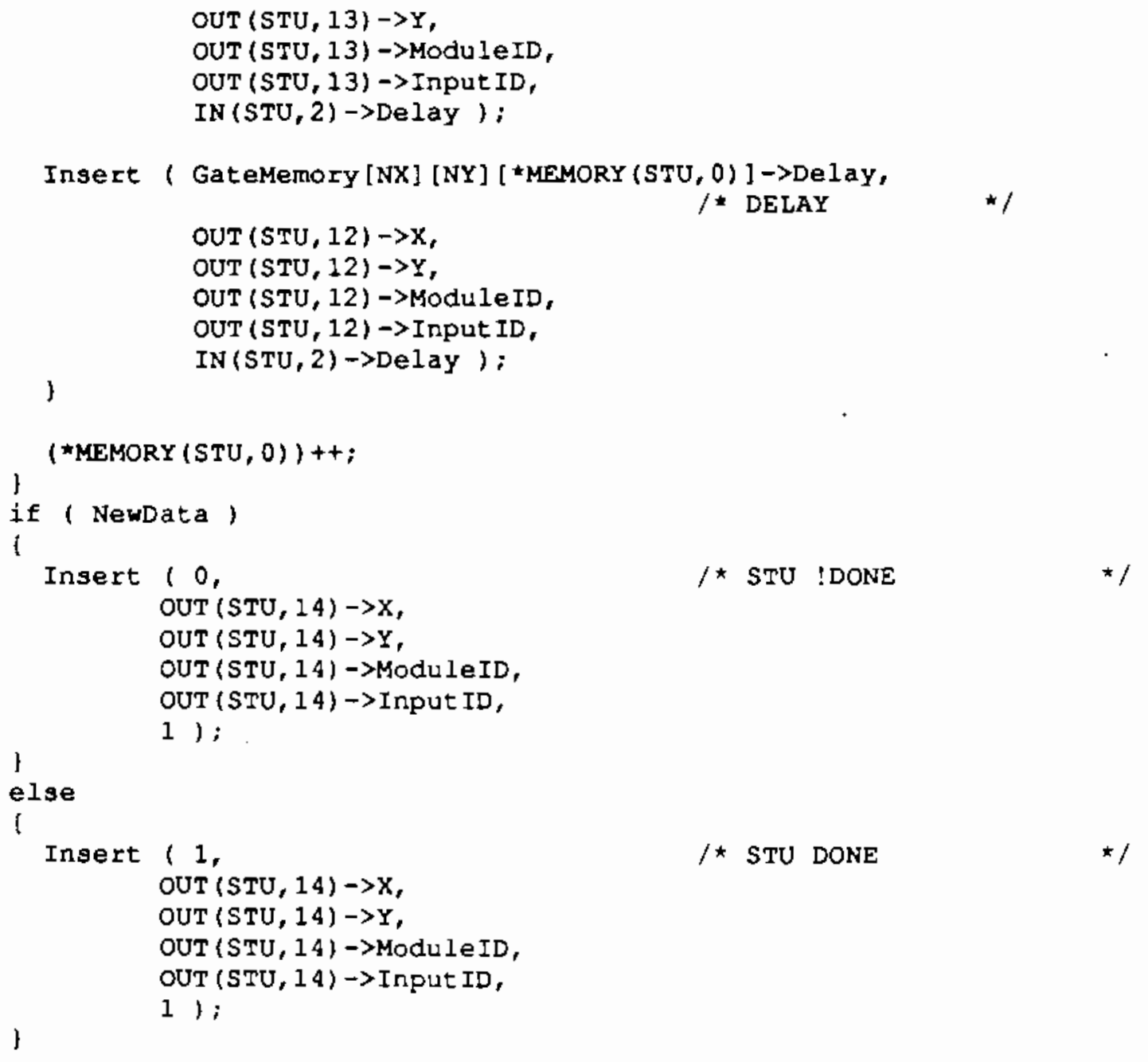




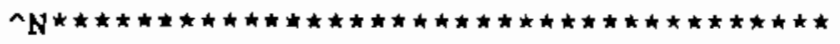

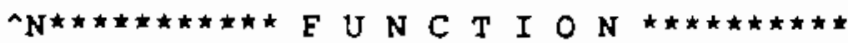

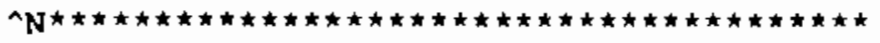

$\wedge \mathbf{N} \star$

^N* C r e a t e L

^N\#

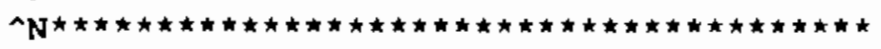

Eunctional Sumary:

This function creates the Boolean Logic unit for a single node.

Module ID $=5$.

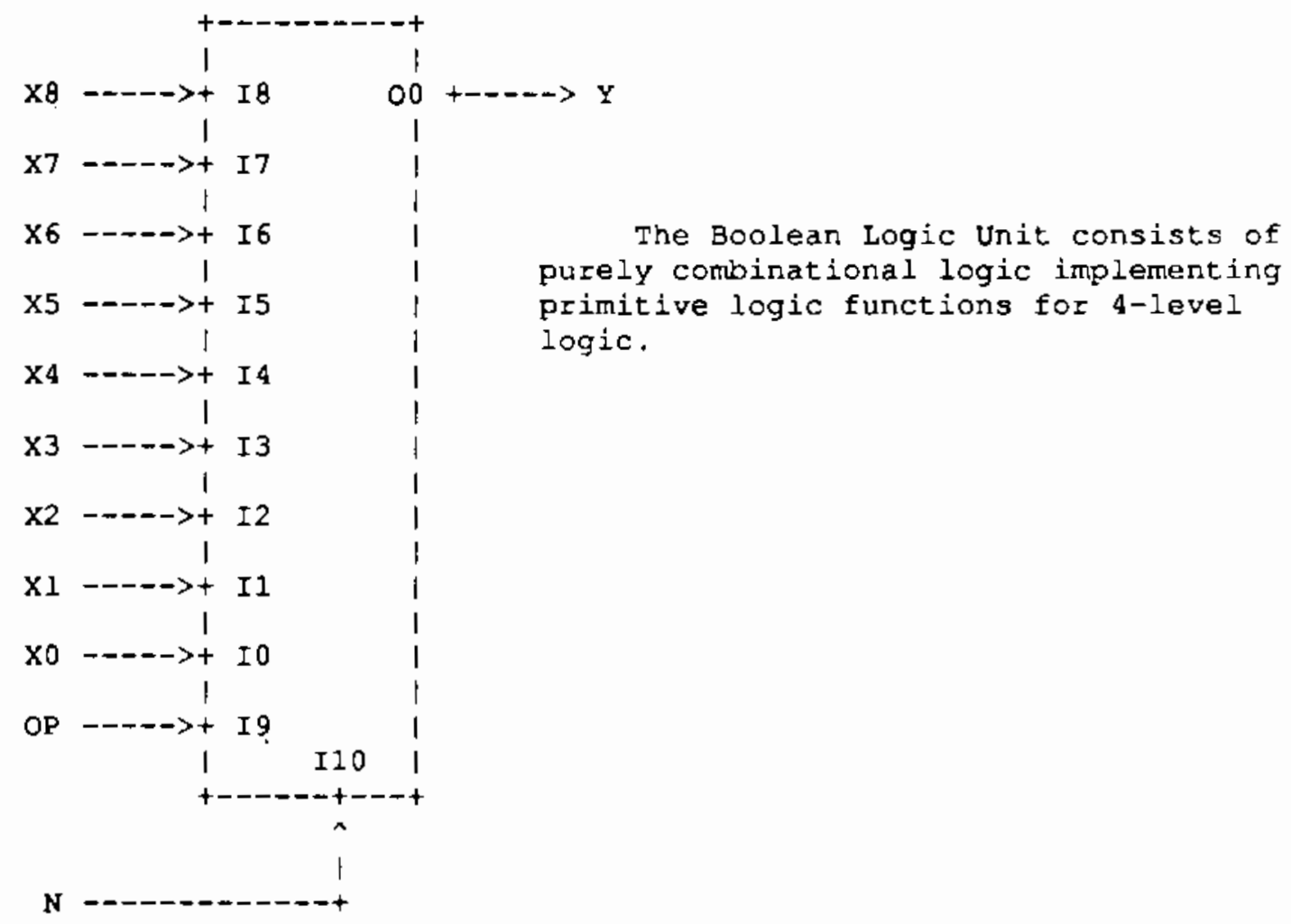

INPUTS

$X_{n}=[D I \mid D 0]-4-l e v e l$ logic expressions.

OP $=$ OpCode 
$\mathbf{N}=$ Number of inputs used in a multiple input gate. E.g., for a multiple input NAND gate, the 0 to the $\mathrm{N}-1$ inputs would be used.

OUTPUT

$Y=[D \mid[D O]$ - Result of boolean expression.

Parameters:

NX, NY - Node Coordinates.

Return Value:

void.

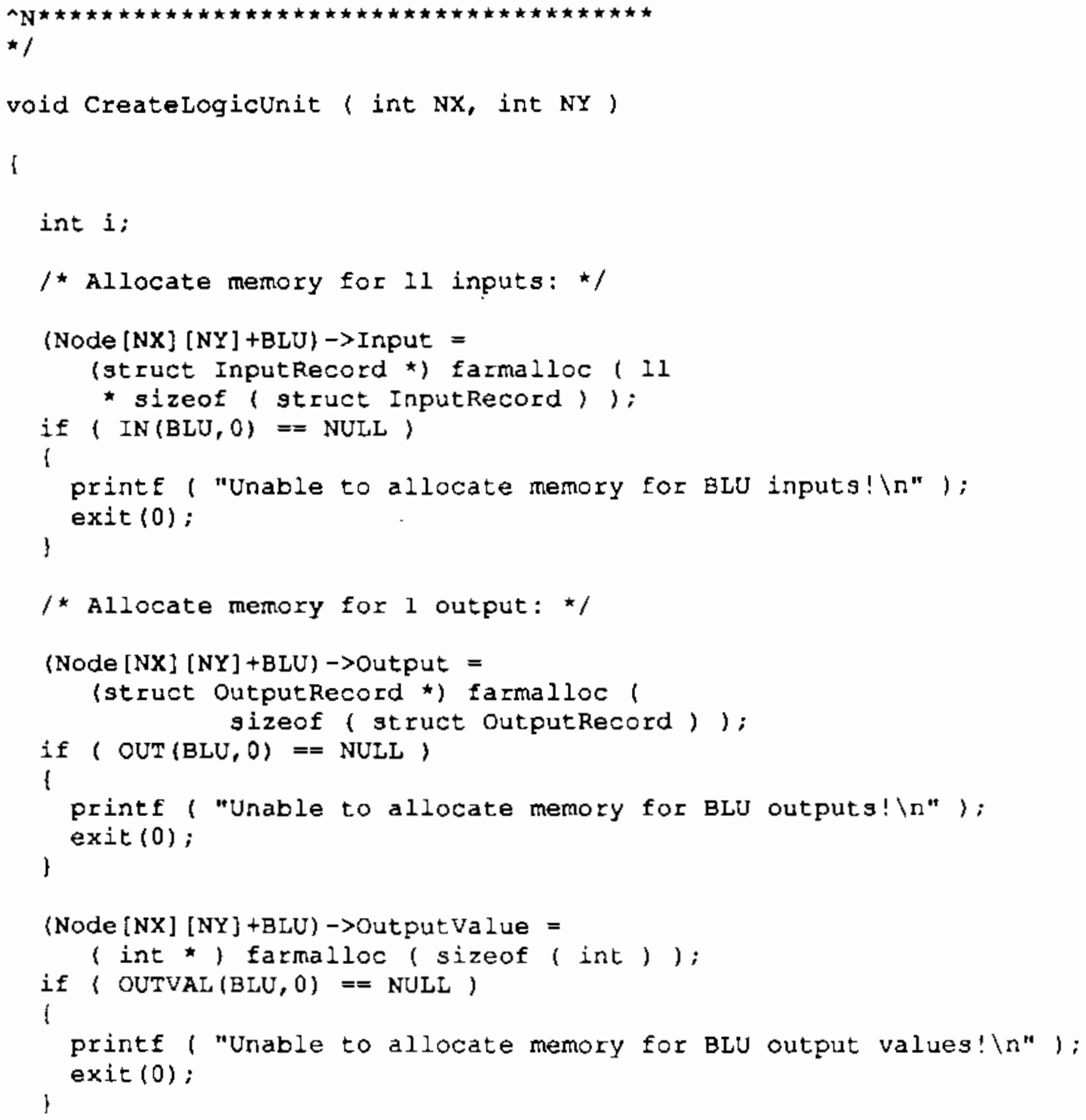




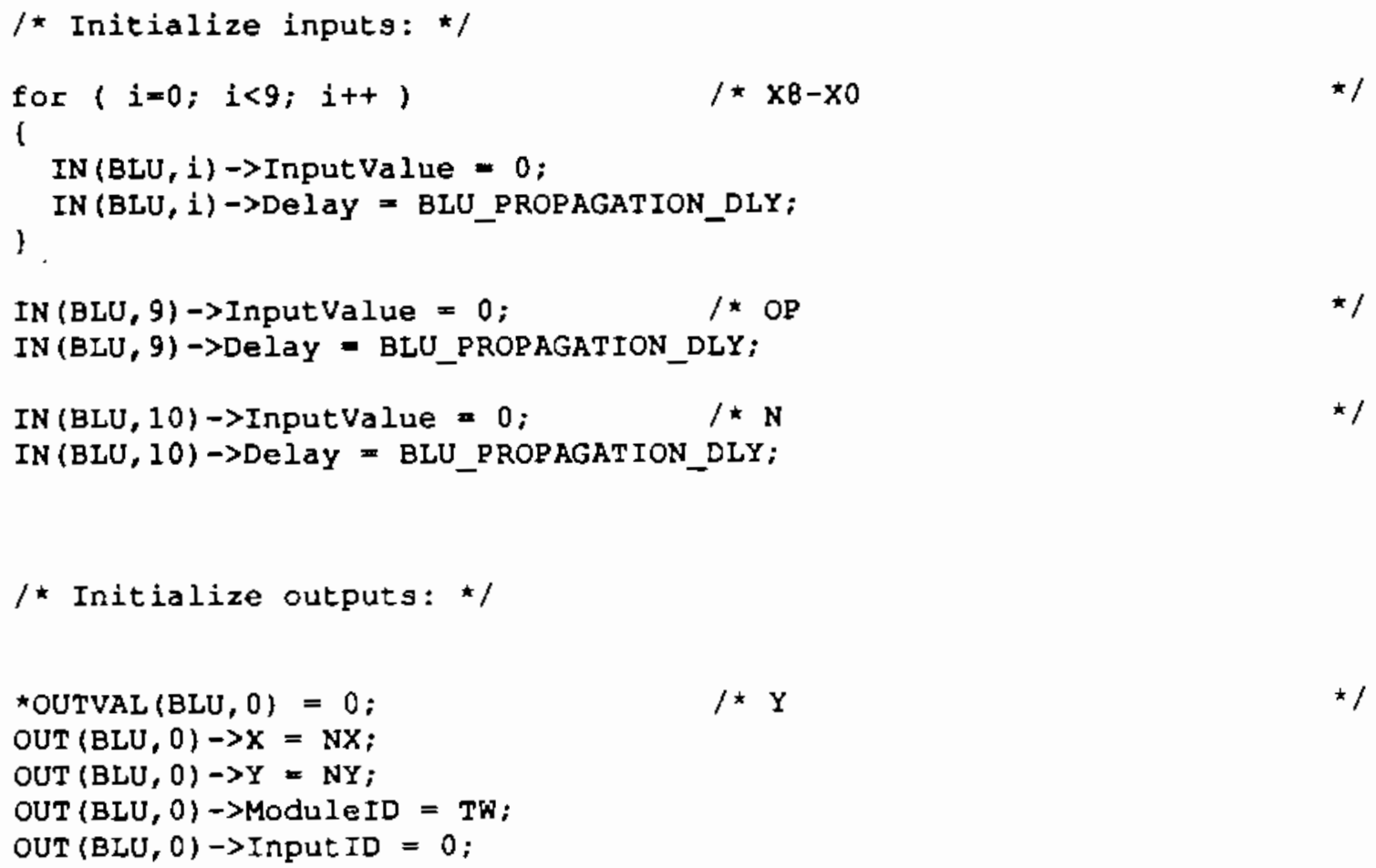




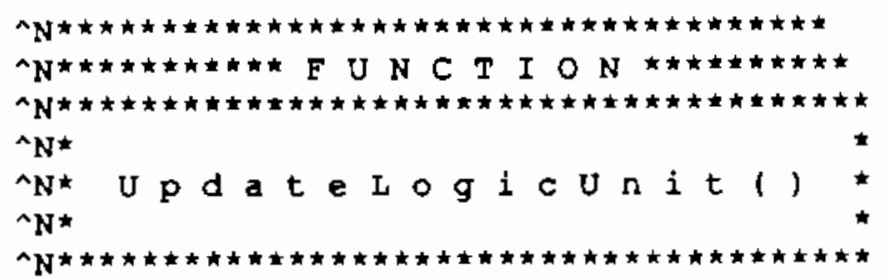

Functional Surmary:

This function executes the Boolean logic modvle for the specified node.

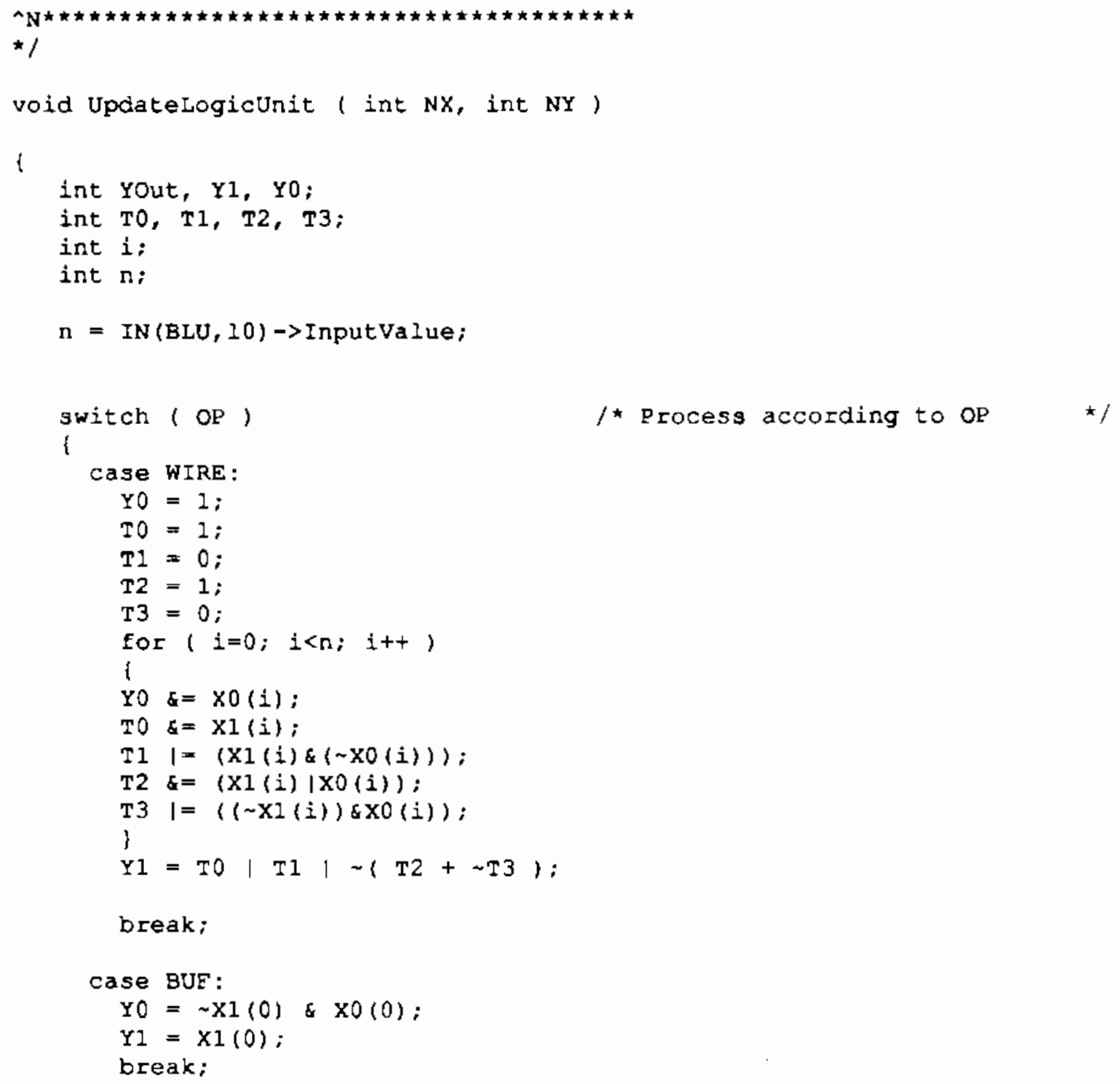




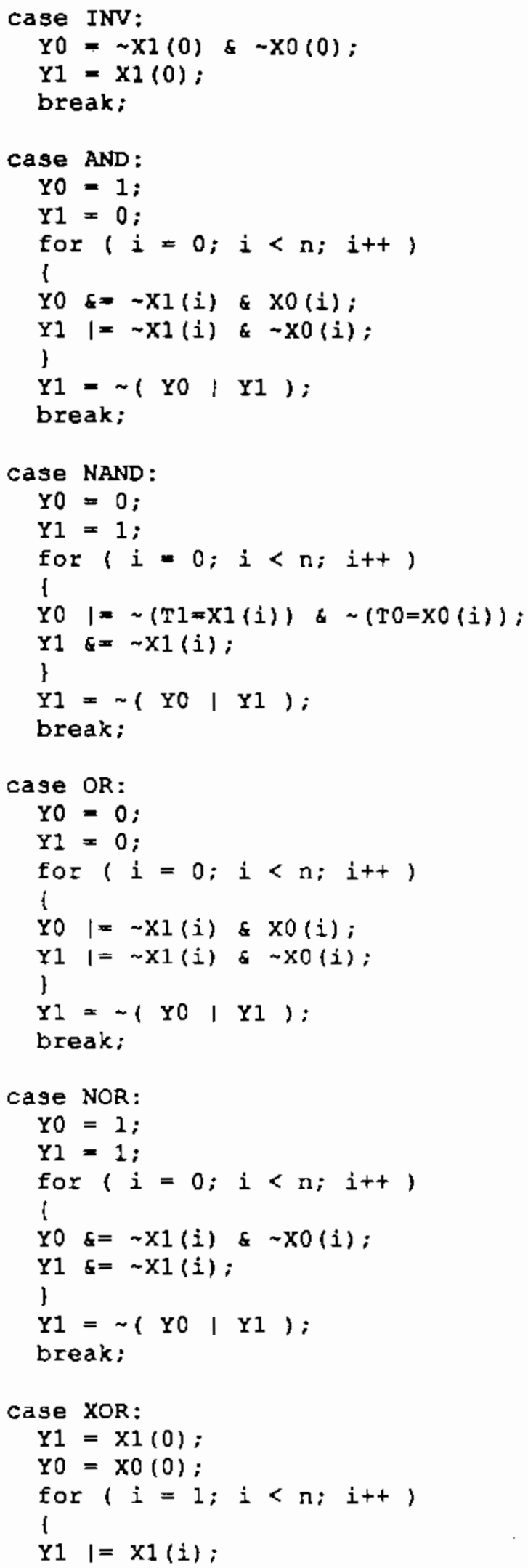




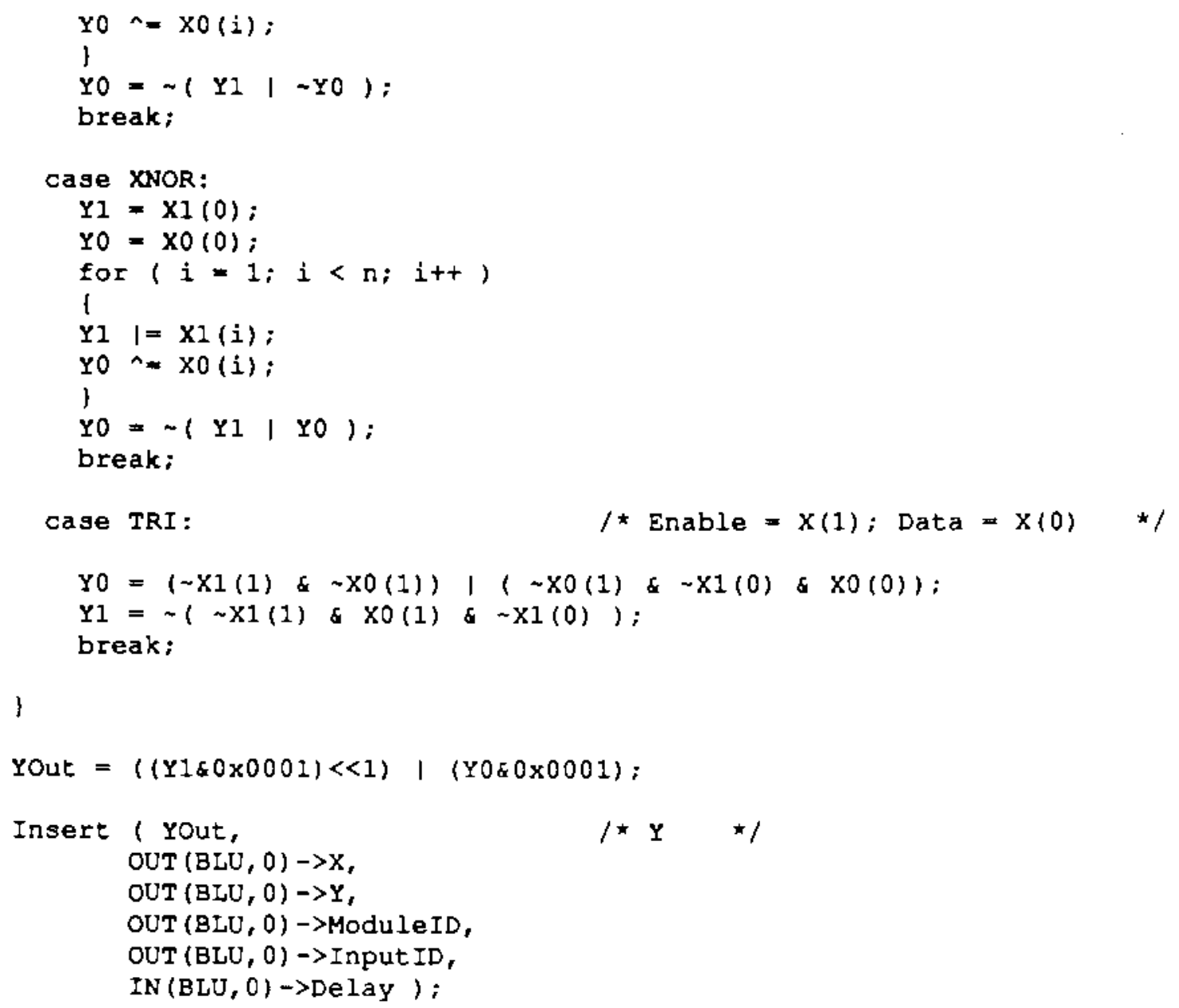




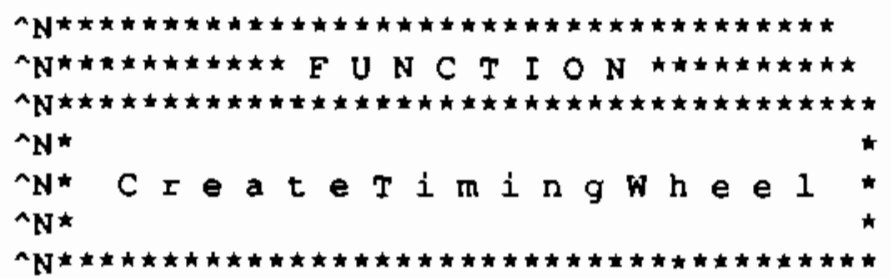

Functional Summary:

This function creates the timing wheel for a single node.

Module ID $=6$.

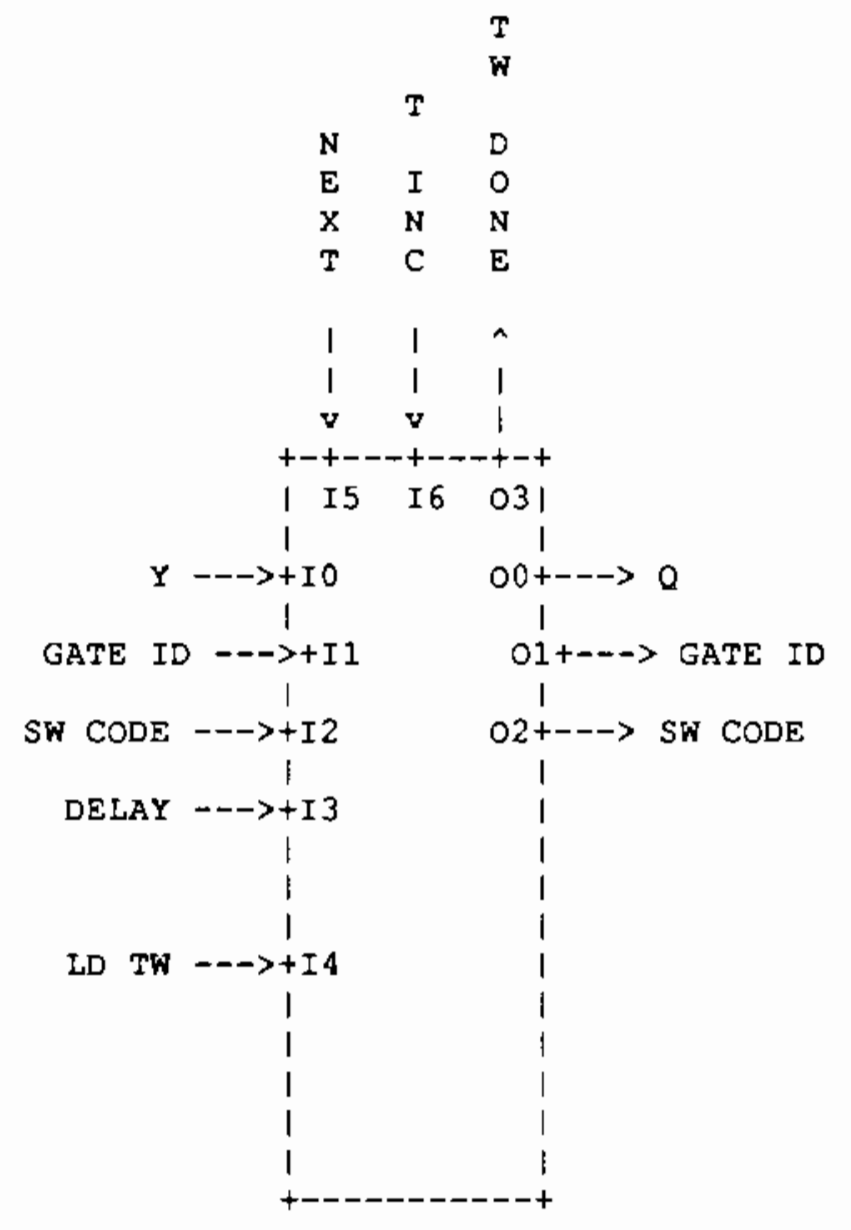

The timing wheel buffer stores data, gate ID and switch code for each event. A prediction, correction algorithm is used in which initial output guesses can be corrected by new guesses until the final (correct) value is obtained. 
INPUTS

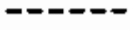

$Y=[D|| D 0]$ - 4-level data value coming from the boolean logic unit.

GATE ID = [G11-GO] - Source gate identification.

DELAY - A value up to MAX DELAY indicating the position of the event relative to the current position in the timing wheel.

SW CODE = [S8|S7|S6|S5|S4|S3|S2|S1|S0] - switch code sent to the Network Switch. For each bit set, the corresponding output is enabled.

LD TW - A signal used to load the timing wheel with new values.

NEXT - A gignal requesting the next event at the current position in the timing wheel. Generated by the Array Controller.

T INC - A signal which increments the timing wheel to the next position. Generated by the Array Controller.

OUTPUTS

OUTPUS

$Q=[D l \mid D 0]$ - 4-level logic value being passed to the network switch.

GATE ID = [G11-G0] - Source gate identification.

SW CODE =[S8|S7|S6|S5|S4|S4|S3|S2|SI|S0] - Switch code for network switch.

TW DONE - A flag indicating that the last event for the current position in the timing wheel has been processed. Input to the Cell controller.

PARAMETERS :

--O--U-O-

NX, NY - Node Coordinates.

RETURN VALUE:

void.

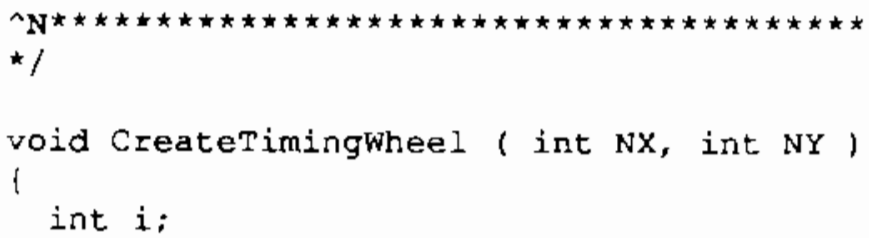




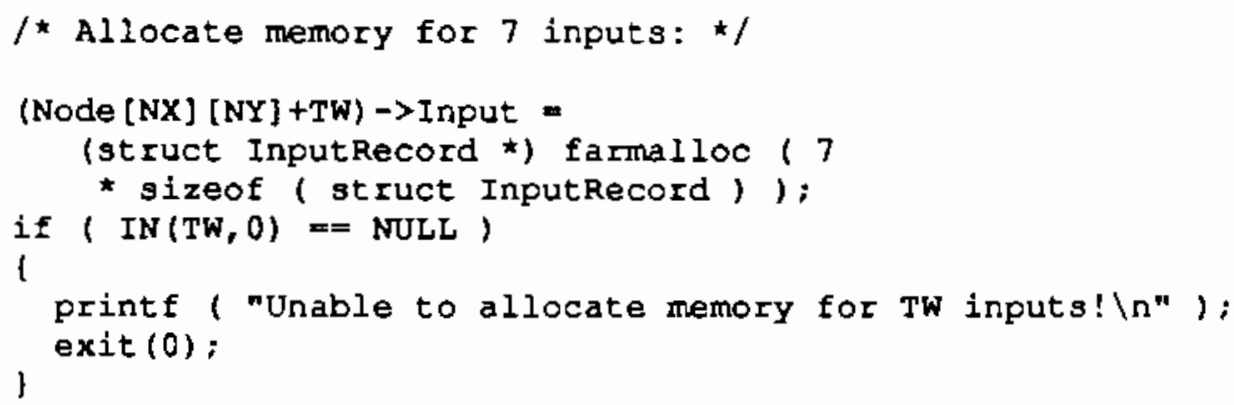




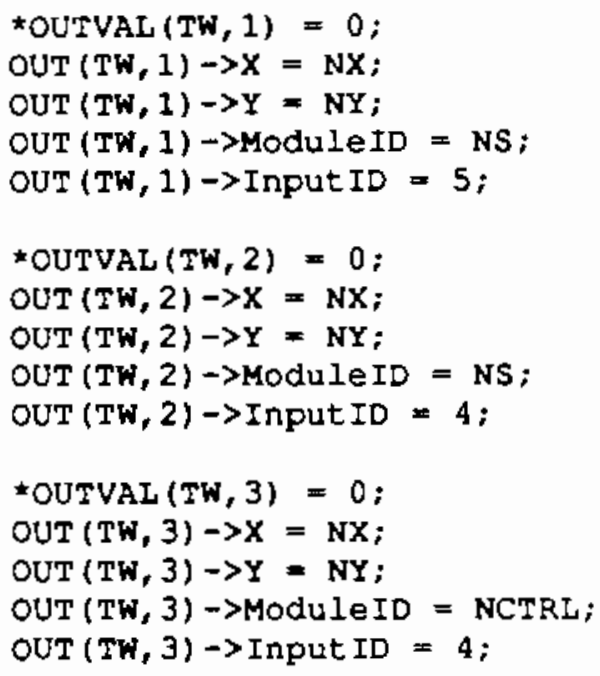




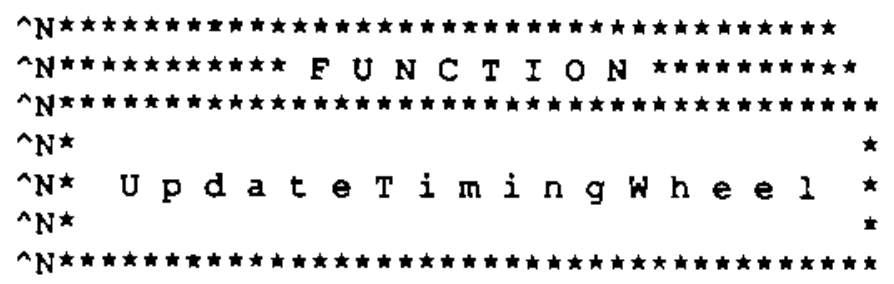

Functional Sumara:

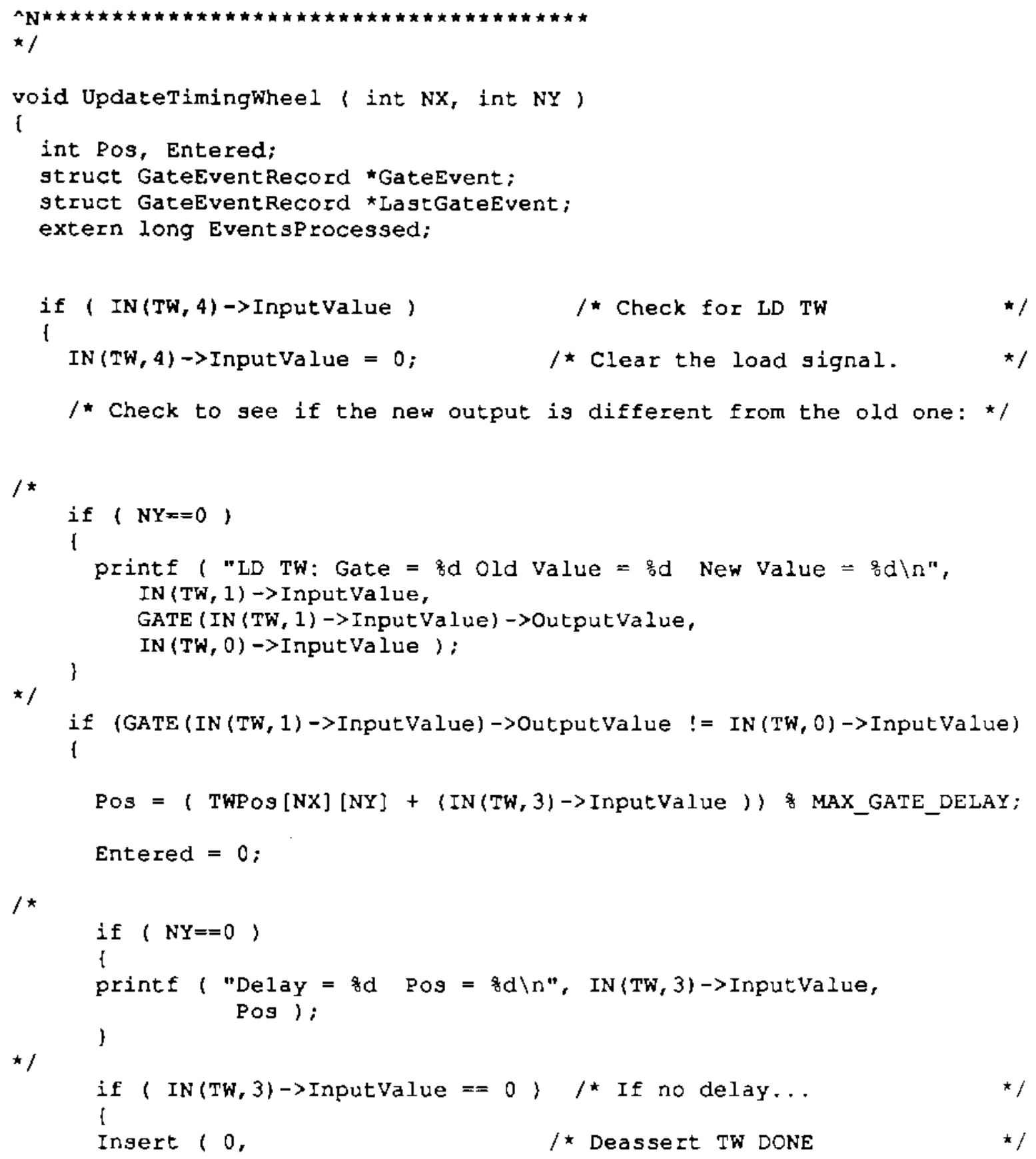




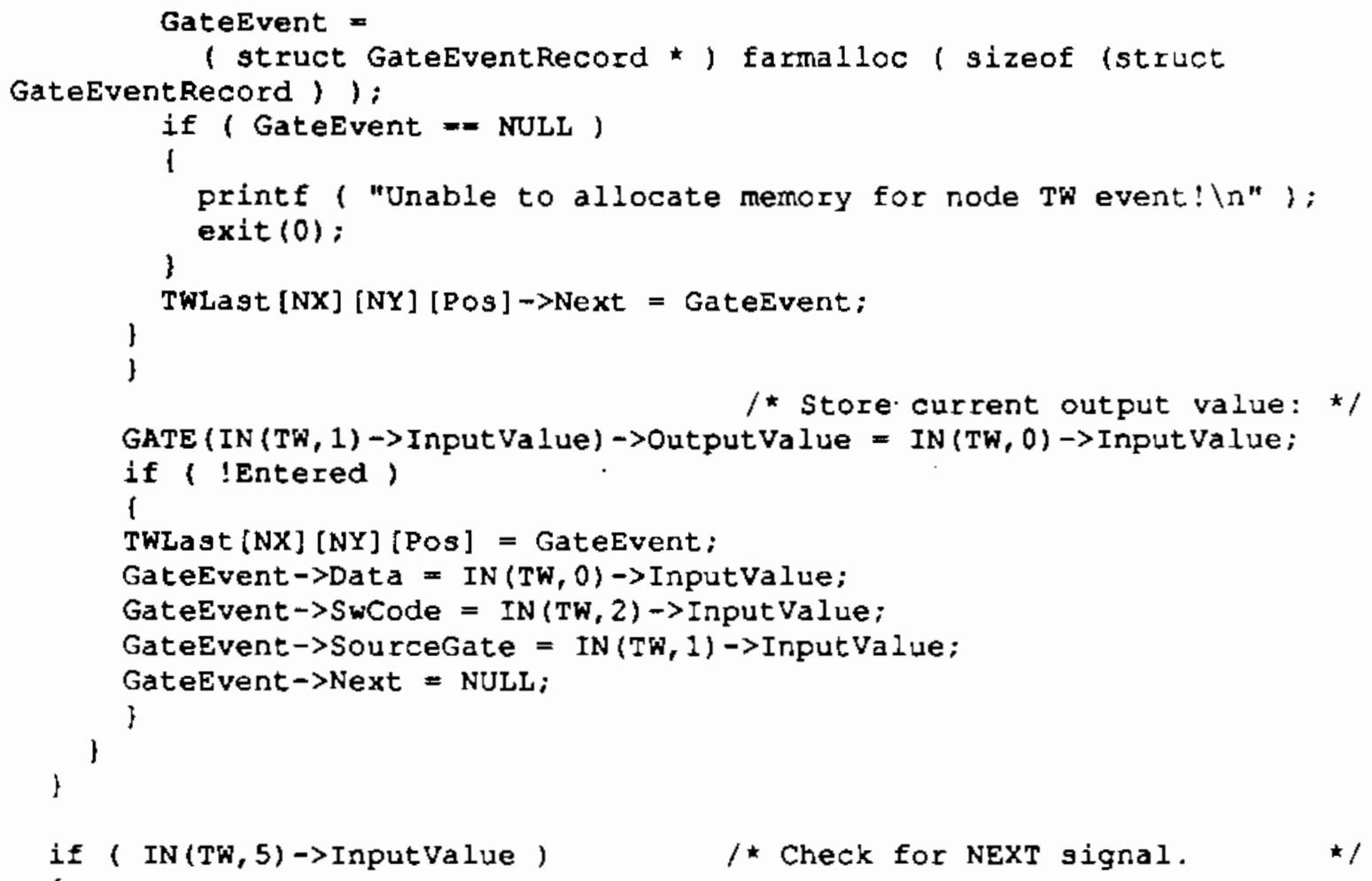


Th_NEXT_TO_OUT_DLY ) ;

Insert ( TwCurrent [NX] [NY] ->SourceGate,

$/$ * Output GATE ID */

OUT (TW, 1) $\rightarrow$ X,

OUT (TW, 1) $\rightarrow$ Y,

OUT $(T W, 1) \rightarrow$ ModuleID,

OUT (TW, 1) $\rightarrow$ Input ID,

TW_NEXT_TO_OUT_DLY );

Insert ( TWCurrent [NX][NY] >SwCode, /* output SW CODE

$\star /$

OUT $(T N, 2) \rightarrow X$,

OUT $(T W, 2) \rightarrow Y$,

OUT (TW, 2) $\rightarrow$ ModuleID,

OUT (TW, 2) $\rightarrow$ InputID,

TW_NEXT_TO_OUT_DLY ) ;

LastGateEvent = TWCurrent $[\mathrm{NX}][\mathrm{NY}]$;

TWCurrent [NX] [NY] = TWCurrent [NX] [NY] $\rightarrow$ Next;

$/ \star$ Point to next event. */

farfree ( LastGateEvent); /* Free last event.

$\star /$

if (TwCurrent [NX] [NY] $=x$ NULL)

1

TWheel[NX] [NY] [TWPOs [NX] [NY]] = NULL;

TWLast [NX] [NY] [TWPOS[NX] [NY]] = NULL;

\}

\}

else

1

Insert $(1$,

OUT (TH, 3) $\rightarrow \mathrm{X}$,

$/$ Assert TW DONE

*/

OUT (TW, 3) $\rightarrow$ Y,

OUT (TW, 3) $>$ ModuleID,

OUT (TW, 3) $>$ Input ID,

TW_NEXT_TO_OUT_DLY) ;

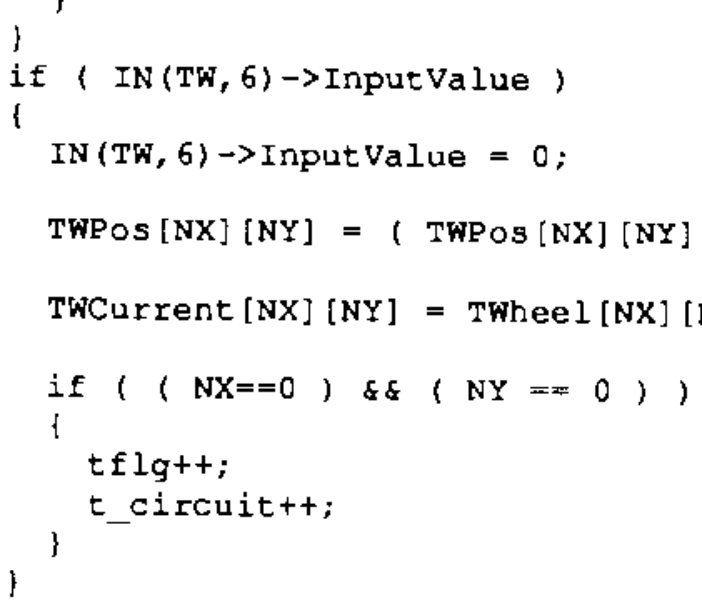




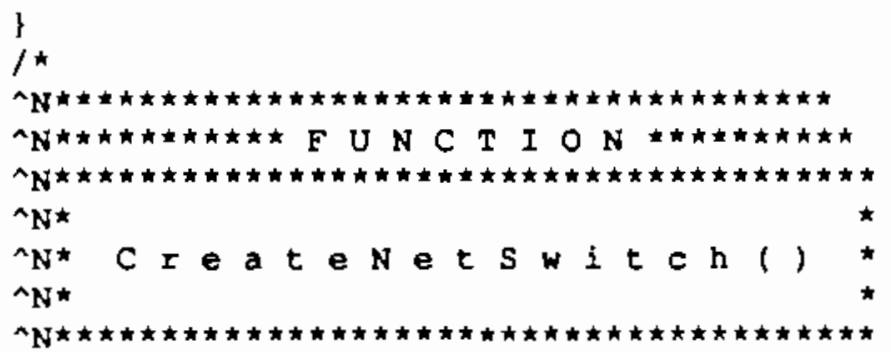

Functional Sumary:

This function creates the Network Switch for a single node.

Module ID $=1$.

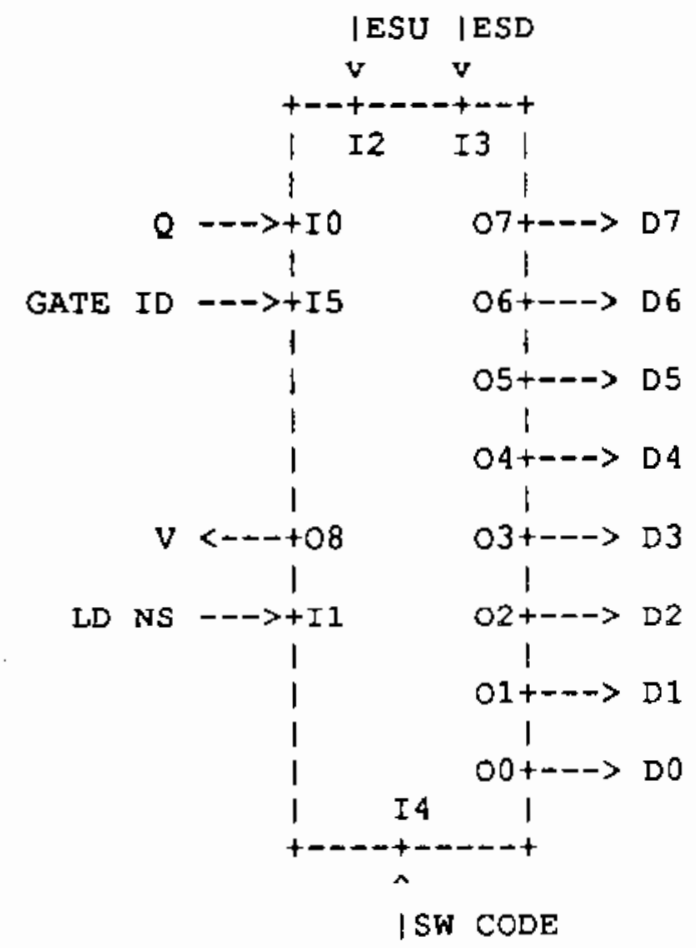

INPUTS

ESU = Enable Shift up. ESD = Enable Shift down.

LD NS is a signal which will latch in the current input.

SW CODE $=|S 8| S 7|S 6| S 5|S 4| S 3|S 2| S 1|S 0|$

For each high bit, the corresponding output is

enabled. ( $S B$ is for the vertical connection.) 
$Q=|D 1| D 0 \mid$

GATE $\cdot I D=[G 11-G 0]$

where,

[gl1-G0] = Source Gate Code. The data source code consists of the path number (0-7 for lateral paths; 8 for vertical) that the data came in on. This identifies which neighboring node was the source. [GI1..GO] identifies the number of the gate within the node.

[D1|D0] = Data. 4-level data value.

OUTPUTS

OUTh-

[D7..D0] Lateral output connections.

$V=$ Vertical output connection.

Where each output consists of:

1---|---|G12|G10|G9 IG8 IG7 |G6 I

IG5 IG4 IG3 IG2 |G2 IGO IDI IDO I

Where

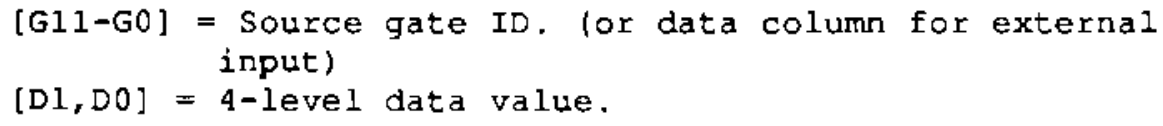
input)

$[D 1, D 0]=4$-level data value.

PARAMETERS :

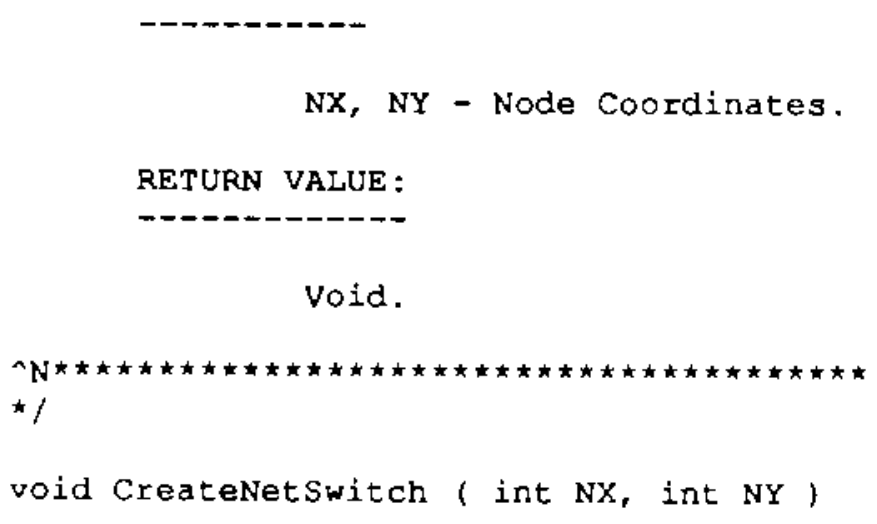




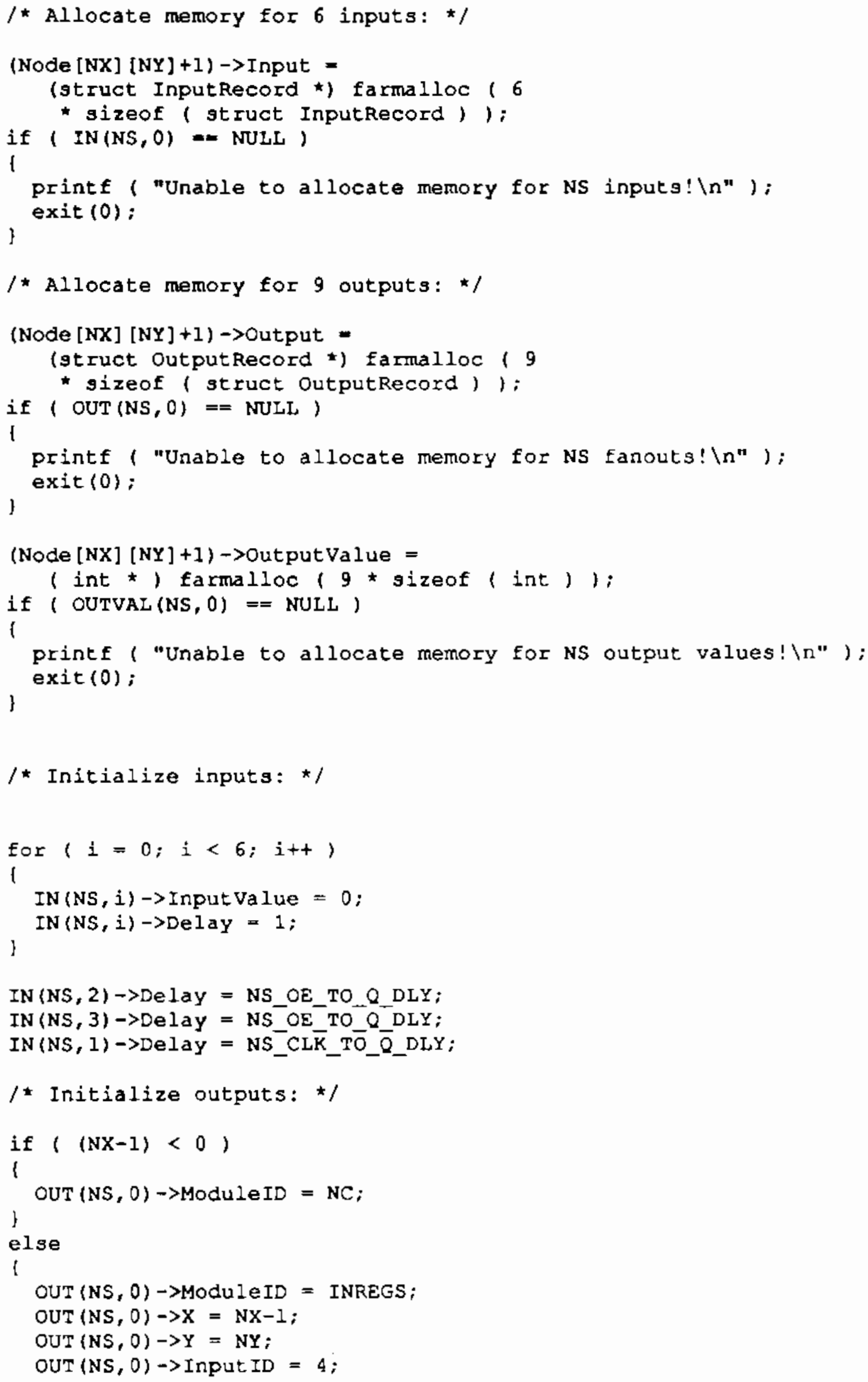




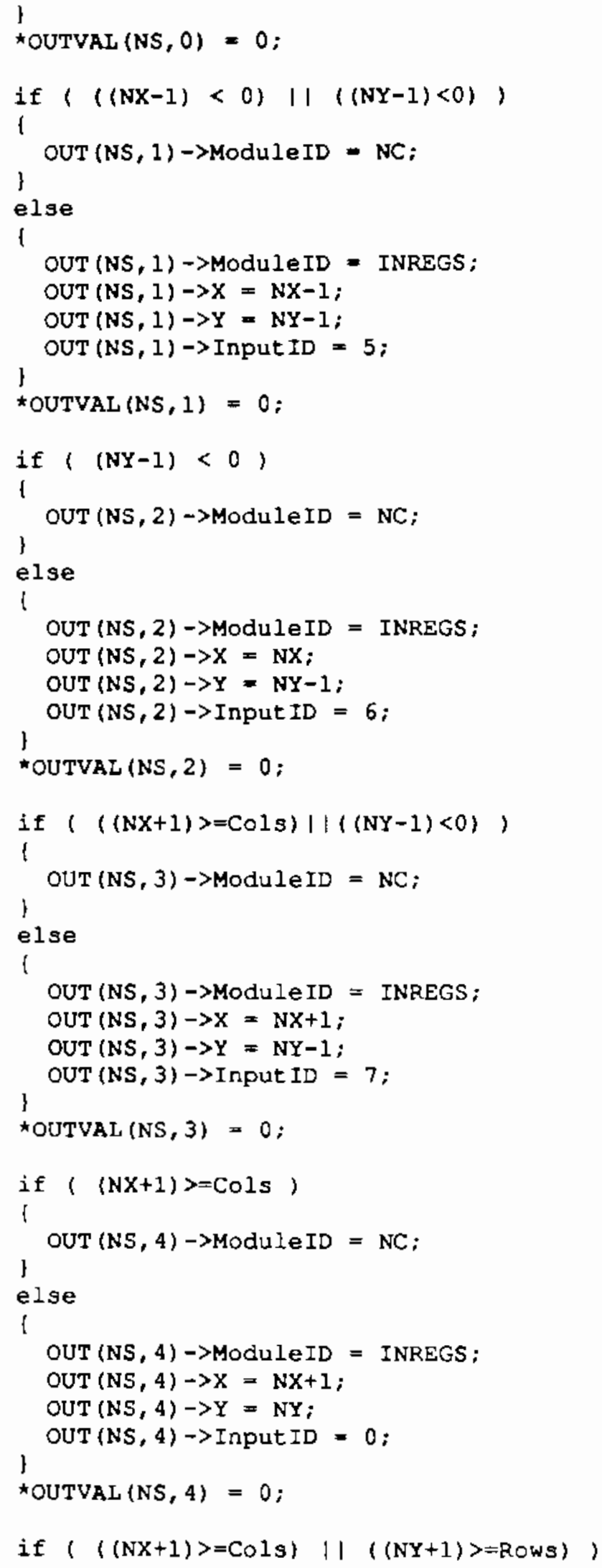




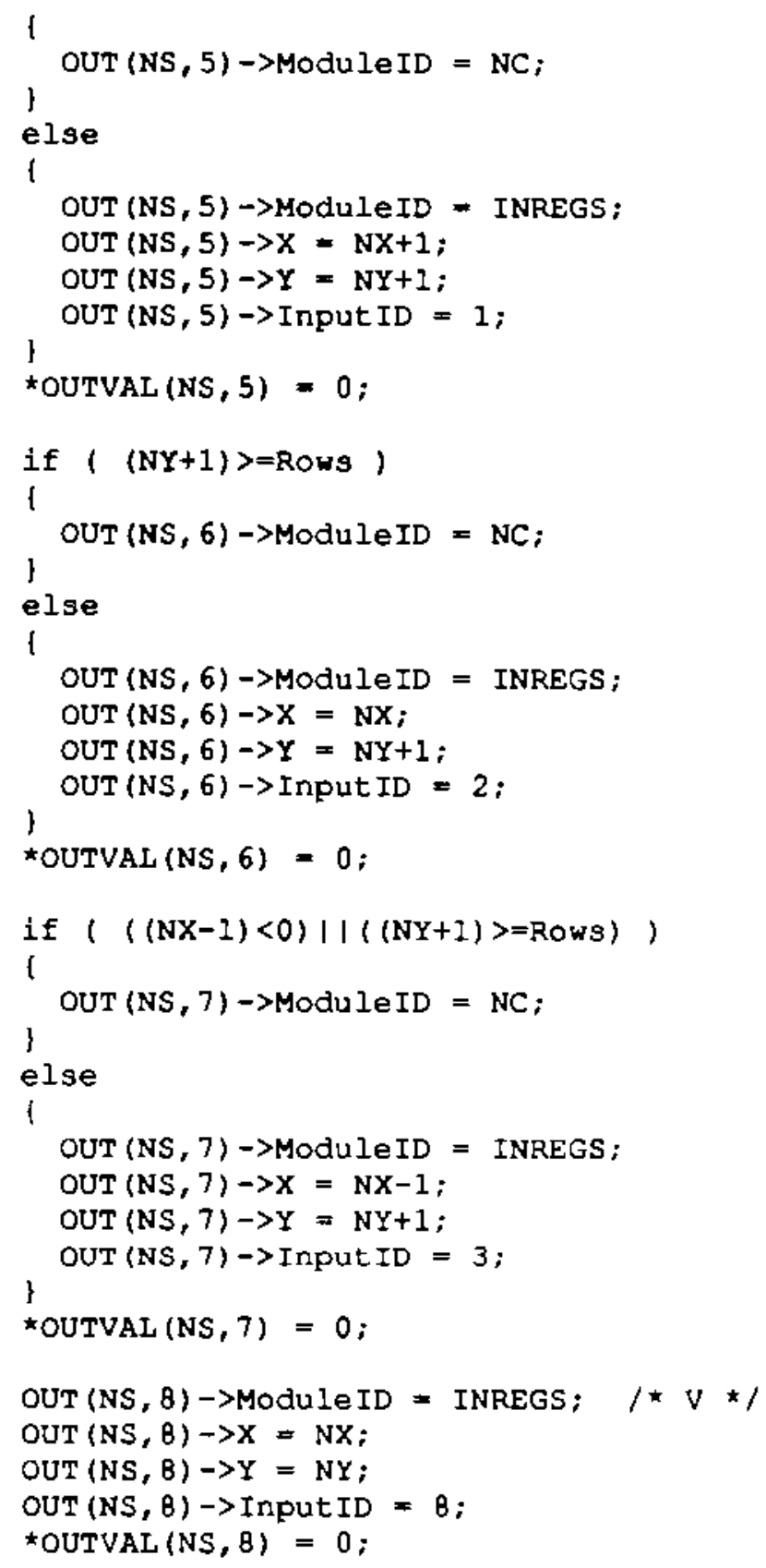




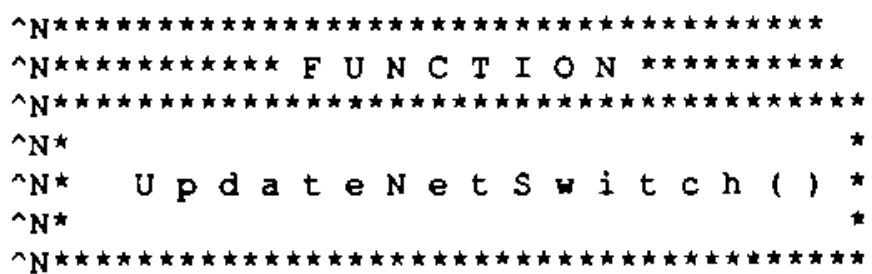

Functional sumnary:

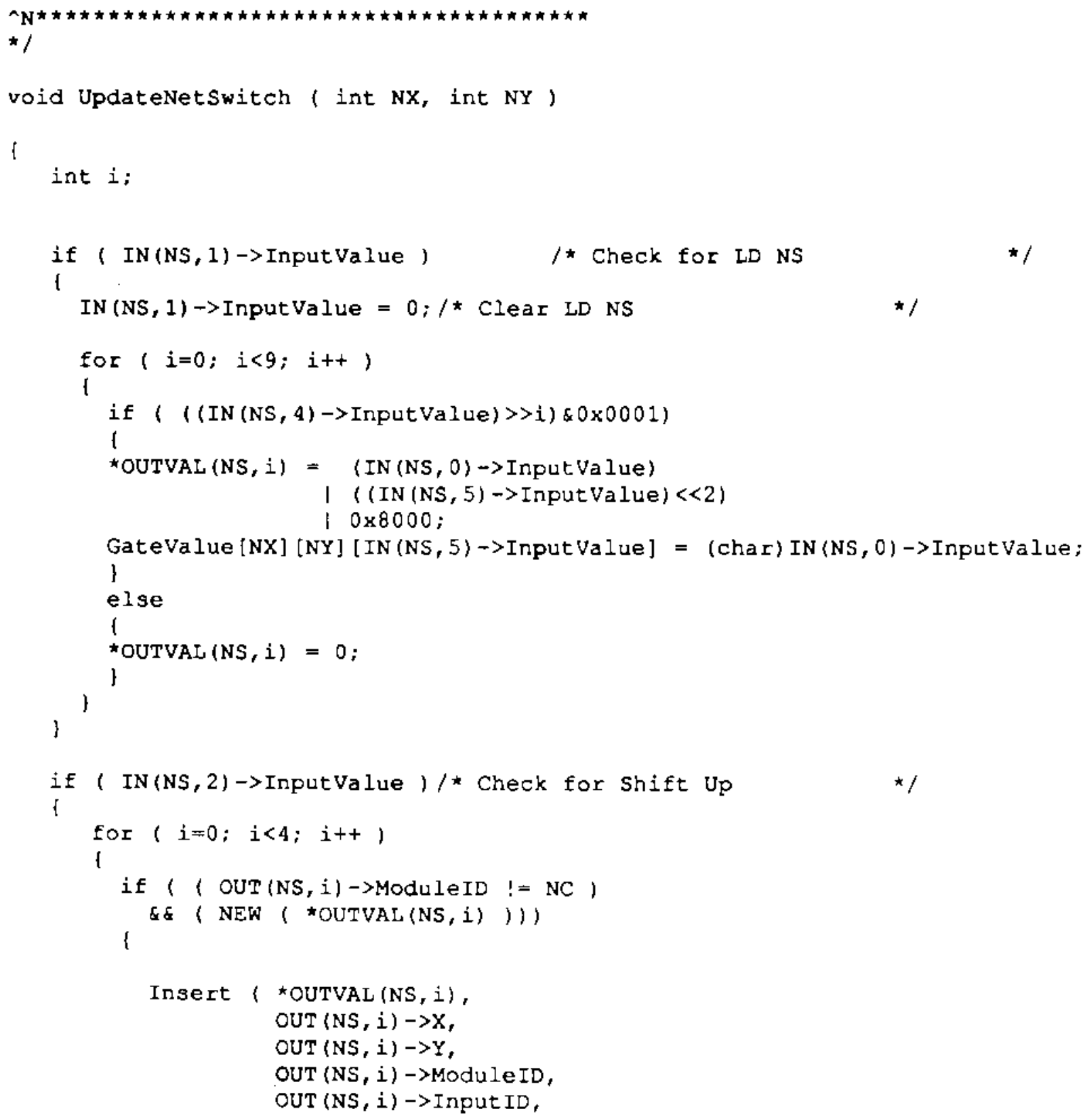




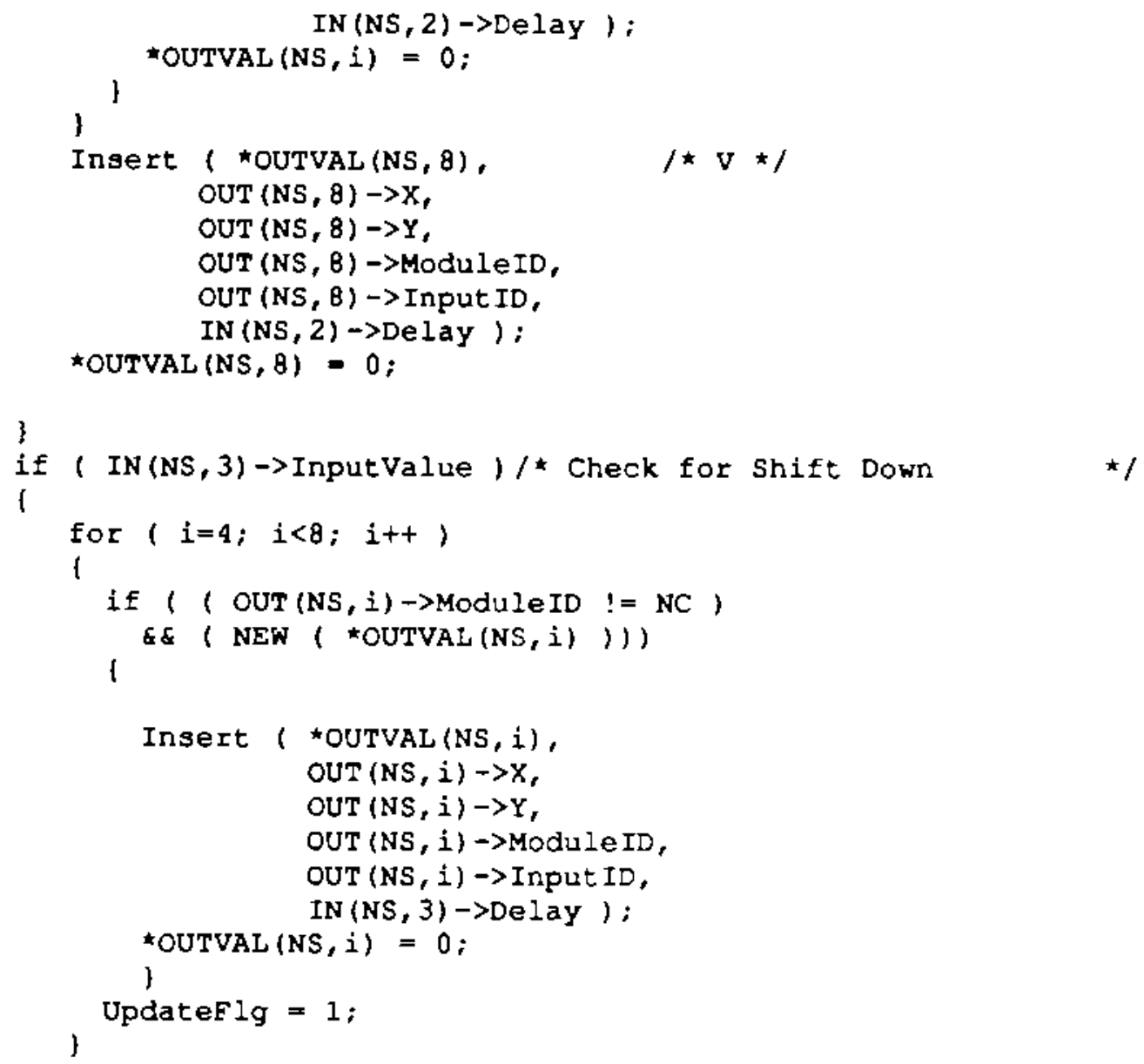

IN (NS, 2) $\rightarrow$ Delay ) ; 
APPENDIX D. Test Circuit Definitions

Single Inverter

Single Inverter (INV.NET)

ARRAY $(1,1)$;

INV ( 1 , OUT, $0,0,0,16,1,1,0)$;

..INP ( $0,0,-1,0,0,0$, IN );

DATA ( INV.DAT);

.DLAG $(0,0,3,0, \mathrm{D} 0,0,0)$;

.DIAG $(0,0,4,1$, DATA $, 1,0)$;

.DIAG $(0,0,5,0, \mathrm{X} 0,2,0)$;

.DIAG $(0,0,6,0, Y, 3,0)$;

.DIAG $(0,0,1,0, Q, 4,0)$;

.DIAG $(0,0,2,4, A R R A Y$ RDY $, 5,0)$;

DIAG $(0,0,2,5$, ARRAY_DONE,6,0);

.DIAG $(0,0,7,1$, NEXT_EVENT, 7,0$)$;

DIAG $(0,0,7,2$, NEXT_TIME, 8,0$)$;

.DIAG $(0,0,0,0$, State, 15,0$)$;

.OUTFILE(INV.OUT);

DUMP(0,IN,\%3s,\%3d,IN,0,0,0,0);

.DUMP(1,OUT,\%4s, \%4d,OUT,0,0,0,0); 


\section{4-inverter Chain (Single Cell)}

Chain of 64 Inverters in one cell (INV64X1.NET)

.ARRAY $(1,1)$;

.INV( 1 , INV0, 0, 0, 0, 256, 1, -1,0);

.INP $(0,0,-1,0,0,0$, Input $)$;

$\operatorname{INV}(1, \operatorname{INV} 1,0,0,1,256,1,-1,0)$;

..INP $(0,8,0,0,-1)$;

.INV( 1 , INV2, 0, 0, 2, 256, 1, -1,0);

..INP $(0,8,1,0,-1)$;

$\operatorname{INV}(1, \operatorname{INV} 3,0,0,3,256,1,-1,0)$;

..INP $(0,8,2,0,-1)$;

INV( 1 , INV4, 0, 0, 4, 256, 1, -1, 0 );

..INP $(0,8,3,0,-1)$;

$\operatorname{INV}(1, \operatorname{INV} 5,0,0,5,256,1,-1,0)$;

.INP $(0,8,4,0,-1)$;

INV( 1, INV6, 0, 0, 6, 256, 1, -1, 0 );

.INP $(0,8,5,0,-1)$;

.INV( $1, \operatorname{INV} 7,0,0,7,256,1,1,0)$;

.INP $(0,8,6,0,-1)$;

. $\operatorname{INV}(1, \mathrm{INV} 8,0,0,8,256,1,-1,0)$;

..INP $(0,8,7,0,-1)$;

$\operatorname{INV}(1, \operatorname{INV9}, 0,0,9,256,1,-1,0)$;

..INP $(0,8,8,0,-1)$;

.INV( $1, \operatorname{INV10}, 0,0,10,256,1,-1,0)$;

..INP $(0,8,9,0,-1)$;

.INV( 1 , INV11, 0, 0, 11, 256, 1, -1, 0);

..INP $(0,8,10,0,-1)$;

.INV( 1 , INV12, 0, 0, 12, 256, 1, -1, 0 );

..INP $(0,8,11,0,-1)$;

.INV( 1 , INV13, 0, 0, 13, 256, 1, -1, 0 );

.INP $(0,8,12,0,-1)$;

.INV( 1 , INV14, 0, 0, 14, 256, 1, -1, 0 );

..INP $(0,8,13,0,-1)$;

INV( 1 , INV15, 0, 0, 15, 256, 1, 2, 0 );

*.INP $(0,8,14,0,-1)$;

INV( 1 , INV16, 0, 0, 16, 256, 1, -1, 0 );

..INP $(0,8,15,0,-1)$;

.INV( 1 , INV17, 0, 0, 17, 256, 1, -1, 0 );

.INP $(0,8,16,0,-1)$;

INV( 1 , INV18, 0, 0, 18, 256, 1, -1, 0 );

..INP $(0,8,17,0,-1)$;

INV( $1, \operatorname{INV} 19,0,0,19,256,1,-1,0)$;

..INP $(0,8,18,0,-1)$;

INV( 1 , INV20, 0, 0, 20, 256, 1, -1, 0 );

..INP $(0,8,19,0,-1)$;

.INV( $1, \operatorname{INV} 21,0,0,21,256,1,-1,0)$;

..INP $(0,8,20,0,-1)$; 
.INV( 1, INV22, $0,0,22,256,1,-1,0)$; ..INP $(0,8,21,0,-1)$;

INV( $1, \operatorname{INV} 23,0,0,23,256,1,3,0)$;

..INP $(0,8,22,0,-1)$;

.INV( 1 , INV24, 0, 0, 24, 256, 1, -1, 0 ); .INP $(0,8,23,0,-1)$;

INV( 1 , INV25, 0, 0, 25, 256, 1, -1,0);

..INP $(0,8,24,0,-1)$;

INV( 1, INV26, $0,0,26,256,1,-1,0)$;

..INP $(0,8,25,0,-1)$;

INV( 1 , INV27, 0, 0, 27, 256, 1, -1, 0 );

..INP $(0,8,26,0,-1)$;

.INV( 1 , INV28, 0, 0, 28, 256, 1, -1, 0 );

..INP $(0,8,27,0,-1)$;

INV( 1, INV29, 0, 0, 29, 256, 1, -1, 0 ); ..INP $(0,8,28,0,-1)$;

.INV( 1 , INV 30, 0, 0, 30, 256, 1, -1, 0 ); ..INP $(0,8,29,0,-1)$;

INV( 1 , INV31, 0, 0, 31, 256, 1, 4, 0 );

.INP $(0,8,30,0,-1)$;

.INV( 1 , INV32, 0, 0, 32, 256, 1, -1, 0 ); ..INP $(0,8,31,0,-1)$;

.INV( 1 , INV33, 0, 0, 33, 256, 1, -1, 0 ); ..INP $(0,8,32,0,-1)$;

INV( 1 , INV34, 0, 0, 34, 256, 1, -1, 0 ); .IINP $(0,8,33,0,-1)$;

.INV( 1 , INV35, 0, 0, 35, 256, 1, -1, 0 ); ..INP $(0,8,34,0,-1)$;

.INV( 1 , INV36, 0, 0, 36, 256, 1, -1, 0); ..INP $(0,8,35,0,-1)$;

INV( 1 , INV $37,0,0,37,256,1,-1,0)$; .INP $(0,8,36,0,-1)$;

INV( 1 , INV38, 0, 0, 38, 256, 1, -1, 0 ); .INP $(0,8,37,0,-1)$;

INV( 1 , INV39, $0,0,39,256,1,5,0)$;

$\ldots \operatorname{INP}(0,8,38,0,-1)$;

INV( 1, INV40, 0, 0, 40, 256, 1, -1, 0 ); ..INP $(0,8,39,0,-1)$;

INV( 1 , INV41, 0, 0, 41, 256, 1, -1, 0); ..INP $(0,8,40,0,-1)$;

INV( $1, \operatorname{INV} 42,0,0,42,256,1,-1,0)$; ..INP $(0,8,41,0,-1)$;

INV( 1 , INV43, 0, 0, 43, 256, 1, -1, 0 ); ..INP $(0,8,42,0,-1)$;

INV( 1, INV44, 0, 0, 44, 256, 1, -1, 0 ); ..INP $(0,8,43,0,-1)$;

INV( 1 INV45, $0,0,45,256,1,-1,0)$; ..INP $(0,8,44,0,-1)$; 
.INV( $1, \operatorname{INV} 46,0,0,46,256,1,-1,0)$; .IINP $(0,8,45,0,-1)$;

$\operatorname{INV}(1, \operatorname{INV} 47,0,0,47,256,1,6,0)$; .INP $(0,8,46,0,-1)$;

.INV( 1, INV48, 0, 0, 48, 256, 1, -1, 0 ); .INP $(0,8,47,0,-1)$;

.INV( $1, \operatorname{INV} 49,0,0,49,256,1,-1,0)$; ..INP $(0,8,48,0,-1)$;

.INV( 1, INV $50,0,0,50,256,1,-1,0)$; ..INP $(0,8,49,0,-1)$;

.INV( 1, INV51, 0, 0, 51, 256, 1, -1, 0 ); .IINP $(0,8,50,0,-1)$;

.INV( 1, INV52, 0, 0, 52, 256, 1, -1, 0 ); ..INP $(0,8,51,0,-1)$;

INV( I, INV53, 0, 0, 53, 256, I, -1, 0 ); .IINP $(0,8,52,0,-1)$;

.INV( 1 , INV54, 0, 0, 54, 256, 1, -1, 0 ); ..INP $(0,8,53,0,-1)$;

.INV( 1 , INV55, 0, 0, 55, 256, 1, 7, 0 ); * .INP $(0,8,54,0,-I)$;

.INV( 1, INV 56, 0, 0, 56, 256, 1, -1, 0 ); ..INP $(0,8,55,0,-1)$;

.INV( 1 , INV57, 0, 0, 57, 256, I, -1, 0 ); ..INP $(0,8,56,0,-1)$;

.INV( I, INV 58, 0, 0, 58, 256, 1, -1, 0 ); .INP $(0,8,57,0,-I)$;

INV( 1 , INV59, 0, 0, 59, 256, 1, -1, 0); ..INP $(0,8,58,0,-1)$;

.INV( 1, INV60, 0, 0, 60, 256, 1, -1, 0 ); ..INP $(0,8,59,0,-1)$

.INV( 1 , INV61, 0, 0, 61, 256, 1, -1, 0); .INP $(0,8,60,0,-1)$;

INV( 1, INV62, 0, 0, 62, 256, 1, -1, 0); .INP $(0,8,61,0,-1)$;

.INV( I, INV63, 0, 0, 63, 256, 1, 8, 0 ); .INP $(0,8,62,0,-1)$;

.DATA (INV64.DAT);

.OUTFILE(INV64XI.OUT);

DUMP ( 0 , INPUT, \%-7s, \%-7d, IN, 0, 0, 0, 0);

.DUMP ( 1 , INV7, \%-6s, \%-6d, OUT, 0, 0, 7, 0 );

.DUMP ( 2 , INV15, \%-7s, \%-7d, OUT, 0, 0, 15, 0 );

.DUMP ( 3, INV23, \%-7s, \%-7d, OUT, 0, 0, 23, 0);

.DUMP ( 4, INV31, \%-7s, \%-7d, OUT, 0, 0, 31, 0);

.DUMP ( 5, INV39, \%-7s, \%-7d, OUT, 0, 0, 39, 0 );

.DUMP ( 6 , INV47, \%-7s, \%-7d, OUT, 0, 0, 47, 0);

.DUMP ( 7, INV55, \%-7s, \%-7d, OUT, 0, 0, 55, 0);

.DUMP ( 8, INV63, \%-7s, \%-7d, OUT, 0, 0, 63, 0 ); 


\section{4-inverter Chain in $4 \times 4$ Array}

Chain of 64 Inverters in $4 \times 4$ array (INV $4 \times 4 \times 4$.NET)

.ARRAY $(4,4)$;

INV( 1 , INV0, 0, 0, 0, 256, 1, -1, 0 );

..INP ( $0,0,-1,0,0,0$, Input $)$;

INV( 1 , INV $1,0,0,1,256,1,-1,0)$;

..INP $(0,8,0,0,-1)$;

. $\operatorname{INV}(1, \operatorname{INV} 2,0,0,2,256,1,-1,0)$;

..INP $(0,8,1,0,-1)$;

INV( $1, \operatorname{INV} 3,0,0,3,16,1,-1,0)$;

..INP $(0,8,2,0,-1)$;

INV( 1, INV4, 1, 0, 0, 256, 1, -1, 0$)$; ..INP $(0,0,3,0,-1)$;

INV( 1 , INV5, 1, 0, 1, 256, 1, -1, 0$)$;

..INP $(0,8,0,0,-1)$;

INV ( $1, \operatorname{INV} 6,1,0,2,256,1,-1,0)$;

..INP $(0,8,1,0,-1)$;

INV( $1, \operatorname{INV7}, 1,0,3,16,1,1,0)$;

*.INP $(0,8,2,0,-1)$;

INV( 1, INV8, 2, 0, 0, 256, 1, -1, 0 );

..INP $(0,0,3,0,-1)$;

INV( 1 , INV9, 2, 0, 1, 256, 1, -1, 0 );

..INP $(0,8,0,0,-1)$;

INV( 1, INV10, 2, 0, 2, 256, 1, -1, 0 );

..INP $(0,8,1,0,-1)$;

$\operatorname{INV}(1, \operatorname{INV} 11,2,0,3,16,1,-1,0)$;

..INP $(0,8,2,0,-1)$;

.INV( 1, INV12, 3, 0, 0, 256, 1, -1, 0 );

..INP $(0,0,3,0,-1)$;

INV( 1 , INV13, 3, 0, 1, 256, 1, -1, 0 );

..INP $(0,8,0,0,-1)$;

INV( $1, \operatorname{INV} 14,3,0,2,256,1,-1,0)$;

.INP $(0,8,1,0,-1)$;

INV( $1, \operatorname{INV} 15,3,0,3,64,1,2,0)$;

..INP $(0,8,2,0,-1)$;

INV( $1, \operatorname{INV} 16,3,1,0,256,1,-1,0)$;

..INP ( 0, 2, 3, 0, -1);

INV( $(1, \operatorname{INV} 17,3,1,1,256,1,-1,0)$;

..INP $(0,8,0,0,-1)$;

INV ( 1, INV 18, 3, 1, 2, 256, 1, -1, 0 );

..INP $(0,8,1,0,-1)$;

INV( $1, \operatorname{INV19}, 3,1,3,1,1,-1,0)$;

..INP $(0,8,2,0,-1)$;

INV( 1, INV20, 2, 1, 0, 256, 1, -1, 0 ); 
178

..INP $(0,4,3,0,-1)$;

INV( $1, \operatorname{INV} 21,2,1,1,256,1,-1,0)$;

..INP $(0,8,0,0,-1)$;

.INV( 1 , INV22, 2, 1, 2, 256, 1, -1, 0 );

.INP $(0,8,1,0,-1)$;

$\operatorname{INV}(1, \operatorname{INV} 23,2,1,3,1,1,3,0)$;

*INP $(0,8,2,0,-1)$;

.INV( 1 , INV24, 1, 1, 0, 256, 1, -1, 0 );

..INP $(0,4,3,0,-1)$;

INV( 1 , INV25, 1, 1, 1, 256, 1, -1, 0 );

..INP $(0,8,0,0,-1)$;

INV( 1 , INV26, 1, 1, 2, 256, 1, -1, 0 );

..INP $(0,8,1,0,-1)$;

INV( 1 , INV27, $1,1,3,1,1,-1,0)$;

* INP $(0,8,2,0,-1)$;

.INV( 1, INV28, 0, 1, 0, 256, 1, -1, 0 ); ..INP $(0,4,3,0,-1)$;

INV( 1 , INV29, 0, 1, 1, 256, I, -1, 0 );

..INP $(0,8,0,0,-1)$;

INV( $1, \operatorname{INV} 30,0,1,2,256,1,-1,0)$;

..INP $(0,8, I, 0,-1)$;

.INV( 1, INV $31,0,1,3,64, \mathrm{I}, 4,0)$;

..INP $(0,8,2,0,-1)$;

.INV( 1, INV32, 0, 2, 0, 256, I, -1, 0 );

..INP $(0,2,3,0,-1)$;

.INV( I, INV33, 0, 2, 1, 256, 1, -1, 0 );

..INP $(0,8,0,0,-I)$;

.INV( 1 , INV34, 0, 2, 2, 256, I, -1, 0 );

.INP $(0,8,1,0,-1)$;

INV( 1 , INV 35, 0, 2, 3, 16, 1, -1, 0 );

*INP $(0,8,2,0,-1)$;

.INV( 1 , INV36, I, 2, 0, 256, 1, -1, 0 );

..INP $(0,0,3,0,-1)$;

.INV( 1 , INV37, 1, 2, 1, 256, 1, -1, 0 );

..INP $(0,8,0,0,-1)$;

.INV( 1 , INV38, 1, 2, 2, 256, 1, -I, 0 );

..INP $(0,8,1,0,-1)$;

.INV( 1 , INV39, 1, 2, 3, 16, 1, 5, 0 );

*INP $(0,8,2,0,-I)$;

INV( 1 , INV40, 2, 2, 0, 256, 1, -1, 0 ); ..INP ( $0,0,3,0,-1)$;

INV( 1 , INV41, 2, 2, 1, 256, 1, -1, 0 );

..INP $(0,8,0,0,-1)$;

.INV( 1 , INV42, 2, 2, 2, 256, 1, -I, 0 );

..1NP $(0,8,1,0,-1)$;

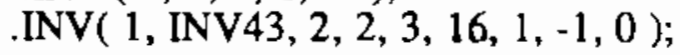


.INP $(0,8,2,0,-1)$;

INV( 1 , INV44, 3, 2, 0, 256, 1, -1, 0 ); ..INP $(0,0,3,0,-1)$;

INV( 1 , INV45, 3, 2, 1, 256, 1, -1, 0 ); ..INP $(0,8,0,0,-1)$;

INV( 1 , INV46, 3, 2, 2, 256, 1, +1, 0 ); ..INP $(0,8,1,0,-1)$;

.INV( $1, \operatorname{INV} 47,3,2,3,64,1,6,0)$;

.INP $(0,8,2,0,-1)$;

INV( $1, \operatorname{INV} 48,3,3,0,256,1,-1,0)$; .INP $(0,2,3,0,-1)$;

INV( 1 , INV49, 3, 3, 1, 256, 1, -1, 0 );

.INP $(0,8,0,0,-1)$;

INV( 1, INV50, 3, 3, 2, 256, 1, -1, 0 );

..INP $(0,8,1,0,-1)$;

.INV( 1 , INV51, 3, 3, 3, 1, 1, -1, 0 );

$\because \operatorname{INP}(0,8,2,0,-1)$;

INV( 1, INVS2, 2, 3, 0, 256, 1, -1, 0 ); ..INP $(0,4,3,0,-1)$;

INV( 1 , INV 53, 2, 3, 1, 256, 1, -1, 0 ); .INP $(0,8,0,0,-1)$;

.INV( 1 , INV54, 2, 3, 2, 256, 1, -1, 0 ); .INP $(0,8,1,0,-1)$;

INV( 1 , INV55, 2, 3, 3, 1, 1, 7, 0 );

*.INP $(0,8,2,0,-1)$;

.INV( 1 , INV56, 1, 3, 0, 256, 1, -1, 0 ); ..INP $(0,4,3,0,-1)$;

INV( $1, \operatorname{INV} 57,1,3,1,256,1,-1,0)$; ..INP $(0,8,0,0,-1)$;

INV( 1 , INV58, 1, 3, 2, 256, 1, -1, 0 ); ..INP $(0,8,1,0,-1)$;

INV( 1 , INV59, 1, 3, 3, 1, 1, -1, 0 );

.INP $(0,8,2,0,-1)$;

INV( 1, INV60, 0, 3, 0, 256, 1, -1, 0);

..INP $(0,4,3,0,-1)$;

INV( 1 , INV61, 0, 3, 1, 256, 1, -1, 0 );

.INP $(0,8,0,0,-1)$;

INV( 1, INV62, 0, 3, 2, 256, 1, -1, 0 );

.INP $(0,8,1,0,-1)$;

INV( 1 , INV63, 0, 3, 3, 64, 1, 8, 0 );

.INP $(0,8,2,0,-1)$;

.DATA (INV64.DAT);

.OUTFILE(INV $4 \times 4 \times 4$.OUT);

DUMP ( 0, INPUT, \%-7s, \%-7d, IN, 0, 0, 0, 0);

.DUMP ( 1 , INV7, \%-6s, \%-6d, OUT, 1, 0, 3, 0); 
180

.DUMP ( 2 , INV15, \%-7s, \%-7d, OUT, 3, 0, 3, 0 );

.DUMP ( 3 , INV23, \%-7s, \%-7d, OUT, 2, 1, 3, 0 );

.DUMP ( 4, INV31, \%-7s, \%-7d, OUT, 0, 1, 3, 0);

.DUMP ( 5 , INV39, \%-7s, \%-7d, OUT, 1, 2, 3, 0 );

.DUMP ( 6, INV47, \%-7s, \%-7d, OUT, 3, 2, 3, 0);

.DUMP ( 7, INV55, \%-7s, \%-7d, OUT, 2, 3, 3, 0 );

.DUMP ( 8, INV63, \%-7s, \%-7d, OUT, 0, 3, 3, 0); 


\section{4-inverter Chain in $8 \times 8$ Amay}

Chain of 64 inverters in 64 cells (INV64.NET)

.ARRAY $(8,8)$;

INV( 1, INV0, 0, 0, 0, 16, 1, -1, 0 ); ..INP ( $0,0,-1,0,0,0$, Input );

INV( $1, \operatorname{INV} 1,1,0,0,16,1,-1,0)$; ..INP $(0,0,0,0,-1)$;

INV( $1, \operatorname{INV} 2,2,0,0,16,1,-1,0)$; ..INP $(0,0,0,0,-1)$;

INV( $1, \operatorname{INV} 3,3,0,0,16,1,-1,0)$; ..INP $(0,0,0,0,-1)$;

INV( 1, INV4, 4, 0, 0, 16, 1,-1, 0 ); ..INP $(0,0,0,0,-1)$;

.INV( 1, INV5, 5, 0, 0, 16, 1, -1, 0 ); ..INP $(0,0,0,0,-1)$;

.INV( 1, INV6, 6, 0, 0, 16, 1, -1, 0$)$; ..INP $(0,0,0,0,-1)$;

.INV( $1, \operatorname{INV} 7,7,0,0,64,1,1,0)$; .INP $(0,0,0,0,-1)$;

INV( 1, INV8, 7, 1, 0, 1, 1, -1, 0$)$; ..INP $(0,2,0,0,-1)$;

INV( 1 , INV9, 6, 1, 0, 1, 1, -1, 0$)$;

..INP $(0,4,0,0,-1)$;

.INV( 1 , INV10, 5, 1, 0, 1, 1,-1, 0$)$;

..INP $(0,4,0,0,-1)$;

INV( 1 , INV11, 4, 1, 0, 1, 1, -1,0);

..INP $(0,4,0,0,-1)$;

INV( 1 , INV12, 3, 1, 0, 1, 1, -1, 0 );

..INP ( 0, 4, 0, 0, -1);

INV( 1 , INV13, 2, 1, 0, 1, 1, -1, 0$)$;

..INP $(0,4,0,0,-1)$;

INV( $1, \operatorname{INV} 14,1,1,0,1,1,-1,0)$;

..INP $(0,4,0,0,-1)$;

INV( 1 , INV 15, 0, 1, 0, 64, 1, 2, 0 );

..INP $(0,4,0,0,-1)$;

INV( $1, \operatorname{INV} 16,0,2,0,16,1,-1,0)$;

..INP ( $0,2,0,0,-1)$;

INV ( $1, \operatorname{INV} 17,1,2,0,16,1,-1,0)$;

..INP $(0,0,0,0,-1)$;

INV( $1, \operatorname{INV} 18,2,2,0,16,1,-1,0)$;

..INP ( 0, 0, 0, 0, -1);

INV( $1, \operatorname{INV} 19,3,2,0,16,1,-1,0)$;

INP ( 0, 0, 0, 0, -1);

.INV( 1 , INV20, 4, 2, 0, 16, 1, -1, 0$)$;

..INP $(0,0,0,0,-1)$;

INV( $1, \operatorname{INV} 21,5,2,0,16,1,-1,0)$; 
. $\operatorname{INP}(0,0,0,0,-1) ;$
. $\operatorname{INV}(1, \operatorname{INV} 22,6,2,0,16,1,-1,0)$;
. $\operatorname{INP}(0,0,0,0,-1) ;$
. $\operatorname{INV}(1, \operatorname{INV} 23,7,2,0,64,1,3,0)$;
. $\operatorname{INP}(0,0,0,0,-1) ;$

.INV( 1, INV24, 7, 3, 0, 1, 1, -1, 0 ); ..INP $(0,2,0,0,-1)$;

$\operatorname{INV}(1, \operatorname{INV} 25,6,3,0,1,1,-1,0)$;

..INP $(0,4,0,0,-1)$;

.INV( 1 , INV26, 5, 3, 0, 1, 1, -1, 0);

.INP $(0,4,0,0,-1)$;

.INV( 1 , INV27, 4, 3, 0, 1, 1, -1, 0 );

.INP $(0,4,0,0,-1)$;

.INV( 1 , INV28, 3, 3, 0, 1, 1, -1, 0 );

..INP $(0,4,0,0,-1)$;

.INV( 1 , INV29, 2, 3, 0, 1, 1, -1, 0 );

..INP $(0,4,0,0,-1)$;

.INV( 1 , INV30, 1, 3, 0, 1, 1, -1, 0 );

..INP $(0,4,0,0,-1)$;

.INV( $1, \operatorname{INV} 31,0,3,0,64,1,4,0)$;

..INP $(0,4,0,0,-1)$;

.INV( 1 , INV32, $0,4,0,16,1,-1,0)$;

..INP $(0,2,0,0,-1)$;

.INV( 1 , INV33, 1, 4, 0, 16, 1, -I, 0 );

.INP $(0,0,0,0,-1)$;

.INV( 1 , INV34, 2, 4, 0, 16, 1, -1,0);

..INP $(0,0,0,0,-1)$;

INV( 1 , INV35, 3, 4, 0, 16, 1,-1, 0 );

.INP $(0,0,0,0,-1)$;

.INV( 1 , INV36, 4, 4, 0, 16, 1, -1,0);

..INP $(0,0,0,0,-1)$;

.INV( 1 , INV37, 5, 4, 0, 16, 1, -1, 0 );

..INP $(0,0,0,0,-1)$;

INV( $1, \operatorname{INV} 38,6,4,0,16,1,-1,0)$;

..INP $(0,0,0,0,-1)$;

.INV( $1, \operatorname{INV} 39,7,4,0,64,1,5,0)$;

..INP $(0,0,0,0,-1)$;

.INV( 1, INV40, 7, 5, 0, 1, 1, -1, 0);

..INP $(0,2,0,0,-1)$;

.INV( 1 , INV41, 6, 5, 0, 1, 1, -1, 0);

.INP $(0,4,0,0,-1)$;

.INV( 1 , INV42, 5, 5, 0, 1, 1, -1, 0);

..INP $(0,4,0,0,-1)$;

.INV( 1 , INV43, 4, 5, 0, 1, 1, -1, 0 );

.INP $(0,4,0,0,-1)$;

.INV( 1 , INV44, 3, 5, 0, 1, 1, -1, 0 );

.INP $(0,4,0,0,-1)$;

.INV( 1 , INV45, 2, 5, 0, 1, 1, -1,0); 


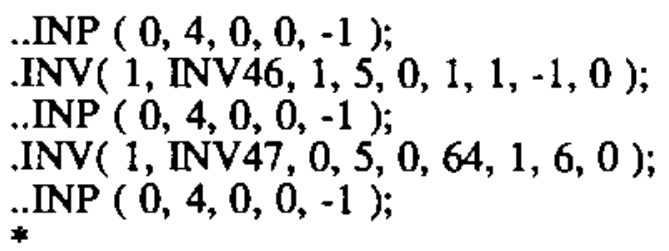

.INV( $1, \operatorname{INV} 48,0,6,0,16,1,-1,0)$; .INP $(0,2,0,0,-1)$;

.INV( 1 , INV49, 1, 6, 0, 16, 1, -1, 0 ); ..INP $(0,0,0,0,-1)$;

INV( 1 , INV50, 2, 6, 0, 16, 1, -1, 0 ); ..INP $(0,0,0,0,-1)$;

INV( 1 , INV51, 3, 6, 0, 16, 1, -1, 0 );

..INP $(0,0,0,0,-1)$;

.INV( 1 , INV52, 4, 6, 0, 16, 1, -1, 0 );

..INP $(0,0,0,0,-1)$;

.INV( 1, INV53, 5, 6, 0, 16, 1, -1, 0 ); ..INP $(0,0,0,0,-1)$;

INV( 1, INV54, 6, 6, 0, 16, 1, -1, 0 ); ..INP $(0,0,0,0,-1)$;

.INV( 1 , INV55, 7, 6, 0, 64, 1, 7,0);

..INP $(0,0,0,0,-1)$;

.INV( 1, INV56, 7, 7, 0, 1, 1, -1, 0 );

..INP $(0,2,0,0,-1)$;

$\operatorname{INV}(1, \operatorname{INV} 57,6,7,0,1,1,-1,0)$;

.INP $(0,4,0,0,-1)$;

.INV( 1 , INV58, 5, 7, 0, 1, 1, -1, 0 );

..INP $(0,4,0,0,-1)$;

INV( $1, \operatorname{INV} 59,4,7,0,1,1,-1,0)$;

..INP $(0,4,0,0,-1)$;

INV( $1, \operatorname{INV60,3,7,~0,~1,~1,~-1,~} 0$ );

..INP $(0,4,0,0,-1)$;

INV( 1 , INV61, 2, 7, 0, 1, 1, -1, 0 );

.INP $(0,4,0,0,-1)$;

INV( 1, INV62, 1, 7, 0, 1, 1, -1, 0$)$;

.INP $(0,4,0,0,-1)$;

INV( 1 , INV63, 0, 7, 0, 64, 1, 8, 0);

$\ldots \operatorname{INP}(0,4,0,0,-1)$;

\section{.DATA( INV64.DAT);}

.OUTFILE(INV64.OUT);

DUMP ( 0, INPUT, \%-7s, \%-7d, IN, 0, 0, 0, 0 );

.DUMP ( 1 , INV7, \%-6s, \%-6d, OUT, 7, 0, 0, 0 );

.DUMP ( 2, INV15, \%-7s, \%-7d, OUT, 0, 1, 0, 0);

DUMP ( 3, INV23, \%-7s, \%-7d, OUT, 7, 2, 0, 0);

.DUMP ( 4, INV31, \%-7s, \%-7d, OUT, 0, 3, 0, 0);

.DUMP ( 5, INV39, \%-7s, \%-7d, OUT, 7, 4, 0, 0);

.DUMP ( 6, INV47, \%-7s, \%-7d, OUT, 0, 5, 0, 0);

DUMP ( 7, INV55, \%-7s, \%-7d, OUT, 7, 6, 0, 0);

.DUMP ( 8, INV63, \%-7s, \%-7d, OUT, 0, 7, 0, 0); 


\section{Pipeline Saturation Test 1}

Only the last file in the test (8-inputs) is included here.

Saturation test 1 ( 8 inputs)

ARRAY $(1,1)$;

.INV ( 1 , INV0, 0, 0, 0, 16, 1, 1, 0);

.INP $(0,0,-1,0,0,0$, IN);

.INV ( 1 , INV1, 0, 0, 1, 16, 1, 2, 0);

.INP $(0,1,-1,0,-1)$;

.INV ( 1, INV2, 0, 0, 2, 16, 1, 3, 0);

..INP $(0,2,-1,0,-1)$;

INV ( 1 , INV3, 0, 0, 3, 16, 1, 4, 0);

..INP $(0,3,-1,0,-1)$;

.INV ( 1, INV4, 0, 0, 4, 16, 1, 5, 0);

...INP $(0,4,-1,0,-1)$;

.INV ( 1, INV $5,0,0,5,16,1,6,0)$;

..INP $(0,5,-1,0,-1)$;

.$I N V(1$, INV6, 0, 0, 6, 16, 1, 7, 0);

..INP $(0,6,-1,0,-1)$;

.INV $(1$, INV7, $0,0,7,16,1,8,0)$;

.INP $(0,7,-1,0,-1)$;

DATA ( TOGGLE.DAT);

.OUTFILE ( SAT1_8.OUT );

.DUMP ( $0, \mathrm{IN}, \% 3 \mathrm{~s}, \% 3 \mathrm{~d}, \mathrm{IN}, 0,0,0,0)$;

.DUMP ( 1, INV0, $\% 4 s, \% 4 d$, OUT, $0,0,0,0)$;

.DUMP ( 2 INV $1, \% 4 s, \% 4 d$, OUT, $0,0,1,0)$;

.DUMP ( 3 ,INV2,\%4s, \%4d,OUT, $0,0,2,0)$;

.DUMP ( 4,INV3,\%4s, \%4d, OUT, $0,0,3,0$ );

.DUMP ( 5 ,INV4,\%4s, \%4d,OUT, $0,0,4,0)$;

.DUMP ( 6, INV 5,\%4s, \%4d,OUT, $0,0,5,0)$;

.DUMP ( 7, INV6,\%4s, \%4d,OUT, $0,0,6,0)$;

.DUMP ( 8, INV7, \% 4s, \%4d,OUT, $0,0,7,0)$; 


\section{Pipeline Saturation Test 2}

Only the last file in the test (8-inputs) is included here.

Saturation test 2 ( 8 inputs)

.ARRAY $(1,1)$;

INV ( 1 , INV0, 0, 0, 0, 16, 1, 1, 0);

.INP $(0,0,-1,0,0,0$, IN);

INV ( 1 , INV $1,0,0,1,16,1,2,0)$;

.INP $(0,0,-1,0,-1)$

.INV ( 1, INV2, $0,0,2,16,1,3,0)$;

..INP $(0,0,-1,0,-1)$;

.INV ( $1, \operatorname{INV} 3,0,0,3,16,1,4,0)$;

..INP $(0,0,-1,0,-1)$;

INV ( 1, INV4, 0, 0, 4, 16, 1, 5, 0);

.INP $(0,0,-1,0,-1)$;

.INV ( 1 , INV 5, $0,0,5,16,1,6,0)$;

..INP $(0,0,-1,0,-1)$;

INV ( 1 , INV6, 0, 0, 6, 16, 1, 7, 0);

.INP $(0,0,-1,0,-1)$;

INV ( 1, INV7, 0, 0, 7, 16, 1, 8, 0);

.INP $(0,0,-1,0,-1)$;

DATA (TOGGLE.DAT);

.OUTFILE ( SAT2_8.OUT);

.DUMP ( 0,IN, \% 3s, \%3d,IN, $0,0,0,0)$;

.DUMP ( 1 ,INV0,\%4s, \%4d,OUT, $0,0,0,0$ );

.DUMP ( 2,INV1,\%4s, \%4d,OUT,0,0,1,0);

.DUMP ( 3 ,INV2,\%4s, \%4d,OUT,0,0,2,0);

.DUMP ( 4,INV3,\%4s, \%4d,OUT, $0,0,3,0$ );

.DUMP ( 5 ,INV4,\%4s, \%4d, OUT, $0,0,4,0$ );

.DUMP ( 6 ,INV5,\%4s, \%4d,OUT, $0,0,5,0$ );

.DUMP ( 7,INV6,\%4s, \%4d,OUT, $0,0,6,0$ );

.DUMP ( 8,INV7, \%4s, \%4d,OUT,0,0,7,0); 


\section{Zero-delay path test}

Only the last file (8 WIRE elements) is included here.

Two inverters - 8 wires (PATHTST8.NET) .ARRAY $(10,1)$;

.INV ( 1 , INV $0,0,0,0,16,1,-1,0)$;

.INP $(0,0,-1,0,0,0$, IN );

.WIRE ( 1 , WIRE0, 1, 0, 0, 16, 0,-1, 0);

..INP $(0,0,0,0,-1)$;

.WIRE ( 1 , WIRE $1,2,0,0,16,0,-1,0)$;

.INP $(0,0,0,0,-1)$;

.WIRE ( 1 , WIRE2, 3, 0, 0, 16, 0,-1,0);

..INP $(0,0,0,0,-1)$;

.WIRE ( 1 , WIRE3, 4, 0, 0, 16, 0, -1, 0 );

..INP $(0,0,0,0,-1)$;

.WIRE ( 1 , WIRE4, 5, 0, 0, 16, 0, -1, 0);

..INP ( $0,0,0,0,-1)$;

.WIRE ( 1 , WIRE5, 6, 0, 0, 16, 0, -1, 0 );

.INP $(0,0,0,0,-1)$;

.WIRE ( 1 , WIRE6, 7, $0,0,16,0,-1,0)$;

..INP $(0,0,0,0,-1)$;

.WIRE ( 1 , WIRE7, 8, $0,0,16,0,-1,0)$;

..INP $(0,0,0,0,-1)$;

.INV ( 1 , OUT, $9,0,0,16,1,1,0)$;

..INP $(0,0,0,0,-1)$;

DATA (INV.DAT);

.OUTFILE(PATHTST8.OUT);

.DUMP(0,IN,\%3s, \%3d,IN $, 0,0,0,0)$;

.DUMP(1,OUT,\%4s, \%4d,OUT, $9,0,0,0)$; 
Cross-coupled NAND.

SR Flip-Flop in two nodes (SR2.NET)

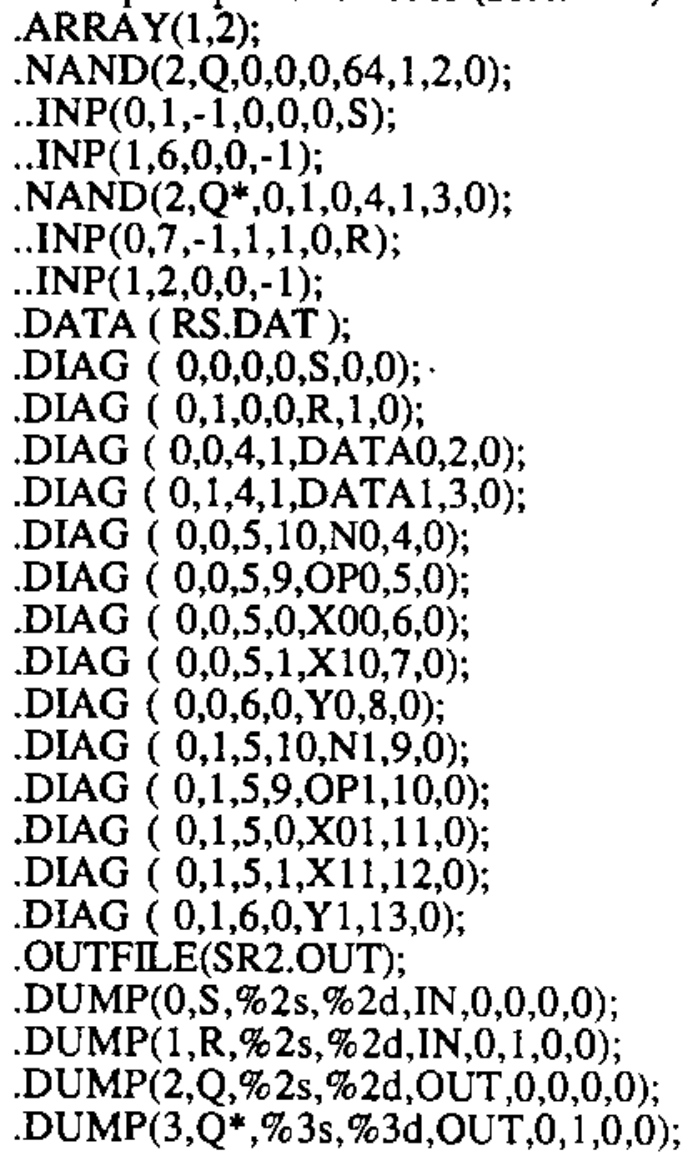


RET D Flip-Flop.

Rising edge trig D FF (RETDFF.NE')

.ARRAY $(3,2)$;

*

.NAND $(2, X, 0,0,0,16,1,-1,0)$;

..INP $(0,6,0,0,-1)$;

..INP(1,4,1,0,-1);

.BUF(1,BUF0,1,0,0,416,1, 1,0);

..INP( $0,2, r 1,1,1,0$, CLR $)$;

.NAND $(3, Y, 1,0,1,81,1,-1,0)$;

..INP(0,6,0,0,-1);

..INP $(1,0,0,0,-1)$;

..JNP $(2,8,0,0,-1)$;

$\star$

.NAND $(2, Q, 2,0,0,64,1,3,0)$;

..INP(0,0,1,0,-1);

..INP( $(1,6,0,0,-1)$;

.NAND $(3, Z, 0,1,0,20,1,-1,0)$;

..INP $(0,6,-1,2,2,0, D)$;

..INP(1,4,1,0,-1);

..INP(2,3,0,0,-1);

.BUF $(1, B U F 1,1,1,0,260,1,-1,0)$;

..INP( $(0,6,-1,0,0,0$, CLK $)$;

.NAND $(3, \mathrm{~W}, 1,1,1,17,1,-1,0)$;

..INP $(0,0,0,0,-1)$;

..INP(1,8,0,0,-1);

..INP $(2,2,1,0,-1)$;

.NAND $\left(3, Q^{*}, 2,1,0,4,1,4,0\right)$;

..INP $(0,0,1,0,-1)$;

..INP( $(1,1,0,0,-1)$;

..INP $(2,2,0,0,-1)$;

.DATA(RETDFF.DAT);

.OUTFILE(RETDFF.OU'T);

.DUMP(0,CLK, \%4s, \%4d,IN , 1, 1,0,0);

.DUMP(1,CLR,\% 4s, \%4d, IN, 1,0,0,0);

.DUMP(2,D,\%2s, \%2d,IN, 0, 1,0,0);

.DUMP(3,Q,\%2s, \%2d,OUT, $2,0,0,0)$;

. $\operatorname{DUMP}\left(4, \mathrm{Q}^{*}, \% 3 \mathrm{~s}, \% 3 \mathrm{~d}, \mathrm{OUT}, 2,1,0,0\right)$; 


\section{4-bit Counter.}

4-Bit Binary Counter (COUNTER.NET) ARRAY $(6,5)$;

*********************************************** $\mathrm{A}$ *

.XOFF(1);

YOFF(0);

*

$\operatorname{NAND}(3, \mathrm{~W}, 0,0,0,64,1,-1,0)$;

..INP $(0,6,0,0,-1)$;

..INP( $(1,5,-1,0,0,0$, CLK);

.INP $(2,4,0,0,-1)$;

*

NAND $(3, Y, 1,0,0,65,1,-1,0)$;

..INP( $0,7,-1,0,-1)$;

..INP(1,6,0,0,-1);

..INP( $2,5,-1,1,1,0$, CLR $)$;

NAND $(3, Z, 0,1,0,20,1,-1,0)$;

..INP $(0,2,0,0,-1)$;

..INP $(1,6,0,0,-1) ; \quad$ *D

..INP $(2,5,-1,1,-1)$;

$\operatorname{NAND}\left(3, Q^{*}, 0,1,1,48,1,-1,0\right)$;

..INP $(0,1,-1,1,-1)$;

..INP(1,2,0,0,-1);

..INP $(2,4,1,0,-1)$;

$\operatorname{NAND}(2, X, 1,1,0,4,1,-1,0)$;

.INP $(0,0,0,0,-1)$;

...INP $(1,2,0,0,-1)$;

$\operatorname{NAND}(2, \mathrm{Qa}, 1,1,1,65,1,2,0)$;

..INP $(0,0,1,0,-1)$;

..INP $(1,2,0,0,-1)$

**************************************************

*********************************************** $\mathrm{B}$ *

.XOFF(3);

YOFF(0);

k

$\operatorname{NAND}(3, \mathrm{~W}, 0,0,0,64,1,-1,0)$;

..INP $(0,6,0,0,-1)$;

..INP( $(1,5,-1,0,-1)$;

.INP $(2,4,0,0,-1)$;

NAND $(3, Y, 1,0,0,65,1,-1,0)$;

..INP $(0,7,-1,0,-1)$;

..INP $(1,6,0,0,-1)$;

..INP( $(2,5,-1,1,-1)$;

$\operatorname{NAND}(3, Z, 0,1,0,20,1,-1,0)$;

..INP $(0,2,0,0,-1)$; 


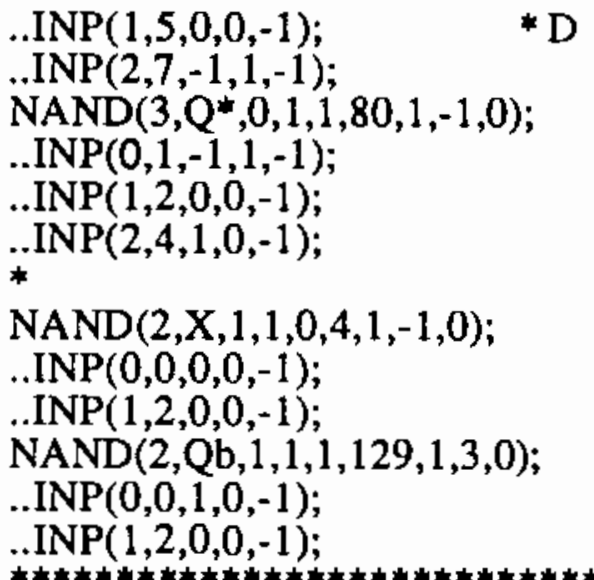

AND $(2, \mathrm{~A} 1,0,0,0,16,1,-1,0)$; ..INP( $0,4,5,0,-1)$; ..INP $(1,4,4,0,-1)$;

$\operatorname{AND}(2, \mathrm{~A} 0,0,0,1,16,1,-1,0)$; ..INP $(0,4,6,0,-1)$; ..INP $(1,4,4,0,-1)$;

*

OR(4,DA, 1,0,0,4,1,-1,0);

..INP( $0,0,0,0,-\mathrm{I})$;

..INP $(1,8,2,0,-1)$;

..INP $(2,4,0,0,-1)$;

..INP( $3,0,1,0,-1)$;

OR $(2, D C, 1,0,1,64,1,-1,0)$;

..INP(0,8,3,0,-1);

..INP $(1,4,1,0,-1)$;

$\operatorname{AND}(2, \mathrm{~A} 2,1,0,2,256,1,-1,0)$;

..INP $(0,4,5,0,-1)$;

...INP( $(1,4,2,0,-1)$;

$\operatorname{AND}(2, \mathrm{Cl}, \mathrm{I}, 0,3,256,1,-1,0)$;

..INP $(0,4,3,0,-1)$;

..INP(I,4,4,0,-1);

WIRE(1,LINEQA, I,0,4,1,0,-1,0);

.INP $(0,4,2,0,-1)$;

WIRE(1,LINEQC* $1,0,5,1,0,-1,0)$;

..INP $(0,4,3,0,-1)$;

WIRE(1,LINEQB* $\mathrm{I}, 0,6,1,0,-1,0)$;

*INP $(0,4,7,0,-1)$;

AND $(4, A 3,2,0,0,1,1,-1,0)$;

..INP(0, I, I, $0,-1)$;

..INP( $(1,6,1,0,-1)$;

..INP(2,4,5,0,-1); 


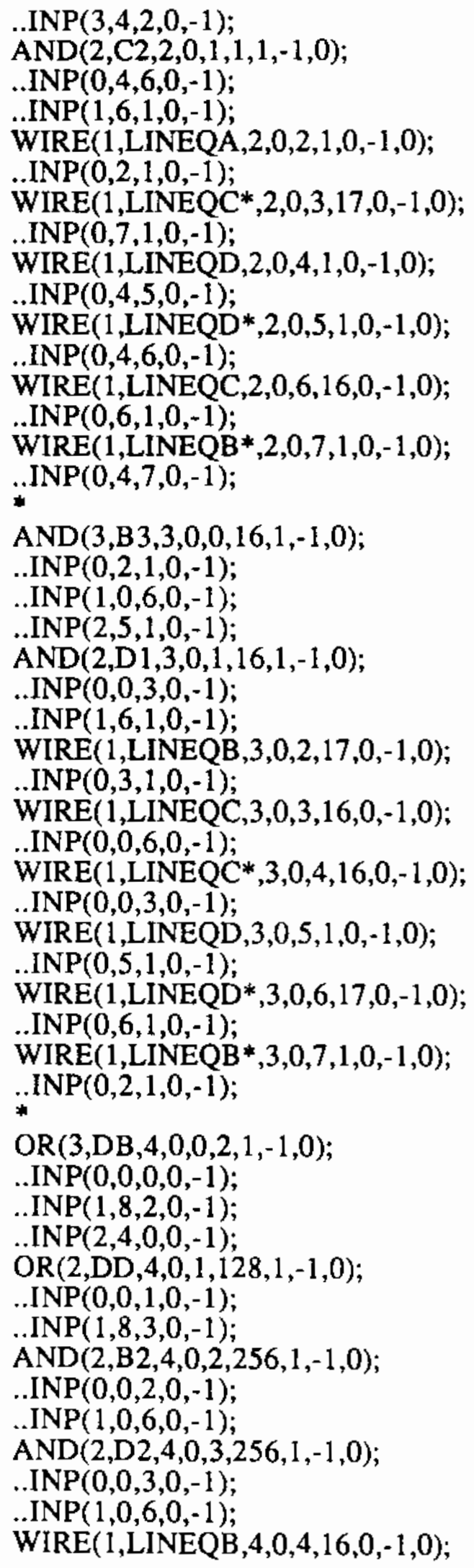


..INP(0,0,2,0,-1);

WIRE $(1$, LINEQC $* 4,0,5,16,0,-1,0)$;

..INP $(0,0,4,0,-1)$;

$+$

$\operatorname{AND}(2, \mathrm{~B} 1,5,0,0,1,1,-1,0)$;

..INP $(0,0,4,0,-1)$;

..INP $(1,0,5,0,-1)$

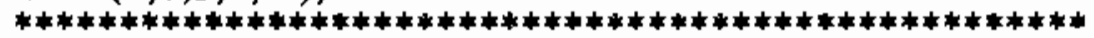

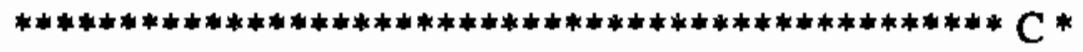

.XOFF(1);

YOFF(3);

$\star$

NAND $(3, Z, 0,0,0,80,1,-1,0)$;

..INP( $(0,2,1,0,-1)$;

*D

..INP( $1,6,0,0,-1)$;

..INP( $2,3,-1,1,-1)$;

$\operatorname{NAND}\left(3, \mathrm{Q}^{*}, 0,0,1,24,1,-1,0\right)$;

..INP $(0,6,0,0,-1)$;

..INP $(1,7,-1,1,-1)$;

..INP $(2,4,1,0,-1)$;

$\operatorname{NAND}(2, X, 1,0,0,64,1,-1,0)$;

..INP $(0,0,0,0,-1)$;

.INP $(1,6,0,0,-1)$;

$\operatorname{NAND}(2, \mathrm{Qc}, 1,0,1,5,1,4,0)$;

.INP $(0,0,1,0,-1)$;

.INP( $(1,6,0,0,-1)$;

$\operatorname{NAND}(3, \mathrm{~W}, 0,1,0,4,1,-1,0)$;

..INP $(0,2,0,0,-1)$;

..INP(1,3,-1,0,-1);

. $\operatorname{INP}(2,4,0,0,-1)$;

$\star$

$\operatorname{NAND}(3, Y, 1,1,0,5,1,-1,0)$;

..INP $(0,1,-1,0,-1)$;

.INP $(1,2,0,0,-1)$

..INP( $(2,3,-1,1,-1)$;

*

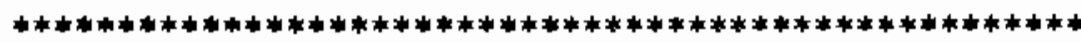

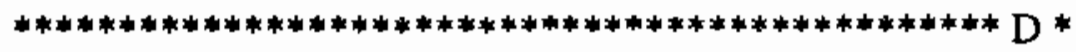

.XOFF(3);

YOFF(3);

*

$\operatorname{NAND}(3, Z, 0,0,0,80,1,-1,0)$;

..INP $(0,3,1,0,-1)$;

..INP(1,6,0,0,-1);

..INP(2,2,-1,1,-1);

$\operatorname{NAND}\left(3, Q^{*}, 0,0,1,20,1,-1,0\right)$;

..INP $(0,6,0,0,-1)$;

..INP $(1,7,-1,1,-1)$;

..INP $(2,4,1,0,-1)$; 
*

NAND $(2, X, 1,0,0,64,1,-1,0)$;

..INP $(0,0,0,0,-1)$;

..INP(1,6,0,0,-1);

NAND(2,Qd, 1,0,1,3,1,5,0);

..INP $(0,0,1,0,-1)$;

..INP(1,6,0,0,-1);

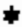

NAND(3,W, $0,1,0,4,1,-1,0)$;

..INP(0,2,0,0,-1);

..INP(1,3,-1,0,-1);

..INP $(2,4,0,0,-1)$;

NAND $(3, Y, 1,1,0,5,1,-1,0)$;

..INP(0,1,-1,0,-1);

..INP $(1,2,0,0,-1)$;

..INP(2,3,-1,1,-1);

*

.DA**********************1

.OUTFILE(COUNTER.OUT);

.DUMP(0,CLK, \%4s, \%4d,IN, $1,0,0,1)$;

.DUMP(1,CLR, \% 4s, \%4d,IN, 2,0,0,2);

.DUMP(2,CNT, \%4s,\%4d,OUT, 4,3,1,0,OUT,2,3,1,0, OUT, 4, 1, 1,0, OUT, $2,1,1,0)$; 
$\underline{2 \times 2 \text { Multiplier Amay }}$

$2 \times 2$ Multiplier Array (MULT2X2.NET)

.ARRAY $(4,4)$;

***********************************************$(0,0)$

.XFF(0);

YOFF(0);

*

SUMin

.WIRE(1,00 LINES0,0,0,0,368,0,-1,0);

..INP(0,1,-1,0,0,0,GND);

*

AND $(2,00 \sim$ AND0,1,0,0,449,1,-1,0);

..INP $(0,8,3,0,-1)$;

..INP $(1,8,2,0,-1)$;

*

.OR(2,00 OR0,1,0,1,64,1,-1,0);

..INP $(0,0,0,0,-1)$;

..INP $(1,8,0,0,-1)$;

*

.AND $(2,00 \sim$ AND 1,0,0,1,256,1,-1,0);

..INP $(0,8,0,0,-1)$;

..INP $(1,4,0,0,-1)$;

.WIRE(1,00 LINEC0,1,1,0,257,0,-1,0);

..INP $(0,4,1,0,-1)$;

.OR(3,00 OR $1,1,1,1,272,1,-1,0)$;

..1NP $(0,1,0,0,-1)$;

..INP(1,2,0,0,-1);

..1NP $(2,8,0,0,-1)$;

$*$

.AND $(3,00 \sim$ AND2, $0,1,0,256,1,-1,0)$;

..INP $(0,2,0,0,-1)$;

..INP(1,3,0,0,-1);

..INP(2,4,0,0,-1);

.AND $(2,00 \sim$ AND3, $1,1,2,2,1,-1,0)$;

..INP(0,8,0,0, -1);

..INP(1,2,1,0,-1);

.NOR $(2,00 \sim N O R 0,0,0,2,96,1,-1,0)$;

..INP $(0,8,1,0,-1)$;

..1NP $(1,5,2,0,-1)$;

*

.INV $(1,00 \sim$ Cout $, 0,1,1,64,1,-1,0)$;

..1NP $(0,2,2,0,-1)$;

*

.AND(2,00 AND4, 1,1,3,1,1,-1,0);

..INP(0,8,1,0,-1);

..INP $(1,1,2,0,-1)$;

Cout 
*

.NOR $(2,00 \sim N O R 1,0,1,2,16,1,-1,0)$;

..INP $(0,8,0,0,-1)$;

... INP $(1,4,3,0,-1)$;

*

.INV(1,00 SUMout, $1,1,4,32,1,-1,0)$;

..INP $(0,0,2,0,-1)$;

$*$

$\mathrm{Ai}$

.WIRE(1,00 LINEA $0,1,0,2,257,0,-1,0)$;

..INP $(0,4,3,0,-1)$;

*

.WIRE(1,00 LINEA 1,0,0,3,1,0,-1,0);

.INP $(0,4,2,0,-1)$;

*

.WIRE(1,00 LINEB0, 1,0,3,320,0,-1,0);

..INP $(0,2,-1,1,1,0, \mathrm{~B} 1)$;

*

.WIRE(1,00 LINEB 1,1,1,5,64,0,-1,0); ..INP $(0,2,3,0,-1)$;

$* * * * * * * * * * * * * * * * * * * * * * * * * * * * * * * * * * * * * * * * * * * * * * * * *)(1,0)$

XOFF(2);

YOFF(0);

.WIRE $(1,10 \sim$ LINES0,0,0,0,368,0, 1,0$)$;

..INP $(0,1,-1,0,-1)$;

AND (2,10 AND0,1,0,0,449,1,-1,0);

..INP $(0,8,3,0,-1)$;

..INP( $(1,8,2,0,-1)$;

*

.OR(2,10 OR0,1,0,1,64,1,-1,0);

..INP $(0,0,0,0,-1)$;

..INP $(1,8,0,0,-1)$

.AND(2,10 AND $1,0,0,1,256,1,-1,0)$;

..INP $(0,8,0,0,-1)$;

..INP $(1,4,0,0,-1)$;

*

WIRE(1,10 LINEC0,1,1,0,257,0,-1,0);

..INP $(0,4,-1,0,-1)$;

.OR(3,10 OR $1,1,1,1,272,1,-1,0)$;

..INP $(0,1,0,0,-1)$;

..INP $(1,2,0,0,-1)$;

.INP $(2,8,0,0,-1)$;

.AND $(3,10 \sim$ AND2, $0,1,0,256,1,-1,0)$;

..INP $(0,2,0,0,-1)$;

..INP( $(1,3,0,0,-1)$;

.INP $(2,4,0,0,-1)$ 
.AND $(2,10 \sim A N D 3,1,1,2,2,1,-1,0)$;

..INP $(0,8,0,0,-1)$;

..INP(1,2,1,0, -1);

.NOR $(2,10 \sim$ NOR0,0,0,2,96,1,-1,0);

..INP $(0,8,1,0,-1)$;

.INP(I,5,2,0,-1);

INV $(1,10 \sim$ Cout, $0,1,1,1,1,-1,0)$;

Cout

..INP $(0,2,2,0,-1)$;

.AND $(2,10 \sim$ AND4, $1,1,3,1,1,-1,0)$;

..INP $(0,8,1,0,-1)$;

..INP( $(1,1,2,0,-1)$;

.NOR(2,10 NOR1,0,1,2,16,1,-1,0);

..INP $(0,8,0,0,-1)$;

..INP $(1,4,3,0,-1)$;

$*$

.INV $(1, P 0,1,1,4,32,1,8,0)$;

SUMout (P0)

..INP(0,0,2,0,-1);

*

WIRE(1,10 LINEA0,1,0,2,257,0,-1,0);

..INP(0,3,-1,4,4,0,A0);

.WIRE(1,10 LINEA $1,0,0,3,1,0,-1,0)$;

..INP $(0,4,2,0,-1)$;

*

.WIRE(1,10 LINEB0,1,0,3,320,0,-1,0);

..INP $(0,2,-1,2,2,0, \mathrm{~B} 0)$;

.WIRE(1,10 LINEB 1, 1, 1,5,64,0,-1,0);

.INP $(0,2,3,0,-1)$

$\mathrm{XOFF}(0)$;

YOFF(2);

* SUMin

.WIRE(1,01 LINES0,0,0,0,368,0,-1,0);

..INP $(0,2,1,0,-1)$;

.AND (2,01 AND0,1,0,0,449,1,-1,0);

..INP( $(0,8,3,0,-1)$;

..INP(1,8,2,0,-1);

.OR $(2,01 \sim$ OR0,1,0,1,64,1,-1,0);

.INP $(0,0,0,0,-1)$

..INP(1,8,0,0,-1);

.AND $(2,01 \sim$ AND1 $1,0,0,1,256,1,-1,0)$;

..INP $(0,8,0,0,-1)$;

..INP( $(1,4,0,0,-1)$; 


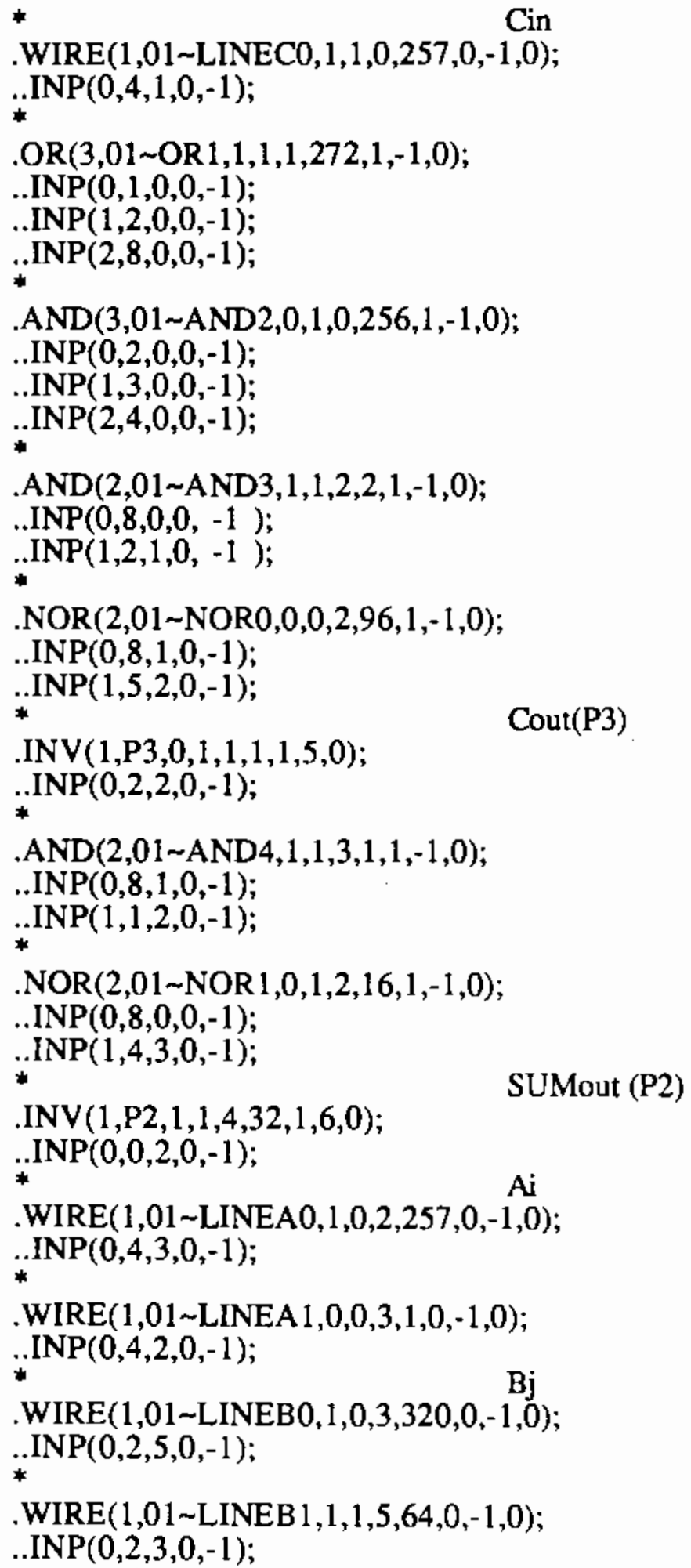


.WIRE(1,11 LINES0,0,0,0,368,0,-1,0);

..INP $(0,1,4,0,-1)$;

.AND $(2,11 \sim$ AND0,1,0,0,449,1,-1,0);

..INP(0,8,3,0,-1);

..INP(1,8,2,0,-1);

.OR $(2,11 \sim \mathrm{OR} 0,1,0,1,64,1,-1,0)$;

..INP $(0,0,0,0,-1)$;

.INP $(1,8,0,0,-1)$;

.AND $(2,11 \sim$ AND $1,0,0,1,256,1,-1,0)$;

..INP $(0,8,0,0,-1)$;

..INP( $(1,4,0,0,-1)$;

*

WIRE(1,11 LINEC0,1,1,0,257,0,-1,0);

.INP( $(0,4,-1,0,-1)$;

*

.OR $(3,11 \sim \mathrm{OR} 1,1,1,1,272,1,-1,0)$;

.INP $(0,1,0,0,-1)$;

..INP( $(1,2,0,0,-1)$;

.INP $(2,8,0,0,-1)$;

AND $(3,11 \sim \operatorname{AND} 2,0,1,0,256,1,-1,0)$;

..INP $(0,2,0,0,-1)$;

..INP( $(1,3,0,0,-1)$;

..INP $(2,4,0,0,-1)$;

$*$

.AND $(2,11 \sim$ AND $3,1,1,2,2,1,-1,0)$;

..INP(0,8,0,0,-1);

..INP(1,2,1,0,-1);

*

.NOR $(2,11 \sim N O R 0,0,0,2,96,1,-1,0)$;

..INP $(0,8,1,0,-1)$;

..INP( $(1,5,2,0,-1)$;

* Cout

INV $(1,11 \sim$ Cout, $0,1,1,1,1,-1,0)$;

..INP $(0,2,2,0,-1)$;

.AND $(2,11 \sim A N D 4,1,1,3,1,1,-1,0)$;

..INP $(0,8,1,0,-1)$;

..INP(1,1,2,0,-1);

.NOR(2,11 NOR $1,0,1,2,16,1,-1,0)$;

..INP $(0,8,0,0,-1)$;

..INP $(1,4,3,0,-1)$;

.INV $(1, P 1,1,1,4,32,1,7,0)$;

SUMout (P1)

..INP $(0,0,2,0,-1)$;

WIRE(1,11 -LINEA0,1,0,2,257,0,-1,0); 
\#.INP(0,3,-1,3,3,0,A1);

.WIRE(1,11 LINEA $1,0,0,3,1,0,-1,0)$;

..INP $(0,4,2,0,-1)$;

* $\mathrm{Bj}$

.WIRE(1,11 LINEB0,1,0,3,320,0,-1,0);

..INP(0,2,5,0,-1);

.WIRE $(1,11 \sim \operatorname{LINEB} 1,1,1,5,64,0,-1,0)$;

..INP(0,2,3,0,-1);

.DATA(MULT2X2.DAT);

.OUTFILE(MULT2X2.OUT);

.DUMP(0,A,\%2s, \%2d,IN,3,0,2,0,IN, 3,2,2,0);

.DUMP(1,B,\%2s, \%2d,IN, 3,0,3,0,IN, 1,0,3,0);

.DUMP(2,P, \%3s, \%3d,OUT, 3, 1,4,0,OUT, 3,3,4,0, OUT, I, 3,4,0, OUT, $0,3,1,0)$; 
$\underline{4 \times 4 \text { Multiplier Array }}$

4x4 Multiplier Array (MULT4X4.NET)

.ARRAY $(8,8)$;

*

* Column 0

*

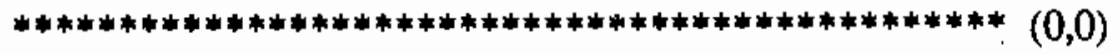

.XOFF(0);

YOFF(0);

*

.WIRE $(1,00$ - LINES0,0,0,0,368,0,-1,0);

.. INP(0,1,-1,8,-1);

.AND $(2,00 \sim$ AND0, $1,0,0,449,1,-1,0)$;

..INP $(0,8,3,0,-1)$;

..INP $(1,8,2,0,-1)$;

.OR $(2,00 \sim \mathrm{OR} 0,1,0,1,64,1,-1,0)$;

..INP $(0,0,0,0,-1)$;

..INP $(1,8,0,0,-1)$;

*

.AND(2,00 AND 1,0,0,1,256,1,-1,0);

..INP( $(0,8,0,0,-1)$;

..INP $(1,4,0,0,-1)$;

*

.WIRE $(1,00 \sim \operatorname{LINEC} 0,1,1,0,257,0,-1,0)$;

.INP $(0,4,1,0,-1)$;

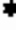

.OR $(3,00 \sim \mathrm{OR} 1,1,1,1,272,1,-1,0)$;

.INP $(0,1,0,0,-1)$;

..INP $(1,2,0,0,-1)$;

..INP(2,8,0,0,-1);

.AND(3,00 AND2,0,1,0,256,1,-1,0);

..INP $(0,2,0,0,-1)$;

.INP( $(1,3,0,0,-1)$;

.INP $(2,4,0,0,-1)$;

.AND $(2,00 \sim \operatorname{AND} 3,1,1,2,2,1,-1,0)$;

.INP( $(0,8,0,0,-1)$;

.. $\operatorname{INP}(1,2,1,0,-1)$;

.NOR(2,00 NOR0,0,0,2,96,1,-1,0);

..INP $(0,8,1,0,-1)$;

.INP $(1,5,2,0,-1)$;

.INV $(1,00 \sim$ Cout, $0,1,1,64,1,-1,0)$;

..INP(0,2,2,0,-1); 


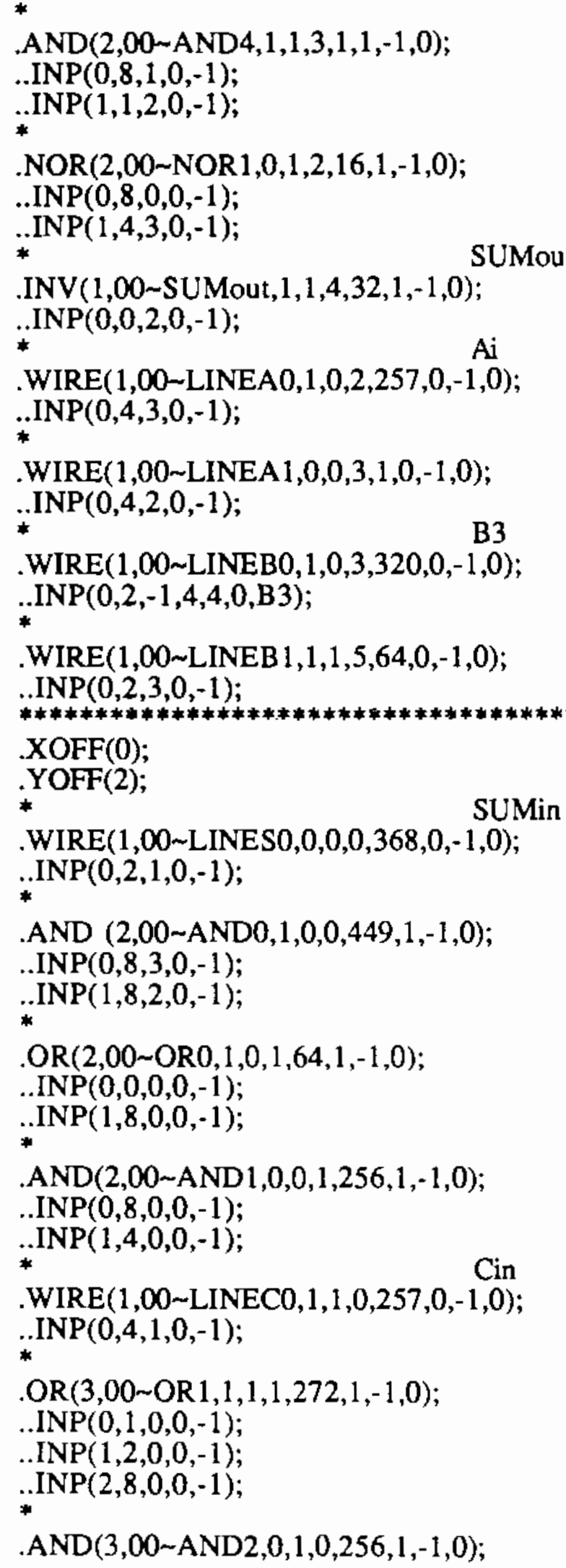


202

.. $\operatorname{INP}(0,2,0,0,-1)$;
.INP( $(1,3,0,0,-1)$;
..INP(2,4,0,0,-1);

.AND $(2,00 \sim$ AND $3,1,1,2,2,1,-1,0)$;

..INP(0,8,0,0, -1);

..INP(1,2,1,0, -1);

*

.NOR $(2,00 \sim N O R 0,0,0,2,96,1,-1,0)$;

..INP(0,8,1,0,-1);

..INP(1,5,2,0,-1);

.INV(1,00 Cout, $0,1,1,64,1,-1,0)$;

.INP $(0,2,2,0,-1)$;

.AND $(2,00 \sim \operatorname{AND} 4,1,1,3,1,1,-1,0)$;

..INP $(0,8,1,0,-1)$;

..INP $(1,1,2,0,-1)$;

.NOR(2,00 NOR $1,0,1,2,16,1,-1,0)$;

..INP( $(0,8,0,0,-1)$;

..INP $(1,4,3,0,-1)$

INV(1,00 SUMout, $1,1,4,32,1,-1,0)$;

..INP $(0,0,2,0,-1)$;

* Ai

.WIRE(1,00 LINEA0,1,0,2,257,0,-1,0);

..INP $(0,4,3,0,-1)$;

.WIRE(1,00 LINEA $1,0,0,3,1,0,-1,0)$;

..INP $(0,4,2,0,-1)$;

*

.WIRE(1,00 LINEB0,1,0,3,320,0,-1,0);

.INP(0,2,5,0,-I);

.WIRE(1,00 LINEB 1,1,1,5,64,0,-1,0);

..INP $(0,2,3,0,-\mathrm{I})$;

XOFF $(0)$

YOFF(4);

* SUMin

WIRE(I,00 LINES0,0,0,0,368,0,-1,0);

..INP $(0,2,1,0,-1)$;

$\downarrow$

AND $(2,00$ AND0,1,0,0,449,1,-1,0);

...INP $(0,8,3,0,-1)$;

..INP(I,8,2,0,-1);

.OR $(2,00 \sim$ OR0,1,0,1,64,1,-1,0);

..INP(0,0,0,0,-1);

..INP( $(1,8,0,0,-1)$; 
*

. $\operatorname{AND}(2,00 \sim \mathrm{AND} 1,0,0,1,256,1,-1,0)$;

..INP $(0,8,0,0,-1)$;

.INP( $(1,4,0,0,-1)$;

* Cin

.WIRE $(1,00-$ LINEC0,1,1,0,257,0,-1,0);

..INP $(0,4,1,0,-1)$;

.OR $(3,00-\mathrm{OR} 1,1,1,1,272,1,-1,0)$;

..INP $(0,1,0,0,-1)$;

..INP $(1,2,0,0,-1)$;

..INP( $(2,8,0,0,-1)$;

.AND $(3,00 \sim$ AND $2,0,1,0,256,1,-1,0)$;

.INP $(0,2,0,0,-1)$;

..INP $(1,3,0,0,-1)$;

.INP $(2,4,0,0,-1)$;

.AND $(2,00 \sim A N D 3,1,1,2,2,1,-1,0)$;

..INP(0,8,0,0, -1);

...INP(1,2,1,0,-1);

.NOR $(2,00-N O R 0,0,0,2,96,1,-1,0)$;

..INP $(0,8,1,0,-1)$;

..INP( $(1,5,2,0,-1)$;

INV(1,00-Cout, $0,1,1,64,1,-1,0)$;

.INP $(0,2,2,0,-1)$;

Cout

.AND $(2,00 \sim$ AND4, 1, 1,3,1,1,-1,0);

..INP $(0,8,1,0,-1)$;

..INP( $(1,1,2,0,-1)$;

.NOR $(2,00 \sim N O R 1,0,1,2,16,1,-1,0)$;

..INP $(0,8,0,0,-1)$;

..INP $(1,4,3,0,-1)$;

* SUMout

INV $(1,00 \sim$ SUMout, $1,1,4,32,1,-1,0)$;

* INP $(0,0,2,0,-1)$;

* $\mathrm{Ai}$

.WIRE $(1,00 \sim$ LINEA0, 1,0,2,257,0,-1,0);

..INP $(0,4,3,0,-1)$;

WIRE(1,00 LINEA $1,0,0,3,1,0,-1,0)$;

..INP $(0,4,2,0,-1)$;

* B3

.WIRE(1,00 LINEB0,1,0,3,320,0,-1,0);

..INP $(0,2,5,0,-1)$;

.WIRE(1,00 LINEB 1, 1,1,5,64,0,-1,0);

..INP $(0,2,3,0,-1)$; 
***********************************************$(0,3)$

.XOFF(0);

YOFF(6);

* SUMin

.WIRE(1,00 LINES0,0,0,0,368,0,-1,0);

$\because \operatorname{INP}(0,2,1,0,-1)$;

AND $(2,00 \sim$ AND0,1,0,0,449,1,-1,0);

..INP $(0,8,3,0,-1)$;

..INP $(1,8,2,0,-1)$;

.OR(2,00 OR0,1,0,1,64,1,-1,0);

..INP $(0,0,0,0,-1)$;

*INP(1,8,0,0,-1);

.AND $(2,00 \sim$ AND $1,0,0,1,256,1,-1,0)$;

..INP $(0,8,0,0,-1)$;

..INP $(1,4,0,0,-1)$

*

Cin

.WIRE $(1,00 \sim \operatorname{LINEC} 0,1,1,0,257,0,-1,0)$;

..INP $(0,4,1,0,-1)$;

.OR(3,00 OR $1,1,1,1,272,1,-1,0)$;

..INP $(0,1,0,0,-1)$;

..INP $(1,2,0,0,-1)$;

..INP $(2,8,0,0,-1)$;

$*$

.AND $(3,00 \sim$ AND2, $0,1,0,256,1,-1,0)$;

...INP $(0,2,0,0,-1)$;

..INP $(1,3,0,0,-1)$;

..INP $(2,4,0,0,-1)$;

$\star$

.AND (2,00 AND3, 1,1,2,2,1,-1,0);

..INP(0,8,0,0, -1);

..INP(1,2,1,0,-1);

.NOR(2,00 NOR0,0,0,2,96,1,-1,0);

..INP $(0,8,1,0,-1)$;

..INP(1,5,2,0,-1);

.INV $(1, \mathrm{P} 7,0, \mathrm{I}, 1,64,1,8,0)$;

Cout(P7)

.INP(0,2,2,0,-1);

.AND $(2,00 \sim$ AND4, $1,1,3,1,1,-1,0)$;

..INP $(0,8,1,0,-1)$;

..INP(1,1,2,0,-1);

.NOR $(2,00 \sim N O R 1,0,1,2,16,1,-1,0)$;

..INP $(0,8,0,0,-1)$;

.. INP $(1,4,3,0,-1)$; 


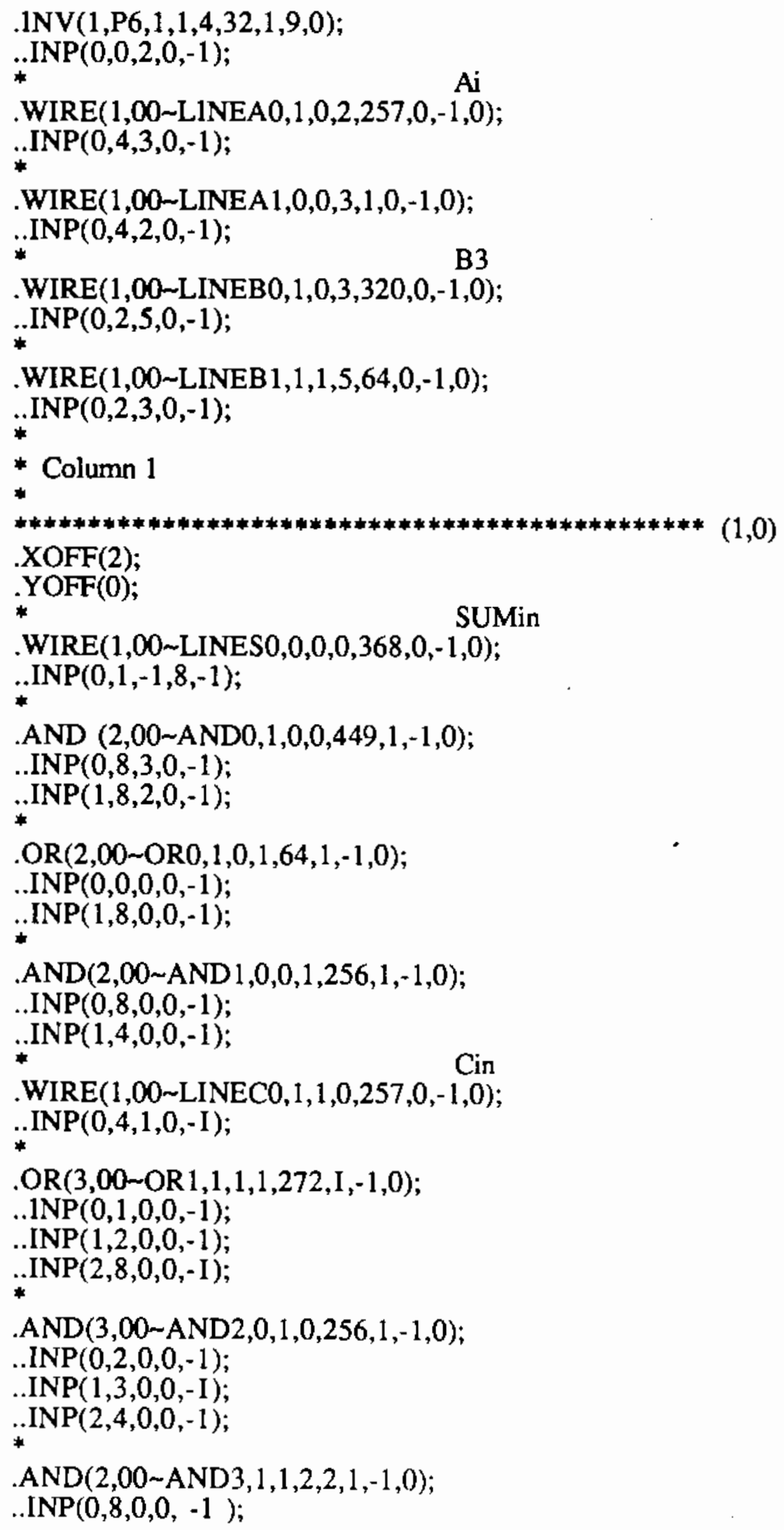


206

*.INP(1,2,1,0, -1);

.NOR(2,00 NOR0,0,0,2,96,1,-1,0);

..INP $(0,8,1,0,-1)$;

..INP $(1,5,2,0,-1)$;

* Cout

.INV $(1,00 \sim$ Cout $0,1,1,1,1,-1,0)$;

..INP( $(0,2,2,0,-1)$;

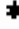

.AND $(2,00 \sim \operatorname{AND} 4,1,1,3,1,1,-1,0)$;

..INP $(0,8,1,0,-1)$;

..INP $(1,1,2,0,-1)$;

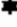

.NOR(2,00 NOR $1,0,1,2,16,1,-1,0)$;

..INP $(0,8,0,0,-1)$;

..INP $(1,4,3,0,-1)$;

.INV(1,00 SUMout, $1,1,4,32,1,-1,0)$;

.INP( $(0,0,2,0,-1)$;

* Ai

.WIRE(1,00 LINEA0,1,0,2,257,0,-1,0);

..INP $(0,4,3,0,-1)$;

.WIRE(1,00 LINEA 1,0,0,3,1,0,-1,0);

..INP $(0,4,2,0,-1)$;

SUMout

* B2

.WIRE(1,00 LINEB0,1,0,3,320,0,-1,0);

..INP(0,2,-1,5,5,0,B2);

.WIRE(1,00 LINEB 1,1,1,5,64,0,-1,0);

..INP( $(0,2,3,0,-1)$;

$* * * * * * * * * * * * * * * * * * * * * * * * * * * * * * * * * * * * * * * * * * * * * * * *)(1,1)$

XOFF(2);

$\operatorname{YOFF}(2)$;

SUMin

.WIRE(1,00 LINES0,0,0,0,368,0,-1,0);

..INP $(0,1,4,0,-1)$;

.AND $(2,00 \sim$ AND0, $1,0,0,449,1,-1,0)$;

..INP $(0,8,3,0,-1)$;

..INP $(1,8,2,0,-1)$;

*

.OR $(2,00 \sim 0 R 0,1,0,1,64,1,-1,0)$;

.INP $(0,0,0,0,-1)$;

..INP $(1,8,0,0,-1)$;

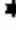

AND $(2,00 \sim$ AND $1,0,0,1,256,1,-1,0)$;

..INP( $(0,8,0,0,-1)$;

..INP( $(1,4,0,0,-1)$;

* Cin

.WIRE $(1,00 \sim \operatorname{LINEC} 0,1,1,0,257,0,-1,0)$; 


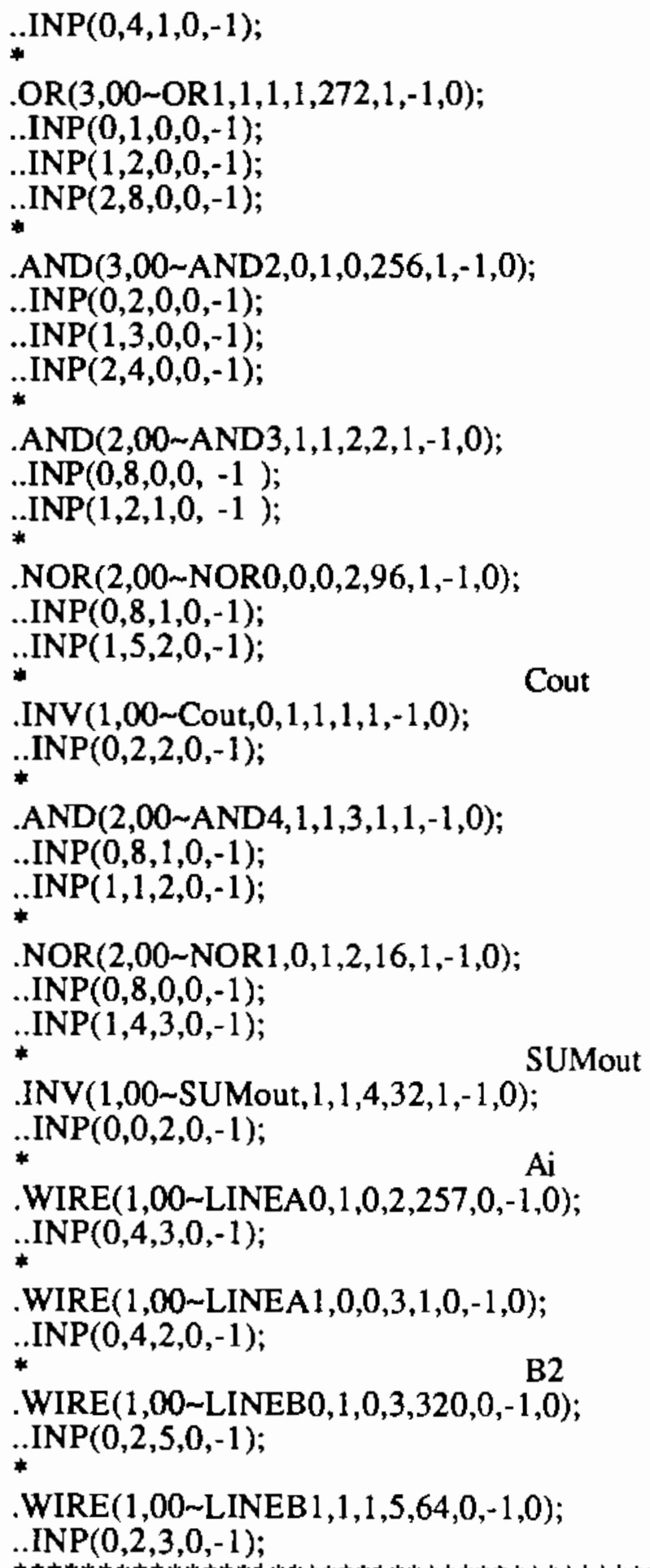


.AND $(2,00 \sim$ AND0,1,0,0,449,1,-1,0);

..INP $(0,8,3,0,-1)$;

..INP(1,8,2,0,-1);

.OR(2,00 OR0,1,0,1,64,1,-1,0);

..INP $(0,0,0,0,-1)$;

..INP $(1,8,0,0,-1)$;

.AND (2,00 AND1,0,0,1,256,1,-1,0);

..INP(0,8,0,0,-1);

..INP(1,4,0,0,-1);

* Cin

.WIRE $(1,00 \sim \operatorname{LINEC} 0,1,1,0,257,0,-1,0)$;

..INP $(0,4,1,0,-1)$;

.OR(3,00 OR $1,1,1,1,272,1,-1,0)$;

..INP( $(0,1,0,0,-1)$;

..INP(I,2,0,0,-1);

..INP $(2,8,0,0,-1)$;

AND(3,00 AND2,0,1,0,256,1,-1,0);

..INP $(0,2,0,0,-1)$;

..INP $(1,3,0,0,-1)$;

..INP $(2,4,0,0,-1)$;

.AND $(2,00-A N D 3,1,1,2,2,1,-1,0)$;

..INP(0,8,0,0, -1);

..INP(1,2,1,0,-1);

.NOR(2,00 NOR0,0,0,2,96,1,-1,0);

..INP $(0,8,1,0,-1)$;

..INP( $(1,5,2,0,-1)$;

* Cout

INV(1,00-Cout, $0,1,1,1,1,-1,0)$;

..INP( $(0,2,2,0,-1)$;

AND(2,00 AND4, 1,1,3,1,1,-1,0);

..INP $(0,8,1,0,-1)$;

..INP $(1,1,2,0,-1)$;

*

.NOR(2,00 NOR $1,0,1,2,16,1,-1,0)$;

..INP $(0,8,0,0,-1)$;

..INP $(1,4,3,0,-1)$;

* SUMout

.INV(1,00 SUMout, 1,1,4,32,1,-1,0);

.INP( $(0,0,2,0,-1)$;

* Ai

.WIRE(1,00 LINEA0, 1,0,2,257,0,-1,0);

..INP $(0,4,3,0,-1)$; 
.WIRE(1,00 LINEA $1,0,0,3,1,0,-1,0)$;

$\ldots$ INP $(0,4,2,0,-1)$;

.WIRE(1,00-LINEB0,1,0,3,320,0,-1,0);

.INP(0,2,5,0,-1);

.WIRE(1,00-LINEB 1,1,1,5,64,0,-1,0); ..INP $(0,2,3,0,-1)$;

************************************************$(1,3)$

XOFF(2);

.YOFF(6);

* SUMin

.WIRE(1,00 LINES0,0,0,0,368,0,-1,0);

..INP $(0,1,4,0,-1)$;

.AND (2,00 AND0,1,0,0,449,1,-1,0);

..INP $(0,8,3,0,-1)$;

..INP $(1,8,2,0,-1)$;

.OR(2,00 OR0,1,0,1,64,1,-1,0);

..INP $(0,0,0,0,-1)$;

.INP(1,8,0,0,-I);

.AND $(2,00 \sim$ AND $1,0,0,1,256,1,-1,0)$;

..INP $(0,8,0,0,-1)$;

.INP( $(1,4,0,0,-1)$;

* Cin

.WIRE $(1,00 \sim \operatorname{LINEC0}, 1,1,0,257,0,-1,0)$;

..INP $(0,4,1,0,-1)$;

.OR(3,00-OR $1,1,1,1,272,1,-1,0)$;

.IINP $(0,1,0,0,-1)$;

..INP $(1,2,0,0,-1)$;

..INP $(2,8,0,0,-1)$;

*

.AND $(3,00 \sim$ AND2, $0,1,0,256,1,-1,0)$;

..INP $(0,2,0,0,-1)$;

..INP $(1,3,0,0,-1)$;

..INP $(2,4,0,0,-\mathrm{I})$;

.AND $(2,00 \sim A N D 3,1, \mathrm{I}, 2,2,1,-1,0)$;

..INP(0,8,0,0, -1);

.. $\operatorname{INP}(1,2,1,0,-1)$;

.NOR $(2,00-N O R 0,0,0,2,96,1,-1,0)$;

..INP $(0,8,1,0,-1)$;

..INP(1,5,2,0,-1);

.INV $(1,00 \sim$ Cout $, 0,1,1,1,1,-1,0)$;

*.INP $(0,2,2,0,-\mathrm{I})$; 


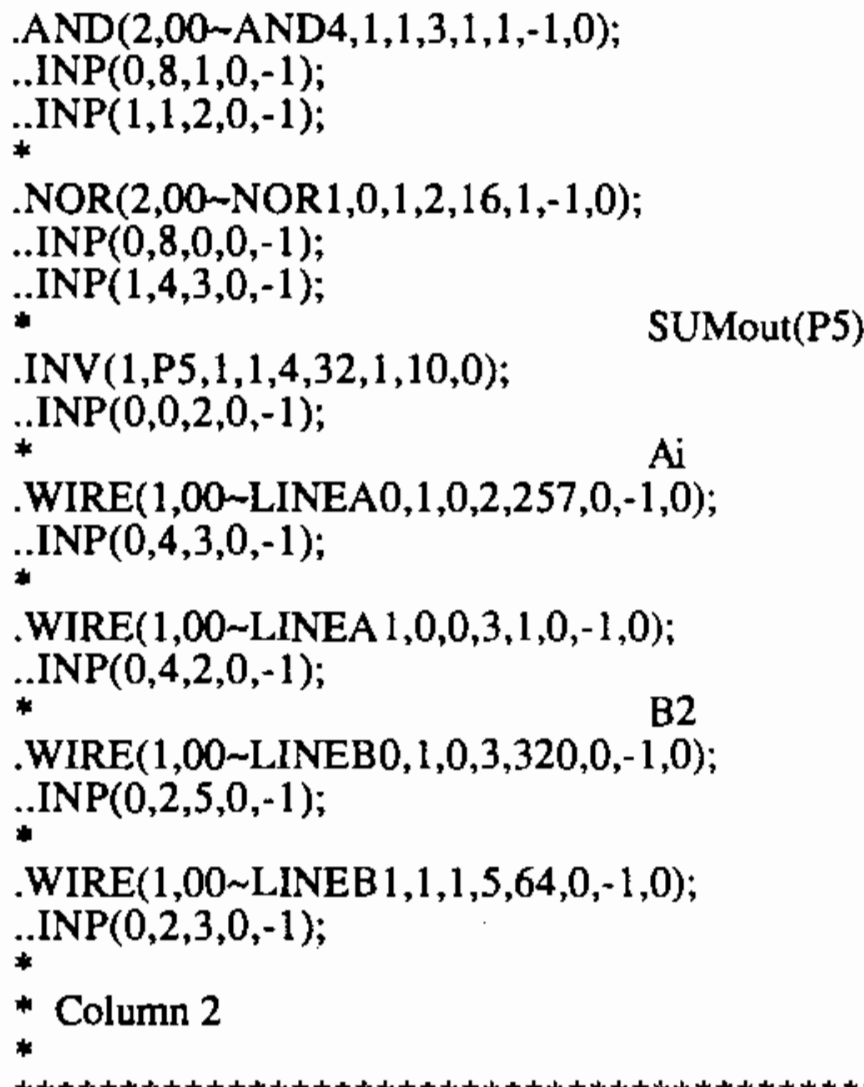

XOFF $(4)$

YOFF $(0)$;

* SUMin

.WIRE(1,00 LINES0,0,0,0,368,0,-1,0);

..INP(0,1,-1,8,-1);

.AND (2,00 AND0,1,0,0,449,1,-1,0);

..INP(0,8,3,0,-1);

..INP(1,8,2,0,-1);

.OR $(2,00 \sim \mathrm{OR} 0,1,0,1,64,1,-1,0)$;

..INP $(0,0,0,0,-1)$;

..INP(1,8,0,0,-1);

.AND $(2,00 \sim A N D 1,0,0,1,256,1,-1,0)$;

..INP( $0,8,0,0,-1)$;

..INP( $(1,4,0,0,-1)$;

* Cin

.WIRE(1,00 LINEC0,1,1,0,257,0,-1,0);

..INP $(0,4,1,0,-1)$;

.OR $(3,00 \sim \mathrm{OR} 1,1,1,1,272,1,-1,0)$;

..INP(0,1,0,0,-1);

..INP(1,2,0,0,-1);

.. INP $(2,8,0,0,-1)$; 
*

.AND $(3,00 \sim$ AND2 $, 0,1,0,256,1,-1,0)$;

..INP( $(0,2,0,0,-1)$;

..INP $(1,3,0,0,-1)$;

..INP $(2,4,0,0,-1)$;

.AND $(2,00 \sim A N D 3,1,1,2,2,1,-1,0)$;

.INP( $0,8,0,0,-1)$;

.INP $(1,2,1,0,-1)$;

.NOR(2,00 NOR0,0,0,2,96,1,-1,0);

..INP( $0,8,1,0,-1)$;

..INP $(1,5,2,0,-1)$;

* Cout

INV $(1,00 \sim$ Cout, $0,1,1,1,1,-1,0)$;

..INP $(0,2,2,0,-1)$;

*

.AND $(2,00 \sim$ AND $4,1,1,3,1,1,-1,0)$;

..INP $(0,8,1,0,-1)$;

..INP( $(1,1,2,0,-1)$;

.NOR $(2,00 \sim N O R 1,0,1,2,16,1,-1,0)$;

..INP $(0,8,0,0,-1)$;

..INP $(1,4,3,0,-1)$;

* SUMout

.INV(1,00 SUMout, $1,1,4,32,1,-1,0)$;

..INP $(0,0,2,0,-1)$;

* $\mathrm{Ai}$

.WIRE(1,00 LINEA0, 1,0,2,257,0,-1,0);

..INP $(0,4,3,0,-1)$;

WIRE(1,00 LINEA $1,0,0,3,1,0,-1,0)$

.INP $(0,4,2,0,-1)$;

* B1

.WIRE(1,00 LINEB0, 1,0,3,320,0,-1,0);

.INP $(0,2,-1,6,6,0, \mathrm{~B} 1)$;

.WIRE(1,00 LINEB 1,1,1,5,64,0,-1,0);

..INP $(0,2,3,0,-1)$;

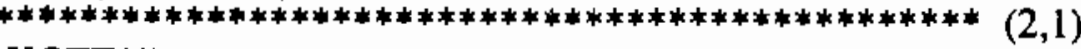

$\mathrm{XOFF}(4)$

YOFF(2);

* SUMin

.WIRE(1,00 LINES0,0,0,0,368,0,-1,0);

..INP $(0,1,4,0,-1)$;

AND $(2,00 \sim$ AND0,1,0,0,449,1, 1,0$)$;

..INP $(0,8,3,0,-1)$

..INP $(1,8,2,0,-1)$

.OR $(2,00 \sim \mathrm{OR} 0,1,0,1,64,1,-1,0)$; 
..INP $(0,0,0,0,-1)$;

..INP(1,8,0,0,-1);

.AND $(2,00 \sim A N D 1,0,0,1,256,1,-1,0)$;

..INP $(0,8,0,0,-1)$;

.INP $(1,4,0,0,-1)$;

* Cin

WIRE(1,00 LINEC0,1,1,0,257,0,-1,0);

..INP $(0,4,1,0,-1)$;

.OR(3,00 OR1,1,1,1,272,1,-1,0);

..INP $(0,1,0,0,-1)$;

..INP( $(1,2,0,0,-1)$;

.INP(2,8,0,0,-1);

.AND(3,00 AND2,0,1,0,256,1,-1,0);

..INP( $(0,2,0,0,-1)$;

..INP( $(1,3,0,0,-1)$;

..INP $(2,4,0,0,-1)$;

.AND $(2,00 \sim A N D 3,1,1,2,2,1,-1,0)$;

..INP( $(0,8,0,0,-1)$;

.INP(1,2,1,0,-1);

$\star$

.NOR $(2,00 \sim N O R 0,0,0,2,96,1,-1,0)$;

..INP $(0,8,1,0,-1)$;

..INP( $(1,5,2,0,-1)$;

* Cout

.INV $(1,00 \sim$ Cout $, 0,1,1,1,1,-1,0)$;

..INP $(0,2,2,0,-1)$;

$*$

.AND $(2,00 \sim \operatorname{AND} 4,1,1,3,1,1,-1,0)$;

..INP $(0,8,1,0,-1)$;

.INP( $(1,1,2,0,-1)$;

.NOR(2,00 NOR $1,0,1,2,16,1,+1,0)$;

..INP $(0,8,0,0,-1)$;

..INP $(1,4,3,0,-1)$;

SUMout

INV(1,00 SUMout, 1,1,4,32,1,-1,0);

..INP $(0,0,2,0,-1)$;

WIRE $(1,00$ LINEA0,1,0,2,257,0,-1,0)

..INP $(0,4,3,0,-1)$;

.WIRE(1,00 LINEA 1,0,0,3,1,0,-1,0);

*. INP $(0,4,2,0,-1)$;

.WIRE(1,00 LINEB0,1,0,3,320,0,-1,0);

*.INP(0,2,5,0,-1); 
.WIRE(1,00 LINEB $1,1,1,5,64,0,-1,0)$;

..INP $(0,2,3,0,-1)$;

***********************************************$(2,2)$

.XOFF(4);

.YOFF(4);

*

.WIRE(1,00 LINES0,0,0,0,368,0,-1,0);

.INP $(0,1,4,0,-1)$;

$*$

.AND $(2,00 \sim$ AND0,1,0,0,449,1,-1,0);

..INP( $(0,8,3,0,-1)$;

..INP( $(1,8,2,0,-1)$;

.OR $(2,00 \sim 0 R 0,1,0,1,64,1,-1,0)$;

.INP $(0,0,0,0,-1)$

..INP( $(1,8,0,0,-1)$;

.AND $(2,00 \sim$ AND $1,0,0,1,256,1,-1,0)$;

.INP $(0,8,0,0,-1)$;

..INP $(1,4,0,0,-1)$;

*

WIRE $(1,00$ - LINEC $0,1,1,0,257,0,-1,0)$;

..INP $(0,4,1,0,-1)$;

*

.OR $(3,00 \sim \mathrm{OR} 1,1,1,1,272,1,-1,0)$;

..INP $(0,1,0,0,-1)$;

..INP( $(1,2,0,0,-1)$;

..INP $(2,8,0,0,-1)$;

.AND $(3,00 \sim$ AND2, $0,1,0,256,1,-1,0)$;

..INP $(0,2,0,0,-1)$;

..INP $(1,3,0,0,-1)$;

... $\mathrm{NP}(2,4,0,0,-1)$;

*

.AND $(2,00 \sim A N D 3,1,1,2,2,1,-1,0)$;

..INP(0,8,0,0,-1);

..INP(1,2,1,0, -1);

.NOR $(2,00 \sim$ NOR0, $0,0,2,96,1,-1,0)$;

..INP $(0,8,1,0,-1)$; .INP( $(1,5,2,0,-1)$;

*

.INV $(1,00 \sim$ Cout $0,1,1,1,1,-1,0)$;

..INP $(0,2,2,0,-1)$;

.AND $(2,00 \sim A N D 4,1,1,3,1,1,-1,0)$;

..INP $(0,8,1,0,-1)$;

..INP( $(1,1,2,0,-1)$;

.NOR(2,00 NOR $1,0,1,2,16,1,-1,0)$;

..INP $(0,8,0,0,-1)$; 
$\ldots$..INP(1,4,3,0,-1);

SUMout

.INV(1,00-SUMout, $1,1,4,32,1,-1,0)$; .INP $(0,0,2,0,-1)$;

* Ai

.WIRE(1,00-LINEA0,1,0,2,257,0,-1,0);

..INP(0,4,3,0,-1);

.WIRE(1,00 LINEA $1,0,0,3,1,0,-1,0)$;

..INP $(0,4,2,0,-1)$;

* B I

.WIRE(1,00 LINEB0 $1,0,3,320,0,-1,0)$;

*.INP $(0,2,5,0,-1)$;

.WIRE(1,00 LINEB $1,1,1,5,64,0,-1,0)$;

..INP $(0,2,3,0,-1)$

$* * * * * * * * * * * * * * * * * * * * * * * * * * * * * * * * * * * * * * * * * * * * * * * * \quad(2,3)$

XOFF(4);

.YOFF(6);

*

SUMin

.WIRE(I,00 LINES $0,0,0,0,368,0,-1,0)$;

..INP $(0,1,4,0,-1)$;

*

AND $(2,00 \sim$ AND0,1,0,0,449,1,-1,0);

..INP(0,8,3,0,-1);

..INP $(1,8,2,0,-1)$;

*

.OR $(2,00 \sim 0 R 0,1,0,1,64,1,-1,0)$;

..INP $(0,0,0,0,-1)$;

..INP(1,8,0,0,-I);

*

.AND $(2,00 \sim$ AND $1,0,0,1,256,1,-1,0)$;

..INP $(0,8,0,0,-1)$;

..INP(1,4,0,0,-1);

*

.WIRE(I,00 LINEC $0,1,1,0,257,0,-1,0)$;

..INP(0,4,1,0,-1);

.OR $(3,00 \sim \mathrm{OR} 1,1,1,1,272,1,-1,0)$;

..INP $(0,1,0,0,-1)$;

..INP(1,2,0,0,-1);

..INP(2,8,0,0,-1);

.AND $(3,00 \sim$ AND2, $0,1,0,256,1,-1,0)$;

..INP $(0,2,0,0,-1)$;

..INP( $(1,3,0,0,-1)$

..INP $(2,4,0,0,-1)$;

.AND $(2,00 \sim$ AND3, $1,1,2,2,1,-1,0)$;

..INP( $0,8,0,0,-1)$;

..INP(1,2,1,0,-1); 
$\star$

.NOR(2,00 NOR0,0,0,2,96,1,-1,0);

..INP $(0,8,1,0,-1)$;

..INP(1,5,2,0,-1);

* Cout

.INV $(1,00 \sim$ Cout $, 0,1,1,1,1,-1,0)$;

..INP(0,2,2,0,-1);

.AND $(2,00 \sim$ AND4, 1,1,3,1,1,-1,0);

...INP $(0,8,1,0,-1)$;

..INP(1,1,2,0,-1);

.NOR $(2,00 \sim N O R 1,0,1,2,16,1,-1,0)$;

..INP $(0,8,0,0,-1)$;

..INP(1,4,3,0,-1);

.INV $(1, P 4,1,1,4,32,1,11,0)$;

SUMout(P4)

..INP $(0,0,2,0,-1)$;

*

.WIRE(I,00 LINEA0, 1,0,2,257,0,-1,0);

.INP $(0,4,3,0,-1)$;

.WIRE(1,00 LINEA1,0,0,3,1,0,-1,0);

..INP $(0,4,2,0,-1)$;

* B1

.WIRE(1,00 LINEB0,1,0,3,320,0,-1,0);

..INP $(0,2,5,0,-1)$;

$+$

.WIRE(1,00 LINEB $1,1,1,5,64,0,-1,0)$;

..INP $(0,2,3,0,-1)$;

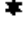

* Column 3

$*$

************************************************$(3,0)$

XOFF(6);

YYFF(0);

* SUMin

.WIRE(1,00 LINES0,0,0,0,368,0,-1,0);

*.INP( $0,1,-1,8,-1)$;

.AND $(2,00 \sim$ AND0, $1,0,0,449,1,-1,0)$;

.INP $(0,8,3,0,-1)$;

..INP( $(1,8,2,0,-1)$;

.OR $(2,00 \sim$ OR0 $1,0,1,64,1,-1,0)$;

..INP $(0,0,0,0,-1)$;

..INP $(1,8,0,0,-1)$;

*

.AND $(2,00 \sim$ AND1 $1,0,0,1,256,1,-1,0)$;

..INP( $(0,8,0,0,-1)$;

..INP $(1,4,0,0,-1)$; 
* WIRE(1,00 LINEC0 $1,1,0,257,0,-1,0)$;in

..INP $(0,4,-1,8,-1)$;

$\star$

.OR $(3,00 \sim \mathrm{OR} 1,1,1,1,272,1,-1,0)$;

..INP $(0,1,0,0,-1)$;

..INP(1,2,0,0,-1);

..INP(2,8,0,0,-1);

.AND $(3,00 \sim \operatorname{AND} 2,0,1,0,256,1,-1,0)$;

..INP $(0,2,0,0,-1)$;

..INP( $(1,3,0,0,-1)$;

$\ldots \operatorname{INP}(2,4,0,0,-1)$;

.AND $(2,00 \sim$ AND $3,1,1,2,2,1,-1,0)$;

..INP(0,8,0,0,-1);

*.INP(1,2,1,0,-1);

.NOR(2,00 NOR0,0,0,2,96,1,-1,0);

..INP $(0,8,1,0,-1)$;

.. INP(1,5,2,0,-1);

.INV $(1,00 \sim$ Cout $0,1,1,1,1,-1,0)$;

Cout

..INP(0,2,2,0,-1);

.AND $(2,00 \sim$ AND4, $1,1,3,1,1,-1,0)$;

..INP $(0,8,1,0,-1)$;

..INP( $(1,1,2,0,-1)$;

-

.NOR(2,00 NOR $1,0,1,2,16,1,-1,0)$;

..INP $(0,8,0,0,-1)$;

... $\operatorname{INP}(1,4,3,0,-1)$;

*

.INV $(1, \mathrm{P} 0,1,1,4,32,1,15,0)$;

SUMout(P0)

..INP $(0,0,2,0,-1)$;

$*$

.WIRE(1,00 LINEA0,1,0,2,257,0,-1,0);

.INP $(0,3,-1,3,3,0, A 0)$;

.WIRE( 1,00 LINEA1,0,0,3,1,0,-1,0);

..INP $(0,4,2,0,-1)$;

$*$

.WIRE(1,00 LINEB0,1,0,3,320,0,-1,0);

...INP $(0,2,-1,7,7,0, \mathrm{~B} 0)$;

.WIRE(1,00 LINEB $1,1,1,5,64,0,-1,0)$;

..INP $(0,2,3,0,-1)$

.XOFF(6);

YOFF(2); 
.WIRE(1,00 LINES0, $0,0,0,368,0,-1,0)$;

.$^{I N P}(0,1,4,0,-1)$;

.AND $(2,00 \sim$ AND0,1,0,0,449,1,-1,0);

..INP $(0,8,3,0,-1)$;

..INP $(1,8,2,0,-1)$;

.OR $(2,00 \sim$ OR0,1,0,1,64,1,-1,0);

..INP $(0,0,0,0,-1)$;

.INP(1,8,0,0,-1);

*

.AND $(2,00 \sim$ AND 1,0,0,1,256,1,-1,0);

..INP( $0,8,0,0,-1)$;

..INP $(1,4,0,0,-1)$;

* Cin

.WIRE(1,00 LINEC0, 1,1,0,257,0,-1,0);

.INP $(0,4,-1,8,-1)$;

.OR(3,00 OR $1,1,1,1,272,1,-1,0)$;

..INP $(0,1,0,0,-1)$;

..INP( $(1,2,0,0,-1)$;

..INP $(2,8,0,0,-1)$;

.AND $(3,00 \sim$ AND2, $0,1,0,256,1,-1,0)$;

.INP( $0,2,0,0,-1)$;

..INP $(1,3,0,0,-1)$;

.. $\operatorname{INP}(2,4,0,0,-1)$;

. $\operatorname{AND}(2,00 \sim \operatorname{AND} 3,1,1,2,2,1,-1,0)$;

..INP(0,8,0,0, -1 );

..INP(1,2,1,0, -1);

.NOR $(2,00 \sim$ NOR0,0,0,2,96, 1,-1,0);

..INP $(0,8,1,0,-1)$;

..INP $(1,5,2,0,-1)$;

* Cout

INV $(1,00 \sim$ Cout $0,1,1,1,1,-1,0)$;

..INP( $(0,2,2,0,-1)$;

.AND $(2,00 \sim A N D 4,1,1,3,1,1,-1,0)$;

..INP $(0,8,1,0,-1)$;

..INP(1,1,2,0,-1);

.NOR(2,00 NOR $1,0,1,2,16,1,-1,0)$;

..INP $(0,8,0,0,-1)$;

..INP $(1,4,3,0,-1)$;

.INV $(1, \mathrm{P} 1,1,1,4,32,1,14,0)$;

SUMout $(\mathrm{P} !)$

..INP( $(0,0,2,0,-1)$;

*

.WIRE(1,00 LINEA0,1,0,2,257,0,-1,0); 
218

$\ldots \operatorname{INP}(0,3,-1,2,2,0, \mathrm{~A} 1)$;

.WIRE(1,00 LINEA 1,0,0,3,1,0,-1,0);

..INP $(0,4,2,0,-1)$;

* B0

.WIRE(1,00 LINEB0,1,0,3,320,0,-1,0);

..INP $(0,2,5,0,-1)$;

.WIRE(1,00 LINEB 1, 1, 1,5,64,0,-1,0); ..INP $(0,2,3,0,-1)$;

.XOFF(6);

.YOFF(4);

* SUMin

.WIRE(1,00 LINES0, $0,0,0,368,0,-1,0)$;

..INP $(0,1,4,0,-1)$;

.AND $(2,00 \sim$ AND0,1,0,0,449,1,-1,0);

..INP $(0,8,3,0,-1)$;

..INP(1,8,2,0,-1);

.OR $(2,00-\mathrm{OR} 0,1,0,1,64,1,-1,0)$;

..INP $(0,0,0,0,-1)$;

. .INP( $(1,8,0,0,-1)$;

.AND $(2,00 \sim$ AND $1,0,0,1,256,1,-1,0)$;

..INP $(0,8,0,0,-1)$;

..INP $(1,4,0,0,-1)$;

*

.WIRE $(1,00 \sim \operatorname{LINEC0}, 1,1,0,257,0,-1,0)$;

.. INP $(0,4,-1,8,-1)$;

.OR(3,00 OR $1,1,1,1,272,1,-1,0)$;

..INP $(0,1,0,0,-1)$;

..INP(1,2,0,0,-1);

... INP $(2,8,0,0,-1)$;

. $\operatorname{AND}(3,00 \sim A N D 2,0,1,0,256,1,-1,0)$;

..INP(0,2,0,0,-1);

..INP $(1,3,0,0,-1)$;

..INP $(2,4,0,0,-1)$;

.AND $(2,00 \sim \operatorname{AND} 3,1,1,2,2,1,-1,0)$;

..INP(0,8,0,0, -1);

..INP(1,2,1,0, -1);

.NOR $(2,00 \sim N O R 0,0,0,2,96,1,-1,0)$;

..INP( $(0,8,1,0,-1)$;

..INP $(1,5,2,0,-1)$;

INV $(1,00 \sim$ Cout, $0,1,1,1,1,-1,0)$; 
..INP(0,2,2,0,-1);

.AND $(2,00 \sim$ AND4, 1, 1,3,1,1,-1,0);

..INP( $(0,8,1,0,-1)$;

..INP(1,1,2,0,-1);

.NOR(2,00 NOR $1,0,1,2,16,1,-1,0)$;

..INP $(0,8,0,0,-1)$;

..INP $(1,4,3,0,-1)$;

*

.INV $(1, \mathrm{P} 2,1,1,4,32,1,13,0)$;

SUMout(P2)

..INP $(0,0,2,0,-1)$;

* A2

.WIRE(1,00 LINEA0,1,0,2,257,0,-1,0);

..INP $(0,3,-1,1,1,0, \mathrm{~A} 2)$;

WIRE(1,00 LINEA1,0,0,3,1,0,-1,0);

..INP $(0,4,2,0,-1)$;

* B0

.WIRE (1,00 LINEB0, 1,0,3,320,0,-1,0);

..INP $(0,2,5,0,-1)$;

.WIRE(1,00 LINEB $1,1,1,5,64,0,-1,0)$;

...INP $(0,2,3,0,-1)$

***********************************************$(3,3)$

. $\mathrm{XOFF}(6)$;

YOFF(6);

*

.WIRE $(1,00 \sim$ LINES0, $0,0,0,368,0,-1,0)$;

.INP $(0,1,4,0,-1)$;

AND $(2,00 \sim$ AND0,1,0,0,449,1,-1,0);

..INP( $(0,8,3,0,-1)$;

..INP $(1,8,2,0,-1)$;

$\star$

.OR $(2,00 \sim$ OR $0,1,0,1,64,1,-1,0)$;

..INP $(0,0,0,0,-1)$;

..INP $(1,8,0,0,-1)$;

AND $(2,00 \sim$ AND $1,0,0,1,256,1,-1,0)$;

..INP $(0,8,0,0,-1)$;

..INP $(1,4,0,0,-1)$;

* Cin

WIRE(1,00 LINEC0,1,1,0,257,0,-1,0);

* INP $(0,4,-1,8,-1)$;

.OR(3,00 OR1,1,1,1,272,1,-1,0);

..INP(0,1,0,0,-1);

..INP(1,2,0,0,-1);

..INP $(2,8,0,0,-1)$; 


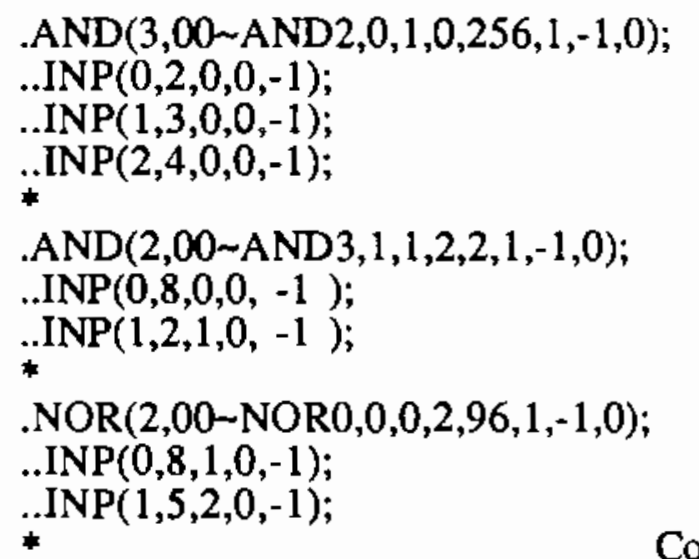

INV(1,00 Cout, $0,1,1,1,1,-1,0)$; 
APPENDIX E. Simulation Reports

Single Inverter.

SIMULATION REPORT

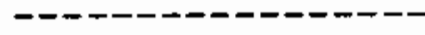

Circuit: Single Inverter (INV.NET)
Wed Feb 27 12:03:25 1991

SIMULATION DATA

Ckt Time IN OUT

$0.000 n s \quad x \quad x$

1.000ns $0 \mathrm{x}$

2.000ns 11

3.000ns 00

4.000 ns 11

5.000ns 00

$6.000 \mathrm{~ns} \quad 1 \quad 1$

$7.000 \mathrm{~ns} \quad 0 \quad 0$

$8.000 \mathrm{~ns} \quad 1 \quad 1$

9.000 ns 00

$10.000 \mathrm{~ns} 11$

$11.000 \mathrm{~ns} \quad 0 \quad 0$

$12.000 \mathrm{~ns} \quad 1 \quad 1$

$13.000 \mathrm{~ns} \quad 0 \quad 0$

$14.000 \mathrm{~ns} 11$

$15.000 \mathrm{~ns} 00$

$16.000 \mathrm{~ns} \quad 1 \quad 1$

$17.000 \mathrm{~ns} \quad 0 \quad 0$

18.000 ns 11

19.000 ns 00

20.000ns 11

PERFORMANCE

--------- -

Total simulation time $=8$.lus

Total circuit time $=21.0 \mathrm{~ns}$

Total events processed $=20$

Event throughput $=2.466 \mathrm{MHz}$ 
64-inverter chain (single cell)

SIMULATION REPORT

Thu Feb 28 11:05:06 1991

Circuit: Chain of 64 Inverters in one node (INV64.NET)

Complexity: 64 gates.

Array size: 1 cell.

SIMULATION DATA

Ckt Time INPUT INV7 INV15 INV23 INV31 INV39 INV47 INV55 INV63

\begin{tabular}{|c|c|c|c|c|c|c|c|c|}
\hline $0.000 \mathrm{~ns}$ & $\mathrm{x}$ & $\mathrm{x}$ & $\mathrm{X}$ & $\mathrm{x}$ & $\mathrm{X}$ & $\mathrm{x}$ & $\mathrm{x}$ & $\mathrm{X}$ \\
\hline $1.000 \mathrm{~ns}$ & 0 & $\mathrm{x}$ & $\mathrm{x}$ & $\mathrm{x}$ & $\mathrm{x}$ & $\mathrm{x}$ & $\mathrm{x}$ & $\mathrm{x}$ \\
\hline $2.000 \mathrm{~ns}$ & 1 & $\mathrm{x}$ & $\mathrm{x}$ & $\mathrm{x}$ & $\mathrm{x}$ & $x$ & $\mathrm{X}$ & $\mathrm{X}$ \\
\hline $3.000 \mathrm{~ns}$ & 0 & $\mathrm{x}$ & $\mathrm{x}$ & $\mathrm{x}$ & $\mathrm{x}$ & $\mathrm{x}$ & $\mathrm{x}$ & $\mathrm{x}$ \\
\hline $4.000 \mathrm{~ns}$ & 1 & $\mathrm{x}$ & $\mathrm{x}$ & $\mathrm{x}$ & $\mathrm{x}$ & $\mathrm{x}$ & $\mathrm{x}$ & $\mathrm{x}$ \\
\hline $5.000 \mathrm{~ns}$ & 0 & $\mathrm{x}$ & $\mathrm{x}$ & $\mathrm{x}$ & $\mathrm{x}$ & $\mathrm{x}$ & $\mathrm{x}$ & $\mathrm{x}$ \\
\hline $6.000 \mathrm{~ns}$ & 1 & $\mathrm{x}$ & $\mathrm{x}$ & $\mathrm{x}$ & $\mathrm{x}$ & $\mathrm{x}$ & $\mathrm{x}$ & $\mathrm{x}$ \\
\hline $7.000 \mathrm{~ns}$ & 0 & $\mathrm{x}$ & $\mathrm{x}$ & $\mathrm{x}$ & $\mathrm{x}$ & $\mathrm{x}$ & $\mathrm{x}$ & $\mathrm{x}$ \\
\hline $8.000 \mathrm{~ns}$ & 1 & $\mathrm{x}$ & $\mathrm{x}$ & $\mathrm{x}$ & $\mathrm{x}$ & $\mathrm{x}$ & $\mathrm{x}$ & $\mathrm{x}$ \\
\hline $9.000 \mathrm{~ns}$ & 0 & 0 & $\mathrm{x}$ & $\mathrm{x}$ & $\mathrm{x}$ & $\mathrm{x}$ & $\mathrm{x}$ & $\mathrm{x}$ \\
\hline $0.000 \mathrm{~ns}$ & 1 & 1 & $\mathrm{x}$ & $\mathrm{x}$ & $\mathrm{x}$ & $\mathrm{x}$ & $\mathrm{x}$ & $\mathrm{x}$ \\
\hline $1.000 \mathrm{~ns}$ & 0 & 0 & $\mathrm{x}$ & $\mathrm{x}$ & $\mathrm{x}$ & $\mathrm{x}$ & $\mathrm{x}$ & $\mathrm{x}$ \\
\hline $2.000 \mathrm{~ns}$ & 1 & 1 & $\mathrm{x}$ & $\mathrm{x}$ & $\mathrm{x}$ & $\mathrm{x}$ & $\mathrm{x}$ & $\mathrm{x}$ \\
\hline $3.000 \mathrm{~ns}$ & 0 & 0 & $\mathrm{x}$ & $\mathrm{x}$ & $\mathrm{x}$ & $\mathrm{x}$ & $\mathrm{x}$ & $\mathrm{x}$ \\
\hline $4.000 \mathrm{~ns}$ & 1 & 1 & $\mathrm{x}$ & $\mathrm{x}$ & $\mathrm{x}$ & $\mathrm{x}$ & $\mathrm{x}$ & $\mathrm{x}$ \\
\hline $5.000 \mathrm{~ns}^{\circ}$ & 0 & 0 & $\mathrm{x}$ & $\mathrm{x}$ & $\mathrm{x}$ & $\mathrm{x}$ & $\mathrm{x}$ & $\mathrm{x}$ \\
\hline $6.000 \mathrm{~ns}$ & 1 & 1 & $\mathrm{x}$ & $\mathrm{x}$ & $\mathrm{x}$ & $\mathrm{x}$ & $\mathrm{x}$ & $\mathrm{x}$ \\
\hline $.7 .000 \mathrm{~ns}$ & 0 & 0 & 0 & $\mathrm{x}$ & $\mathrm{x}$ & $\mathrm{x}$ & $\mathrm{x}$ & $\mathrm{x}$ \\
\hline $8.000 \mathrm{~ns}$ & 1 & 1 & 1 & $\mathrm{x}$ & $\mathrm{x}$ & $\mathrm{x}$ & $\mathrm{x}$ & $\mathrm{x}$ \\
\hline $9.000 \mathrm{~ns}$ & 0 & 0 & 0 & $\mathrm{x}$ & $\mathrm{x}$ & $\mathrm{x}$ & $\mathrm{x}$ & $\mathrm{X}$ \\
\hline $20.000 \mathrm{~ns}$ & 1 & 1 & 1 & $\mathrm{x}$ & $\mathrm{x}$ & $\mathrm{x}$ & $\mathrm{x}$ & $\mathrm{x}$ \\
\hline 1.000 ns & 0 & 0 & 0 & $\mathrm{x}$ & $\mathrm{x}$ & $\mathrm{x}$ & $\mathrm{x}$ & $\mathrm{x}$ \\
\hline $2.000 \mathrm{~ns}$ & 1 & 1 & 1 & $\mathrm{x}$ & $\mathrm{x}$ & $\mathrm{x}$ & $\mathrm{x}$ & $\mathrm{X}$ \\
\hline $3.000 \mathrm{~ns}$ & 0 & 0 & 0 & $\mathrm{x}$ & $\mathrm{x}$ & $\mathrm{x}$ & $\mathrm{x}$ & $\mathrm{x}$ \\
\hline $4.000 \mathrm{~ns}$ & 1 & 1 & 1 & $x$ & $\mathrm{x}$ & $\mathrm{x}$ & $\mathrm{x}$ & $\mathrm{x}$ \\
\hline $5.000 \mathrm{~ns}$ & 0 & 0 & 0 & 0 & $\mathrm{x}$ & $\mathrm{x}$ & $\mathrm{x}$ & $\mathrm{x}$ \\
\hline $6.000 \mathrm{~ns}$ & 1 & 1 & 1 & 1 & $\mathrm{x}$ & $\mathrm{x}$ & $\mathrm{x}$ & $\mathrm{x}$ \\
\hline $.7 .000 \mathrm{~ns}$ & 0 & 0 & 0 & 0 & $\mathrm{x}$ & $\mathrm{x}$ & $\mathrm{x}$ & $\mathrm{X}$ \\
\hline $8.000 \mathrm{~ns}$ & 1 & 1 & 1 & 1 & $\mathrm{x}$ & $\mathrm{x}$ & $\mathrm{x}$ & $\mathrm{x}$ \\
\hline $9.000 \mathrm{~ns}$ & 0 & 0 & 0 & 0 & $\mathrm{x}$ & $\mathrm{x}$ & $\mathrm{x}$ & $\mathrm{x}$ \\
\hline
\end{tabular}




\begin{tabular}{|c|c|c|c|c|c|c|c|c|}
\hline $30.000 \mathrm{~ns}$ & 1 & 1 & 1 & 1 & $\mathrm{x}$ & $x$ & $\mathrm{x}$ & $\mathrm{x}$ \\
\hline $31.000 \mathrm{~ns}$ & 0 & 0 & 0 & 0 & $\mathrm{x}$ & $x$ & $\mathrm{x}$ & $\mathrm{X}$ \\
\hline $32.000 \mathrm{~ns}$ & 1 & 1 & 1 & 1 & $\mathrm{x}$ & $\mathrm{x}$ & $\mathrm{x}$ & $\mathrm{X}$ \\
\hline $33.000 \mathrm{~ns}$ & 0 & 0 & 0 & 0 & 0 & $\mathrm{X}$ & $\mathrm{x}$ & $\mathrm{X}$ \\
\hline $34.000 n s$ & 1 & 1 & 1 & 1 & 1 & $\mathrm{X}$ & $\mathrm{x}$ & $\mathrm{x}$ \\
\hline $35.000 \mathrm{~ns}$ & 0 & 0 & 0 & 0 & 0 & $\mathrm{x}$ & $\mathrm{x}$ & $\mathrm{x}$ \\
\hline $36.000 \mathrm{~ns}$ & 1 & 1 & 1 & 1 & 1 & $\mathrm{x}$ & $\mathrm{x}$ & $\mathrm{x}$ \\
\hline $37.000 \mathrm{~ns}$ & 0 & 0 & 0 & 0 & 0 & $\mathrm{x}$ & $\mathrm{x}$ & $\mathrm{x}$ \\
\hline $38.000 \mathrm{~ns}$ & 1 & 1 & 1 & 1 & 1 & $x$ & $x$ & $x$ \\
\hline $39.000 \mathrm{~ns}$ & 0 & 0 & 0 & 0 & 0 & $x$ & $x$ & $\mathrm{x}$ \\
\hline $40.000 \mathrm{~ns}$ & 1 & 1 & 1 & 1 & 1 & $x$ & $x$ & $\mathrm{x}$ \\
\hline $41.000 \mathrm{~ns}$ & 0 & 0 & 0 & 0 & 0 & 0 & $\mathrm{x}$ & $\mathrm{X}$ \\
\hline $42.000 \mathrm{~ns}$ & 1 & 1 & 1 & 1 & 1 & 1 & $\mathrm{x}$ & $\mathrm{X}$ \\
\hline $43.000 \mathrm{~ns}$ & 0 & 0 & 0 & 0 & 0 & 0 & $\mathrm{x}$ & $x$ \\
\hline 44.000 ns & 1 & 1 & 1 & 1 & 1 & 1 & $\mathrm{x}$ & $x$ \\
\hline $45.000 \mathrm{~ns}$ & 0 & 0 & 0 & 0 & 0 & 0 & $\mathrm{x}$ & $\mathrm{X}$ \\
\hline 46.000ns & 1 & 1 & 1 & 1 & 1 & 1 & $\mathrm{X}$ & $\mathrm{X}$ \\
\hline $47.000 \mathrm{~ns}$ & 0 & 0 & 0 & 0 & 0 & 0 & $\mathrm{x}$ & $x$ \\
\hline $48.000 \mathrm{~ns}$ & 1 & 1 & 1 & 1 & 1 & 1 & $\mathrm{X}$ & $\mathrm{x}$ \\
\hline $49.000 \mathrm{~ns}$ & 0 & 0 & 0 & 0 & 0 & 0 & 0 & $x$ \\
\hline $50.000 \mathrm{~ns}$ & 1 & 1 & 1 & 1 & 1 & 1 & 1 & $\mathrm{x}$ \\
\hline $51.000 \mathrm{~ns}$ & 0 & 0 & 0 & 0 & 0 & 0 & 0 & $\mathrm{X}$ \\
\hline $52.000 \mathrm{~ns}$ & 1 & 1 & 1 & 1 & 1 & 1 & 1 & $\mathrm{x}$ \\
\hline $53.000 \mathrm{~ns}$ & 0 & 0 & 0 & 0 & 0 & 0 & 0 & $\mathrm{X}$ \\
\hline $54.000 \mathrm{~ns}$ & 1 & 1 & 1 & 1 & 1 & 1 & 1 & $x$ \\
\hline $55.000 \mathrm{~ns}$ & 0 & 0 & 0 & 0 & 0 & 0 & 0 & $\mathrm{x}$ \\
\hline $56.000 \mathrm{~ns}$ & 1 & 1 & 1 & 1 & 1 & 1 & 1 & $\mathrm{X}$ \\
\hline $57.000 \mathrm{~ns}$ & 0 & 0 & 0 & 0 & 0 & 0 & 0 & 0 \\
\hline $58.000 \mathrm{~ns}$ & 1 & 1 & 1 & 1 & 1 & 1 & 1 & 1 \\
\hline $59.000 \mathrm{~ns}$ & 0 & 0 & 0 & 0 & 0 & 0 & 0 & 0 \\
\hline $60.000 \mathrm{~ns}$ & 1 & 1 & 1 & 1 & 1 & 1 & 1 & 1 \\
\hline $61.000 \mathrm{~ns}$ & 0 & 0 & 0 & 0 & 0 & 0 & 0 & 0 \\
\hline $62.000 \mathrm{~ns}$ & 1 & 1 & 1 & 1 & 1 & 1 & I & 1 \\
\hline $63.000 \mathrm{~ns}$ & 0 & 0 & 0 & 0 & 0 & 0 & 0 & 0 \\
\hline $64.000 \mathrm{~ns}$ & 1 & 1 & 1 & 1 & 1 & 1 & 1 & 1 \\
\hline $65.000 \mathrm{~ns}$ & 0 & 0 & 0 & 0 & 0 & 0 & 0 & 0 \\
\hline
\end{tabular}

\section{PERFORMANCE}

$$
\begin{aligned}
& \text { Total simulation time }=561.8 \mathrm{uS} \\
& \text { Total circuit time }=66.0 \mathrm{~ns} \\
& \text { Total events processed }=\quad 2144 \\
& \text { Event throughput }=3.816 \mathrm{MHz}
\end{aligned}
$$


64-inverter Chain in $4 \times 4$ Array.

SIMULATION REPORT

Thu Feb $28 \quad 11: 12: 45 \quad 1991$

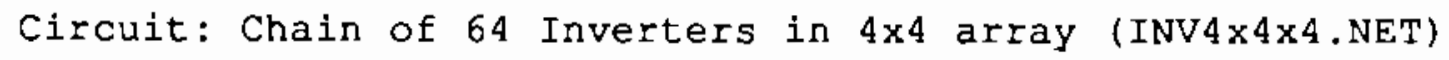

Complexity: 64 gates.

Array size: 16 cells.

SIMULATION DATA

Ckt Time INPUT INV7 INV15 INV23 INV31 INV39 INV47 INV55 INV63

\begin{tabular}{|c|c|c|c|c|c|c|c|c|}
\hline $0.000 \mathrm{~ns}$ & $\mathrm{x}$ & $x$ & $x$ & $x$ & $\mathrm{x}$ & $\mathrm{X}$ & $X$ & $x$ \\
\hline $1.000 \mathrm{~ns}$ & 0 & $\mathrm{x}$ & $\mathrm{x}$ & $\mathrm{x}$ & $\mathrm{X}$ & $x$ & $\mathrm{X}$ & $x$ \\
\hline $2.000 \mathrm{~ns}$ & 1 & $\mathrm{X}$ & $\mathrm{x}$ & $x$ & $\mathrm{X}$ & $\mathrm{X}$ & $\mathrm{x}$ & $\mathrm{x}$ \\
\hline $3.000 \mathrm{~ns}$ & 0 & $\mathrm{X}$ & $\mathrm{X}$ & $\mathrm{x}$ & $x$ & $\mathrm{x}$ & $\mathrm{x}$ & $\mathrm{X}$ \\
\hline $4.000 \mathrm{~ns}$ & 1 & $\mathrm{x}$ & $\mathrm{X}$ & $x$ & $\mathrm{x}$ & $\mathrm{X}$ & $\mathrm{x}$ & $x$ \\
\hline $5.000 \mathrm{~ns}$ & 0 & $\mathrm{X}$ & $\mathrm{X}$ & $\mathrm{X}$ & $\mathrm{X}$ & $\mathrm{X}$ & $\mathrm{x}$ & $\mathrm{x}$ \\
\hline $6.000 \mathrm{~ns}$ & 1 & $\mathrm{x}$ & $\mathrm{X}$ & $x$ & $\mathrm{x}$ & $\mathrm{x}$ & $\mathrm{x}$ & $\mathrm{x}$ \\
\hline $7.000 \mathrm{~ns}$ & 0 & $\mathrm{x}$ & $\mathrm{x}$ & $\mathrm{x}$ & $\mathrm{x}$ & $\mathrm{x}$ & $\mathrm{X}$ & $\mathrm{x}$ \\
\hline $8.000 \mathrm{~ns}$ & 1 & $\mathrm{x}$ & $\mathrm{X}$ & $\mathrm{X}$ & $\mathrm{x}$ & $\mathrm{x}$ & $\mathrm{X}$ & $\mathrm{x}$ \\
\hline $9.000 \mathrm{~ns}$ & 0 & 0 & $\mathrm{x}$ & $\mathrm{X}$ & $x$ & $x$ & $x$ & $\mathrm{x}$ \\
\hline $10.000 \mathrm{~ns}$ & 1 & 1 & $\mathrm{x}$ & $x$ & $\mathrm{x}$ & $\mathrm{x}$ & $x$ & $x$ \\
\hline $11.000 \mathrm{~ns}$ & 0 & 0 & $\mathrm{X}$ & $\mathrm{x}$ & $\mathrm{X}$ & $\mathrm{X}$ & $x$ & $x$ \\
\hline $12.000 \mathrm{~ns}$ & 1 & 1 & $\mathrm{x}$ & $\mathrm{x}$ & $\mathrm{x}$ & $x$ & $\mathrm{x}$ & $\mathrm{x}$ \\
\hline $13.000 \mathrm{~ns}$ & 0 & 0 & $\mathrm{x}$ & $x$ & $\mathrm{x}$ & $\mathrm{x}$ & $\mathrm{x}$ & $\mathrm{X}$ \\
\hline $14.000 \mathrm{~ns}$ & 1 & 1 & $\mathrm{x}$ & $\mathrm{x}$ & $\mathrm{x}$ & $x$ & $\mathrm{x}$ & $\mathrm{x}$ \\
\hline $15.000 \mathrm{~ns}$ & 0 & 0 & $\mathrm{X}$ & $x$ & $\mathrm{x}$ & $x$ & $\mathrm{x}$ & $\mathrm{x}$ \\
\hline $16.000 \mathrm{~ns}$ & 1 & 1 & $\mathrm{X}$ & $\mathrm{x}$ & $x$ & $\mathrm{x}$ & $\mathrm{X}$ & $x$ \\
\hline $17.000 \mathrm{~ns}$ & 0 & 0 & 0 & $\mathrm{X}$ & $x$ & $\mathrm{X}$ & $\mathrm{x}$ & $\mathrm{x}$ \\
\hline $18.000 \mathrm{~ns}$ & 1 & 1 & 1 & $x$ & $x$ & $x$ & $\mathrm{x}$ & $x$ \\
\hline $19.000 \mathrm{~ns}$ & 0 & 0 & 0 & $x$ & $\mathrm{x}$ & $\mathrm{x}$ & $\mathrm{X}$ & $\mathrm{X}$ \\
\hline $20.000 \mathrm{~ns}$ & 1 & 1 & 1 & $x$ & $\mathrm{x}$ & $\mathrm{X}$ & $x$ & $\mathrm{x}$ \\
\hline $21.000 \mathrm{~ns}$ & 0 & 0 & 0 & $x$ & $x$ & $x$ & $x$ & $\mathrm{x}$ \\
\hline $22.000 \mathrm{~ns}$ & 1 & 1 & 1 & $\mathrm{X}$ & $\mathrm{x}$ & $x$ & $\mathrm{x}$ & $x$ \\
\hline $23.000 \mathrm{~ns}$ & 0 & 0 & 0 & $x$ & $\mathrm{x}$ & $x$ & $\mathrm{x}$ & $x$ \\
\hline $24.000 \mathrm{~ns}$ & 1 & 1 & 1 & $\mathrm{x}$ & $\mathrm{X}$ & $\mathrm{X}$ & $x$ & $\mathrm{X}$ \\
\hline $25.000 \mathrm{~ns}$ & 0 & 0 & 0 & 0 & $\mathrm{x}$ & $\mathrm{x}$ & $x$ & $\mathrm{x}$ \\
\hline $26.000 \mathrm{~ns}$ & 1 & 1 & 1 & 1 & $\mathrm{x}$ & $\mathrm{x}$ & $\mathrm{x}$ & $x$ \\
\hline $27.000 \mathrm{~ns}$ & 0 & 0 & 0 & 0 & $x$ & $\mathrm{X}$ & $X$ & $\mathrm{X}$ \\
\hline $28.000 \mathrm{~ns}$ & 1 & 1 & 1 & 1 & $\mathrm{X}$ & $x$ & $x$ & $x$ \\
\hline $29.000 \mathrm{~ns}$ & 0 & 0 & 0 & 0 & $\mathrm{x}$ & $x$ & $x$ & $\mathrm{x}$ \\
\hline
\end{tabular}




\begin{tabular}{|c|c|c|c|c|c|c|c|c|}
\hline $30.000 \mathrm{~ns}$ & 1 & 1 & 1 & 1 & $\mathrm{X}$ & $\mathrm{x}$ & $\mathrm{X}$ & $\mathrm{x}$ \\
\hline $31.000 \mathrm{~ns}$ & 0 & 0 & 0 & 0 & $\mathrm{x}$ & $\mathrm{X}$ & $\mathrm{x}$ & $x$ \\
\hline $32.000 \mathrm{~ns}$ & 1 & 1 & 1 & 1 & $\mathrm{x}$ & $\mathrm{X}$ & $\mathrm{x}$ & $\mathrm{X}$ \\
\hline $33.000 \mathrm{~ns}$ & 0 & 0 & 0 & 0 & 0 & $x$ & $x$ & $\mathrm{x}$ \\
\hline $34.000 \mathrm{~ns}$ & 1 & 1 & 1 & 1 & 1 & $x$ & $\mathrm{x}$ & $\mathrm{x}$ \\
\hline $35.000 \mathrm{~ns}$ & 0 & 0 & 0 & 0 & 0 & $\mathrm{x}$ & $\mathrm{x}$ & $\mathrm{x}$ \\
\hline $36.000 \mathrm{~ns}$ & 1 & 1 & 1 & 1 & 1 & $\mathrm{x}$ & $\mathrm{x}$ & $\mathrm{x}$ \\
\hline $37.000 \mathrm{~ns}$ & 0 & 0 & 0 & 0 & 0 & $\mathrm{x}$ & $x$ & $x$ \\
\hline $38.000 \mathrm{~ns}$ & 1 & 1 & 1 & 1 & 1 & $\mathrm{x}$ & $\mathrm{x}$ & $\mathrm{x}$ \\
\hline $39.000 \mathrm{~ns}$ & 0 & 0 & 0 & 0 & 0 & $\mathrm{x}$ & $x$ & $x$ \\
\hline $40.000 \mathrm{~ns}$ & 1 & 1 & 1 & 1 & 1 & $x$ & $\mathrm{x}$ & $\mathrm{x}$ \\
\hline $41.000 \mathrm{~ns}$ & 0 & 0 & 0 & 0 & 0 & 0 & $\mathrm{x}$ & $\mathrm{x}$ \\
\hline $42.000 \mathrm{~ns}$ & 1 & 1 & 1 & 1 & 1 & 1 & $\mathrm{x}$ & $\mathrm{x}$ \\
\hline $43.000 \mathrm{~ns}$ & 0 & 0 & 0 & 0 & 0 & 0 & $\mathrm{x}$ & $x$ \\
\hline $44.000 \mathrm{~ns}$ & 1 & 1 & 1 & 1 & 1 & 1 & $x$ & $\mathrm{x}$ \\
\hline $45.000 \mathrm{~ns}$ & 0 & 0 & 0 & 0 & 0 & 0 & $\mathrm{x}$ & $\mathrm{x}$ \\
\hline $46.000 \mathrm{~ns}$ & 1 & 1 & 1 & 1 & 1 & 1 & $x$ & $\mathrm{x}$ \\
\hline $47.000 \mathrm{~ns}$ & 0 & 0 & 0 & 0 & 0 & 0 & $\mathrm{x}$ & $\mathrm{x}$ \\
\hline $48.000 \mathrm{~ns}$ & 1 & 1 & 1 & 1 & 1 & 1 & $x$ & $\mathrm{x}$ \\
\hline $49.000 \mathrm{~ns}$ & 0 & 0 & 0 & 0 & 0 & 0 & 0 & $\mathrm{x}$ \\
\hline $50.000 \mathrm{~ns}$ & 1 & 1 & 1 & 1 & 1 & 1 & 1 & $\mathrm{x}$ \\
\hline $51.000 \mathrm{~ns}$ & 0 & 0 & 0 & 0 & 0 & 0 & 0 & $\mathrm{x}$ \\
\hline $52.000 \mathrm{~ns}$ & 1 & 1 & 1 & 1 & 1 & 1 & 1 & $\mathrm{x}$ \\
\hline $53.000 \mathrm{~ns}$ & 0 & 0 & 0 & 0 & 0 & 0 & 0 & $\mathrm{x}$ \\
\hline 54.000 ns & 1 & 1 & 1 & 1 & 1 & 1 & 1 & $\mathrm{x}$ \\
\hline $55.000 \mathrm{~ns}$ & 0 & 0 & 0 & 0 & 0 & 0 & 0 & $\mathrm{x}$ \\
\hline $56.000 \mathrm{~ns}$ & 1 & 1 & 1 & 1 & 1 & 1 & 1 & $\mathrm{x}$ \\
\hline $57.000 \mathrm{~ns}$ & 0 & 0 & 0 & 0 & 0 & 0 & 0 & 0 \\
\hline $58.000 \mathrm{~ns}$ & 1 & 1 & 1 & 1 & 1 & 1 & 1 & 1 \\
\hline $59.000 \mathrm{~ns}$ & 0 & 0 & 0 & 0 & 0 & 0 & 0 & 0 \\
\hline $60.000 \mathrm{~ns}$ & 1 & 1 & 1 & 1 & 1 & 1 & 1 & 1 \\
\hline $61.000 \mathrm{~ns}$ & 0 & 0 & 0 & 0 & 0 & 0 & 0 & 0 \\
\hline $62.000 n s$ & 1 & 1 & 1 & 1 & 1 & 1 & 1 & 1 \\
\hline $63.000 \mathrm{~ns}$ & 0 & 0 & 0 & 0 & 0 & 0 & 0 & 0 \\
\hline $64.000 \mathrm{~ns}$ & 1 & 1 & 1 & 1 & 1 & 1 & 1 & 1 \\
\hline $65.000 \mathrm{~ns}$ & 0 & 0 & 0 & 0 & 0 & 0 & 0 & 0 \\
\hline
\end{tabular}

\section{PEREORMANCE}

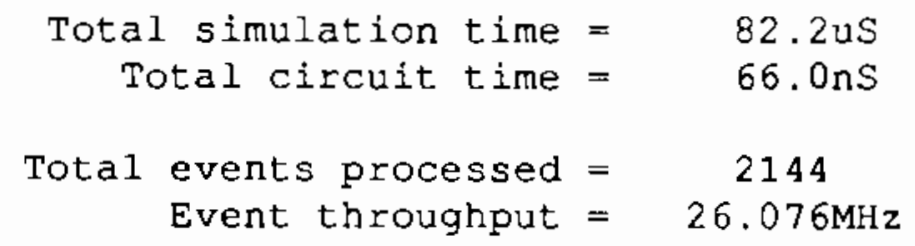


64-inverter Chain in $8 \times 8$ Array.

SIMULATION REPORT

Thu Feb 28 11:16:31 1991

Circuit: Chain of 64 inverters in 64 nodes (INV64.NET)

Complexity: 64 gates.

Array size: 64 cells.

SIMULATION DATA

Ckt Time INPUT INV7 INV15 INV23 INV31 INV39 INV47 INV55 INV63

\begin{tabular}{|c|c|c|c|c|c|c|c|c|}
\hline $0.000 \mathrm{~ns}$ & $\mathrm{x}$ & $\mathrm{x}$ & $\mathrm{x}$ & $\mathrm{x}$ & $x$ & $\mathrm{x}$ & $\mathrm{x}$ & $\mathrm{x}$ \\
\hline $1.000 \mathrm{~ns}$ & 0 & $\mathrm{x}$ & $x$ & $\mathrm{X}$ & $\mathrm{x}$ & $\mathrm{x}$ & $\mathrm{x}$ & $\mathrm{x}$ \\
\hline $2.000 \mathrm{~ns}$ & 1 & $\mathrm{x}$ & $x$ & $\mathrm{X}$ & $\mathrm{x}$ & $\mathrm{x}$ & $\mathrm{x}$ & $x$ \\
\hline $3.000 \mathrm{~ns}$ & 0 & $x$ & $\mathrm{x}$ & $x$ & $x$ & $x$ & $x$ & $\mathrm{x}$ \\
\hline $4.000 \mathrm{~ns}$ & 1 & $x$ & $\mathrm{x}$ & $\mathrm{x}$ & $x$ & $\mathrm{x}$ & $x$ & $\mathrm{x}$ \\
\hline $5.000 \mathrm{~ns}$ & 0 & $x$ & $\mathrm{x}$ & $x$ & $x$ & $x$ & $\mathrm{x}$ & $\mathrm{x}$ \\
\hline $6.000 \mathrm{~ns}$ & 1 & $x$ & $x$ & $x$ & $x$ & $x$ & $\mathrm{x}$ & $\mathrm{x}$ \\
\hline $7.000 \mathrm{~ns}$ & 0 & $\mathrm{x}$ & $x$ & $x$ & $\mathrm{x}$ & $x$ & $x$ & $x$ \\
\hline $8.000 n \mathrm{~s}$ & 1 & $\mathrm{x}$ & $\mathrm{x}$ & $x$ & $\mathrm{x}$ & $x$ & $x$ & $x$ \\
\hline $9.000 \mathrm{~ns}$ & 0 & 0 & $x$ & $x$ & $x$ & $\mathrm{x}$ & $x$ & $x$ \\
\hline $10.000 \mathrm{~ns}$ & 1 & 1 & $x$ & $x$ & $x$ & $\mathrm{x}$ & $x$ & $\mathrm{x}$ \\
\hline $11.000 \mathrm{~ns}$ & 0 & 0 & $x$ & $\mathrm{x}$ & $x$ & $x$ & $\mathrm{x}$ & $\mathrm{x}$ \\
\hline $12.000 \mathrm{~ns}$ & 1 & 1 & $\mathrm{x}$ & $\mathrm{x}$ & $\mathrm{x}$ & $\mathrm{x}$ & $\mathrm{x}$ & $\mathrm{x}$ \\
\hline $3.000 \mathrm{~ns}$ & 0 & 0 & $x$ & $x$ & $\mathrm{x}$ & $x$ & $x$ & $x$ \\
\hline $4.000 \mathrm{~ns}$ & 1 & 1 & $x$ & $x$ & $\mathrm{x}$ & $x$ & $x$ & $x$ \\
\hline $15.000 \mathrm{~ns}$ & 0 & 0 & $x$ & $x$ & $\mathrm{x}$ & $x$ & $x$ & $x$ \\
\hline $16.000 \mathrm{~ns}$ & 1 & 1 & $x$ & $x$ & $\mathrm{x}$ & $\mathrm{x}$ & $\mathrm{x}$ & $x$ \\
\hline $17.000 \mathrm{~ns}$ & 0 & 0 & 0 & $\mathrm{x}$ & $\mathrm{X}$ & $\mathrm{x}$ & $x$ & $\mathrm{x}$ \\
\hline $18.000 \mathrm{~ns}$ & 1 & 1 & 1 & $\mathrm{x}$ & $x$ & $\mathrm{x}$ & $\mathrm{x}$ & $\mathrm{x}$ \\
\hline $19.000 \mathrm{~ns}$ & 0 & 0 & 0 & $\mathrm{x}$ & $\mathrm{X}$ & $x$ & $\mathrm{x}$ & $\mathrm{x}$ \\
\hline $20.000 \mathrm{~ns}$ & 1 & 1 & 1 & $x$ & $x$ & $x$ & $\mathrm{x}$ & $\mathrm{x}$ \\
\hline $21.000 \mathrm{~ns}$ & 0 & 0 & 0 & $\mathrm{X}$ & $x$ & $\mathrm{x}$ & $x$ & $x$ \\
\hline $22.000 \mathrm{~ns}$ & 1 & 1 & 1 & $x$ & $\mathrm{x}$ & $x$ & $x$ & $x$ \\
\hline $23.000 \mathrm{~ns}$ & 0 & 0 & 0 & $x$ & $\mathrm{x}$ & $x$ & $x$ & $\mathrm{X}$ \\
\hline $24.000 \mathrm{~ns}$ & 1 & 1 & 1 & $\mathrm{x}$ & $\mathrm{X}$ & $\mathrm{x}$ & $\mathrm{x}$ & $\mathrm{X}$ \\
\hline $25.000 \mathrm{~ns}$ & 0 & 0 & 0 & 0 & $x$ & $x$ & $\mathrm{x}$ & $\mathrm{X}$ \\
\hline $26.000 \mathrm{~ns}$ & 1 & 1 & 1 & 1 & $x$ & $x$ & $\mathrm{X}$ & $x$ \\
\hline $27.000 \mathrm{~ns}$ & 0 & 0 & 0 & 0 & $\mathrm{X}$ & $x$ & $\mathrm{x}$ & $x$ \\
\hline $28.000 \mathrm{~ns}$ & 1 & 1 & 1 & 1 & $\mathrm{x}$ & $\mathrm{x}$ & $x$ & $x$ \\
\hline $29.000 \mathrm{~ns}$ & 0 & 0 & 0 & 0 & $\mathrm{x}$ & $x$ & $x$ & $\mathrm{X}$ \\
\hline
\end{tabular}




\begin{tabular}{|c|c|c|c|c|c|c|c|c|}
\hline $30.000 \mathrm{~ns}$ & 1 & 1 & 1 & 1 & $\mathrm{x}$ & $\mathrm{X}$ & $\mathrm{X}$ & $\mathrm{x}$ \\
\hline $31.000 \mathrm{~ns}$ & 0 & 0 & 0 & 0 & $\mathrm{x}$ & $\mathrm{x}$ & $\mathrm{x}$ & $\mathrm{x}$ \\
\hline $32.000 \mathrm{~ns}$ & 1 & 1 & 1 & 1 & $\mathrm{x}$ & $x$ & $\mathrm{x}$ & $\mathrm{x}$ \\
\hline $33.000 \mathrm{~ns}$ & 0 & 0 & 0 & 0 & 0 & $\mathrm{x}$ & $\mathrm{x}$ & $\mathrm{x}$ \\
\hline $34.000 \mathrm{~ns}$ & 1 & 1 & 1 & 1 & 1 & $\mathrm{x}$ & $\mathrm{X}$ & $\mathrm{x}$ \\
\hline $35.000 \mathrm{~ns}$ & 0 & 0 & 0 & 0 & 0 & $x$ & $x$ & $\mathrm{X}$ \\
\hline $36.000 \mathrm{~ns}$ & 1 & 1 & 1 & 1 & 1 & $\mathrm{x}$ & $x$ & $x$ \\
\hline $37.000 \mathrm{~ns}$ & 0 & 0 & 0 & 0 & 0 & $\mathrm{x}$ & $x$ & $\mathrm{x}$ \\
\hline 38.000 ns & 1 & 1 & 1 & 1 & 1 & $\mathrm{X}$ & $\mathrm{x}$ & $x$ \\
\hline $39.000 \mathrm{~ns}$ & 0 & 0 & 0 & 0 & 0 & $\mathrm{x}$ & $\mathrm{x}$ & $x$ \\
\hline $40.000 \mathrm{~ns}$ & 1 & 1 & 1 & 1 & 1 & $\mathrm{x}$ & $x$ & $\mathrm{x}$ \\
\hline $41.000 n s$ & 0 & 0 & 0 & 0 & 0 & 0 & $\mathrm{x}$ & $\mathrm{x}$ \\
\hline $42.000 \mathrm{~ns}$ & 1 & 1 & 1 & 1 & 1 & 1 & $\mathrm{x}$ & $\mathrm{x}$ \\
\hline $43.000 \mathrm{~ns}$ & 0 & 0 & 0 & 0 & 0 & 0 & $x$ & $x$ \\
\hline $44.000 \mathrm{~ns}$ & 1 & 1 & 1 & 1 & 1 & 1 & $x$ & $\mathrm{x}$ \\
\hline $45.000 \mathrm{~ns}$ & 0 & 0 & 0 & 0 & 0 & 0 & $x$ & $\mathrm{x}$ \\
\hline $46.000 \mathrm{~ns}$ & 1 & 1 & 1 & 1 & 1 & 1 & $\mathrm{X}$ & $\mathrm{X}$ \\
\hline $47.000 \mathrm{~ns}$ & 0 & 0 & 0 & 0 & 0 & 0 & $x$ & $\mathrm{x}$ \\
\hline $48.000 \mathrm{~ns}$ & 1 & 1 & 1 & 1 & 1 & 1 & $\mathrm{x}$ & $\mathrm{x}$ \\
\hline $49.000 n s$ & 0 & 0 & 0 & 0 & 0 & 0 & 0 & $x$ \\
\hline $50.000 \mathrm{~ns}$ & 1 & 1 & 1 & 1 & 1 & 1 & 1 & $\mathrm{X}$ \\
\hline $51.000 \mathrm{~ns}$ & 0 & 0 & 0 & 0 & 0 & 0 & 0 & $x$ \\
\hline $52.000 \mathrm{~ns}$ & 1 & 1 & 1 & $I$ & 1 & 1 & 1 & $\mathrm{x}$ \\
\hline $53.000 \mathrm{~ns}$ & 0 & 0 & 0 & 0 & 0 & 0 & 0 & $\mathrm{X}$ \\
\hline $54.000 \mathrm{~ns}$ & 1 & 1 & 1 & 1 & 1 & 1 & 1 & $\mathrm{X}$ \\
\hline $55.000 \mathrm{~ns}$ & 0 & 0 & 0 & 0 & 0 & 0 & 0 & $x$ \\
\hline $56.000 \mathrm{~ns}$ & 1 & 1 & 1 & 1 & 1 & 1 & 1 & $\mathrm{x}$ \\
\hline $57.000 n s$ & 0 & 0 & 0 & 0 & 0 & 0 & 0 & 0 \\
\hline $58.000 n s$ & 1 & 1 & 1 & 1 & 1 & 1 & 1 & 1 \\
\hline $59.000 \mathrm{~ns}$ & 0 & 0 & 0 & 0 & 0 & 0 & 0 & 0 \\
\hline $60.000 \mathrm{~ns}$ & 1 & 1 & 1 & 1 & 1 & 1 & 1 & 1 \\
\hline $61.000 \mathrm{~ns}$ & 0 & 0 & 0 & 0 & 0 & 0 & 0 & 0 \\
\hline $62.000 \mathrm{~ns}$ & 1 & 1 & 1 & 1 & 1 & 1 & 1 & 1 \\
\hline $63.000 \mathrm{~ns}$ & 0 & 0 & 0 & 0 & 0 & 0 & 0 & 0 \\
\hline $64.000 \mathrm{~ns}$ & 1 & 1 & 1 & 1 & 1 & 1 & 1 & 1 \\
\hline $65.000 \pi \mathrm{s}$ & 0 & 0 & 0 & 0 & 0 & 0 & 0 & 0 \\
\hline
\end{tabular}

PERFORMANCE

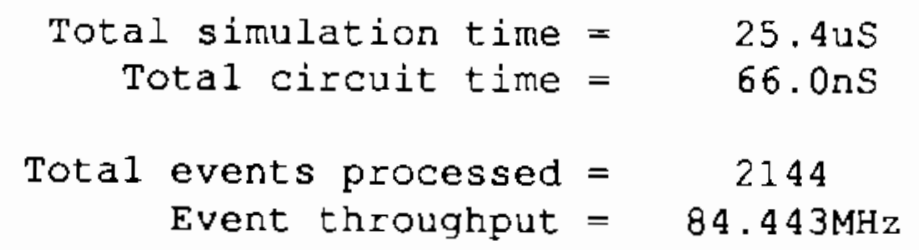


Pipeline Saturation Test 1 (1 Input).

SIMULATION REPORT

Thu Feb 28 11:29:22 1991

Circuit: Saturation test 1 ( 1 input)

Complexity: 1 gate.

Array size: 1 cell.

\section{SIMULATION DATA}

- - - - - - - - - -

$\begin{array}{ccc}\text { Ckt Time } & \text { IN } & \text { INV0 } \\ & & \\ 0.000 \mathrm{~ns} & \mathrm{X} & \mathrm{X} \\ 1.000 \mathrm{~ns} & 0 & \mathrm{X} \\ 2.000 \mathrm{~ns} & 1 & 1 \\ 3.000 \mathrm{~ns} & 0 & 0 \\ 4.000 \mathrm{~ns} & 1 & 1 \\ 5.000 \mathrm{~ns} & 0 & 0 \\ 6.000 \mathrm{~ns} & 1 & 1 \\ 7.000 \mathrm{~ns} & 0 & 0 \\ 8.000 \mathrm{~ns} & 1 & 1 \\ 9.000 \mathrm{~ns} & 0 & 0 \\ 10.000 \mathrm{~ns} & 1 & 1 \\ 11.000 \mathrm{~ns} & 0 & 0 \\ 12.000 \mathrm{~ns} & 1 & 1 \\ 13.000 \mathrm{~ns} & 0 & 0 \\ 14.000 \mathrm{~ns} & 1 & 1 \\ 15.000 \mathrm{~ns} & 0 & 0 \\ 16.000 \mathrm{~ns} & 1 & 1 \\ 17.000 \mathrm{~ns} & 0 & 0 \\ 18.000 \mathrm{~ns} & 1 & 1 \\ 19.000 \mathrm{~ns} & 0 & 0 \\ 20.000 \mathrm{~ns} & 1 & 1\end{array}$

\section{PERFORMANCE}

$$
\begin{array}{rc}
\text { Total simulation time }= & 8.0 \mathrm{us} \\
\text { Total circuit time }= & 21.0 \mathrm{nS} \\
\text { Total events processed }= & 20 \\
\text { Event throughput }= & 2.486 \mathrm{MHz}
\end{array}
$$


Ripeline Saturation Test 1 (2 inputs).

SIMULATION REPORT

Thu Eeb 28 11:29:42.1991

Circuit: Saturation test 1 (2 inputs)

Complexity: 2 gates.

Array size: 1 cell.

\section{SIMULATION DATA}

Ckt Time IN INVO INV1

0.000 ns $x \quad x \quad x$

$1.000 n$ s $0 \quad x \quad x$

2.000ns 111

3.000 ns 0 o 0

4.000ns 111

$5.000 \mathrm{~ns} \quad 0 \quad 0 \quad 0$

6.000 ns $11 \quad 1 \quad 1$

$7.000 \mathrm{~ns} \quad 0 \quad 0 \quad 0$

$8.000 \mathrm{~ns} \quad 1 \quad 1 \quad 1$

$9.000 \mathrm{~ns} \quad 0 \quad 0 \quad 0$

$10.000 \mathrm{~ns} \quad 1 \quad 1 \quad 1$

$11.000 \mathrm{~ns} \quad 0 \quad 0 \quad 0$

12.000 ns 1111

$13.000 \mathrm{~ns} 000$

14.000 ns 1111

$25.000 \mathrm{~ns} \quad 0 \quad 0 \quad 0$

$16.000 \mathrm{~ns} \quad 1 \quad 1 \quad 1$

$17.000 \mathrm{~ns} \quad 0 \quad 0 \quad 0$

18.000 ns 1111

$19.000 \mathrm{~ns} 000$

20.000ns $1 \quad 1 \quad 1$

\section{PERFORMANCE}

\footnotetext{
Total simulation time $=13.2 \mathrm{uS}$ Total circuit time $=21.0 \mathrm{~ns}$

Total events processed $=$ Event throughput $=3.038 \mathrm{MHz}$
} 
Ripeline Saturation Test 1 ( 3 inputs).

Circuit: Saturation test 1 ( 3 inputs)

Complexity: 3 gates.

Array size: 1 cell.

\section{SIMULATION DATA}

\begin{tabular}{|c|c|c|c|c|}
\hline Ckt Time & IN & INVO & INV1 & INV2 \\
\hline $0.000 \mathrm{~ns}$ & $x$ & $\mathrm{x}$ & $\mathrm{X}$ & $\mathrm{x}$ \\
\hline $1.000 \mathrm{~ns}$ & 0 & $\mathrm{x}$ & $\mathrm{x}$ & $\mathrm{x}$ \\
\hline $2.000 \mathrm{~ns}^{2}$ & 1 & 1 & 1 & 1 \\
\hline $3.000 \mathrm{~ns}$ & 0 & 0 & 0 & 0 \\
\hline $4.000 \mathrm{~ns}$ & 1 & 1 & 1 & 1 \\
\hline $5.000 \mathrm{~ns}$ & 0 & 0 & 0 & 0 \\
\hline $6.000 \mathrm{~ns}$ & 1 & 1 & 1 & 1 \\
\hline $7.000 \mathrm{~ns}$ & 0 & 0 & 0 & 0 \\
\hline $8.000 \mathrm{~ns}$ & 1 & 1 & 1 & 1 \\
\hline $9.000 \mathrm{~ns}$ & 0 & 0 & 0 & 0 \\
\hline $10.000 \mathrm{~ns}$ & 1 & 1 & 1 & 1 \\
\hline $11.000 \mathrm{~ns}$ & 0 & 0 & 0 & 0 \\
\hline $12.000 \mathrm{~ns}$ & 1 & 1 & 1 & $I$ \\
\hline $13.000 n s$ & 0 & 0 & 0 & 0 \\
\hline $14.000 \mathrm{~ns}$ & 1 & 1 & 1 & 1 \\
\hline $15.000 \mathrm{~ns}$ & 0 & 0 & 0 & 0 \\
\hline $16.000 \mathrm{~ns}$ & 1 & 1 & 1 & 1 \\
\hline $17.000 \mathrm{~ns}$ & 0 & 0 & 0 & 0 \\
\hline $18.000 \mathrm{~ns}$ & 1 & 1 & 1 & 1 \\
\hline $19.000 \mathrm{~ns}$ & 0 & 0 & 0 & 0 \\
\hline $20.000 \mathrm{~ns}$ & 1 & 1 & 1 & 1 \\
\hline
\end{tabular}

\section{PERFORMANCE}

$$
\begin{aligned}
& \text { Total simulation time }=18.3 \mathrm{us} \\
& \text { Total circuit time }=21.0 \mathrm{~ns} \\
& \text { Total events processed }=60 \\
& \text { Event throughput }=3.281 \mathrm{MHz}
\end{aligned}
$$


Pipeline Saturation Test 1 (4 input). SIMULATION REPORT

Circuit: Saturation test 1 ( 4 inputs)

Complexity: 4 gates.

Array size: 1 cell.

\section{SIMULATION DATA}

Ckt Time IN INVO INV1 INV2 INV3

$\begin{array}{llllll}0.000 n s & x & x & x & x & x \\ 1.000 n s & 0 & x & x & x & x \\ 2.000 n s & 1 & 1 & 1 & 1 & 1 \\ 3.000 n s & 0 & 0 & 0 & 0 & 0 \\ 4.000 n s & 1 & 1 & 1 & 1 & 1 \\ 5.000 n s & 0 & 0 & 0 & 0 & 0 \\ 6.000 n s & 1 & 1 & 1 & 1 & 1 \\ 7.000 n s & 0 & 0 & 0 & 0 & 0 \\ 8.000 n s & 1 & 1 & 1 & 1 & 1 \\ 9.000 n s & 0 & 0 & 0 & 0 & 0 \\ 10.000 n s & 1 & 1 & 1 & 1 & 1 \\ 11.000 n s & 0 & 0 & 0 & 0 & 0 \\ 12.000 n s & 1 & 1 & 1 & 1 & 1 \\ 13.000 n s & 0 & 0 & 0 & 0 & 0 \\ 14.000 n s & 1 & 1 & 1 & 1 & 1 \\ 15.000 n s & 0 & 0 & 0 & 0 & 0 \\ 16.000 n s & 1 & 1 & 1 & 1 & 1 \\ 17.000 n s & 0 & 0 & 0 & 0 & 0 \\ 18.000 n s & 1 & 1 & 1 & 1 & 1 \\ 19.000 n s & 0 & 0 & 0 & 0 & 0 \\ 20.000 n s & 1 & 1 & 1 & 1 & 1\end{array}$

\section{PERFORMANCE}

Total simulation time = Total circuit time $=$

Total events processed = Event throughput $=$
23. 4us

$21.0 n s$ 
Pipeline Saturation Test 1 (5 inputs 1

SIMULATION REPORT

Thu Feb $28 \quad 11: 30: 461991$

Circuit: Saturation test 1 (5 inputs)

Complexity: 5 gates.

Array size: 1 cell.

SIMULATION DATA

Ckt Time IN INVO INV1 INV2 INV3 INV4

$\begin{array}{lllllll}0.000 \text { s } & X & X & X & X & x & x\end{array}$

$\begin{array}{lllllll}1.000 n s & 0 & X & X & X & X & X\end{array}$

$\begin{array}{lllllll}2.000 \mathrm{~ns} & 1 & 1 & 1 & 1 & 1 & 1\end{array}$

$3.000 \mathrm{~ns} \quad 0 \quad 00100000$

$\begin{array}{lllllll}4.000 \mathrm{~ns} & 1 & 1 & 1 & 1 & 1 & 1\end{array}$

5.000ns 00000000

$\begin{array}{lllllll}6.000 \mathrm{~ns} & 1 & 1 & 1 & 1 & 1 & 1\end{array}$

$7.000 \mathrm{~ns} \quad 0 \quad 0000000$

$\begin{array}{lllllll}8.000 \mathrm{~ns} & 1 & 1 & 1 & 1 & 1 & 1\end{array}$

$9.000 \mathrm{~ns} \quad 0 \quad 0 \quad 000000$

$\begin{array}{lllllll}10.000 \mathrm{~ns} & 1 & 1 & 1 & 1 & 1 & 1\end{array}$

$11.000 \mathrm{~ns} \quad 0 \quad 0 \quad 000000$

$\begin{array}{lllllll}12.000 \mathrm{~ns} & 1 & 1 & 1 & 1 & 1 & 1\end{array}$

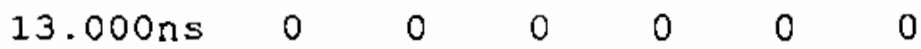

$\begin{array}{lllllll}14.000 \text { ns } & 1 & 1 & 1 & 1 & 1 & 1\end{array}$

15.000ns 00000000

$\begin{array}{lllllll}16.000 \mathrm{~ns} & 1 & 1 & 1 & 1 & 1 & 1\end{array}$

$17.000 \mathrm{~ns} \quad 0 \quad 0 \quad 000000$

$\begin{array}{lllllll}18.000 \mathrm{~ns} & 1 & 1 & 1 & 1 & 1 & 1\end{array}$

$19.000 \mathrm{~ns} \quad 0 \quad 0 \quad 000000$

$\begin{array}{lllllll}20.000 \mathrm{~ns} & 1 & 1 & 1 & 1 & 1 & 1\end{array}$

\section{PERFORMANCE}

\footnotetext{
Total simulation time $=28.5$ us

Total circuit time $=21.0 \mathrm{nS}$

Total events processed $=\quad 100$ Event throughput $=3.506 \mathrm{MHz}$
} 
Pipeline Saturation Test $1 .(6$ inputs $)$.

SIMULATION REPORT

Thu Feb $28 \quad 11: 31: 17 \quad 1991$

Circuit: Saturation test 1 (6 inputs)

Complexity: 6 gates.

Array size: $\quad 1$ cell.

\section{SIMULATION DATA}

Ckt Time IN INV0 INV1 INV2 INV3 INV4 INV5

$\begin{array}{llllllll}0.000 n s & \mathrm{X} & \mathrm{x} & \mathrm{x} & \mathrm{x} & \mathrm{x} & \mathrm{X} & \mathrm{X} \\ 1.000 \mathrm{~ns} & 0 & \mathrm{x} & \mathrm{x} & \mathrm{x} & \mathrm{x} & \mathrm{x} & \mathrm{X} \\ 2.000 \mathrm{~ns} & 1 & 1 & 1 & 1 & 1 & 1 & 1 \\ 3.000 \mathrm{~ns} & 0 & 0 & 0 & 0 & 0 & 0 & 0 \\ 4.000 \mathrm{~ns} & 1 & 1 & 1 & 1 & 1 & 1 & 1 \\ 5.000 \mathrm{~ns} & 0 & 0 & 0 & 0 & 0 & 0 & 0 \\ 6.000 \mathrm{~ns} & 1 & 1 & 1 & 1 & 1 & 1 & 1 \\ 7.000 \mathrm{~ns} & 0 & 0 & 0 & 0 & 0 & 0 & 0 \\ 8.000 \mathrm{~ns} & 1 & 1 & 1 & 1 & 1 & 1 & 1 \\ 9.000 \mathrm{~ns} & 0 & 0 & 0 & 0 & 0 & 0 & 0 \\ 10.000 \mathrm{~ns} & 1 & 1 & 1 & 1 & 1 & 1 & 1 \\ 11.000 \mathrm{~ns} & 0 & 0 & 0 & 0 & 0 & 0 & 0 \\ 12.000 \mathrm{~ns} & 1 & 1 & 1 & 1 & 1 & 1 & 1 \\ 13.000 \mathrm{~ns} & 0 & 0 & 0 & 0 & 0 & 0 & 0 \\ 14.000 \mathrm{~ns} & 1 & 1 & 1 & 1 & 1 & 1 & 1 \\ 15.000 \mathrm{~ns} & 0 & 0 & 0 & 0 & 0 & 0 & 0 \\ 16.000 \mathrm{~ns} & 1 & 1 & 1 & 1 & 1 & 1 & 1 \\ 17.000 \mathrm{~ns} & 0 & 0 & 0 & 0 & 0 & 0 & 0 \\ 18.000 \mathrm{~ns} & 1 & 1 & 1 & 1 & 1 & 1 & 1 \\ 19.000 \mathrm{~ns} & 0 & 0 & 0 & 0 & 0 & 0 & 0 \\ 20.000 \mathrm{~ns} & 1 & 1 & 1 & 1 & 1 & 1 & 1\end{array}$

PEREORMANCE

$$
\begin{aligned}
& \text { Total simulation time }=33.6 \mathrm{us} \\
& \text { Total circuit time }=21.0 \text { s } \\
& \text { Total events processed }=120 \\
& \text { Event throughput }=3.567 \mathrm{MHz}
\end{aligned}
$$


Pipeline Saturation Test 1 (7 inputs).

SIMULATION REPORT

Thu Eeb 28 11:31:52 1991

Circuit: Saturation test 1 ( 7 inputs)

Complexity: 7 gates.

Array size: $\quad 1$ cell.

SIMULATION DATA

Ckt Time IN INV0 INV1 INV2 INV3 INV4 INV5 INV6

$\begin{array}{lllllllll}0.000 n s & X & X & X & x & x & x & x & x\end{array}$

$\begin{array}{lllllllll}1.000 n s & 0 & X & X & X & X & X & x & x\end{array}$

$\begin{array}{lllllllll}2.000 n s & 1 & 1 & 1 & 1 & 1 & 1 & 1 & 1\end{array}$

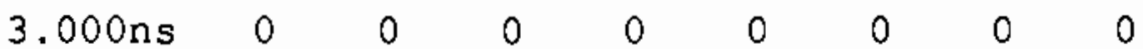

$\begin{array}{lllllllll}4.000 \mathrm{~ns} & 1 & 1 & 1 & 1 & 1 & 1 & 1 & 1\end{array}$

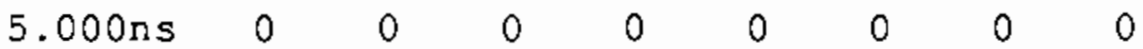

$\begin{array}{lllllllll}6.000 \text { ns } & 1 & 1 & 1 & 1 & 1 & 1 & 1 & 1\end{array}$

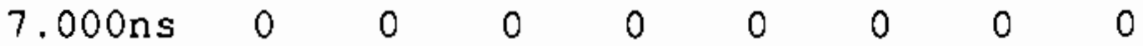

$\begin{array}{lllllllll}8.000 n s & 1 & 1 & 1 & 1 & 1 & 1 & 1 & 1\end{array}$

$\begin{array}{lllllllll}9.000 \mathrm{~ns} & 0 & 0 & 0 & 0 & 0 & 0 & 0 & 0\end{array}$

$\begin{array}{lllllllll}10.000 \mathrm{~ns} & 1 & 1 & 1 & 1 & 1 & 1 & 1 & 1\end{array}$

$11.000 \mathrm{~ns} \quad 0 \quad 0 \quad 00000000$

$\begin{array}{lllllllll}12.000 \mathrm{~ns} & 1 & 1 & 1 & 1 & 1 & 1 & 1 & 1\end{array}$

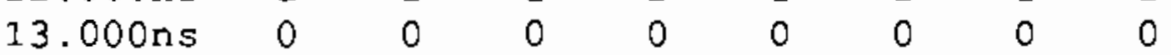

$\begin{array}{lllllllll}14.000 \mathrm{~ns} & 1 & 1 & 1 & 1 & 1 & 1 & 1 & 1\end{array}$

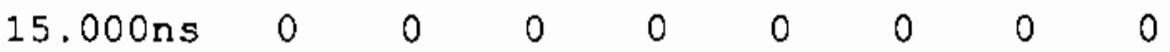

$\begin{array}{lllllllll}16.000 \mathrm{~ns} & 1 & 1 & 1 & 1 & 1 & 1 & 1 & 1\end{array}$

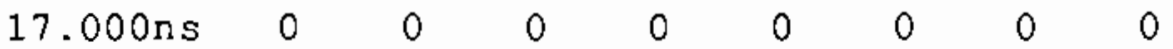

$\begin{array}{lllllllll}18.000 \mathrm{~ns} & 1 & 1 & 1 & 1 & 1 & 1 & 1 & 1\end{array}$

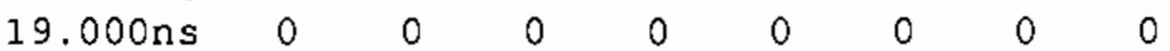

$\begin{array}{lllllllll}20.000 \mathrm{~ns} & 1 & 1 & 1 & 1 & 1 & 1 & 1 & 1\end{array}$

\section{PEREORMANCE}

$$
\begin{aligned}
& \text { Total simulation time }=38.8 \mathrm{uS} \\
& \text { Total circuit time }=21.0 \mathrm{nS} \\
& \text { Total events processed }=\quad 140 \\
& \text { Event throughput }=3.611 \mathrm{MHz}
\end{aligned}
$$


Ripeline Saturation Test 1 ( 8 inputs).

SIMULATION REPORT

Thu Eeb 28 11:32:24 1991

Circuit: Saturation test 1 ( 8 inputs)

Complexity: 8 gates.

Array size: 1 cell.

SIMULATION DATA

Ckt Time IN INV0 INV1 INV2 INV3 INV4 INV5 INV6 INV7

$\begin{array}{llllllllll}0.000 n s & x & x & x & x & x & x & x & x & x \\ 1.000 n s & 0 & x & x & x & x & x & x & x & x \\ 2.000 n s & 1 & 1 & 1 & 1 & 1 & 1 & 1 & 1 & 1 \\ 3.000 n s & 0 & 0 & 0 & 0 & 0 & 0 & 0 & 0 & 0 \\ 4.000 n s & 1 & 1 & 1 & 1 & 1 & 1 & 1 & 1 & 1 \\ 5.000 n s & 0 & 0 & 0 & 0 & 0 & 0 & 0 & 0 & 0 \\ 6.000 n s & 1 & 1 & 1 & 1 & 1 & 1 & 1 & 1 & 1 \\ 7.000 n s & 0 & 0 & 0 & 0 & 0 & 0 & 0 & 0 & 0 \\ 8.000 n s & 1 & 1 & 1 & 1 & 1 & 1 & 1 & 1 & 1 \\ 9.000 n s & 0 & 0 & 0 & 0 & 0 & 0 & 0 & 0 & 0 \\ 10.000 n s & 1 & 1 & 1 & 1 & 1 & 1 & 1 & 1 & 1 \\ 11.000 n s & 0 & 0 & 0 & 0 & 0 & 0 & 0 & 0 & 0 \\ 12.000 n s & 1 & 1 & 1 & 1 & 1 & 1 & 1 & 1 & 1 \\ 13.000 n s & 0 & 0 & 0 & 0 & 0 & 0 & 0 & 0 & 0 \\ 14.000 n s & 1 & 1 & 1 & 1 & 1 & 1 & 1 & 1 & 1 \\ 15.000 n s & 0 & 0 & 0 & 0 & 0 & 0 & 0 & 0 & 0 \\ 16.000 n s & 1 & 1 & 1 & 1 & 1 & 1 & 1 & 1 & 1 \\ 17.000 n s & 0 & 0 & 0 & 0 & 0 & 0 & 0 & 0 & 0 \\ 18.000 n s & 1 & 1 & 1 & 1 & 1 & 1 & 1 & 1 & 1 \\ 19.000 n s & 0 & 0 & 0 & 0 & 0 & 0 & 0 & 0 & 0 \\ 20.000 n s & 1 & 1 & 1 & 1 & 1 & 1 & 1 & 1 & 1\end{array}$

\section{PEREORMANCE}

$$
\begin{aligned}
& \text { Total simulation time }=43.9 \text { us } \\
& \text { Total circuit time }=21 \text {.0ns } \\
& \text { Total events processed }=160 \\
& \text { Event throughput }=3.646 \mathrm{MHz}
\end{aligned}
$$


Pipeline Saturation Test 2 (1 input).

Circuit: Saturation test 2 (1 input)

Complexity: 1 gate.

Array size: 1 cell.

\section{SIMULATION DATA}

Ckt Time IN INVO

0.000 ns $x \quad x$

1.000 ns $0 \quad x$

2.000ns 11

3.000 ns $0 \quad 0$

4.000 ns 11

$5.000 \mathrm{~ns} 00$

$6.000 \mathrm{~ns} \quad 1 \quad 1$

$7.000 n s \quad 0 \quad 0$

8.000 ns 11

$9.000 \mathrm{~ns} 00$

10.000 ns 11

$11.000 \mathrm{~ns} \quad 0 \quad 0$

$12.000 \mathrm{~ns} \quad 1 \quad 1$

$13.000 \mathrm{~ns} \quad 0 \quad 0$

14.000 ns 11

$15.000 \mathrm{~ns} 00$

$16.000 \mathrm{~ns} \quad 1 \quad 1$

$17.000 \mathrm{~ns} 00$

$18.000 \mathrm{~ns} \quad 1 \quad 1$

$19.000 \mathrm{~ns} 00$

20.000ns 11

\section{PERFORMANCE}

- - - - - - - -

Total simulation time $=\quad 8.0$ uS

Total circuit time $=21.0 \mathrm{~ns}$

Total events processed $=20$

Event throughput $=2.486 \mathrm{MHz}$ 
Pipeline Saturation Test 2 (2 inputs).

SIMULATION REPORT

Thu Feb 28 11:44:41 1991

Circuit: Saturation test 2 (2 inputs)

Complexity: 2 gates.

Array size: 1 cell.

SIMULATION DATA

Ckt Time IN INVO INV1

0.000 ns $x \quad x \quad x$

1.000 ns $0 \quad x \quad x$

$2.000 \mathrm{~ns} \quad 1 \quad 1 \quad 1$

$3.000 \mathrm{~ns} 0000$

4.000ns 1111

5.000ns 0000

6.000 ns 1111

$7.000 \mathrm{~ns} \quad 0 \quad 0 \quad 0$

$8.000 \mathrm{~ns} \quad 1 \quad 1 \quad 1$

$9.000 \mathrm{~ns} 000$

$10.000 \mathrm{~ns} \quad 1 \quad 1 \quad 1$

$11.000 \mathrm{~ns} \quad 0 \quad 0 \quad 0$

$\begin{array}{llll}12.000 \mathrm{~ns} & 1 & 1 & 1\end{array}$

$13.000 \mathrm{~ns} \quad 0 \quad 0 \quad 0$

$14.000 \mathrm{~ns} \quad 1 \quad 1 \quad 1$

15.000 ns $0 \quad 000$

$16.000 \mathrm{~ns} \quad 1 \quad 1 \quad 1$

17.000 ns $0 \quad 000$

$18.000 \mathrm{~ns} \quad 1 \quad 1 \quad 1$

$19.000 \mathrm{~ns} \quad 0 \quad 0 \quad 0$

20.000ns 1111

\section{PERFORMANCE}

\footnotetext{
Total simulation time $=13.2 \mathrm{uS}$

Total circuit time $=21.0 \mathrm{nS}$

Total events processed $=40$

Event throughput $=3.038 \mathrm{MHz}$
} 
Pipeline Saturation Test 2 ( 3 inputs).

Circuit: Saturation test 2 (3 inputs)

Complexity: 3 gates.

Array size: 1 cell.

SIMULATION DATA

Ckt Time IN INVO INV1 INV2

0.000 ns $x \quad x \quad x \quad x$

$\begin{array}{lllll}0.000 n s & x & x & x\end{array}$

$\begin{array}{lllll}2.000 \mathrm{~ns} & 1 & 1 & 1 & 1\end{array}$

3.000ns 000000

$\begin{array}{lllll}4.000 n s & 1 & 1 & 1 & 1\end{array}$

$5.000 \pi \mathrm{n} \quad 0 \quad 0 \quad 000$

$\begin{array}{lllll}6.000 \mathrm{~ns} & 1 & 1 & 1 & 1\end{array}$

7.000 ns 000000

8.000 ns 110111

$9.000 \mathrm{~ns} \quad 0 \quad 0 \quad 000$

$10.000 \mathrm{~ns} \quad 1 \quad 1 \quad 11$

11.000 ns $0 \quad 0 \quad 000$

$12.000 \mathrm{~ns} \quad 1 \quad 1 \quad 11$

$13.000 \mathrm{~ns} \quad 0 \quad 0 \quad 000$

$\begin{array}{lllll}14.000 \mathrm{~ns} & 1 & 1 & 1 & 1\end{array}$

$15.000 \mathrm{~ns} \quad 0 \quad 0 \quad 000$

$16.000 \mathrm{~ns} \quad 1 \quad 1 \quad 11$

$17.000 \mathrm{~ns} \quad 0 \quad 0 \quad 000$

$18.000 \mathrm{~ns} \quad 1 \quad 1 \quad 111$

$19.000 \mathrm{~ns} \quad 0 \quad 0 \quad 000$

20.000ns 111111

\section{PEREORMANCE}

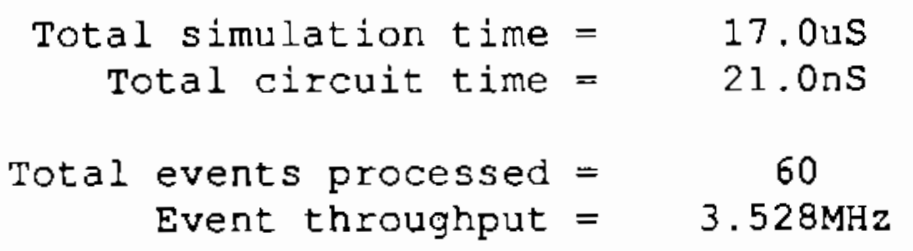


Pipeline Saturation Test 2 (4 inputs).

SIMULATION REPORT

Thu Feb 28 11:45:20 1991

Circuit: Saturation test 2 (4 inputs)

Complexity: $\quad 4$ gates.

Array size: 1 cell.

SIMULATION DATA

Ckt Time IN INV0 INV1 INV2 INV3

0.000 ns $x \quad x \quad x \quad x \quad x$

1.000ns $0 \quad x \quad x \quad x \quad x$

$\begin{array}{llllll}2.000 \mathrm{~ns} & 1 & 1 & 1 & 1 & 1\end{array}$

$3.000 n s \quad 0 \quad 0 \quad 00000$

$\begin{array}{llllll}4.000 \text { ns } & 1 & 1 & 1 & 1 & 1\end{array}$

$5.000 \mathrm{~ns} \quad 0 \quad 000000$

$\begin{array}{llllll}6.000 \mathrm{~ns} & 1 & 1 & 1 & 1 & 1\end{array}$

7.000 ns $0 \quad 0000000$

$\begin{array}{llllll}8.000 \mathrm{~ns} & 1 & 1 & 1 & 1 & 1\end{array}$

$9.000 \mathrm{~ns} \quad 0 \quad 0 \quad 00000$

$\begin{array}{llllll}10.000 n s & 1 & 1 & 1 & 1 & 1\end{array}$

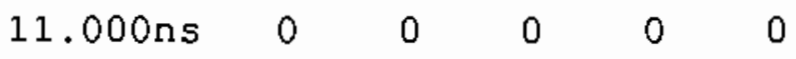

$\begin{array}{llllll}12.000 n s & 1 & 1 & 1 & 1 & 1\end{array}$

13.000 ns $0 \quad 0 \quad 0 \quad 0 \quad 000$

$\begin{array}{llllll}14.000 \mathrm{~ns} & 1 & 1 & 1 & 1 & 1\end{array}$

$15.000 \mathrm{~ns} \quad 0 \quad 000000$

$\begin{array}{llllll}16.000 \mathrm{~ns} & 1 & 1 & 1 & 1 & 1\end{array}$

$17.000 \mathrm{~ns} \quad 0 \quad 0000000$

$\begin{array}{llllll}18.000 \mathrm{~ns} & 1 & 1 & 1 & 1 & 1\end{array}$

19.000 ns 00100000

$\begin{array}{llllll}20.000 \mathrm{~ns} & 1 & 1 & 1 & 1 & 1\end{array}$

\section{PERFORMANCE}

\footnotetext{
Total simulation time $=22.1 \mathrm{uS}$

Total circuit time $=21.0 \mathrm{~ns}$

Total events processed $=\quad 80$

Event throughput $=3.616 \mathrm{MHz}$
} 
Pipeline Saturation Test 2 (5 inputs).

Circuit: Saturation test 2 (5 inputs)

Complexity: 5 gates.

Array size: 1 cell.

SIMULATION DATA

Ckt Time IN INV0 INV1 INV2 INV3 INV4

$\begin{array}{lllllll}0.000 n s & X & x & x & x & x & x\end{array}$

$\begin{array}{lllllll}0.000 n s & 0 & x & x & x & x & x\end{array}$

$\begin{array}{lllllll}2.000 \mathrm{~ns} & 1 & 1 & 1 & 1 & 1 & 1\end{array}$

3.000ns $0 \quad 0 \quad 000000$

$\begin{array}{lllllll}4.000 \mathrm{~ns} & 1 & 1 & 1 & 1 & 1 & 1\end{array}$

$5.000 \mathrm{~ns} \quad 0 \quad 0000000$

$\begin{array}{lllllll}6.000 \mathrm{~ns} & 1 & 1 & 1 & 1 & 1 & 1\end{array}$

$7.000 \mathrm{~ns} \quad 0 \quad 0000000$

$\begin{array}{lllllll}8.000 \mathrm{~ns} & 1 & 1 & 1 & 1 & 1 & 1\end{array}$

$9.000 \mathrm{~ns} \quad 0 \quad 0000000$

$\begin{array}{lllllll}10.000 \mathrm{~ns} & 1 & 1 & 1 & 1 & 1 & 1\end{array}$

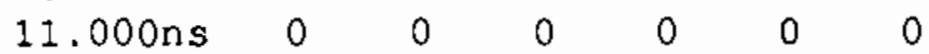

$\begin{array}{lllllll}12.000 \mathrm{~ns} & 1 & 1 & 1 & 1 & 1 & 1\end{array}$

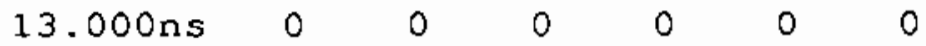

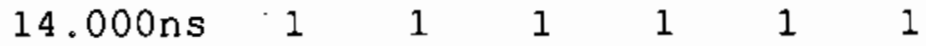

$15.000 \mathrm{~ns} \quad 0 \quad 0 \quad 000000$

$\begin{array}{lllllll}16.000 \mathrm{~ns} & 1 & 1 & 1 & 1 & 1 & 1\end{array}$

$17.000 \mathrm{~ns} \quad 0 \quad 0 \quad 000000$

$\begin{array}{lllllll}18.000 \mathrm{~ns} & 1 & 1 & 1 & 1 & 1 & 1\end{array}$

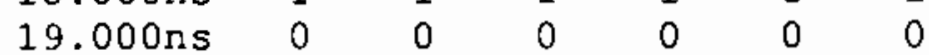

$\begin{array}{lllllll}20.000 \mathrm{~ns} & 1 & 1 & 1 & 1 & 1 & 1\end{array}$

\section{PERFORMANCE}

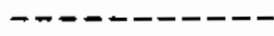

Total simulation time $=$

26.0us

Total circuit time $=$

$21.0 n s$

Total events processed $=$

Event throughput $=$ 
Ripeline Saturation Test 2 (6 inputs).

SIMULATION REPORT

Thu Feb 28 11:48:11 1991

Circuit: Saturation test 2 (6 inputs)

Complexity: 6 gates.

Array size: $\quad 1$ cell.

\section{SIMULATION DATA}

Ckt Time IN INV0 INV1 INV2 INV3 INV4 INV5

$\begin{array}{llllllll}0.000 n s & X & X & X & X & x & x & X\end{array}$

1.000 ns $0 \quad x \quad x \quad x \quad x \quad x \quad x$

$\begin{array}{llllllll}2.000 n s & 1 & 1 & 1 & 1 & 1 & 1 & 1\end{array}$

$\begin{array}{llllllll}3.000 n s & 0 & 0 & 0 & 0 & 0 & 0 & 0\end{array}$

$\begin{array}{llllllll}4.000 \text { ns } & 1 & 1 & 1 & 1 & 1 & 1 & 1\end{array}$

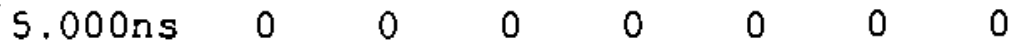

$\begin{array}{llllllll}6.000 \mathrm{~ns} & 1 & 1 & 1 & 1 & 1 & 1 & 1\end{array}$

$7.000 \mathrm{~ns} \quad 0 \quad 001000000$

$\begin{array}{llllllll}8.000 \text { ns } & 1 & 1 & 1 & 1 & 1 & 1 & 1\end{array}$

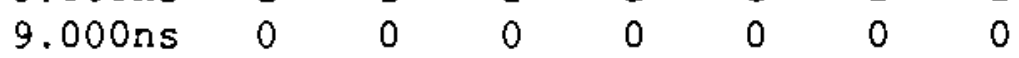

$\begin{array}{llllllll}10.000 \mathrm{~ns} & 1 & 1 & 1 & 1 & 1 & 1 & 1\end{array}$

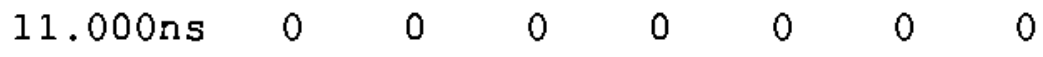

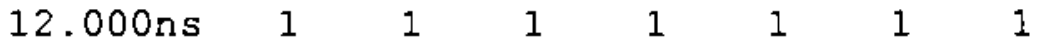

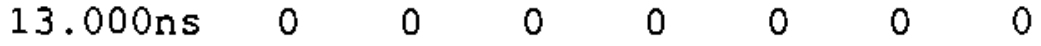

$\begin{array}{llllllll}14.000 \text { ns } & 1 & 1 & 1 & 1 & 1 & 1 & 1\end{array}$

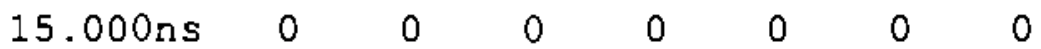

$\begin{array}{llllllll}16.000 \mathrm{~ns} & 1 & 1 & 1 & 1 & 1 & 1 & 1\end{array}$

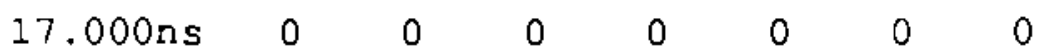

$\begin{array}{llllllll}18.000 n s & 1 & 1 & 1 & 1 & 1 & 1 & 1\end{array}$

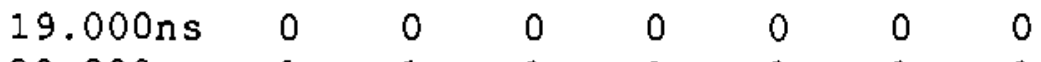

$\begin{array}{llllllll}20.000 n s & 1 & 1 & 1 & 1 & 1 & 1 & 1\end{array}$

\section{PERFORMANCE}

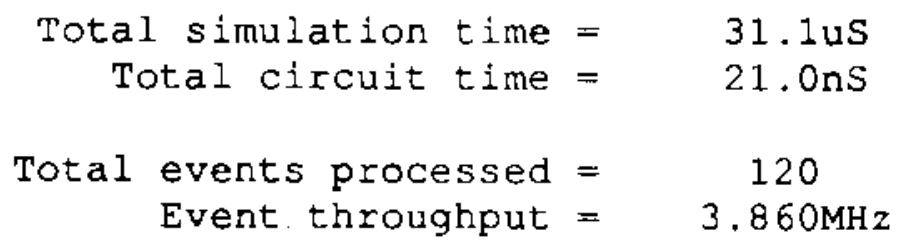


Pipeline Saturation Test 2 ( 7 inputs).

Circuit: Saturation test 2 ( 7 inputs)

Complexity: $\quad 7$ gates.

Array size: 1 cell.

\section{SIMULATION DATA}

Ckt Time IN INVO INV1 INV2 INV3 INV4 INVS INV6

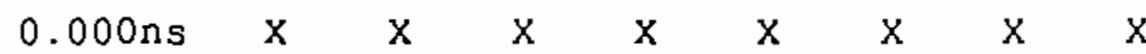

$\begin{array}{lllllllll}1.000 \text { ns } & 0 & x & x & x & x & x & x & x\end{array}$

$\begin{array}{lllllllll}2.000 \mathrm{~ns} & 1 & 1 & 1 & 1 & 1 & 1 & 1 & 1\end{array}$

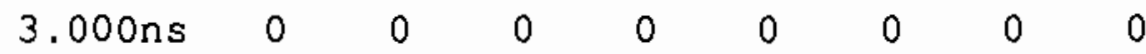

$\begin{array}{lllllllll}4.000 \text { ns } & 1 & 1 & 1 & 1 & 1 & 1 & 1 & 1\end{array}$

$\begin{array}{lllllllll}5.000 \mathrm{~ns} & 0 & 0 & 0 & 0 & 0 & 0 & 0 & 0\end{array}$

$\begin{array}{lllllllll}6.000 \mathrm{~ns} & 1 & 1 & 1 & 1 & 1 & 1 & 1 & 1\end{array}$

$\begin{array}{lllllllll}7.000 \mathrm{~ns} & 0 & 0 & 0 & 0 & 0 & 0 & 0 & 0\end{array}$

$\begin{array}{lllllllll}8.000 \mathrm{~ns} & 1 & 1 & 1 & 1 & 1 & 1 & 1 & 1\end{array}$

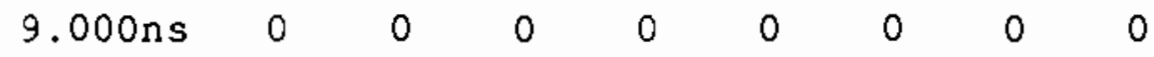

$\begin{array}{lllllllll}10.000 \mathrm{~ns} & 1 & 1 & 1 & 1 & 1 & 1 & 1 & 1\end{array}$

$11.000 \mathrm{~ns} \quad 0 \quad 0 \quad 00000000$

$\begin{array}{lllllllll}12.000 \mathrm{~ns} & 1 & 1 & 1 & 1 & 1 & 1 & 1 & 1\end{array}$

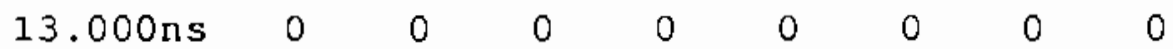

$\begin{array}{lllllllll}14.000 \mathrm{~ns} & 1 & 1 & 1 & 1 & 1 & 1 & 1 & 1\end{array}$

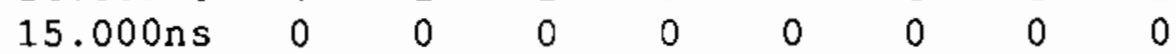

$\begin{array}{lllllllll}16.000 \mathrm{~ns} & 1 & 1 & 1 & 1 & 1 & 1 & 1 & 1\end{array}$

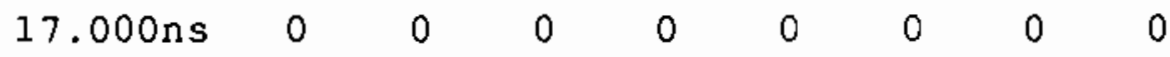

$\begin{array}{lllllllll}18.000 \mathrm{~ns} & 1 & 1 & 1 & 1 & 1 & 1 & 1 & 1\end{array}$

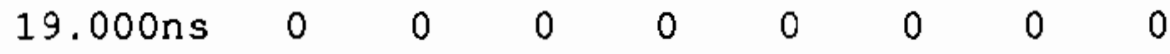

$\begin{array}{lllllllll}20.000 \mathrm{~ns} & 1 & 1 & 1 & 1 & 1 & 1 & 1 & 1\end{array}$

\section{PERFORMANCE}

\footnotetext{
Total simulation time $=34.9$ us

Total circuit time $=21.0 \mathrm{nS}$

Total events processed $=\quad 140$ Event throughput $=4.008 \mathrm{MHz}$
} 
Ripeline Saturation Test 2 (8 inputs).

SIMULATION REPORT

Thu Feb $28 \quad 11: 49: 37 \quad 1991$

Circuit: Saturation test 2 (8 inputs)

Complexity: 8 gates.

Array size: $\quad 1$ cell.

SIMULATION DATA

Ckt Time IN INV0 INV1 INV2 INV3 INV4 INV5 INV6 INV7

$\begin{array}{llllllllll}0.000 \mathrm{~ns} & \mathrm{X} & \mathrm{X} & \mathrm{X} & \mathrm{X} & \mathrm{X} & \mathrm{X} & \mathrm{X} & \mathrm{X} & \mathrm{X} \\ 1.000 \mathrm{~ns} & 0 & \mathrm{X} & \mathrm{X} & \mathrm{X} & \mathrm{X} & \mathrm{X} & \mathrm{X} & \mathrm{X} & \mathrm{X} \\ 2.000 \mathrm{~ns} & 1 & 1 & 1 & 1 & 1 & 1 & 1 & 1 & 1 \\ 3.000 \mathrm{~ns} & 0 & 0 & 0 & 0 & 0 & 0 & 0 & 0 & 0 \\ 4.000 \mathrm{~ns} & 1 & 1 & 1 & 1 & 1 & 1 & 1 & 1 & 1 \\ 5.000 \mathrm{~ns} & 0 & 0 & 0 & 0 & 0 & 0 & 0 & 0 & 0 \\ 6.000 \mathrm{~ns} & 1 & 1 & 1 & 1 & 1 & 1 & 1 & 1 & 1 \\ 7.000 \mathrm{~ns} & 0 & 0 & 0 & 0 & 0 & 0 & 0 & 0 & 0 \\ 8.000 \mathrm{~ns} & 1 & 1 & 1 & 1 & 1 & 1 & 1 & 1 & 1 \\ 9.000 \mathrm{~ns} & 0 & 0 & 0 & 0 & 0 & 0 & 0 & 0 & 0 \\ 10.000 \mathrm{~ns} & 1 & 1 & 1 & 1 & 1 & 1 & 1 & 1 & 1 \\ 11.000 \mathrm{~ns} & 0 & 0 & 0 & 0 & 0 & 0 & 0 & 0 & 0 \\ 12.000 \mathrm{~ns} & 1 & 1 & 1 & 1 & 1 & 1 & 1 & 1 & 1 \\ 13.000 \mathrm{~ns} & 0 & 0 & 0 & 0 & 0 & 0 & 0 & 0 & 0 \\ 14.000 \mathrm{~ns} & 1 & 1 & 1 & 1 & 1 & 1 & 1 & 1 & 1 \\ 15.000 \mathrm{~ns} & 0 & 0 & 0 & 0 & 0 & 0 & 0 & 0 & 0 \\ 16.000 \mathrm{~ns} & 1 & 1 & 1 & 1 & 1 & 1 & 1 & 1 & 1 \\ 17.000 \mathrm{~ns} & 0 & 0 & 0 & 0 & 0 & 0 & 0 & 0 & 0 \\ 18.000 \mathrm{~ns} & 1 & 1 & 1 & 1 & 1 & 1 & 1 & 1 & 1 \\ 19.000 \mathrm{~ns} & 0 & 0 & 0 & 0 & 0 & 0 & 0 & 0 & 0 \\ 20.000 \mathrm{~ns} & 1 & 1 & 1 & 1 & 1 & 1 & 1 & 1 & 1\end{array}$

PERFORMANCE

$\begin{array}{rlr}\text { Total simulation time } & = & 40.0 \mathrm{us} \\ \text { Total circuit time } & = & 21.0 \mathrm{nS} \\ \text { Total events processed } & = & 160 \\ \text { Event throughput } & = & 3.995 \mathrm{MHz}\end{array}$




\section{4}

zero-delay path test ( $Q$ wires)

SIMULATION REPORT

Wed Mar $2015: 12: 561991$

Circuit: Two inverters - no wires (PATHTSTO.NET)

Complexity: $\quad 2$ gates.

Array size: 2 cells.

\section{SIMULATION DATA}

Ckt Time IN OUT

$\begin{array}{ccc}0.000 \mathrm{~ns} & \mathrm{x} & \mathrm{x} \\ 1.000 \mathrm{~ns} & 0 & \mathrm{x} \\ 2.000 \mathrm{~ns} & 1 & \mathrm{x} \\ 3.000 \mathrm{~ns} & 0 & 0 \\ 4.000 \mathrm{~ns} & 1 & 1 \\ 5.000 \mathrm{~ns} & 0 & 0 \\ 6.00 \mathrm{~ns} & 1 & 1 \\ 7.00 \mathrm{~ns} & 0 & 0 \\ 8.000 \mathrm{~ns} & 1 & 1 \\ 9.000 \mathrm{~ns} & 0 & 0 \\ 10.000 \mathrm{~ns} & 1 & 1 \\ 11.000 \mathrm{~ns} & 0 & 0 \\ 12.000 \mathrm{~ns} & 1 & 1 \\ 13.000 \mathrm{~ns} & 0 & 0 \\ 14.000 \mathrm{~ns} & 1 & 1 \\ 15.000 \mathrm{~ns} & 0 & 0 \\ 16.000 \mathrm{~ns} & 1 & 1 \\ 17.000 \mathrm{~ns} & 0 & 0 \\ 18.000 \mathrm{~ns} & 1 & 1 \\ 19.000 \mathrm{~ns} & 0 & 0 \\ 20.000 \mathrm{~ns} & 1 & 1\end{array}$

PERFORMANCE

$$
\begin{aligned}
& \text { Total simulation time }=8.1 \text { us } \\
& \text { Total circuit time }=21.0 \mathrm{nS} \\
& \text { Total events processed }=\quad 39 \\
& \text { Event throughput }=4.809 \mathrm{MHz}
\end{aligned}
$$


Zero-delay path test (1 wire)

SIMULATION REPORT

Wed Mar $20 \quad 15: 13: 421991$

Circuit: Two inverters - 1 wire (PATHTST1.NET)

$\begin{array}{ll}\text { Complexity: } & 2 \text { gates. } \\ \text { Array size: } & 3 \text { cells. }\end{array}$

Array size: 3 cells.

SIMULATION DATA

Ckt Time IN OUT

0.000 ns $\mathrm{x} x$

1.000 ns $0 \quad x$

2.000ns $1 \mathrm{x}$

3.000 ns 00

4.000ns 11

5.000ns 00

$6.000 \mathrm{~ns} 11$

7.000 ns 00

$8.000 \mathrm{~ns} 11$

$9.000 \mathrm{~ns} \quad 0 \quad 0$

$10.000 \mathrm{~ns} \quad 1 \quad 1$

$11.000 \mathrm{~ns} 00$

$12.000 \mathrm{~ns} 11$

$13.000 \mathrm{~ns} 00$

$14.000 \mathrm{~ns} \quad 1 \quad 1$

$15.000 \mathrm{~ns} 00$

$16.000 \mathrm{~ns} \quad 1 \quad 1$

$17.000 \mathrm{~ns} 00$

$18.000 \mathrm{~ns} 1$

$19.000 \mathrm{~ns} \quad 0 \quad 0$

20.000ns 11

\section{PEREORMANCE}

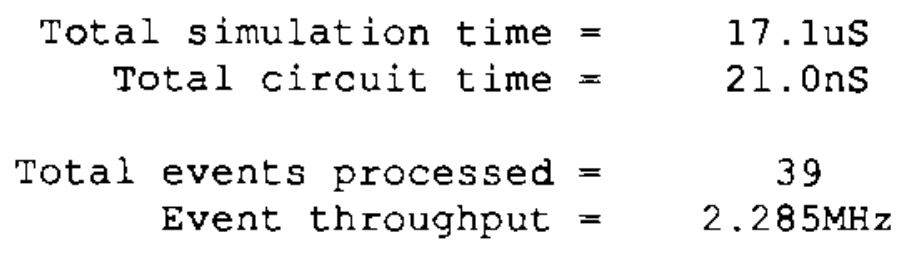


Zero-delay path test (2 wires) SIMULATION REPORT

Wed Mar $2015: 16: 441991$

Circuit: Two inverters - 2 wires (PATHTST2.NET)

Complexity: 2 gates.

Array size: 4 cells.

\section{SIMULATION DATA}

$\begin{array}{ccc}\text { Ckt Time } & \text { IN } & \text { OUT } \\ 0.000 \mathrm{~ns} & \mathrm{X} & \mathrm{X} \\ 1.000 \mathrm{~ns} & 0 & \mathrm{X} \\ 2.000 \mathrm{~ns} & 1 & \mathrm{X} \\ 3.00 \mathrm{~ns} & 0 & 0 \\ 4.000 \mathrm{~ns} & 1 & 1 \\ 5.000 \mathrm{~ns} & 0 & 0 \\ 6.000 \mathrm{~ns} & 1 & 1 \\ 7.000 \mathrm{~ns} & 0 & 0 \\ 8.000 \mathrm{~ns} & 1 & 1 \\ 9.000 \mathrm{~ns} & 0 & 0 \\ 10.000 \mathrm{~ns} & 1 & 1 \\ 11.000 \mathrm{~ns} & 0 & 0 \\ 12.000 \mathrm{~ns} & 1 & 1 \\ 13.000 \mathrm{~ns} & 0 & 0 \\ 14.000 \mathrm{~ns} & 1 & 1 \\ 15.000 \mathrm{~ns} & 0 & 0 \\ 16.000 \mathrm{~ns} & 1 & 1 \\ 17.000 \mathrm{~ns} & 0 & 0 \\ 18.000 \mathrm{~ns} & 1 & 1 \\ 19.000 \mathrm{~ns} & 0 & 0 \\ 20.000 \mathrm{~ns} & 1 & 1\end{array}$

\section{PERFORMANCE}

\footnotetext{
Total simulation time $=26.0 u s$ Total circuit time $=21.0 n S$

Total events processed $=\quad 39$ Event throughput $=1.498 \mathrm{MHz}$
} 
Zere-delay path test ( 3 wires) SIMULATION REPORT

Wed Mar 20 15:18:41 1991

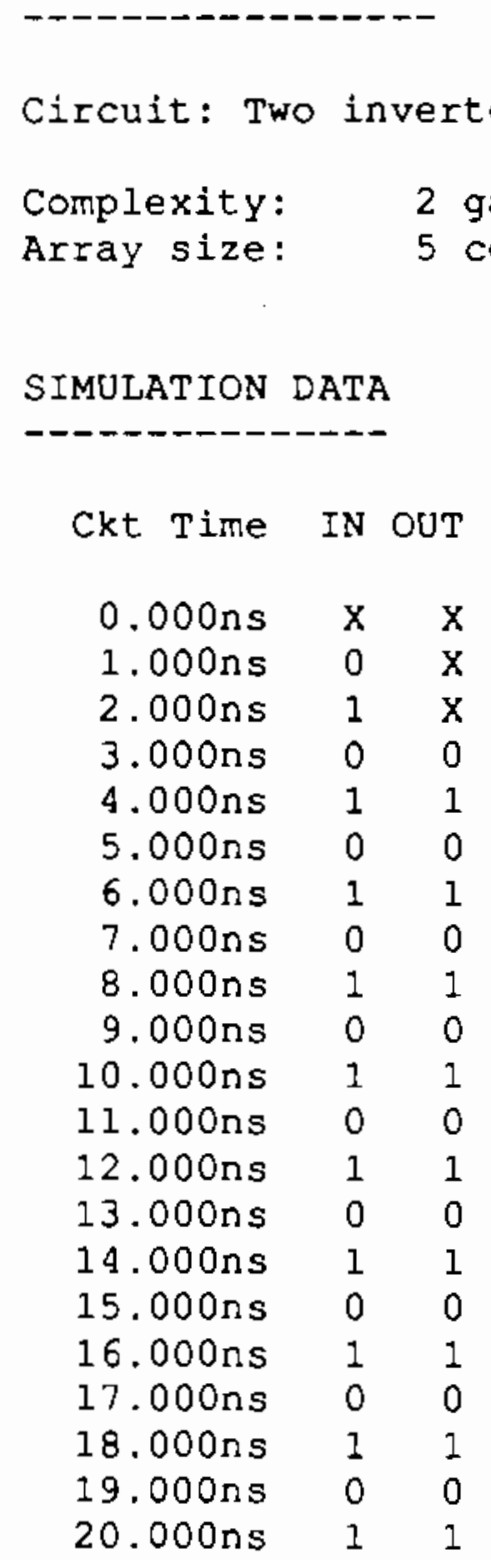

PERFORMANCE

$$
\begin{aligned}
& \text { Total simulation } \text { time }=35 \text {.0us } \\
& \text { Total circuit time }=21.0 \mathrm{~ns} \\
& \text { Total events processed }=\quad 39 \\
& \text { Event throughput }=1.115 \mathrm{MHz}
\end{aligned}
$$


Zero-delay path test (4 wires)

SIMULATION REPORT

Wed Mar 20 15:23:30 1991

Circuit: Two inverters - 4 wires (PATHTST4.NET)

Complexity: $\quad 2$ gates.

Array size: 6 cells.

SIMULATION DATA

Ckt Time IN OUT

$0.000 n s \quad x \quad x$

1.000 ns $0 \quad x$

2.000ns $1 \mathrm{X}$

$3.000 \mathrm{~ns} 00$

4.000ns 111

5.000 ns $0 \quad 0$

6.000ns 11

7.000 ns 00

8.000 ns 11

$9.000 \mathrm{~ns} 00$

$10.000 \mathrm{~ns} \quad 1 \quad 1$

$11.000 \mathrm{~ns} 00$

$12.000 \mathrm{~ns} 11$

13.000 ns 00

$14.000 \mathrm{~ns} 1$

$15.000 \mathrm{~ns} 00$

$16.000 \mathrm{~ns} 1$

$17.000 \mathrm{~ns} 00$

$18.000 \mathrm{~ns} 1$

$19.000 \mathrm{~ns} \quad 0 \quad 0$

20.000ns 11

\section{PEREORMANCE}

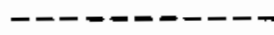

Total simulation time $=44.0 u \mathrm{~S}$

Total circuit time $=21.0 \mathrm{nS}$

Total events processed $=\quad 39$

Event throughput $=0.887 \mathrm{MHz}$ 
Zero-delay path test (5 wires) SIMULATION REPORT

Wed Mar 20 15:24:31 1991

Circuit: Two inverters - 5 wires (PATHTST5.NET)

Complexity: 2 gates.

Array size: 7 cells.

SIMULATION DATA

Ckt Time IN OUT

$0.000 \mathrm{~ns} \quad \mathrm{x} x$

1.000ns $0 \mathrm{x}$

2.000ns $1 \mathrm{x}$

$3.000 \mathrm{~ns} \quad 0 \quad 0$

4.000ns 11

5.000ns 00

6.000ns 111

7.000 ns 00

$8.000 \mathrm{~ns} 11$

$9.000 \mathrm{~ns} \quad 0 \quad 0$

$10.000 \mathrm{~ns} \quad 1 \quad 1$

$11.000 \mathrm{~ns} 00$

$12.000 \mathrm{~ns} \quad 1 \quad 1$

$13.000 \mathrm{~ns} \quad 0 \quad 0$

$14.000 \mathrm{~ns} \quad 1 \quad 1$

$15.000 \mathrm{~ns} 00$

$16.000 \mathrm{~ns} \quad 1 \quad 1$

$17.000 \mathrm{~ns} 00$

$18.000 \mathrm{~ns} \quad 1 \quad 1$

$19.000 \mathrm{~ns} 00$

20.000 ns 11

PERFORMANCE

--D---D-D-D
Total simulation time =
52. 9us
Total circuit time $=$
$21.0 \mathrm{nS}$
Total events processed = 
Zero-delay path test ( 6 wires)

Circuit: Two inverters - 6 wires (PATHTST6.NET)

Complexity: 2 gates.

Array size: 8 cells.

\section{SIMULATION DATA}

Ckt Time IN OUT

0.000 ns $\mathrm{X} x$

1.000ns $0 \quad x$

2.000ns $1 \mathrm{x}$

$3.000 \mathrm{~ns} \quad 0 \quad 0$

4.000ns 11

$5.000 n s \quad 00$

6.000 ns 11

7.000 ns 00

$8.000 \mathrm{~ns} \quad 1 \quad 1$

$9.000 \mathrm{~ns} 00$

$10.000 \mathrm{~ns} \quad 1 \quad 1$

$11.000 \mathrm{~ns} 00$

$12.000 \mathrm{~ns} \quad 1 \quad 1$

$13.000 \mathrm{~ns} 00$

$14.000 \mathrm{~ns} \quad 1 \quad 1$

$15.000 \mathrm{~ns} 00$

$16.000 \mathrm{~ns} \quad 1 \quad 1$

$17.000 \mathrm{~ns} 00$

$18.000 \mathrm{~ns} \quad 1 \quad 1$

$19.000 \mathrm{~ns} 00$

20.000 ns 111

\section{PEREORMANCE}

\footnotetext{
- - - - - - - -

Total simulation time $=61.9 \mathrm{uS}$ Total circuit time $=21.0 \mathrm{~s}$

Total events processed $=\quad 39$ Event throughput $=0.630 \mathrm{MHz}$
} 
2ero-delay path test (7 wires)

SIMULATION REPORT

Wed Mar 20 15:32:21 1991

Circuit: Two inverters - 7 wires (PATHTST7.NET)

Complexity: $\quad 2$ gates.

Array size: 9 cells.

SIMULATION DATA

Ckt Time IN OUT

0.000 ns $x \quad x$

1.000ns $0 \mathrm{X}$

2.000ns $1 \mathrm{x}$

$3.000 \mathrm{~ns} 00$

4.000 ns 11

5.000 ns 00

$6.000 \mathrm{~ns} \quad 1 \quad 1$

$7.000 \mathrm{~ns} \quad 00$

8.000ns 11

$9.000 \mathrm{~ns} \quad 0 \quad 0$

$10.000 \mathrm{~ns} \quad 1 \quad 1$

$11.000 \mathrm{~ns} \quad 0 \quad 0$

$12.000 \mathrm{~ns} 1$

$13.000 \mathrm{~ns} 00$

$14.000 \mathrm{~ns} \quad 1 \quad 1$

$15.000 \mathrm{~ns} 00$

$16.000 \mathrm{~ns} \quad 1 \quad 1$

$17.000 \mathrm{~ns} 00$

$18.000 \mathrm{~ns} 1$

$19.000 \mathrm{~ns} \quad 0 \quad 0$

$20.000 \mathrm{~ns} \quad 1 \quad 1$

PERFORMANCE

- - - - - - -

Total simulation time $=70.8 \mathrm{us}$

Total circuit time $=21.0 \mathrm{~ns}$

Total events processed $=\quad 39$

Event throughput $=0.551 \mathrm{MHz}$ 
Zero-delay path test 18 wires 1

SIMULATION REPORT

Wed Mar 20 15:34:02 1991

Circuit: Two inverters - 8 wires (PATHTST8.NET)

Complexity: 2 gates.

Array size: 10 cells.

\section{SIMULATION DATA}

Ckt Time IN OUT

$0.000 n s \quad x \quad x$

1.000 ns $0 \quad X$

2.000ns $1 \mathrm{X}$

3.000 ns 00

$4.000 \mathrm{~ns} 11$

$5.000 \mathrm{~ns} \quad 0 \quad 0$

6.000 ns 11

7.000 ns 00

8.000 ns 11

$9.000 \mathrm{~ns} 00$

$10.000 \mathrm{~ns} \quad 1 \quad 1$

$11.000 \mathrm{~ns} 00$

$12.000 \mathrm{~ns} \quad 1 \quad 1$

$13.000 \mathrm{~ns} 00$

14.000 ns 11

$15.000 \mathrm{~ns} 00$

$16.000 \mathrm{~ns} \quad 1 \quad 1$

17.000 ns 00

18.000 ns 11

19.000 ns 00

20.000ns 11

\section{PEREORMANCE}

\footnotetext{
Total simulation time $=79.8 \mathrm{uS}$

Total circuit time $=21.0 \mathrm{~s}$

Total events processed $=\quad 39$

Event throughput $=0.489 \mathrm{MHz}$
} 
cross-coupled NAND.

SIMULATION REPORT

Thu Feb 28 09:32:14 1991

Circuit: SR Flip-Flop in two nodes (SR2.NET)

Complexity: 2 gates.

Array size: 2 cells.

\section{SIMULATION DATA}

$\begin{array}{lllll}\text { Ckt Time } & \text { S R } & Q & Q^{*} \\ 0.000 \mathrm{~ns} & \mathrm{X} & \mathrm{X} & \mathrm{X} & \mathrm{X} \\ 1.000 \mathrm{~ns} & 1 & 1 & \mathrm{X} & \mathrm{X} \\ 2.000 \mathrm{~ns} & 1 & 1 & \mathrm{X} & \mathrm{X} \\ 3.000 \mathrm{~ns} & 0 & 0 & \mathrm{X} & \mathrm{X} \\ 4.000 \mathrm{~ns} & 0 & 0 & 1 & 1 \\ 5.000 \mathrm{~ns} & 1 & 1 & 1 & 1 \\ 6.000 \mathrm{~ns} & 1 & 1 & 0 & 0 \\ 7.000 \mathrm{~ns} & 1 & 1 & 1 & 1 \\ 8.000 \mathrm{~ns} & 1 & 1 & 0 & 0 \\ 9.000 \mathrm{~ns} & 1 & 1 & 1 & 1 \\ 10.000 \mathrm{~ns} & 1 & 1 & 0 & 0 \\ 11.000 \mathrm{~ns} & 1 & 1 & 1 & 1 \\ 12.000 \mathrm{~ns} & 1 & 1 & 0 & 0 \\ 13.000 \mathrm{~ns} & 1 & 1 & 1 & 1 \\ 14.000 \mathrm{~ns} & 1 & 1 & 0 & 0 \\ 15.000 \mathrm{~ns} & 1 & 1 & 1 & 1 \\ 16.000 \mathrm{~ns} & 1 & 1 & 0 & 0 \\ 17.000 \mathrm{~ns} & 1 & 1 & 1 & 1 \\ 18.000 \mathrm{~ns} & 1 & 1 & 0 & 0 \\ 19.000 \mathrm{~ns} & 1 & 1 & 1 & 1 \\ 20.000 \mathrm{~ns} & 1 & 1 & 0 & 0 \\ 21.000 \mathrm{~ns} & 1 & 1 & 1 & 1 \\ 22.000 \mathrm{~ns} & 0 & 1 & 0 & 0 \\ 23.000 \mathrm{~ns} & 0 & 1 & 1 & 1 \\ 24.000 \mathrm{~ns} & 1 & 1 & 1 & 0 \\ 25.000 \mathrm{~ns} & 1 & 1 & 1 & 0 \\ 26.000 \mathrm{~ns} & 1 & 1 & 1 & 0 \\ 27.000 \mathrm{~ns} & 1 & 1 & 1 & 0 \\ 28.000 \mathrm{~ns} & 1 & 0 & 1 & 0 \\ 29.000 \mathrm{~ns} & 1 & 0 & 1 & 1 \\ 30.000 \mathrm{~ns} & 1 & 1 & 0 & 1 \\ & & & & \end{array}$




\section{4}

$\begin{array}{lllll}31.000 \mathrm{~ns} & 1 & 1 & 0 & 1 \\ 32.000 \mathrm{~ns} & 1 & 1 & 0 & 1 \\ 33.000 \mathrm{~ns} & 1 & 1 & 0 & 1 \\ 34.000 \mathrm{~ns} & 1 & 1 & 0 & 1 \\ 35.000 \mathrm{~ns} & 1 & 1 & 0 & 1 \\ 36.000 \mathrm{~ns} & 1 & 1 & 0 & 1\end{array}$

\section{PERFORMANCE}

\section{ーーーローーーーーーー}

Total simulation time = Total circuit time $=$

Total events processed $=$ Event throughput $=$
12.1 us

$37.0 \mathrm{nS}$

42

$3.459 \mathrm{MHz}$ 
BET D FIIR-FIOR.

SIMULATION REPORT

Thu Feb 28 08:31:44 1991

Circuit: Rising edge trig D FF (RETDFF.NET)

SIMULATION DATA

Ckt Time CLK CLR D Q Q*

0.000 ns $\mathrm{X} \times \mathrm{x} \times \mathrm{x}$

$1.000 \mathrm{~ns} \quad 0 \quad 00 \mathrm{x} x$

2.000ns $000 x \quad x$

3.000ns 00001

4.000 ns $\quad 0 \quad 000001$

5.000ns $11 \quad 000001$

$\begin{array}{llllll}6.000 n s & 1 & 1 & 0 & 0 & 1\end{array}$

$7.000 \mathrm{~ns} \quad 1 \quad 10001$

$8.000 \mathrm{~ns} \quad 1 \quad 11001$

$9.000 \mathrm{~ns} \quad 0 \quad 111001$

$10.000 \mathrm{~ns} \quad 0 \quad 111001$

11.000 ns $\quad 0 \quad 111001$

$12.000 n 5 \quad 0 \quad 111001$

13.000ns $11 \quad 110001$

14.000ns 11011001

15.000ns 111110

16.000ns $\quad 1 \quad 10001$

$17.000 \mathrm{~ns} \quad 0 \quad 1 \quad 00110$

$18.000 \mathrm{~ns} \quad 0 \quad 10010$

I9.000ns 00100

20.000ns $0 \quad 1 \quad 00110$

21.000ns $\quad 1 \quad 100110$

$22.000 \mathrm{~ns} \quad 1 \quad 120110$

23.000ns 1110110

24.000ns $\quad 1 \quad 10011$

25.000ns $\quad 0 \quad 100001$

26.000ns $\quad 0 \quad 10001$

27.000ns $\quad 0 \quad 1 \quad 00001$

28.000ns $\quad 0 \quad 160001$

29.000ns $11 \quad 1 \quad 0001$

30.000ns $11 \quad 10001$

31.000ns $\quad 1 \quad 110001$

32.000ns 1110001 


\section{PERFORMANCE}

-----------

Total simulation time $=\quad 12.7 \mathrm{us}$

Total circuit time $=33.0 \mathrm{~ns}$

Total events processed =

31

Event throughput $=2.437 \mathrm{MHz}$ 
4-bit counter.

SIMULATION REPORT

Thu Feb 28 08:41:00 1991

Circuit: 4-Bit Binary Counter (COUNTER.NET)

\section{SIMULATION DATA}

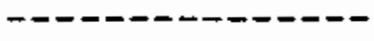

Ckt Time CLK CLR CNT

$\begin{array}{llll}0.000 \mathrm{~ns} & \mathrm{x} & \mathrm{x} & \mathrm{x} \\ 1.000 \mathrm{~ns} & 0 & 0 & \mathrm{x} \\ 2.000 \mathrm{~ns} & 0 & 0 & \mathrm{x} \\ 3.000 \mathrm{~ns} & 0 & 0 & 0 \\ 4.000 \mathrm{~ns} & 0 & 0 & 0 \\ 5.000 \mathrm{~ns} & 0 & 0 & 0 \\ 6.000 \mathrm{~ns} & 0 & 1 & 0 \\ 7.000 \mathrm{~ns} & 0 & 1 & 0 \\ 8.000 \mathrm{~ns} & 1 & 1 & 0 \\ 9.000 \mathrm{~ns} & 1 & 1 & 0 \\ 10.000 \mathrm{~ns} & 1 & 1 & 1 \\ 11.000 \mathrm{~ns} & 1 & 1 & 1 \\ 12.000 \mathrm{~ns} & 0 & 1 & 1 \\ 13.000 \mathrm{~ns} & 0 & 1 & 1 \\ 14.000 \mathrm{~ns} & 0 & 1 & 1 \\ 15.000 \mathrm{~ns} & 0 & 1 & 1 \\ 16.000 \mathrm{~ns} & 1 & 1 & 1 \\ 17.000 \mathrm{~ns} & 1 & 1 & 1 \\ 18.000 \mathrm{~ns} & 1 & 1 & 3 \\ 19.000 \mathrm{~ns} & 1 & 1 & 2 \\ 20.000 \mathrm{~ns} & 0 & 1 & 2 \\ 21.000 \mathrm{~ns} & 0 & 1 & 2 \\ 22.000 \mathrm{~ns} & 0 & 1 & 2 \\ 23.000 \mathrm{~ns} & 0 & 1 & 2 \\ 24.000 \mathrm{~ns} & 1 & 1 & 2 \\ 25.000 \mathrm{~ns} & 1 & 1 & 2 \\ 26.000 \mathrm{~ns} & 1 & 1 & 3 \\ 27.000 \mathrm{~ns} & 1 & 1 & 3 \\ 28.000 \mathrm{~ns} & 0 & 1 & 3 \\ 29.000 \mathrm{~ns} & 0 & 1 & 3 \\ 30.000 \mathrm{~ns} & 0 & 1 & 3 \\ 31.000 \mathrm{~ns} & 0 & 1 & 3 \\ 32.000 \mathrm{~ns} & 1 & 1 & 3\end{array}$


33.000ns 1113

34.000ns 11117

35.000ns 11144

36.000ns $\quad 0 \quad 1 \quad 4$

37.000 ns $\quad 0 \quad 144$

38.000ns $\quad 0 \quad 1 \quad 4$

39.000ns $\quad 0 \quad 144$

40.000ns $\quad 1 \quad 144$

41.000 ns $\quad 1 \quad 114$

$42.000 \mathrm{~ns} \quad 1.115$

43.000ns 11115

$44.000 \mathrm{~ns} \quad 0 \quad 1 \quad 5$

$45.000 \mathrm{~ns} \quad 0 \quad 1 \quad 5$

$46.000 n s \quad 0 \quad 1 \quad 5$

$47.000 \mathrm{~ns} \quad 0 \quad 115$

48.000 ns 11115

49.000 ns 11115

$\begin{array}{llll}50.000 \mathrm{~ns} & 1 & 1 & 7\end{array}$

51.000ns 11116

$52.000 \mathrm{~ns} \quad 0 \quad 116$

53.000ns 00116

$54.000 \mathrm{~ns} \quad 0 \quad 116$

$55.000 \mathrm{~ns} \quad 0 \quad 1 \quad 6$

$56.000 \mathrm{~ns} \quad 1 \quad 1 \quad 6$

$\begin{array}{llll}57.000 n^{2} & 1 & 1 & 6\end{array}$

58.000ns 11117

59.000ns 11117

60.000 ns $\quad 0 \quad 1 \quad 7$

$61.000 \mathrm{~ns} \quad 0 \quad 117$

$62.000 \mathrm{~ns} \quad 0 \quad 1 \quad 7$

$63.000 \mathrm{~ns} \quad 0 \quad 117$

$64.000 \mathrm{~ns} \quad 1 \quad 1 \quad 7$

65.000ns 11177

66.000ns 1115

$\begin{array}{llll}67.000 \mathrm{~ns} & 1 & 1 & 8\end{array}$

68.000 ns $\quad 0 \quad 1 \quad 8$

69.000 ns $\quad 0 \quad 1 \quad 8$

$\begin{array}{llll}70.000 \mathrm{~ns} & 0 & 1 & 8\end{array}$

$71.000 \mathrm{~ns} \quad 0 \quad 118$

$\begin{array}{llll}72.000 n s & 1 & 1 & 8\end{array}$

$73.000 \mathrm{~ns} \quad 1 \quad 1 \quad 8$

$74.000 \mathrm{~ns} \quad 1 \quad 1 \quad 9$

$75.000 \mathrm{~ns} \quad 1 \quad 19$

$76.000 \mathrm{~ns} \quad 0 \quad 1 \quad 9$

77.000 ns $\quad 0 \quad 119$

$78.000 \mathrm{~ns} \quad 0 \quad 1 \quad 9$

$\begin{array}{llll}79.000 n s & 0 & 1 & 9\end{array}$ 


\begin{tabular}{|c|c|c|}
\hline $80.000 \mathrm{~ns}$ & 1 & 1 \\
\hline $81.000 \mathrm{~ns}$ & 1 & 1 \\
\hline 82.000 ns & 1 & 1 \\
\hline 83.000 ns & 1 & 1 \\
\hline 84.000 ns & 0 & 1 \\
\hline $85.000 \mathrm{~ns}$ & 0 & 1 \\
\hline $86.000 \mathrm{~ns}$ & 0 & 1 \\
\hline $87.000 \mathrm{~ns}$ & 0 & 1 \\
\hline $88.000 \mathrm{~ns}$ & 1 & 1 \\
\hline $89.000 \mathrm{~ns}$ & 1 & 1 \\
\hline $90.000 \mathrm{~ns}$ & 1 & 1 \\
\hline $91.000 \mathrm{~ns}$ & 1 & 1 \\
\hline $92.000 \mathrm{~ns}$ & 0 & 1 \\
\hline 93.000 ns & 0 & 1 \\
\hline $94.000 \mathrm{~ns}$ & 0 & 1 \\
\hline $95.000 \mathrm{~ns}$ & 0 & 1 \\
\hline $96.000 \mathrm{~ns}$ & 1 & 1 \\
\hline $97.000 \mathrm{~ns}$ & 1 & 1 \\
\hline $98.000 \mathrm{~ns}$ & 1 & 1 \\
\hline $99.000 \mathrm{~ns}$ & 1 & 1 \\
\hline $100.000 \mathrm{~ns}$ & 0 & 1 \\
\hline $101.000 \mathrm{~ns}$ & 0 & 1 \\
\hline $102.000 \mathrm{~ns}$ & 0 & 1 \\
\hline 103.000 ns & 0 & 1 \\
\hline $104.000 \mathrm{~ns}$ & 1 & 1 \\
\hline $105.000 \mathrm{~ns}$ & 1 & 1 \\
\hline $106.000 \mathrm{~ns}$ & 1 & 1 \\
\hline $107.000 \mathrm{~ns}$ & 1 & 1 \\
\hline $108.000 \mathrm{~ns}$ & 0 & 1 \\
\hline $109.000 \mathrm{~ns}$ & 0 & 1 \\
\hline $110.000 \mathrm{~ns}$ & 0 & 1 \\
\hline $111.000 \mathrm{~ns}$ & 0 & 1 \\
\hline $112.000 \mathrm{~ns}$ & 1 & 1 \\
\hline $113.000 \mathrm{~ns}$ & 1 & 1 \\
\hline $114.000 \mathrm{~ns}$ & 1 & 1 \\
\hline $115.000 \mathrm{~ns}$ & 1 & 1 \\
\hline $116.000 \mathrm{~ns}$ & 0 & 1 \\
\hline $117.000 \mathrm{~ns}$ & 0 & 1 \\
\hline $118.000 \mathrm{~ns}$ & 0 & 1 \\
\hline $119.000 \mathrm{~ns}$ & 0 & 1 \\
\hline $120.000 \mathrm{~ns}$ & 1 & 1 \\
\hline $121.000 \mathrm{~ns}$ & 1 & 1 \\
\hline $122.000 \mathrm{~ns}$ & 1 & 1 \\
\hline $123.000 \mathrm{~ns}$ & 1 & 1 \\
\hline $124.000 \mathrm{~ns}$ & 0 & 1 \\
\hline $125.000 \mathrm{~ns}$ & 0 & 1 \\
\hline $126.000 \mathrm{~ns}$ & 0 & 1 \\
\hline
\end{tabular}




$\begin{array}{lllr}127.000 \mathrm{~ns} & 0 & 1 & 15 \\ 128.000 \mathrm{~ns} & 1 & 1 & 15 \\ 129.000 \mathrm{~ns} & 1 & 1 & 15 \\ 130.000 \mathrm{~ns} & 1 & 1 & 15 \\ 131.000 \mathrm{~ns} & 1 & 1 & 0 \\ 132.000 \mathrm{~ns} & 0 & 1 & 0 \\ 133.000 \mathrm{~ns} & 0 & 1 & 0 \\ 134.000 \mathrm{~ns} & 0 & 1 & 0 \\ 135.000 \mathrm{~ns} & 0 & 1 & 0 \\ 136.000 \mathrm{~ns} & 1 & 1 & 0 \\ 137.000 \mathrm{~ns} & 1 & 1 & 0 \\ 138.000 \mathrm{~ns} & 1 & 1 & 1 \\ 139.000 \mathrm{~ns} & 1 & 1 & 1 \\ 140.000 \mathrm{~ns} & 0 & 1 & 1 \\ 141.000 \mathrm{~ns} & 0 & 1 & 1 \\ 142.000 \mathrm{~ns} & 0 & 1 & 1 \\ 143.000 \mathrm{~ns} & 0 & 1 & 1\end{array}$

PEREORMANCE

$$
\begin{array}{rc}
\text { Total simulation time }= & 113.9 \mathrm{uS} \\
\text { Total circuit time }= & 144.0 \mathrm{nS} \\
\text { Total events processed }= & 487 \\
\text { Event throughput }= & 4.276 \mathrm{MHz}
\end{array}
$$


$2 \times 2$ Multiplier Array.

SIMULATION REPORT

Thu Feb $28 \quad 09: 33: 26 \quad 1991$

Circuit: $2 \times 2$ Multiplier Array (MULT2X2.NET)

Complexity: 44 gates.

Array size: 16 cells.

\section{SIMULATION DATA}

$\begin{array}{llll}\text { Ckt Time } & \text { A B } & \text { P } \\ 0.000 \mathrm{~ns} & \mathrm{X} & \mathrm{X} & \mathrm{X} \\ 1.000 \mathrm{~ns} & 0 & 0 & \mathrm{X} \\ 2.000 \mathrm{~ns} & 0 & 0 & \mathrm{X} \\ 3.000 \mathrm{~ns} & 0 & 0 & \mathrm{X} \\ 4.000 \mathrm{~ns} & 0 & 0 & \mathrm{X} \\ 5.000 \mathrm{~ns} & 0 & 0 & \mathrm{X} \\ 6.000 \mathrm{~ns} & 0 & 0 & 0 \\ 7.000 \mathrm{~ns} & 0 & 0 & 0 \\ 8.000 \mathrm{~ns} & 0 & 0 & 0 \\ 9.000 \mathrm{~ns} & 0 & 0 & 0 \\ 10.000 \mathrm{~ns} & 0 & 0 & 0 \\ 11.000 \mathrm{~ns} & 0 & 0 & 0 \\ 12.000 \mathrm{~ns} & 0 & 0 & 0 \\ 13.000 \mathrm{~ns} & 0 & 0 & 0 \\ 14.000 \mathrm{~ns} & 0 & 0 & 0 \\ 15.000 \mathrm{~ns} & 0 & 0 & 0 \\ 16.000 \mathrm{~ns} & 0 & 0 & 0 \\ 17.000 \mathrm{~ns} & 0 & 1 & 0 \\ 18.000 \mathrm{~ns} & 0 & 1 & 0 \\ 19.000 \mathrm{~ns} & 0 & 1 & 0 \\ 20.000 \mathrm{~ns} & 0 & 1 & 0 \\ 21.000 \mathrm{~ns} & 0 & 1 & 0 \\ 22.000 \mathrm{~ns} & 0 & 1 & 0 \\ 23.000 \mathrm{~ns} & 0 & 1 & 0 \\ 24.000 \mathrm{~ns} & 0 & 1 & 0 \\ 25.000 \mathrm{~ns} & 0 & 1 & 0 \\ 26.000 \mathrm{~ns} & 0 & 1 & 0 \\ 27.000 \mathrm{~ns} & 0 & 1 & 0 \\ 28.000 \mathrm{~ns} & 0 & 1 & 0 \\ 29.000 \mathrm{~ns} & 0 & 1 & 0\end{array}$




\begin{tabular}{|c|c|c|}
\hline $30.000 \mathrm{~ns}$ & 0 & 1 \\
\hline $31.000 \mathrm{~ns}$ & 0 & 1 \\
\hline $32.000 \mathrm{~ns}$ & 0 & 1 \\
\hline $33.000 \mathrm{~ns}$ & 0 & 2 \\
\hline $34.000 \mathrm{~ns}$ & 0 & 2 \\
\hline $35.000 \mathrm{~ns}$ & 0 & 2 \\
\hline $6.000 \mathrm{~ns}$ & 0 & 2 \\
\hline $7.000 \mathrm{~ns}^{2}$ & 0 & 2 \\
\hline $38.000 \mathrm{~ns}$ & 0 & 2 \\
\hline $9.000 \mathrm{~ns}$ & 0 & 2 \\
\hline $0.000 \mathrm{~ns}$ & 0 & 2 \\
\hline $41.000 \mathrm{~ns}$ & 0 & 2 \\
\hline $42.000 \mathrm{~ns}$ & 0 & 2 \\
\hline $43.000 \mathrm{~ns}$ & 0 & 2 \\
\hline $44.000 \mathrm{~ns}$ & 0 & 2 \\
\hline $45.000 \mathrm{~ns}$ & 0 & 2 \\
\hline 46.000 ns & 0 & 2 \\
\hline $47.000 \mathrm{~ns}$ & 0 & 2 \\
\hline 48.000 ns & 0 & 2 \\
\hline $49.000 \mathrm{~ns}$ & 0 & 3 \\
\hline $50.000 \mathrm{~ns}$ & 0 & 3 \\
\hline $51.000 \mathrm{~ns}$ & 0 & 3 \\
\hline $52.000 \mathrm{~ns}$ & 0 & 3 \\
\hline $53.000 \mathrm{~ns}$ & 0 & 3 \\
\hline $54.000 \mathrm{~ns}$ & 0 & 3 \\
\hline $55.000 \mathrm{~ns}$ & 0 & 3 \\
\hline $56.000 \mathrm{~ns}$ & 0 & 3 \\
\hline $57.000 \mathrm{~ns}^{\circ}$ & 0 & 3 \\
\hline $58.000 \mathrm{~ns}$ & 0 & 3 \\
\hline $59.000 \mathrm{~ns}$ & 0 & 3 \\
\hline $60.000 \mathrm{~ns}$ & 0 & 3 \\
\hline $61.000 \mathrm{~ns}$ & 0 & 3 \\
\hline $62.000 \mathrm{~ns}$ & 0 & 3 \\
\hline 63.000 ns & 0 & 3 \\
\hline $64.000 \mathrm{~ns}$ & 0 & 3 \\
\hline $65.000 \mathrm{~ns}$ & 1 & 0 \\
\hline $66.000 \mathrm{~ns}$ & 1 & 0 \\
\hline $67.000 \mathrm{~ns}$ & 1 & 0 \\
\hline $68.000 \mathrm{~ns}$ & 1 & 0 \\
\hline $69.000 \mathrm{~ns}$ & $I$ & 0 \\
\hline $70.000 \mathrm{~ns}$ & 1 & 0 \\
\hline $71.000 \mathrm{~ns}$ & 1 & 0 \\
\hline $72.000 \mathrm{~ns}$ & 1 & 0 \\
\hline 73.000 ns & $I$ & 0 \\
\hline $74.000 \mathrm{~ns}$ & 1 & 0 \\
\hline $75.000 \mathrm{~ns}$ & 1 & 0 \\
\hline $76.000 \mathrm{~ns}$ & 1 & 0 \\
\hline
\end{tabular}




\begin{tabular}{|c|c|c|}
\hline $77.000 \mathrm{~ns}$ & 1 & 0 \\
\hline $78.000 \mathrm{~ns}$ & 1 & 0 \\
\hline $79.000 \mathrm{~ns}$ & 1 & 0 \\
\hline $80.000 \mathrm{~ns}$ & 1 & 0 \\
\hline $81.000 \mathrm{~ns}$ & 1 & 1 \\
\hline $82.000 \mathrm{~ns}$ & 1 & 1 \\
\hline $83.000 \mathrm{~ns}$ & 1 & 1 \\
\hline $84.000 n s$ & 1 & 1 \\
\hline $85.000 \mathrm{~ns}$ & 1 & 1 \\
\hline $86.000 \mathrm{~ns}$ & 1 & 1 \\
\hline $87.000 \mathrm{~ns}$ & 1 & 1 \\
\hline $88.000 \mathrm{~ns}$ & 1 & 1 \\
\hline $89.000 \mathrm{~ns}$ & 1 & 1 \\
\hline $90.000 n s$ & 1 & 1 \\
\hline $91.000 \mathrm{~ns}$ & 1 & 1 \\
\hline $92.000 \mathrm{~ns}$ & 1 & 1 \\
\hline $93.000 \mathrm{~ns}$ & 1 & 1 \\
\hline $94.000 \mathrm{~ns}$ & 1 & 1 \\
\hline $95.000 \mathrm{~ns}$ & 1 & 1 \\
\hline $96.000 \mathrm{~ns}$ & 1 & 1 \\
\hline $97.000 \mathrm{~ns}$ & 1 & 2 \\
\hline $98.000 \mathrm{~ns}$ & 1 & 2 \\
\hline $9.000 \mathrm{~ns}$ & 1 & 2 \\
\hline 000ns & 1 & 2 \\
\hline 000ns & 1 & 2 \\
\hline $.000 n \mathrm{~s}$ & 1 & 2 \\
\hline $000 \mathrm{~ns}$ & 1 & 2 \\
\hline $.000 \mathrm{~ns}$ & 1 & 2 \\
\hline $.000 \pi s$ & 1 & 2 \\
\hline 000ns & 1 & 2 \\
\hline $.000 \mathrm{~ns}$ & 1 & 2 \\
\hline $.000 \mathrm{~ns}$ & 1 & 2 \\
\hline 000ns & 1 & 2 \\
\hline .000ns & 1 & 2 \\
\hline $.000 \mathrm{~ns}$ & 1 & 2 \\
\hline 000 ns & 1 & 2 \\
\hline $.000 \mathrm{~ns}$ & 1 & 3 \\
\hline $000 n s$ & $I$ & 3 \\
\hline $.000 \mathrm{~ns}$ & 1 & 3 \\
\hline $000 n s$ & 1 & 3 \\
\hline $.000 \mathrm{~ns}$ & 1 & 3 \\
\hline $.000 \mathrm{~ns}$ & 1 & 3 \\
\hline $.000 \mathrm{~ns}$ & 1 & 3 \\
\hline $.000 \mathrm{~ns}$ & 1 & 3 \\
\hline $.000 \mathrm{~ns}$ & 1 & 3 \\
\hline $000 n$ & 1 & \\
\hline $3.000 n$ & 1 & \\
\hline
\end{tabular}


264

\begin{tabular}{|c|c|c|}
\hline $124.000 \mathrm{~ns}$ & 1 & \\
\hline $125.000 \mathrm{~ns}$ & 1 & 3 \\
\hline $126.000 \mathrm{~ns}$ & 1 & 3 \\
\hline $127.000 \mathrm{~ns}$ & 1 & 3 \\
\hline $128.000 \mathrm{~ns}$ & 1 & 3 \\
\hline $129.000 \mathrm{~ns}$ & 2 & 0 \\
\hline $130.000 \mathrm{~ns}$ & 2 & 0 \\
\hline $131.000 \mathrm{~ns}$ & 2 & 0 \\
\hline $132.000 \mathrm{~ns}$ & 2 & 0 \\
\hline $133.000 \mathrm{~ns}$ & 2 & 0 \\
\hline 134.000 ns & 2 & 0 \\
\hline $135.000 \mathrm{~ns}$ & 2 & 0 \\
\hline $136.000 \mathrm{~ns}$ & 2 & 0 \\
\hline $137.000 \mathrm{~ns}$ & 2 & 0 \\
\hline $138.000 \mathrm{~ns}$ & 2 & 0 \\
\hline $139.000 \mathrm{~ns}$ & 2 & 0 \\
\hline $140.000 \mathrm{~ns}$ & 2 & 0 \\
\hline $141.000 \mathrm{~ns}$ & 2 & 0 \\
\hline $142.000 \mathrm{~ns}$ & 2 & 0 \\
\hline $143.000 \mathrm{~ns}$ & 2 & 0 \\
\hline $144.000 \mathrm{~ns}$ & 2 & 0 \\
\hline $145.000 \mathrm{~ns}$ & 2 & 1 \\
\hline $146.000 \mathrm{~ns}$ & 2 & 1 \\
\hline $147.000 \mathrm{~ns}$ & 2 & 1 \\
\hline $148.000 \mathrm{~ns}$ & 2 & 1 \\
\hline 149.000 ns & 2 & 1 \\
\hline $150.000 \mathrm{~ns}$ & 2 & 1 \\
\hline $151.000 \mathrm{~ns}$ & 2 & 1 \\
\hline $152.000 \mathrm{~ns}$ & 2 & 1 \\
\hline $153.000 \mathrm{~ns}$ & 2 & 1 \\
\hline 154.000 ns & 2 & 1 \\
\hline $155.000 \mathrm{~ns}$ & 2 & 1 \\
\hline $156.000 \mathrm{~ns}$ & 2 & 1 \\
\hline $157.000 \mathrm{~ns}$ & 2 & 1 \\
\hline $158.000 \mathrm{~ns}$ & 2 & 1 \\
\hline $159.000 \mathrm{~ns}$ & 2 & 1 \\
\hline $160.000 \mathrm{~ns}$ & 2 & 1 \\
\hline $161.000 \mathrm{~ns}$ & 2 & 2 \\
\hline $162.000 \mathrm{~ns}$ & 2 & 2 \\
\hline $163.000 \mathrm{~ns}$ & 2 & 2 \\
\hline $164.000 \mathrm{~ns}$ & 2 & 2 \\
\hline 165.000 ns & 2 & 2 \\
\hline $166.000 \mathrm{~ns}$ & 2 & 2 \\
\hline $167.000 \mathrm{~ns}$ & 2 & 2 \\
\hline $168.000 \mathrm{~ns}$ & 2 & 2 \\
\hline $169.000 \mathrm{~ns}$ & 2 & 2 \\
\hline $170.000 \mathrm{~ns}$ & 2 & 2 \\
\hline
\end{tabular}


265

$\begin{array}{llll}171.000 \mathrm{~ns} & 2 & 2 & 4 \\ 172.000 \mathrm{~ns} & 2 & 2 & 4 \\ 173.000 \mathrm{~ns} & 2 & 2 & 4 \\ 174.000 \mathrm{~ns} & 2 & 2 & 4 \\ 175.000 \mathrm{~ns} & 2 & 2 & 4 \\ 176.000 \mathrm{~ns} & 2 & 2 & 4 \\ 177.000 \mathrm{~ns} & 2 & 3 & 4 \\ 178.000 \mathrm{~ns} & 2 & 3 & 4 \\ 179.000 \mathrm{~ns} & 2 & 3 & 4 \\ 180.000 \mathrm{~ns} & 2 & 3 & 4 \\ 181.000 \mathrm{~ns} & 2 & 3 & 4 \\ 182.000 \mathrm{~ns} & 2 & 3 & 6 \\ 183.000 \mathrm{~ns} & 2 & 3 & 6 \\ 184.000 \mathrm{~ns} & 2 & 3 & 6 \\ 185.000 \mathrm{~ns} & 2 & 3 & 6 \\ 186.000 \mathrm{~ns} & 2 & 3 & 6 \\ 187.000 \mathrm{~ns} & 2 & 3 & 6 \\ 188.000 \mathrm{~ns} & 2 & 3 & 6 \\ 189.000 \mathrm{~ns} & 2 & 3 & 6 \\ 190.000 \mathrm{~ns} & 2 & 3 & 6 \\ 191.000 \mathrm{~ns} & 2 & 3 & 6 \\ 192.00 \mathrm{~ns} & 2 & 3 & 6 \\ 193.000 \mathrm{~ns} & 3 & 0 & 6 \\ 194.000 \mathrm{~ns} & 3 & 0 & 6 \\ 195.000 \mathrm{~ns} & 3 & 0 & 6 \\ 196.000 \mathrm{~ns} & 3 & 0 & 6 \\ 197.000 \mathrm{~ns} & 3 & 0 & 6 \\ 198.000 \mathrm{~ns} & 3 & 0 & 0 \\ 199.000 \mathrm{~ns} & 3 & 0 & 0 \\ 200.000 \mathrm{~ns} & 3 & 0 & 0 \\ 201.000 \mathrm{~ns} & 3 & 0 & 0 \\ 202.000 \mathrm{~ns} & 3 & 0 & 0 \\ 203.000 \mathrm{~ns} & 3 & 0 & 0 \\ 204.000 \mathrm{~ns} & 3 & 0 & 0 \\ 205.000 \mathrm{~ns} & 3 & 0 & 0 \\ 217.00 .000 \mathrm{~ns} & 3 & 0 & 0 \\ 207.000 \mathrm{~ns} & 3 & 0 & 0 \\ 208.000 \mathrm{~ns} & 3 & 0 & 0 \\ 209.000 \mathrm{~ns} & 3 & 1 & 0 \\ 210.000 \mathrm{~ns} & 3 & 1 & 0 \\ 211.000 \mathrm{~ns} & 3 & 1 & 0 \\ 212.000 \mathrm{~ns} & 3 & 1 & 0 \\ 213.000 \mathrm{~ns} & 3 & 1 & 0 \\ 214.000 \mathrm{~ns} & 3 & 1 & 3 \\ \text { 115.000ns } & 3 & 1 & 3 \\ 116.000 \mathrm{~ns} & 3 & 1 & 3 \\ 117 & 3 & 1 & 3\end{array}$




\section{6}

$\begin{array}{lllr}218.000 n s & 3 & 1 & 3 \\ 219.000 n s & 3 & 1 & 3 \\ 220.000 n s & 3 & 1 & 3 \\ 221.000 n s & 3 & 1 & 3 \\ 222.000 n s & 3 & 1 & 3 \\ 223.000 n s & 3 & 1 & 3 \\ 224.000 n s & 3 & 1 & 3 \\ 225.000 n s & 3 & 2 & 3 \\ 226.000 n s & 3 & 2 & 3 \\ 227.000 n s & 3 & 2 & 3 \\ 228.000 n s & 3 & 2 & 3 \\ 229.000 n s & 3 & 2 & 3 \\ 230.000 n s & 3 & 2 & 4 \\ 231.000 n s & 3 & 2 & 4 \\ 232.000 n s & 3 & 2 & 4 \\ 233.000 n s & 3 & 2 & 4 \\ 234.000 n s & 3 & 2 & 6 \\ 235.000 n s & 3 & 2 & 6 \\ 236.000 n s & 3 & 2 & 6 \\ 237.000 n s & 3 & 2 & 6 \\ 238.000 n s & 3 & 2 & 6 \\ 239.000 n s & 3 & 2 & 6 \\ 240.000 n s & 3 & 2 & 6 \\ 241.000 n s & 3 & 3 & 6 \\ 242.000 n s & 3 & 3 & 6 \\ 243.000 n s & 3 & 3 & 6 \\ 244.000 n s & 3 & 3 & 6 \\ 245.000 n s & 3 & 3 & 6 \\ 246.000 n s & 3 & 3 & 7 \\ 247.000 n s & 3 & 3 & 5 \\ 248.000 n s & 3 & 3 & 13 \\ 249.000 n s & 3 & 3 & 13 \\ 250.000 n s & 3 & 3 & 9 \\ 251.000 n s & 3 & 3 & 9 \\ 252.000 n s & 3 & 3 & 9 \\ 253.000 n s & 3 & 3 & 9 \\ 254.000 n s & 3 & 3 & 9 \\ 255.000 n s & 3 & 3 & 9 \\ 256.000 n s & 3 & 3 & 9\end{array}$

PERFORMANCE

Total simulation time $=91.5 \mathrm{us}$ Total circuit time $=257.0 n S$ 
Total events processed = Event throughput $=2.076 \mathrm{MHz}$ 
$4 \times 4$ Multiplier Array.

SIMULATION REPORT

Thu Feb 28 09:37:28 1991

Circuit: $4 \times 4$ Multiplier Array (MULT4X4.NET)

Complexity: 176 gates.

Array size: 64 cells.

\section{SIMULATION DATA}

$\begin{array}{lrrr}\text { Ckt Time } & \text { A } & \text { B } & \text { P } \\ 0.000 n s & \text { X } & \text { X } & \text { X } \\ 1.000 n s & 0 & 15 & \text { X } \\ 2.000 n s & 0 & 15 & \text { X } \\ 3.000 n s & 0 & 15 & \text { X } \\ 4.000 n s & 0 & 15 & \text { X } \\ 5.000 n s & 0 & 15 & \text { X } \\ 6.000 n s & 0 & 15 & 0 \\ 7.000 n s & 0 & 15 & 0 \\ 8.000 n s & 0 & 15 & 0 \\ 9.000 n s & 0 & 15 & 0 \\ 10.000 n s & 0 & 15 & 0 \\ 11.000 n s & 0 & 15 & 0 \\ 12.000 n s & 0 & 15 & 0 \\ 13.000 n s & 0 & 15 & 0 \\ 14.000 n s & 0 & 15 & 0 \\ 15.000 n s & 0 & 15 & 0 \\ 16.000 n s & 0 & 15 & 0 \\ 17.000 n s & 0 & 15 & 0 \\ 18.000 n s & 0 & 15 & 0 \\ 19.000 n s & 0 & 15 & 0 \\ 20.000 n s & 0 & 15 & 0 \\ 21.000 n s & 0 & 15 & 0 \\ 22.000 n s & 0 & 15 & 0 \\ 23.000 n s & 0 & 15 & 0 \\ 24.000 n s & 0 & 15 & 0 \\ 25.000 n s & 0 & 15 & 0 \\ 26.000 n s & 0 & 15 & 0 \\ 27.000 n s & 0 & 15 & 0 \\ 28.000 n s & 0 & 15 & 0 \\ 29.000 n s & 0 & 15 & 0\end{array}$




\begin{tabular}{|c|c|c|}
\hline $30.000 \mathrm{~ns}$ & 0 & 15 \\
\hline $31.000 \mathrm{~ns}$ & 0 & 15 \\
\hline $32.000 \mathrm{~ns}$ & 0 & 15 \\
\hline $33.000 \mathrm{~ns}$ & 0 & 15 \\
\hline $34.000 \mathrm{~ns}$ & 0 & 15 \\
\hline $35.000 \mathrm{~ns}$ & 0 & 15 \\
\hline $36.000 \mathrm{~ns}$ & 0 & 15 \\
\hline $37.000 \mathrm{~ns}$ & 0 & 15 \\
\hline $38.000 n s$ & 0 & 15 \\
\hline $39.000 \mathrm{~ns}$ & 0 & 15 \\
\hline $40.000 \mathrm{~ns}$ & 0 & 15 \\
\hline $41.000 n s$ & 15 & 0 \\
\hline $42.000 \mathrm{~ns}$ & 15 & 0 \\
\hline $43.000 \mathrm{~ns}$ & 15 & 0 \\
\hline 44.000 ns & 15 & 0 \\
\hline $45.000 \mathrm{~ns}$ & 15 & 0 \\
\hline $46.000 \mathrm{~ns}$ & 15 & 0 \\
\hline $47.000 \mathrm{~ns}$ & 15 & 0 \\
\hline $48.000 \mathrm{~ns}$ & 15 & 0 \\
\hline $49.000 \mathrm{~ns}$ & 15 & 0 \\
\hline 50.000 ns & 15 & 0 \\
\hline $51.000 n s$ & 15 & 0 \\
\hline $52.000 \mathrm{~ns}$ & 15 & 0 \\
\hline $53.000 \mathrm{~ns}$ & 15 & 0 \\
\hline $54.000 \mathrm{~ns}$ & 15 & 0 \\
\hline $55.000 n s$ & 15 & 0 \\
\hline $56.000 \mathrm{~ns}$ & 15 & 0 \\
\hline $57.000 \mathrm{~ns}$ & 15 & 0 \\
\hline $58.000 \mathrm{~ns}$ & 15 & 0 \\
\hline $59.000 \mathrm{~ns}$ & 15 & 0 \\
\hline $60.000 \mathrm{~ns}$ & 15 & 0 \\
\hline $61.000 \mathrm{~ns}$ & 15 & 0 \\
\hline $62.000 \mathrm{~ns}$ & 15 & 0 \\
\hline $63.000 \mathrm{~ns}$ & 15 & 0 \\
\hline $64.000 \mathrm{~ns}$ & 15 & 0 \\
\hline $65.000 \mathrm{~ns}$ & 15 & 0 \\
\hline $66.000 \mathrm{~ns}$ & 15 & 0 \\
\hline $67.000 \mathrm{~ns}$ & 15 & 0 \\
\hline 68.000 ns & 15 & 0 \\
\hline $69.000 \mathrm{~ns}$ & 15 & 0 \\
\hline $70.000 \mathrm{~ns}$ & 15 & 0 \\
\hline $71.000 \mathrm{~ns}$ & 15 & 0 \\
\hline $72.000 \mathrm{~ns}$ & 15 & 0 \\
\hline $73.000 \mathrm{~ns}$ & 15 & 0 \\
\hline $74.000 \mathrm{~ns}$ & 15 & 0 \\
\hline 75.000 ns & 15 & 0 \\
\hline $76.000 \mathrm{~ns}$ & 15 & 0 \\
\hline
\end{tabular}




$\begin{array}{lrll}77.000 \mathrm{~ns} & 15 & 0 & 0 \\ 78.000 \mathrm{~ns} & 15 & 0 & 0 \\ 79.00 \mathrm{~ns} & 15 & 0 & 0 \\ 80.00 \mathrm{~ns} & 15 & 0 & 0 \\ 81.000 \mathrm{~ns} & 1 & 1 & 0 \\ 82.000 \mathrm{~ns} & 1 & 1 & 0 \\ 83.000 \mathrm{~ns} & 1 & 1 & 0 \\ 84.000 \mathrm{~ns} & 1 & 1 & 0 \\ 85.00 \mathrm{~ns} & 1 & 1 & 0 \\ 86.000 \mathrm{~ns} & 1 & 1 & 1 \\ 87.000 \mathrm{~ns} & 1 & 1 & 1 \\ 88.000 \mathrm{~ns} & 1 & 1 & 1 \\ 89.000 \mathrm{~ns} & 1 & 1 & 1 \\ 90.000 \mathrm{~ns} & 1 & 1 & 1 \\ 91.000 \mathrm{~ns} & 1 & 1 & 1 \\ 92.000 \mathrm{~ns} & 1 & 1 & 1 \\ 93.000 \mathrm{~ns} & 1 & 1 & 1 \\ 94.000 \mathrm{~ns} & 1 & 1 & 1 \\ 95.000 \mathrm{~ns} & 1 & 1 & 1 \\ 96.000 \mathrm{~ns} & 1 & 1 & 1 \\ 97.000 \mathrm{~ns} & 1 & 1 & 1 \\ 98.000 \mathrm{~ns} & 1 & 1 & 1 \\ 99.000 \mathrm{~ns} & 1 & 1 & 1 \\ 100.000 \mathrm{~ns} & 1 & 1 & 1 \\ 101.000 \mathrm{~ns} & 1 & 1 & 1 \\ 102.000 \mathrm{~ns} & 1 & 1 & 1 \\ 103.000 \mathrm{~ns} & 1 & 1 & 1 \\ 104.000 \mathrm{~ns} & 1 & 1 & 1 \\ 105.000 \mathrm{~ns} & 1 & 1 & 1 \\ 106.000 \mathrm{~ns} & 1 & 1 & 1 \\ 107.000 \mathrm{~ns} & 1 & 1 & 1 \\ 108.000 \mathrm{~ns} & 1 & 1 & 1 \\ 109.000 \mathrm{~ns} & 1 & 1 & 1 \\ 110.000 \mathrm{~ns} & 1 & 1 & 1 \\ 111.000 \mathrm{~ns} & 1 & 1 & 1 \\ 112.00 \mathrm{~ns} & 1 & 1 & 1 \\ 113.000 \mathrm{~ns} & 1 & 1 & 1 \\ 114.000 \mathrm{~ns} & 1 & 1 & 1 \\ 115.000 \mathrm{~ns} & 1 & 1 & 1 \\ 116.000 \mathrm{~ns} & 1 & 1 & 1 \\ 117.00 \mathrm{~ns} & 1 & 1 & 1 \\ 118.000 \mathrm{~ns} & 1 & 1 & 1 \\ 119.000 \mathrm{~ns} & 1 & 1 & 1 \\ 120.000 \mathrm{~ns} & 1 & 1 & 1 \\ 121.000 \mathrm{~ns} & 2 & 2 & 1 \\ 122.000 \mathrm{~ns} & 2 & 2 & 1 \\ 123.000 \mathrm{~ns} & 2 & 2 & 1\end{array}$




$\begin{array}{llll}124.000 \mathrm{~ns} & 2 & 2 & 1 \\ 125.000 \mathrm{~ns} & 2 & 2 & 1 \\ 126.000 \mathrm{~ns} & 2 & 2 & 0 \\ 127.000 \mathrm{~ns} & 2 & 2 & 0 \\ 128.000 \mathrm{~ns} & 2 & 2 & 0 \\ 129.000 \mathrm{~ns} & 2 & 2 & 0 \\ 130.000 \mathrm{~ns} & 2 & 2 & 4 \\ 131.000 \mathrm{~ns} & 2 & 2 & 4 \\ 132.000 \mathrm{~ns} & 2 & 2 & 4 \\ 133.000 \mathrm{~ns} & 2 & 2 & 4 \\ 134.000 \mathrm{~ns} & 2 & 2 & 4 \\ 135.000 \mathrm{~ns} & 2 & 2 & 4 \\ 136.000 \mathrm{~ns} & 2 & 2 & 4 \\ 137.000 \mathrm{~ns} & 2 & 2 & 4 \\ 138.000 \mathrm{~ns} & 2 & 2 & 4 \\ 139.000 \mathrm{~ns} & 2 & 2 & 4 \\ 140.000 \mathrm{~ns} & 2 & 2 & 4 \\ 141.000 \mathrm{~ns} & 2 & 2 & 4 \\ 142.000 \mathrm{~ns} & 2 & 2 & 4 \\ 143.000 \mathrm{~ns} & 2 & 2 & 4 \\ 144.000 \mathrm{~ns} & 2 & 2 & 4 \\ 145.000 \mathrm{~ns} & 2 & 2 & 4 \\ 146.000 \mathrm{~ns} & 2 & 2 & 4 \\ 147.000 \mathrm{~ns} & 2 & 2 & 4 \\ 148.000 \mathrm{~ns} & 2 & 2 & 4 \\ 149.000 \mathrm{~ns} & 2 & 2 & 4 \\ 150.000 \mathrm{~ns} & 2 & 2 & 4 \\ 151.000 \mathrm{~ns} & 2 & 2 & 4 \\ 152.000 \mathrm{~ns} & 2 & 2 & 4 \\ 153.000 \mathrm{~ns} & 2 & 2 & 4 \\ 154.000 \mathrm{~ns} & 2 & 2 & 4 \\ 155.000 \mathrm{~ns} & 2 & 2 & 4 \\ 156.000 \mathrm{~ns} & 2 & 2 & 4 \\ 157.000 \mathrm{~ns} & 2 & 2 & 4 \\ 158.000 \mathrm{~ns} & 2 & 2 & 4 \\ 159.000 \mathrm{~ns} & 2 & 2 & 4 \\ 160.000 \mathrm{~ns} & 2 & 2 & 4 \\ 161.000 \mathrm{~ns} & 3 & 3 & 4 \\ 162.000 \mathrm{~ns} & 3 & 3 & 4 \\ 163.000 \mathrm{~ns} & 3 & 3 & 4 \\ 164.000 \mathrm{~ns} & 3 & 3 & 4 \\ 165.000 \mathrm{~ns} & 3 & 3 & 4 \\ 166.000 \mathrm{~ns} & 3 & 3 & 7 \\ 167.000 \mathrm{~ns} & 3 & 3 & 7 \\ 168.000 \mathrm{~ns} & 3 & 3 & 7 \\ 169.000 \mathrm{~ns} & 3 & 3 & 7 \\ 170.000 \mathrm{~ns} & 3 & 3 & 7\end{array}$




$\begin{array}{lllr}171.000 \mathrm{~ns} & 3 & 3 & 5 \\ 172.000 \mathrm{~ns} & 3 & 3 & 5 \\ 173.000 \mathrm{~ns} & 3 & 3 & 5 \\ 174.000 \mathrm{~ns} & 3 & 3 & 5 \\ 175.000 \mathrm{~ns} & 3 & 3 & 5 \\ 176.000 \mathrm{~ns} & 3 & 3 & 5 \\ 177.000 \mathrm{~ns} & 3 & 3 & 5 \\ 178.000 \mathrm{~ns} & 3 & 3 & 1 \\ 179.000 \mathrm{~ns} & 3 & 3 & 1 \\ 180.000 \mathrm{~ns} & 3 & 3 & 1 \\ 181.000 \mathrm{~ns} & 3 & 3 & 1 \\ 182.000 \mathrm{~ns} & 3 & 3 & 1 \\ 183.000 \mathrm{~ns} & 3 & 3 & 1 \\ 184.000 \mathrm{~ns} & 3 & 3 & 9 \\ 185.000 \mathrm{~ns} & 3 & 3 & 9 \\ 186.000 \mathrm{~ns} & 3 & 3 & 9 \\ 187.000 \mathrm{~ns} & 3 & 3 & 9 \\ 188.000 \mathrm{~ns} & 3 & 3 & 9 \\ 189.000 \mathrm{~ns} & 3 & 3 & 9 \\ 190.000 \mathrm{~ns} & 3 & 3 & 9 \\ 191.000 \mathrm{~ns} & 3 & 3 & 9 \\ 192.000 \mathrm{~ns} & 3 & 3 & 9 \\ 193.000 \mathrm{~ns} & 3 & 3 & 9 \\ 194.000 \mathrm{~ns} & 3 & 3 & 9 \\ 195.000 \mathrm{~ns} & 3 & 3 & 9 \\ 196.000 \mathrm{~ns} & 3 & 3 & 9 \\ 197.000 \mathrm{~ns} & 3 & 3 & 9 \\ 198.000 \mathrm{~ns} & 3 & 3 & 9 \\ 199.000 \mathrm{~ns} & 3 & 3 & 9 \\ 200.000 \mathrm{~ns} & 3 & 3 & 9 \\ 201.000 \mathrm{~ns} & 4 & 6 & 9 \\ 202.000 \mathrm{~ns} & 4 & 6 & 9 \\ 203.000 \mathrm{~ns} & 4 & 6 & 9 \\ 204.000 \mathrm{~ns} & 4 & 6 & 9 \\ 2116.000 \mathrm{~ns} & 4 & 6 & 9 \\ 206.000 \mathrm{~ns} & 4 & 6 & 8 \\ 207.000 \mathrm{~ns} & 4 & 6 & 10 \\ 208.000 \mathrm{~ns} & 4 & 6 & 10 \\ 209.000 \mathrm{~ns} & 4 & 6 & 10 \\ 210.000 \mathrm{~ns} & 4 & 6 & 24 \\ 211.000 \mathrm{~ns} & 4 & 6 & 16 \\ 212.000 \mathrm{~ns} & 4 & 6 & 20 \\ 213.000 \mathrm{~ns} & 4 & 6 & 16 \\ 214.000 \mathrm{~ns} & 4 & 6 & 0 \\ & 4 & 6 & 0 \\ 117.000 \mathrm{~ns} & 4 & 6 & 32 \\ 19 & 32\end{array}$




\begin{tabular}{|c|c|c|c|}
\hline $218.000 \mathrm{~ns}$ & 4 & 6 & 32 \\
\hline $219.000 \mathrm{~ns}$ & 4 & 6 & 40 \\
\hline $20.000 \mathrm{~ns}$ & 4 & 6 & 40 \\
\hline $221.000 \mathrm{~ns}$ & 4 & 6 & 40 \\
\hline $222.000 \mathrm{~ns}$ & 4 & 6 & 56 \\
\hline $223.000 \mathrm{~ns}$ & 4 & 6 & 56 \\
\hline $224.000 \mathrm{~ns}$ & 4 & 6 & 24 \\
\hline $225.000 \mathrm{~ns}$ & 4 & 6 & 24 \\
\hline $226.000 \mathrm{~ns}$ & 4 & 6 & 24 \\
\hline $227.000 \mathrm{~ns}$ & 4 & 6 & 24 \\
\hline $228.000 \mathrm{~ns}$ & 4 & 6 & 24 \\
\hline $229.000 \mathrm{~ns}$ & 4 & 6 & 24 \\
\hline $230.000 \mathrm{~ns}$ & 4 & 6 & 24 \\
\hline $231.000 \mathrm{~ns}$ & 4 & 6 & 24 \\
\hline $232.000 \mathrm{~ns}$ & 4 & 6 & 24 \\
\hline $233.000 \mathrm{~ns}$ & 4 & 6 & 24 \\
\hline $234.000 \mathrm{~ns}$ & 4 & 6 & 24 \\
\hline $235.000 \mathrm{~ns}$ & 4 & 6 & 24 \\
\hline $236.000 \mathrm{~ns}$ & 4 & 6 & 24 \\
\hline $237.000 \mathrm{~ns}$ & 4 & 6 & 24 \\
\hline $238.000 \mathrm{~ns}$ & 4 & 6 & 24 \\
\hline $239.000 \mathrm{~ns}$ & 4 & 6 & 24 \\
\hline 240.000 ns & 4 & 6 & 24 \\
\hline $241.000 \mathrm{~ns}$ & 8 & 7 & 24 \\
\hline $242.000 \mathrm{~ns}^{2}$ & 8 & 7 & 24 \\
\hline $243.000 \mathrm{~ns}$ & 8 & 7 & 24 \\
\hline $244.000 \mathrm{~ns}$ & 8 & 7 & 24 \\
\hline $245.000 \mathrm{~ns}$ & 8 & 7 & 24 \\
\hline $246.000 \mathrm{~ns}$ & 8 & 7 & 56 \\
\hline $247.000 \mathrm{~ns}$ & 8 & 7 & 32 \\
\hline $248.000 \mathrm{~ns}$ & 8 & 7 & 48 \\
\hline $249.000 \mathrm{~ns}$ & 8 & 7 & 32 \\
\hline $250.000 \mathrm{~ns}$ & 8 & 7 & 0 \\
\hline $251.000 \mathrm{~ns}$ & 8 & 7 & \\
\hline $252.000 \mathrm{~ns}$ & 8 & 7 & 72 \\
\hline $253.000 \mathrm{~ns}$ & 8 & 7 & 72 \\
\hline $254.000 \mathrm{~ns}$ & 8 & 7 & 88 \\
\hline $255.000 \mathrm{~ns}$ & 8 & 7 & 8 \\
\hline $256.000 \mathrm{~ns}$ & 8 & 7 & 88 \\
\hline $257.000 \mathrm{~ns}$ & 8 & 7 & 120 \\
\hline $258.000 \mathrm{~ns}$ & 8 & 7 & 120 \\
\hline $259.000 \mathrm{~ns}$ & 8 & 7 & 5 \\
\hline $260.000 \mathrm{~ns}$ & 8 & 7 & 5 \\
\hline $261.000 \mathrm{~ns}$ & 8 & 7 & \\
\hline $262.000 \mathrm{~ns}$ & 8 & 7 & 5 \\
\hline $263.000 \mathrm{~ns}$ & 8 & 7 & 5 \\
\hline .00 & 8 & 7 & \\
\hline
\end{tabular}




$\begin{array}{lrrr}265.000 \mathrm{~ns} & 8 & 7 & 56 \\ 266.000 \mathrm{~ns} & 8 & 7 & 56 \\ 267.000 \mathrm{~ns} & 8 & 7 & 56 \\ 268.000 \mathrm{~ns} & 8 & 7 & 56 \\ 269.000 \mathrm{~ns} & 8 & 7 & 56 \\ 270.000 \mathrm{~ns} & 8 & 7 & 56 \\ 271.000 \mathrm{~ns} & 8 & 7 & 56 \\ 272.000 \mathrm{~ns} & 8 & 7 & 56 \\ 273.000 \mathrm{~ns} & 8 & 7 & 56 \\ 274.000 \mathrm{~ns} & 8 & 7 & 56 \\ 275.000 \mathrm{~ns} & 8 & 7 & 56 \\ 276.000 \mathrm{~ns} & 8 & 7 & 56 \\ 277.000 \mathrm{~ns} & 8 & 7 & 56 \\ 278.000 \mathrm{~ns} & 8 & 7 & 56 \\ 279.000 \mathrm{~ns} & 8 & 7 & 56 \\ 280.000 \mathrm{~ns} & 8 & 7 & 56 \\ 281.000 \mathrm{~ns} & 12 & 13 & 56 \\ 282.000 \mathrm{~ns} & 12 & 13 & 56 \\ 283.000 \mathrm{~ns} & 12 & 13 & 56 \\ 284.000 \mathrm{~ns} & 12 & 13 & 56 \\ 285.000 \mathrm{~ns} & 12 & 13 & 56 \\ 286.000 \mathrm{~ns} & 12 & 13 & 108 \\ 287.000 \mathrm{~ns} & 12 & 13 & 108 \\ 288.000 \mathrm{~ns} & 12 & 13 & 108 \\ 289.000 \mathrm{~ns} & 12 & 13 & 108 \\ 290.000 \mathrm{~ns} & 12 & 13 & 124 \\ 291.000 \mathrm{~ns} & 12 & 13 & 92 \\ 292.000 \mathrm{~ns} & 12 & 13 & 220 \\ 293.000 \mathrm{~ns} & 12 & 13 & 220 \\ 294.000 \mathrm{~ns} & 12 & 13 & 156 \\ 295.000 \mathrm{~ns} & 12 & 13 & 156 \\ 310.000 \mathrm{~ns} & 12 & 13 & 156 \\ 311.000 \mathrm{~ns} & 12 & 13 & 156\end{array}$




$\begin{array}{llll}312.000 \mathrm{~ns} & 12 & 13 & 156 \\ 313.000 \mathrm{~ns} & 12 & 13 & 156 \\ 314.000 \mathrm{~ns} & 12 & 13 & 156 \\ 315.000 \mathrm{~ns} & 12 & 13 & 156 \\ 316.000 \mathrm{~ns} & 12 & 13 & 156 \\ 317.000 \mathrm{~ns} & 12 & 13 & 156 \\ 318.000 \mathrm{~ns} & 12 & 13 & 156 \\ 319.000 \mathrm{~ns} & 12 & 13 & 156 \\ 320.000 \mathrm{~ns} & 12 & 13 & 156 \\ 321.000 \mathrm{~ns} & 15 & 15 & 156 \\ 322.000 \mathrm{~ns} & 15 & 15 & 156 \\ 323.000 \mathrm{~ns} & 15 & 15 & 156 \\ 324.000 \mathrm{~ns} & 15 & 15 & 156 \\ 325.000 \mathrm{~ns} & 15 & 15 & 156 \\ 326.000 \mathrm{~ns} & 15 & 15 & 159 \\ 327.000 \mathrm{~ns} & 15 & 15 & 143 \\ 328.000 \mathrm{~ns} & 15 & 15 & 175 \\ 329.000 \mathrm{~ns} & 15 & 15 & 175 \\ 330.000 \mathrm{~ns} & 15 & 15 & 175 \\ 331.000 \mathrm{~ns} & 15 & 15 & 161 \\ 332.000 \mathrm{~ns} & 15 & 15 & 177 \\ 333.000 \mathrm{~ns} & 15 & 15 & 177 \\ 334.000 \mathrm{~ns} & 15 & 15 & 161 \\ 335.000 \mathrm{~ns} & 15 & 15 & 241 \\ 336.000 \mathrm{~ns} & 15 & 15 & 253 \\ 337.000 \mathrm{~ns} & 15 & 15 & 193 \\ 338.000 \mathrm{~ns} & 15 & 15 & 241 \\ 339.000 \mathrm{~ns} & 15 & 15 & 249 \\ 340.000 \mathrm{~ns} & 15 & 15 & 225 \\ 341.000 \mathrm{~ns} & 15 & 15 & 225 \\ 342.000 \mathrm{~ns} & 15 & 15 & 249 \\ 343.000 \mathrm{~ns} & 15 & 15 & 193 \\ 344.000 \mathrm{~ns} & 15 & 15 & 225 \\ 345.000 \mathrm{~ns} & 15 & 15 & 241 \\ 346.000 \mathrm{~ns} & 15 & 15 & 193 \\ 347.000 \mathrm{~ns} & 15 & 15 & 225 \\ 348.000 \mathrm{~ns} & 15 & 15 & 225 \\ 349.000 \mathrm{~ns} & 15 & 15 & 225 \\ 350.000 \mathrm{~ns} & 15 & 15 & 225 \\ 351.000 \mathrm{~ns} & 15 & 15 & 225 \\ 352.000 \mathrm{~ns} & 15 & 15 & 225\end{array}$

PERFORMANCE

Total simulation time $=144.2 \mathrm{us}$ 


\section{6}

Total circuit time $=353.0 \mathrm{nS}$

Total events processed $=$

790

Event throughput $=5.479 \mathrm{MHz}$ 